\title{
Untersuchung zur wechselseitigen Beeinflussung von Chemotaxinen und Dendritischen Zellen
}

\author{
Dissertation \\ zur Erlangung des Doktorgrades \\ der Mathematisch-Naturwissenschaftlichen Fakultäten \\ der Georg-August-Universität zu Göttingen
}

vorgelegt von

Claudia Dettmer-Richardt

aus Mühlhausen

Göttingen 2007 
D 7

Referent: Herr Prof. Dr. Rüdiger Hardeland Koreferent: Herr Prof. Dr. Wolfgang Liebl

Tag der mündlichen Prüfung: 23.01.2008 
Für Jana 


\section{INHALTSVERZEICHNIS}

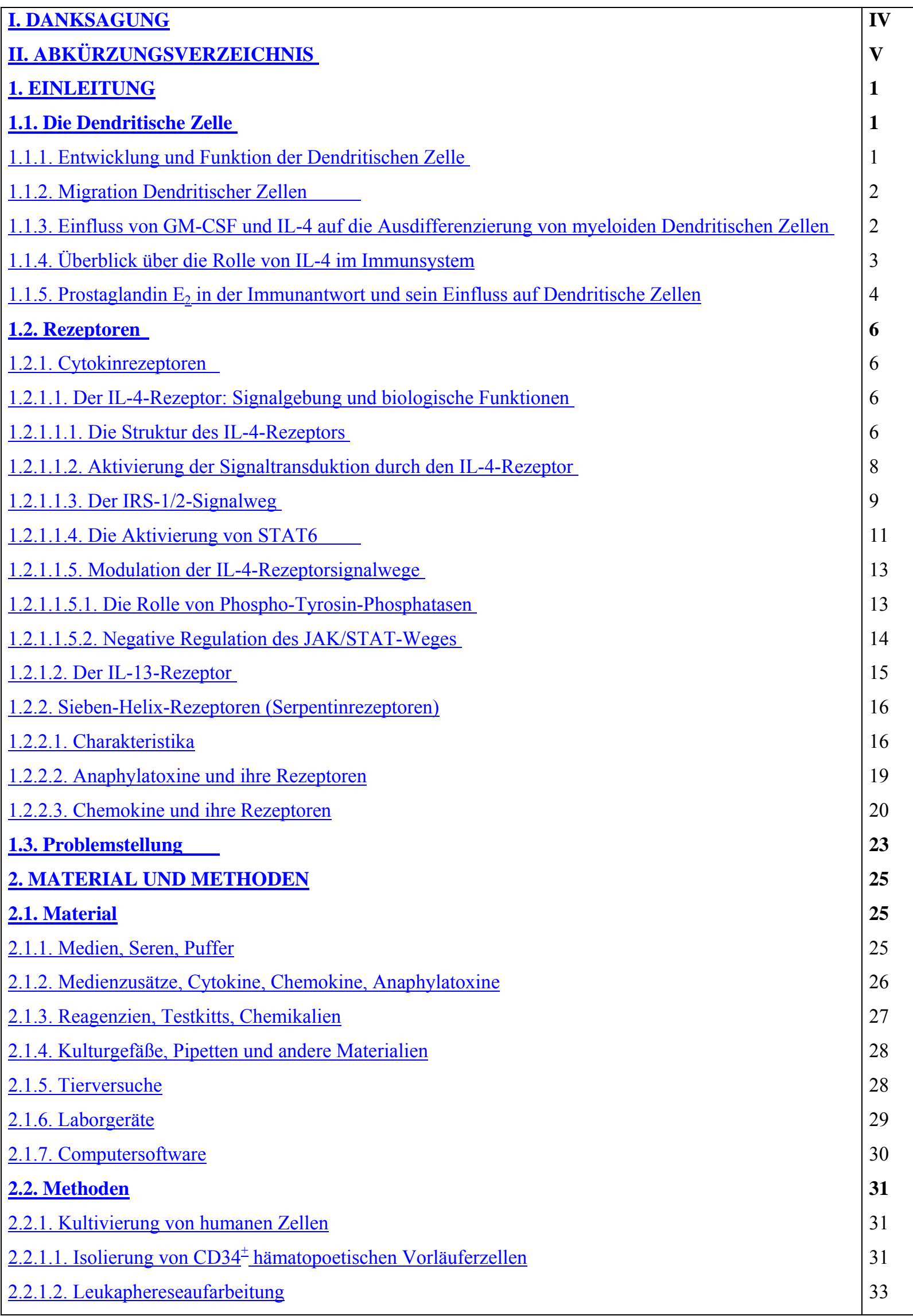




\begin{tabular}{|c|c|}
\hline 2.2.1.3. Gewinnung von Monozyten durch Adhärenz und ihre Kultivierung & 34 \\
\hline 2.2.1.4. Kulturzusätze im humanen System & 36 \\
\hline 2.2.1.5. Kryokonservierung & 37 \\
\hline 2.2.1.5.1. Einfrieren von hämatopoetischen Vorläuferzellen aus Nabelschnurblut & 37 \\
\hline 2.2.1.5.2. Auftauen von hämatopoetischen Vorläuferzellen aus Nabelschnurblut & 38 \\
\hline 2.2.1.6. Vitalitätstest & 38 \\
\hline 2.2.1.7. Ernte der Zellen aus Leukapherese & 39 \\
\hline 2.2.1.8. Ernte der aus Nabelschnurblut generierten Zellen & 39 \\
\hline 2.2.2. Kultivierung von Mauszellen & 40 \\
\hline 2.2.2.1. Gewinnung, Kultivierung und Ernte von Mausknochenmarkszellen & 40 \\
\hline 2.2.2.2. Kulturzusätze im Maussystem & 41 \\
\hline 2.2.3. Zellbiologie & 42 \\
\hline 2.2.3.1. FACS-Färbung & 42 \\
\hline 2.2.3.1.1. Direkte Färbung membranständiger Antigene & 44 \\
\hline 2.2.3.1.2. Indirekte Färbung membranständiger Antigene & 44 \\
\hline 2.2.3.2. PKH26-Färbung & 45 \\
\hline$\underline{\text { 2.2.3.3. Messung der } \mathrm{Ca}^{2+}} \underline{\text {-Freisetzung }}$ & 45 \\
\hline 2.2.3.4. Cytospin & 47 \\
\hline 2.2.3.5. Färbung der Cytospins & 47 \\
\hline 2.2.3.6. Chemotaxis & 48 \\
\hline 2.2.3.6.1. Chemotaxis in vitro & 48 \\
\hline 2.2.3.6.2. Chemotaxis in vivo & 49 \\
\hline 2.2.3.6.3. Peritoneallavage & 51 \\
\hline 2.3. Statistik & 51 \\
\hline 3. ERGEBNISSE & 52 \\
\hline 3.1. Rezeptorexpression und Chemotaxis im murinen System & 52 \\
\hline 3.1.1. Der Einfluss von IL-4 und IL-13 auf Anaphylatoxinrezeptoren im murinen System & 52 \\
\hline 3.1.2. Die in vivo Migration gegen einen Liganden ist zeit- und dosisabhängig & 55 \\
\hline 3.1.3. Bedeutung des Transkriptionsfaktors STAT6 in der Expression von Anaphylatoxinrezeptoren & 56 \\
\hline 3.1.4. Einsatz von Inhibitoren zur Klärung der Beteiligung von Signalmolekülen & 57 \\
\hline 3.1.5. Einfluss von IL-4 und IL-13 auf Chemokinrezeptoren im murinen System & 59 \\
\hline 3.1.6. Bedeutung des Transkriptionsfaktors STAT6 in der Expression von Chemokinrezeptoren & 64 \\
\hline 3.1.7. Einfluss von IL-4 auf den Calciuminflux von murinen DC & 65 \\
\hline 3.2. Rezeptorexpression und Chemotaxis im humanen System & 67 \\
\hline 3.2.1. Generierung von DC aus CD34 $4^{ \pm}$hämatopoetischen Vorläuferzellen & 67 \\
\hline 3.2.2. Einfluss von IL-4 und IL-13 auf Anaphylatoxinrezeptoren im humanen System & 71 \\
\hline 3.2.3. Einfluss von IL-4 auf Chemokinrezeptoren von humanen Monozyten und MoDC & 73 \\
\hline 3.2.4. Einfluss von $\mathrm{PGE}_{2}$ auf chemotaktische Rezeptoren im humanen System & 75 \\
\hline$\underline{3.2 .5}$ Einfluss von $\mathrm{PGE}_{2}$ auf $\mathrm{C} 5 \mathrm{aR}$ und CCR7 im SCID-Mausmodell & 79 \\
\hline 3.2.6. Einfluss von IL-4 und $\mathrm{PGE}_{2}$ auf das Wanderungsverhalten von DC in vitro & 82 \\
\hline 3.2.7. Einfluss von IL-4 und $\mathrm{PGE}_{2}$ auf den Calciuminflux in humanen DC & 83 \\
\hline
\end{tabular}




\begin{tabular}{|l|l|}
\hline 4. DISKUSSION & 86 \\
\hline 4.1. Expression und Funktionalität von Chemotaxinrezeptoren im murinen System & 86 \\
\hline 4.2. Expression und Funktionalität von Chemotaxinrezeptoren im humanen System & 88 \\
\hline 4.3. Der Einfluss von Prostaglandin E2_auf Chemotaxinrezeptoren im humanen System & 90 \\
\hline 5. ZUSAMMENFASSUNG & 93 \\
\hline 6. LITERATURQUELLEN & 96 \\
\hline 7. LEBENSLAUF & 116 \\
\hline
\end{tabular}




\section{DANKSAGUNG}

Ich möchte mich ganz herzlich bei Frau PD Dr. rer. nat. Afsaneh Soruri sowie Herrn Prof. Dr. med. Jörg Zwirner für die freundliche Überlassung meines Promotionsthemas und für ihre ständige Unterstützung meiner Arbeit und ihren Ansporn bedanken.

Mein Dank gilt Herrn Prof. Dr. Rüdiger Hardeland für seine Tätigkeit als Referent sowie Herrn Prof. Dr. Wolfgang Liebl für das Koreferat.

Ich danke den Mitgliedern meiner Arbeitsgruppe Frau Dr. rer. nat. Jasmin Grigat, Frau Kerstin Eckelmann, Frau Olga Walter und Frau Jutta Wollenweber für die familiäre Atmosphäre, die freundschaftlichen Bande, die wir knüpfen konnten, und die ausgezeichnete persönliche Unterstützung. Weiterhin möchte ich auch Frau Dr. rer. nat. Ziba Kiafard für ihre wissenschaftliche Hilfe und Frau Amina Bassibas, Frau Ines Heine und Frau Gabi Sonntag für die technische Unterstützung danken.

Mein besonderer Dank gilt meiner Familie für ihren Rückhalt in jeglicher Hinsicht. Meinem Mann, Herrn Marco Richardt, danke ich für sein Verständnis und seine Geduld, meinen Eltern, Frau Heidrun Dettmer und Herrn Dr. med. Martin Dettmer, und meinen Großeltern, Frau Ilse Apel und Herrn Herbert Apel, für ihre stete Unterstützung, meinem Bruder, Herrn Matthias Dettmer, für seinen technischen Support. 


\section{ABKÜRZUNGSVERZEICHNIS}

Abb.

AS

BMDC

BSA

CB

$\mathrm{CD}$

DC

DMSO

ERK

FACS

FCS

FITC

Flt3 Ligand

fMLP

GM-CSF

$\mathrm{h}$

HLA-DR

$\operatorname{Ig} \mathrm{E}$

IL

i.p.

i.v.

JNK

KMDC

LPS

$\mathrm{MACS}^{\circledR}$

MAPK

M-CSF

MCP-1

MDC

$\mathrm{MHC}$

MIP-1 $\alpha$

MIP-3 $\alpha$
Abbildung

Aminosäure

Bone marrow dendritic cells

Bovines Serumalbumin

Cord blood (Nabelschnurblut)

Cluster of differentiation

Dendritische Zellen

Dimethylsulfoxid

extrazellulär regulierte Kinase

Fluoreszenz-aktivierte Zellsortierung

fetales Kälberserum

Fluoreszeinisothiocyanat

FMS like Tyrosinkinase-3 Ligand

formyl-Methionin-Leucin-Phenylalanin

Granulocyten/Monocyten-Kolonie stimulierender Faktor

Stunde

Humanes Leukozyten Antigen-Isotyp HLA Klasse II

Immunglobulin $\mathrm{E}$

Interleukin

intraperitoneal

intravenös

cJun N-terminale Kinase

Knochenmarks-Dendritische Zellen

Lipopolysaccharid

magnetisch aktivierte Zellsortierung

Mitogen-aktivierte Phospho-Kinase

Makrophagen-Kolonie stimulierender Faktor

Monocyte Chemoattractant Protein-1

Macrophage-Derived Chemokine

Haupthistokompatibilitätskomplex

Macrophage Inflammatory Protein-1 alpha

Macrophage Inflammatory Protein-3 alpha 
MIP-1 $\beta$

MoDC

PBMNL

PBS

PE

$\mathrm{PGE}_{2}$

RANTES

rh

rm

RT

$\mathrm{SCF}$

SCID

TPO
Macrophage Inflammatory Protein-1 beta

monocyte derived dendritic cell(s)

mononukleäre Zellen des peripheren Blutes

Phosphat-gepufferte Kochsalzlösung

Phycoerythrin

Prostaglandin $\mathrm{E}_{2}$

Regulated upon activation normal T-Cell expressed and secreted rekombinant human

rekombinant Maus

Raumtemperatur

Stem cell factor

Severe combined immunodeficience

Thrombopoietin 


\section{EINLEITUNG}

\subsection{Die Dendritische Zelle}

\subsubsection{Entwicklung und Funktion der Dendritischen Zelle}

Dendritische Zellen sind die potentesten Antigen Präsentierenden Zellen des Immunsystems. Charakterisiert sind sie durch folgende Merkmale:

- $\quad$ unvergleichliche Sentinelfunktion, d.h. Antigen wird aufgespürt, aufgenommen und präsentiert

- $\quad$ Migration der DC zum Entzündungsherd und anschließend zu den T-Zell-Arealen der lymphatischen Organe

- Bindung an antigenspezifische T-Lymphozyten, die DC präsentieren dabei die prozessierten Antigenpeptide

- eine aktivierende, kostimulierende Funktion auf T-Lymphozyten, das T-Zell-Wachstum und die Effektorfunktionen der T-Zellen werden induziert (STEINMAN, R., 1991; STEINMAN, INABA, 1999; BANCHEREAU et. al., 2000)

Die myeloide DC entwickelt sich aus hämatopoetischen Stammzellen des Knochenmarks, wobei zwei verschiedene Entwicklungswege beschritten werden können, der CD14-unabhängige und der CD14-abhängige Pfad. Die CD14-unabhängigen DC können in vitro aus $\mathrm{CD} 4^{+}$hämatopoetischen Vorläuferzellen (aus Knochenmark oder Nabelschnurblut) (CAUX et al., 1992; SANTIAGO-SCHWARZ et al., 1992) gewonnen werden. Ein prototypischer Vertreter stellt hierbei die Langerhanszelle der Haut dar. Die CD14-abhängigen DC hingegen gehen aus $\mathrm{CD}_{14}{ }^{+}$zur Adhärenz befähigten PBMNL, den peripheren Blutmonozyten, hervor (SANTIAGO-SCHWARZ, 1999). Monozyten können sich in Abhängigkeit der externen Stimuli entweder zu DC oder zu Makrophagen entwickeln. Diese Polarisation kann in vitro durch die Zugabe von Cytokinen erreicht werden (SALLUSTO, LANZAVECCHIA, 1994). Monozyten, durch GM-CSF und IL-4 kultiviert, besitzen Merkmale unreifer DC wie hohe Endozytoseaktivität, aber schlechte T-Zell-Stimulationsaktivität. Die Zellen sind für die Antigenaufnahme und deren Prozessierung kompetent (ZHOU, TEDDER, 1996). Die so generierten Zellen können durch die Zugabe bestimmter Stimuli, wie TNF- $\alpha$, IL-1 oder LPS, vollständig ausreifen (SALLUSTO, LANZAVECCHIA, 1994, BANCHEREAU et al., 2000). 


\subsubsection{Migration Dendritischer Zellen}

Die Wanderung von Leukozyten, inklusive Dendritischer Zellen, zu Entzündungsherden ist abhängig von einer Reihe von Faktoren, den so genannten Chemotaxinen und deren komplementären Rezeptoren auf den Leukozyten. $\mathrm{Zu}$ den Chemotaxinen gehören die Anaphylatoxine und die inflammatorischen Chemokine (chemotaktische Cytokine) (BAgGiolini, 1997; Allavena et al., 2000; ZlotniK, Yoshie, 2000). Die lokale Produktion inflammatorischer Chemokine, z. B. CCL2 (MCP-1), CCL3 (MIP-1 $\alpha$ ), CCL5 (RANTES), CCL20 (MIP-3 $\alpha$ ), ist verantwortlich für die Einwanderung von unreifen DC oder ihren Vorläufern (CYSTER, 1999; SALLUSTO, LANZAVECCHIA, 1999; ALLAVENA et al., 2000; McCOLL, 2002), da diese Zellen Rezeptoren für inflammatorische Chemokine wie z. B. RANTES, MIP-1 $\alpha$ und MCP-3 exprimieren. In gleicher Weise sind die konstitutiven Chemokine CCL21 (6Ckine) und CCL19 (MIP-3 $\beta$ ) für die Migration der DC in die lymphatischen Organe verantwortlich und sind für die Anlockung reifer dendritischer Zellen an den Ort der T-Zell-Stimulation von großer Bedeutung (SOZZANI et al., 1998; FÖRSTER et al., 1999; GUNN et al., 1999). Reife DC haben das Potential große Mengen an IL-12 zu produzieren. Dieses Cytokin bewirkt die Entwicklung einer TH1-Antwort (GATELY et al., 1998). Im Gegensatz dazu können IL-10, TGF- $\beta$, Corticosteroide, Vitamin D und $\mathrm{PGE}_{2}$ die DC-Reifung dahingehend beeinflussen, dass sich anstatt einer TH1- eine TH2-Antwort etabliert (BANCHEREAU et al., 2000).

\subsubsection{Einfluss von GM-CSF und IL-4 auf die Ausdifferenzierung von myeloiden Dendritischen Zellen}

Das von GOUGH et al. (1984) isolierte und charakterisierte GM-CSF (Granulocyte-macrophage colony stimulating factor) ist ein Wachstumsfaktor mit breitem Wirkungsspektrum. Es stimuliert in vitro die Differenzierung und Proliferation der Vorläuferzellen von Granulozyten, Makrophagen und DC (BURGESS, METCALF, 1980; METCALF et al., 1986; INABA et al., 1992). GM-CSF wird in vivo von Monozyten und auch von Zellen, die nicht zum Immunsystem gehören, z.B. Fibroblasten, nach Aktivierung durch Entzündungsmediatoren gebildet (KAPLAN et al., 1992; KIRCHNER et al., 1994; BANCHEREAU, STEINMAN, 1998). In vitro ist GM-CSF für Überleben, Funktion und immunologische Ausreifung der DC als auch für die Ausbildung DC-typischer Oberflächenmarker z.B. eine starke MHC-Klasse-II Expression, essentiell (WITMER-PACK et 
al., 1987; HeUfler et al., 1987; WITMER-PACK et al.,1987; AlVARO-GRACIA et al. 1989; GERRARD et al., 1990; STEINMAN, 1991). Durch GM-CSF können größere Mengen an DC in vitro produziert werden. Anhand der Effekte des Cytokins auf die Überlebensfähigkeit, die Funktion und das Wachstum von DC sollte das Cytokin eigentlich GMD-CSF (Granulocytemacrophage-dendritic cell colony stimulating factor) genannt werden (INABA et al., 1992).

Zusammen mit IL-2, IL-3, IL-5, IL-7, IL-9, IL-13, IL-15 und GM-CSF gehört IL-4 zu den kurzkettigen Vier-Helix-Bündel-Cytokinen. (NICOLA, 1995) Dieses Glykoprotein ist ein Produkt der TH2-Zellen (PAUL, 1991). IL-4 erhöht die Expression von MHC-Klasse-II-Molekülen auf der Oberfläche von Monozyten und verbessert somit deren Antigenpräsentationsfähigkeit (KIRCHNER et al., 1994; PAUL, 1991; TE VELDE et al., 1988), vergrößert in vitro die Anzahl unreifer DC, verringert die Menge an CD14 ${ }^{+}$Zellen (LAUENER et al., 1990; XU et al., 1996) und inhibiert die Differenzierung von Makrophagen (JANSEN et al., 1989). GERRARD et al. haben zeigen können, dass IL-4 einen direkten Effekt auf Monozyten hat (GERRARD et al., 1990). In vitro wird die APC-Funktion von humanen (ZLOTNIK et al., 1987) und von murinen Monozyten (TE VELDE et al., 1990) durch die Anwesenheit von IL-4 verbessert.

SALLUSTO und LANZAVECCHIA (1994) konnten in Zusammenfassung dieser Erkenntnisse zeigen, dass adhärente PBMNL, die mit GM-CSF und IL-4 kultiviert wurden, nach dem Einfluss von Reifungsstimuli den Phänotyp und die kostimulierende Aktivität reifer DC ausbildeten.

\subsection{4. Überblick über die Rolle von IL-4 im Immunsystem}

IL-4 übt seine biologische Funktion über den IL-4-Rezeptor (IL-4R) aus. Es spielt eine zentrale Rolle in der Regulation der Differenzierung von antigenstimulierten naiven T-Zellen (SEDER et al., 1992; HSIEH et al., 1992). IL-4 unterdrückt sehr wirksam die Generierung von IFN- $\gamma$ produzierenden TH1-Zellen und kontrolliert die Spezifität des Immunglobulinklassenswitches (GASCAN et al., 1991; COFFMAN et al., 1986; VITETTA et al., 1985). IL-4 besitzt noch andere Effekte im hämatopoetischen Gewebe. Es erhöht die Expression von MHC Klasse II auf B-Lymphozyten (NOELLE et al., 1984), stimuliert die Expression des IL-4-Rezeptors (OHARA, PAUL, 1988) und fungiert als Co-Mitogen für das B-Zell-Wachstum (HOWARD et al., 1982). Obwohl IL-4 selbst kein Wachstumsfaktor für ruhende Lymphozyten ist, kann es die Lebensdauer von T- und B-Zellen in vitro verlängern und Apoptose verhindern (DANCESCU et al., 1992; ILLERA et al., 1993; ZAMORANO et al., 
1996; BOISE et al., 1995; MiNSHALL et al., 1997). Zusätzlich zeigt dieses Cytokin weitreichende und vielfältige Wirkung auf Mastzellen, Makrophagen, hämatopoetische Vorläuferzellen und Stromazellen (JANSEN et al., 1989). IL-4 kommt weiterhin eine bedeutende Rolle bei der Zelladhäsion und in Entzündungsreaktionen zu. Es ist beteiligt an der Induktion der Expression des Adhäsionsmoleküls VCAM-1 (vascular cell adhesion molecule-1) auf Gefäßendothel (THORNHILL et al., 1991) und blockiert dort die Expression von E-Selektin (BENNETT et al., 1997). Diese Änderung in der Balance von Adhäsionsmolekülen während einer Entzündungsreaktion durch IL-4 favorisiert die Rekrutierung von T-Zellen und Eosinophilen gegenüber neutrophilen Granulozyten.

\subsubsection{Prostaglandin $E_{2}$ in der Immunantwort und sein Einfluss auf Dendritische Zellen}

Die Prostaglandine, eine Signalmolekülgruppe, die sich von der Arachidonsäure ableitet, sind Fettsäuren mit 20 Kohlenstoffatomen und einem Ring aus fünf Kohlenstoffen. $\mathrm{PGH}_{2}$ ist das Substrat für beide Isoformen der Cyclooxygenase COX-1 und COX-2 und bildet somit das Edukt für die Synthese von $\mathrm{PGD}_{2}, \mathrm{PGE}_{2}, \mathrm{PGF}_{2} \alpha$ und $\mathrm{PGI}_{2}$. Die Prostaglandine binden an G-Protein gekoppelte Rezeptoren und sind kurzlebige lokale Hormone mit entzündungsstimulierender Wirkung (STRYER, 1995). Während in nicht entzündetem Gewebe die Menge an Prostaglandinen sehr niedrig ist, steigt sie bei inflammatorischen Prozessen rapide an. Sobald die dadurch rekrutierten Immunzellen den Entzündungsherd infiltrieren, wird die Prostaglandinmenge weiter gesteigert. Einige der Enzyme der Prostaglandinsynthese sind induzierbar. Deshalb ist das Synthesemuster während einer Immunantwort abhängig von der Zellart und von deren Aktivierungsstadium.

In inflammatorischen Modellen wurde beobachtet, dass in der frühen Entzündungsphase vor allem $\mathrm{PGE}_{2}$ gebildet wird (GILROY, 1999). $\mathrm{PGE}_{2}$ agiert über vier verschiedene Rezeptoren (EP1 bis EP4). Jeder dieser Rezeptoren wird von einem eigenen Gen codiert. Weil die $\mathrm{PGE}_{2}$-Rezeptoren von verschiedenen Zellen in verschiedenen Mengenverhältnissen exprimiert werden, ist die Wirkung von $\mathrm{PGE}_{2}$ auf die einzelnen Zellpopulationen sehr unterschiedlich. Jeder $\mathrm{PGE}_{2}$-Rezeptor vermittelt ein anderes intrazelluläres Signal. Dies ermöglicht der Zelle, eine fein abgestimmte Antwort auf dieses Signal zu geben. Die Expression der verschiedenen $\mathrm{PGE}_{2}$-Rezeptoren wird unabhängig von einander reguliert. Ein bestimmter Signaltransduktionsweg überwiegt und andere treten in den Hintergrund. Beispielsweise erhöht sich die Menge an EP2 auf Makrophagen nach LPS-Stimulation um das Fünffache, während sich die Menge an EP4 kaum erhöht (TILLEY et al., 2001). 
$\mathrm{PGE}_{2}$ übt den gegenteiligen Effekt zu IL-12 auf die TH1 und die TH2 Antwort aus. Beide Mediatoren werden in Monozyten, Makrophagen und DC als Antwort auf verschiedene Stimuli, wie bakterielle Produkte gebildet (HILKENS et al., 1996). Folge dessen wird die TH1/TH2-Balance durch Cytokine und Prostaglandine moduliert. PGE $_{2}$ ist hierbei ein TH2-favorisierender Faktor (PALMBLAD, 1990). Es unterdrückt also die zellvermittelte Immunantwort, während es die humorale Antwort begünstigt (ROPER, PHIPPS, 1994; SNIJDEWINT et al., 1993). Es moduliert damit APC-Funktionen (HARIZI et al., 2001) und die Produktion von inflammatorischen Cytokinen (WILliAMS, SHACTER, 1997). Studien haben gezeigt, dass $\mathrm{PGE}_{2}$ ein starker Inhibitor der IL-12 Produktion ist, was wiederum das Vorhandensein eines Feedbackmechanismus auf der Ebene der APC impliziert (VAN der POUW KRAAN et al., 1995, STRAUSSMANN et al., 1994).

$\mathrm{PGE}_{2}$ ist ein potenter Induktor für die Produktion von IL-10 (VAN der POUW KRAAN et al., 1995, STRAUSSMANN et al., 1994, STOLINA et al., 2000). IL-10 wird von einer Reihe von Zellen inklusive Monozyten gebildet (GROUX et al., 1998) und besitzt einen inhibierenden Effekt auf die TH1-Antwort (MOORE et al., 2001; JGIETSEME et al., 2000; FIORENTINO et al., 1991). $\mathrm{PGE}_{2}$ moduliert die DC vermittelte Immunantwort über die Induktion von IL-10 (HARIZI et al., 2002).

Die vier $\mathrm{PGE}_{2}$ Rezeptoren des Menschen (EP1 bis EP4) werden alle von humanen unreifen DC exprimiert, aber nur EP2 und EP4, die über Adenylatcyclase und damit über cAMP ihre Funktion ausüben, werden im Rahmen der DC Aktivität hochreguliert (HARIZI et al., 2003). $\mathrm{PGE}_{2}$ nimmt an der Regulation der Sensitivität von CCR7 teil (CHEN et al., 2004, LUFT et al., 2002). Deshalb besitzt es eine duale Rolle in der Migration von DC: Die Regulation der Expression und der Empfindlichkeit von CCR7. In Mäusen mit einer EP4-Defizienz zeigen die DC eine stark eingeschränkte Wanderungsfähigkeit in Richtung Lymphknoten (KABASHIMA et al., 2003).

Genau wie TNF- $\alpha$, IL-1 $\beta$ und IL-6 ist PGE $_{2}$ an der Reifung von humanen MoDC beteilgt (JONULEIT et al., 1997, KALINSKI et al., 1997). Obwohl selbst als proinflammatorischer Mediator determiniert, hemmt $\mathrm{PGE}_{2}$ die Freisetzung von proinflammatorischen Cytokinen (TNF- $\alpha$, IL-6, IL-12) (KALINSKI et al., 1997; JOZEFOWSKI et al., 2003; VASSILIOU et al., 2003) und von proinflammatorischen Chemokinen wie CCL3 (MIP-1 $\alpha$ ), CCL4 (MIP-1 $\beta$ ) und CXCL10 (IP-10) (JING et al., 2003; KURODA et al., 2001) in LPS-stimulierten humanen MoDC und murinen KMDC. Die Bedeutung von $\mathrm{PGE}_{2}$ wird deutlich in EP4-defizienten Mäuse, die eine schwere Colitis entwickeln (NARUMIYA et al., 1999). Weiterhin werden beim Menschen durch die Einnahme nichtsteroider antiinflammatorischer Substanzen, die als 
COX-Hemmer fungieren, entzündliche Erkrankungen der Harnblase begünstigt (AABAKKEN et al., 1989). Diese Studien zeigen eine antiinflammatorische Rolle des $\mathrm{PGE}_{2}$ übereinstimmend mit früheren Beobachtungen des antiproliferativen Einflusses von $\mathrm{PGE}_{2}$ auf aktivierte T-Zellen (TILLEY et al., 2001).

\subsection{Rezeptoren}

\subsubsection{Cytokinrezeptoren}

\subsubsection{Der IL-4-Rezeptor: Signalgebung und biologische Funktionen}

\subsection{Die Struktur des IL-4-Rezeptors}

Der IL-4-Rezeptor ist Mitglied der Hämatopoetinrezeptorsuperfamilie und ein pleiotroper Typ I Cytokinrezeptor, der von TH2-Zellen, Basophilen und Mastzellen exprimiert wird. IL-4 wird von bestimmten Subtypen der T-Lymphozyten und Natürlichen Killerzellen produziert und ebenfalls von $\gamma / \delta$ T-Zellen und Eosinophilen. Der IL-4-Rezeptor findet sich außerdem in hämatopoetischem, endothelialem, epithelialem Gewebe sowie auf Muskelzellen, Fibroblasten, Hepatozyten und Hirnzellen. Der Rezeptor besteht aus einer 140 kDa IL-4R $\alpha$-Kette, die IL-4 mit hoher Affinität bindet. Obwohl die künstliche Homodimerisierung der IL-4R $\alpha$-Kette in der Auslösung eines Signals mündet, spielt physiologisch nur die Heterodimerisierung mit einer zweiten Kette eine Rolle. Die allgemeine $\gamma$-Kette ( $\gamma \mathrm{c}$-Kette), zuerst beim IL-2-Rezeptor entdeckt, ist der vorrangige Bindungspartner in vielen Geweben. Die $\gamma c-K e t t e$ erkennt dabei einen Komplex aus IL-4 und IL-4R $\alpha$. Obwohl die $\gamma c-K e t t e ~ d i e$ Affinität des IL-4 Rezeptors für IL-4 nur wenig erhöht, wird sie für die Aktivierung der Signaltransduktion benötigt (NELMS et al., 1999).

Mitglieder der Hämatopoetinrezeptorsuperfamilie teilen Strukturmotive in der extrazellulären Region. Diese besteht aus Typ III Fibronektindomänen, die konservierte gepaarte Cysteinreste und in der Membranproximalregion ein WSXWS-Motiv aufweisen, welches für die Cytokinbindung benötigt wird (MIYAJIMA et. al., 1992; LIVNAH et al., 1996). Strukturelle Abweichungen in der extrazellulären Domäne der IL-4R $\alpha$-Kette führen zu verändertem Rezeptorsignalverhalten. In der Tat weist eine Variante der IL-4R $\alpha$-Kette mit einer Ile50Val Substitution bei atopischen Patienten eine gesteigerte Signaltransduktion auf, die wiederum in einer erhöhten IgE-Produktion mündet (MITSUYASU et al., 1998). 
In der cytoplasmatischen Domäne der IL-4R $\alpha$-Kette gibt es fünf Tyrosinreste, deren Positionen und umgebenden Sequenzen stark konserviert sind und bei verschiedenen Spezies vorkommen, was wiederum den Schluss zulässt, dass diese Bereiche funktionell bedeutsam sind (siehe Abb. 1, NELMS et al., 1999). Eine kleine prolinreiche Sequenz in der membrannahen Region der Kette, genannt Box-1-Motiv, ist in einer Reihe von Hämatopoetinrezeptoren $\mathrm{zu}$ finden. Die daran angrenzende saure Region und das Box-1-Motiv selbst sind ähnlich denen in der IL-2R $\beta$-Kette, welche mit Kinasen der SrcFamilie interagiert (MURAKAMI et al., 1991; MINAMI et al., 1993).

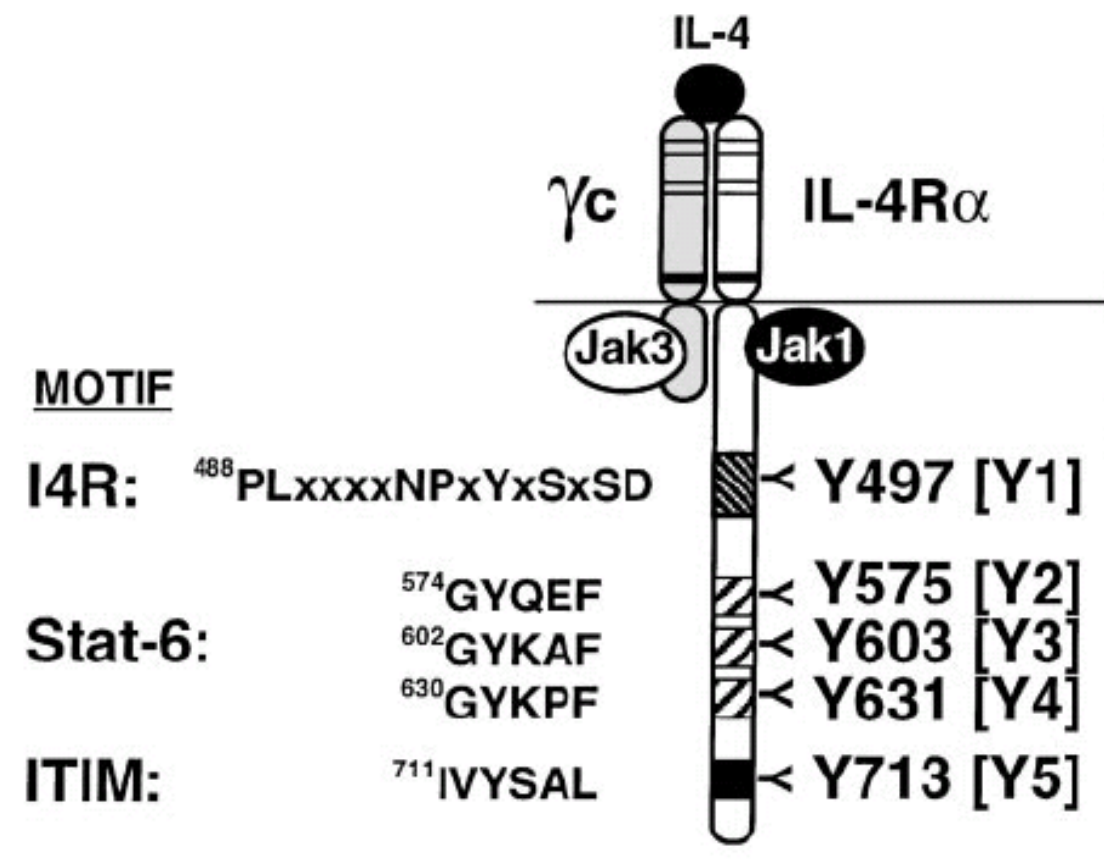

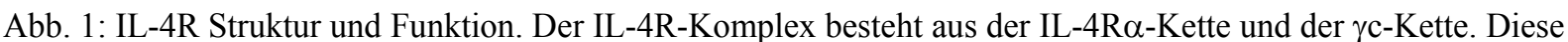
sind mit den Tyrosinkinasen Jak1 und Jak3 assoziiert. Die cytoplasmatische Domäne der humanen IL-4R $\alpha-K e t t e$ enthält fünf konservierte Tyrosinreste. Das der Cytoplasmamembran am nächsten liegende (Y497) ist Teil des I4R-Motivs, welches für die Interaktion mit IRS-1/2 und damit für die Ausbildung von Proliferationssignalen und Antiapoptosesignalen wichtig ist. Die Tyrosinreste zwei, drei und vier (Y575, Y603 und Y631) sind eingebettet in stark konservierte Sequenzen, die für die Bindung und Aktivierung von STAT6 unabdingbar sind. Das C-terminale Tyrosin (Y713) dient als Bindestelle für regulierende Phosphatasen wie SHIP (NELMS et al., 1999). 


\subsection{Aktivierung der Signaltransduktion durch den IL-4-Rezeptor}

Die ligandeninduzierte Dimerisierung oder Multimerisierung von Cytokinrezeptoren mündet in der Aktivierung von Tyrosinkinasen, die zelluläre Substrate phosphorylieren und damit Signalkaskaden initiieren (MIYAJIMA et. al., 1992). Die Bindung von IL-4 an seinen Rezeptorkomplex führt zur intrazellulären Tyrosinphosphorylierung an der IL-4R $\alpha$-Kette.

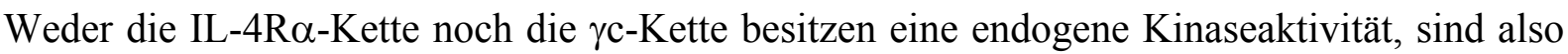
keine Rezeptortyrosinkinasen. Der IL-4R und alle anderen Mitglieder der Hämatopoetinrezeptorfamilie benötigen rezeptorassoziierte Kinasen für die Initiierung der Signaltransduktion. Cytoplasmatische Proteintyrosinkinasen wie Src und Jak sind mit Typ I Cytokinrezeptoren wie dem IL-4R assoziiert. Die Familie der Janustyrosinkinasen (Jak) ist hierbei von großer Wichtigkeit (TANIGUCHI, 1995).

Drei Mitglieder der Familie der Januskinasen, nämlich Jak1, Jak2 und Jak3, werden IL-4R abhängig aktiviert und sind verbunden mit Komponenten des IL-4R-Komplexes (RANE, REDDY, 2000). In den meisten hämatopoetischen Zellen erfolgt nach IL-4-Stimulation die Phosphorylierung von Jak1 und Jak3 (WiTTHUHN, et al., 1994; YIN et al., 1994). Jak1

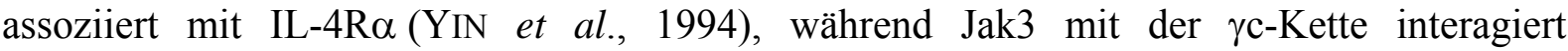

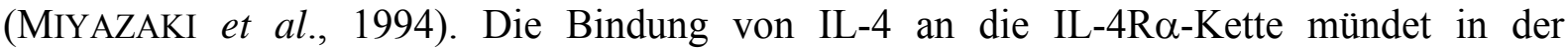
Tyrosinphosphorylierung von Jak1 und Jak3. In nichthämatopoetischen Zellen erfolgt eine IL-4 bedingte Phosphorylierung von Jak1, Jak2 und Tyk2, nicht aber von Jak3. Für die Interaktion von Jak1 mit der IL-4R $\alpha$-Kette scheinen das Box-1-Motiv und die saure Region verantwortlich $\mathrm{zu}$ sein. Jak1 ist hierbei für die IL-4 stimulierte Induktion der IRS-1/2 Phosphorylierung absolut unverzichtbar (WANG et al., 1997; CHEN et al., 1997).

Die Aktivierung der IL-4R assoziierten Kinasen führt zur Tyrosinphosphorylierung der IL-4R $\alpha$-Kette, ein Prozess, der sehr schnell nach der Ligandenbindung stattfindet. Die fünf konservierten Tyrosinreste der cytoplasmatischen Domäne der IL-4R $\alpha$-Kette sind potentielle Phosphorylierungsstellen und damit involviert in die Interaktion mit Signalproteinen, die SH2 (Src-homology 2) oder PTB (phosphotyrosinbindende) Domänen aufweisen.

Die cytoplasmatische Domäne von IL-4R $\alpha$ enthält drei funktionell verschiedene Regionen, eine für die Interaktion mit Jak1, eine zweite für die Aktivierung von Proliferation und Apoptosehemmung und die dritte für die Initiierung von Signalen, die über die Aktivierung von STAT6 zur Induktion IL-4 abhängiger Gene führen (NELMS et al., 1999). 


\subsection{Der IRS-1/2-Signalweg}

Bei der IL-4-induzierten Signaltransduktion spielt neben dem STAT6 ein weiteres Signalmoleküle, welches in Folge der Ligation des IL-4R phosphoryliert wird, eine wichtige Rolle. Es handelt sich hierbei um das $170 \mathrm{kDa}$ Phosphoprotein 4PS/IRS-2 (IL-4 induced phosphotyrosine substrate/insulin receptor substrate 2) (siehe Abb. 2). Seine Funktion liegt in der Aktivierung einer Klasse I PI3K, die verschiedene Proteinkinasen reguliert. Das Signalmolekül 4PS ist mit dem IRS-1 (Insulinrezeptorsubstrat-1) verwandt. Die Gene für 4PS und IRS-1 weisen einen hohen Grad an Übereinstimmung auf, so dass 4PS in IRS-2 umbenannt wurde (SuN et al., 1995).

Die Bedeutung von 4PS/IRS-2 als IL-4-abhängiges Molekül wurde an der myeloiden Vorläuferzelllinie 32D demonstriert. Diese Zellen exprimieren keine nachweisbaren Mengen an IRS-Molekülen (WANG et al., 1993; SUN et al., 1995). Während andere myeloide Linien, die IRS-2 bilden und nach IL-4-Stimulation proliferieren, tun 32D Zellen dies nicht. 32D Transfektanten, die IRS-2 exprimieren, zeigen nach IL-4-Stimulation eine Zellvermehrung. Dies lässt den Schluss zu, dass IRS-1/2 eine Verbindung zwischen IL-4R und den Signalwegen herstellt, die in der Induktion zellulärer Proliferation involviert sind.

Die Region zwischen den Resten 437 und 557 mit der darin eingebetteten Aminosäuresequenz ${ }^{488}$ PLXXXXNPXYXSXSD (siehe Abb. 1) der IL-4R $\alpha-$ Kette ist für die Aktivierung von IRS-1/2 und der damit verbundenen IL-4-induzierten Aktivierung der Proliferation verantwortlich. Sie enthält ein stark konserviertes Tyrosin. Die Sequenz besitzt eine große Homologie zu Sequenzen der cytoplasmatischen Domäne des Insulinrezeptors und des Rezeptors für IGF-1, die ebenfalls mit dem IRS-1/2-Signalweg interagiert. Die Substitution des Tyrosins durch Phenylalanin blockiert den IRS-1/2-Signalweg, da in der IL-4R $\alpha$-Kette an der Position 497 nun keine Phosphorylierung mehr stattfinden kann (KEEGAN et al., 1994). Da diese Sequenz sowohl für Funktionalität des Insulinrezeptor als auch für die des IL-4R $\alpha$ bedeutsam ist, wird sie I4R-Motiv (Insulin IL-4 Rezeptor Motiv) genannt. IRS-1/2 Moleküle binden an das phosphorylierte Y497 mittels einer N-terminale PTB-Domäne an (GUSTAFSON et al., 1995). Weiterhin sind die Reste L489, P488 und I491 im I4R-Motiv der IL-4R $\alpha$-Kette für die Interaktion mit IRS-2 notwendig (WANG et al., 1998).

Der N-Terminus von IRS-1/2 enthält eine PH-Domäne (Pleckstrinhomologiedomäne) wie sie in einer Vielzahl von Signalmolekülen vorhanden ist (ZHOU et al., 1995). PH-Domänen scheinen eine Rolle in der Lokalisierung von Proteinen an der Plasmamembran zu spielen, da sie direkt mit Phosphatidylinositolmembranlipiden interagieren können (LEMMON et al., 
1995). IRS-1/2 werden phosphoryliert als Resultat der Interaktion mit dem aktivierten IL-4R. Eine Reihe der phosphorylierten Stellen interagiert direkt mit SH2-Domänen verschiedener Signalmoleküle, z.B. der SH2-Domäne der regulatorischen Untereinheit von PI3K. Dies verdeutlicht die Bedeutung von IRS-1/2 als cytosolische Brückenproteine (SUN et al., 1991; Sun et al., 1993; Sun et al., 1995).

Die primäre PI3K-Isoform, die durch IL-4 aktiviert werden kann, ist eine Klasse IA PI3K (siehe Abb. 5) bestehend aus der regulatorischen Untereinheit p85 und der katlytischen Untereinheit p110. Die p85 Untereinheit enthält zwei SH2-Domänen im C-Terminus und eine SH3-Domäne im N-Terminus (KAPELLER et al., 1994A; KAPELLER et al., 1994B). Die SH2-Domänen von p85 flankieren eine 104 AS-Sequenz, welche die Interaktion mit p110 ermöglicht (KLIPPEL et al., 1993, DHAND et al., 1994). Die p85 Untereinheit agiert als Adaptermolekül, indem es p110 mit tyrosinphosphorylierten Molekülen verbindet (FRUMAN, CANTLEY, 2002). Die IL-4R-Stimulation führt zur Bindung von p85 an phosphoryliertes IRS-1/2 Moleküle. IRS-1 hat vier, IRS-2 zehn potentielle p85 Bindestellen (SUN et al., 1995; Sun et al., 1993).

Die Interaktion von p85 mit IRS-1/2 mündet in einer Konformationsänderung der mit ihr fest verbundenen p110 Untereinheit und führt damit zur Aktivierung ihrer katalytischen Eigenschaften (DHAND et. al., 1994). Durch die Lipidkinaseaktivität der PI3K wird in vitro die Hydroxylgruppe am dritten C-Atom des Inositolringes von Phosphatidylinositolen der Zellmembran phosphoryliert (FRUMAN, CANTLEY, 2002). Die schnelle Produktion von Phosphatidylinositol-(3,4,5)-triphosphat und Phosphatidylinositol-(3,4)-dipahosphat gewährleistet die Aktivierung von zahlreichen Kinasen wie Proteinkinase $\mathrm{C}$ und die Akt Kinase (Proteinkinase B) (FrAnKe et al., 1997B; FrumAn, CANTLEY, 2002). Einmal aktiviert, phosphoryliert p110 auch Serin- und Threoninreste von Proteinen (DHAND et. al., 1994), besitzt also neben der Lipidkinaseaktivität auch Proteinkinaseaktivität. PI3K phosphoryliert Ser/Thr an IRS-1. Es ist durchaus möglich, dass eine Phosphorylierung von IRS-1/2 an Ser/Thr die Interaktion mit dem I4R-Motiv von IL-4R $\alpha$ verringert oder gar blockiert, so dass eine weitere IRS-1/2-Aktivierung verhindert wird. Dies würde als negatives Feedback der Regulierung des IRS-1/2-Signalweges dienen (PAZ et al., 1997).

Die Aktivierung des IRS-1/2-Signalweges ist unter Umständen verbunden mit der Aktivierung des Ras/MAPK-Weges in einer Reihe von Cytokinrezeptorstimulationen und Insulin. Die IL-4-bedingte Aktivierung des Ras/MAPK-Weges konnte in hämatopoetischen Zellen nicht durchgängig nachgewiesen werden (DURONIO et al., 1992; WELHAM et al., 
1994A; Welham et al., 1994B; Welham et al., 1995). Dies könnte ganz speziell von der untersuchten Zelllinie und dem Entwicklungsstadium der Zellen abhängen.

\subsection{Die Aktivierung von STAT6}

Während das I4R-Motiv von IL-4R $\alpha$ bedeutsam ist für die Aktivierung von Signalwegen, welche die Zellproliferation regulieren, sind andere Regionen des cytoplasmatischen Teils der IL-4R $\alpha-K e t t e$ für die Aktivierung von IL-4-induzierter Genexpression zuständig. Dies betrifft die Genregulierungsdomäne zwischen den Aminosäureresten 557 bis 657 (RYAN et al., 1996). Sie enthält drei konservierte Tyrosinreste (Y575, Y603, Y631) als potentielle Phosphorylierungsstellen und Interaktionsareale für SH2-Domänen von Signalproteinen. Die Mutation aller drei Tyrosinreste führt $\mathrm{zu}$ einer stark verminderten IL-4-induzierten Genexpression. Die Genregulierungsdomäne benötigt wenigstens ein intaktes Tyrosin, um seiner Funktion gerecht $\mathrm{zu}$ werden. Die Reste, welche die Tyrosine der Genregulationsdomäne unmittelbar umgeben, sind GYK/QXF (Y575 in GYQEF, Y603 in GYKAF, Y631 in GYKPF, siehe Abb. 1). Sie stellen den Anbindungsbereich für die STAT6-Moleküle dar. Das zentrale Tyrosin des I4R-Motivs ist eingebettet in die Sequenz AYRSF. Durch seine Ähnlichkeit mit den tyrosinhaltigen Sequenzen der Genregulationsdomäne kann auch das I4R-Motiv als schwache Bindestelle für STAT6 fungieren (NELMS et al., 1999).

Die Entdeckung der STAT-Moleküle (Signal transducers and activators of transcription) enträtselte den Mechanismus der cytokinabhängigen Expression für IL-4 und für andere Cytokine. Ein oder mehrere STAT-Moleküle werden von jedem Mitglied der Hämatopoetinrezeptorfamilie und von den mit ihnen verwandten Rezeptoren aktiviert. STATs dienen der direkten Verbindung zwischen dem Cytokinrezeptor und dem Transkriptionsapparat. Die Phosphorylierung durch Jak ist für die STAT-Aktivierung essentiell. Deshalb wird diese Art der Signaltransduktion auch Jak-STAT-Weg genannt (DARNELL, 1997).

STAT6 wird durch IL-4-Stimulation aktiviert und ist essentiell für die Expression vieler IL-4-abhängiger Gene oder verbessert zumindest deren Expression, z.B. VCAM-1, Eotaxin, MCP-1, MCP-3, MHC Klasse II, CD23, IgE, IgG1, IL-4Ra (KAPLAN et al., 1996; MALERBA, PIGNATTI, 2005; RYAN et al., 1996; NAKANISHI et al., 1996). STAT6 bindet am phosphorylierten Rezeptor (Y575, Y603, Y631) über seine stark konservierte SH2-Domäne. Dies führt zur Phosphorylierung von STAT6 an einem C-terminalen Tyrosinrest (DARNELL, 
1997). STAT6 dissoziiert vom Rezeptor und bildet Homodimere über die SH2-Domänen und den phosphorylierten C-terminalen Tyrosinresten. Diese Komplexe wandern zum Kern wo sie an spezifische DNA-Sequenzen in der Promotorregion von IL-4-abhängigen Genen binden. STAT-Moleküle erkennen palindrome Sequenzen. Diese variieren in Abhängigkeit des zu bindenden STAT, weisen aber meistens das Grundmuster TTC $(\mathrm{N})_{\mathrm{n}} \mathrm{GAA}$ auf. Jedes Monomer eines STAT-Komplexes assoziiert mit einer Hälfte des Palindroms (CHATTERJEE-KISHORE et al., 2000). STAT6 bindet vorrangig an die Sequenz TTC(N)$)_{4}$ GAA (EHRET, et al., 2001; SEIDEL, et al., 1995).

Es ist bekannt, dass STATs mit Transkriptionsfaktoren stabile Komplexe bilden. Dies konnte für STAT6 und NF-кB mittels Coimmunpräzipitation nachgewiesen werden (SHEN, STAVNEZER, 1998). Die Kooperation mit NF-кB ist wichtig für die Transkriptionsaktivierung des IgE-Gens durch STAT6 (MikitA et al., 1996; SHEN, STAVNEZER, 1998).

Die Bedeutung von STAT6 wurde in verschiedenen Studien an knockout Mäusen demonstriert. STAT6-knockout Mäuse zeigen keine nachweisbare Menge an IgE. Sie reagieren auf die Infektion mit dem Helminthen Nippostrongylus brasiliensis oder auf die Injektion von anti-IgD mit einem sehr geringen Anstieg von IgE (ca. 1\% des IgE-Wertes des Wildtyp). STAT6-knockout Mäuse sind nicht in der Lage, eine TH2-Antwort gegen Nippostrongylus brasiliensis zu initiieren. Sie können den Parasiten dadurch nicht erfolgreich abwehren. Lymphozyten von STAT6-knockout Mäusen können keinen Klassenswitch zu IgE und IgG1 nach Stimulation durch LPS und IL-4 durchführen. Diese Tiere zeigen keine IL-4-induzierte Genexpression, wie die Hochregulierung von CD23, MHC Klasse II und IL-4R. Nach IL-4-Gabe erfolgt keine Unterdrückung der Differenzierung von naiven T-Zellen in IFN $\gamma$-produzierende TH1-Zellen. Diese spezifische Immundefizienz von STAT6-/- Mäusen stammt von der Blockade der IL-4-abhängigen TH2-Zellentwicklung und von der Unfähigkeit einen Klassenswitch in B-Zellen zu initiieren, weil IL-4 nicht gebildet wird und weil STAT6-/- Zellen unempfänglich für die IL-4-Stimulation sind (NAKANISHI et al., 1996; URBAN et al., 1998). Die Symptomatik, welche von STAT6-knockout Mäusen gezeigt wird,

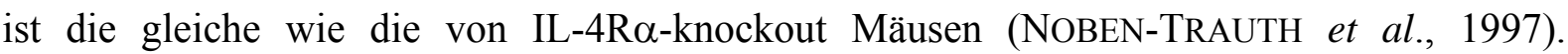
Analysen von STAT6-defizienten Mäusen zeigen, dass IL-4 als Co-Mitogen für B- und T-Zellen trotzdem wirksam ist. IL-4 schützt auch hier B- und T-Lymphozyten vor spontaner Apoptose (VELLA et al., 1998).

Ein Polymorphismus in der Kernsequenz der STAT6-Bindestelle um das Tyrosin 575 der IL-4R $\alpha$-Kette (Q576R) wurde bei Patienten mit Hyper-IgE-Syndrom und bei Patienten mit atopischer Dermatitis gefunden. Dieser Polymorphismus geht mit einer gesteigerten 
Expression von CD23 und verstärkter IgE-Produktion einher. Der Austausch von Q nach R scheint die Bindungsfähigkeit für STAT6 zu verbessern (HERSHEY et al., 1997).

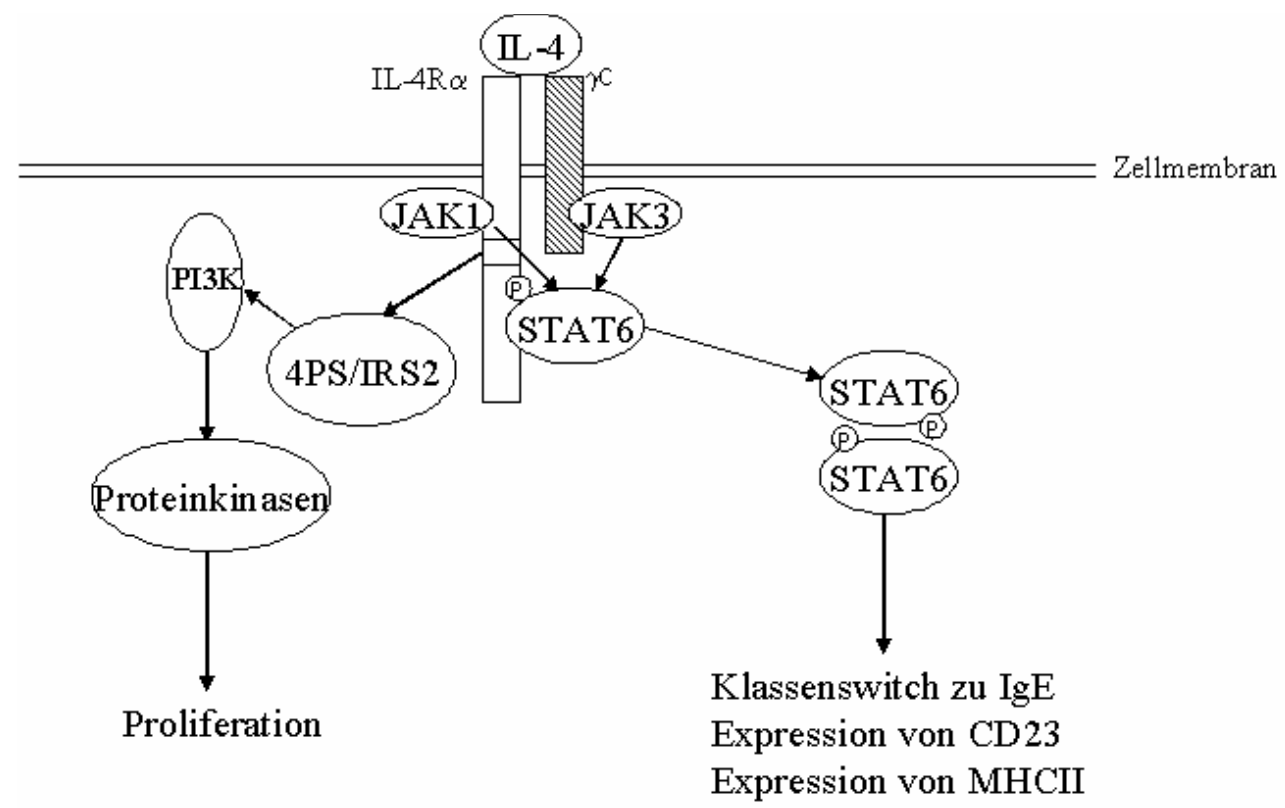

Abb. 2: Schema der IL-4-Signaltransduktionskaskade im Typ I IL-4R in hämatopoetischen Zellen (TAKEDA et al., 1997; CHATILA, T. A., 2004).

\subsection{Modulation der IL-4-Rezeptor-Signalwege}

\subsection{Die Rolle von Phospho-Tyrosin-Phosphatasen}

Die Tyrosinphosphorylierung und Interaktion von Signalproteinen repräsentiert den Beginn vieler Signalwege. Die allgemeine Kontrolle von Tyrosinphosphorylierungen obliegt den Phospho-Tyrosin-Phosphatasen (PTP). Die SH2-enthaltenden Phosphatasen SHP-1 und SHP-2 als auch die SH2-enthaltende Inositol-5-Phosphatase (SHIP) sind wichtige Modulatoren in Cytokinsignalwegen (SCHARENBERG, KINET, 1996).

SHP-1/2 interagieren über ihre SH2-Domäne mit so genannten ITIMs (immunregulatory tyrosine based inhibitory motif). Während SHP-2 in vielen Geweben exprimiert wird, kommt SHP-1 vorrangig in hämatopoetischem Gewebe vor und ist dort unabdingbar für die Regulation von cytokininduzierten Signalwegen (DAVID et al., 1995). Eine ITIM-Region ist am C-Terminus der IL-4R $\alpha$-Kette zu finden. Es ist daher wahrscheinlich, dass SHP-1/2 über diese Region eine regulierende Funktion auf die Phosphorylierungsreaktionen, die in Assoziation mit dem IL-4R stattfinden, ausübt. HAQUE et. al. wiesen nach, dass eine spezifische Hemmung dieser Phosphataseaktivitäten zu einer Jak1 und STAT6-Aktivierung 
führt. Damit wäre die Regulationsfunktion von SHP-1/2 belegt (HAQUE et al., 1998). Laut DAVID et al. wirkt SHP-1 auf Jak1 ein und ist deshalb sein direkter Regulator (DAVID et al., 1995). KASHIWADA et al. zeigten, dass Zellen mit einer Mutation in Position 713 von IL-4R $\alpha$ gleiche Level an Jak1 und phosphoryliertem IRS-2 aufweisen wie diejenigen, die keine Mutation an Tyrosin 713 trugen, was wiederum vermuten lässt, dass frühe Prozesse in der Signaltransduktion des IL-4R durch die Funktionen des ITIM nicht beeinflusst werden (KASHIWADA et al., 2001). Dies würde den Ergebnissen von DAVID et al. und HAQUE et. al., welche eine Beeinflussung der Jak1 Aktionen beobachteten, widersprechen. Das ITIM der IL-4R $\alpha$-Kette scheint vielmehr Teil eines gezielten Regulationsmechanismus für STAT6 zu sein. Die Mutation Y713F im ITIM bewirkt eine signifikante Erhöhung der STAT6-Phosphorylierung, was wiederum eine höhere Bindungsaktivität der STAT6-Moleküle untereinander und damit eine stärkere Aktivierung des IL-4R $\alpha$-abhängigen Jak-STAT-Weges zur Folge hat (KASHIWADA et al., 2001).

Im Gegensatz zu SHP-1/2, die auf Phosphoproteine Einfluss nehmen, agiert SHIP mit dem 5'Phosphat von Phosphatidylinositol-(3,4,5)-triphosphat und reguliert somit den PI3K-Weg durch Dephosphorylierung der PI3K-Produkte (SchARENBERG, KINET, 1996). Diese Phosphataseaktivität mündet nicht zwangsläufig in eine negative Regulation des PI3K-Weges. Die Bildung von Phosphatidyinositol-(3,4)-diphosphat ist ein wichtiger Aktivator der antiapoptotischen Kinase Akt (FRANKE et al., 1997).

\subsection{Negative Regulation des Jak-STAT-Weges}

Ein zweiter regulatorischer Mechanismus spielt eine spezifische Rolle in der Modulation des Jak-STAT-Weges. Es handelt sich hierbei um eine Reihe von Proteinen mit SH2-Domänen, deren Expression durch die cytokinstimulierte STAT-Aktivierung induziert wird: CIS (cytokin induzierte SH2), SOCS-1, 2, 3 (Suppressoren der Cytokinsignale), JAB (Jak bindend), SSI-1 (STAT induzierter STAT Inhibitor). Sie werden innerhalb einer Stunde nach Cytokinstimulation gebildet. Die Mengen dieser Regulatoren sind cytokinabhängig. IL-4 erhöht die Expression von CIS und SOCS-3 vor allem in Knochenmarkzellen, stimuliert ebenso die Bildung von SOCS-1 und SOCS-2, aber in geringerem Umfang. Diese Regulationsproteine scheinen direkt mit aktivierten Januskinasen $\mathrm{zu}$ interagieren und sie dadurch zu hemmen. (STARR et al, 1997, NAKATA et al., 1997, ENDO et al., 1997). 


\subsubsection{Der IL-13-Rezeptor}

IL-13 wird von aktivierten T-Zellen sezerniert und ist mit IL-4 verwandt. Beide Cytokine liegen auf dem humanen Chromosom 5 und bei der Maus auf Chromosom 11. Das Protein IL-13 zeigt eine große Homologie zu IL-4. Biologisch teilen beide Cytokine viele Funktionen miteinander wie z.B. die Expressionssteigerung von MHC Klasse II auf B-Zellen und Makrophagen und den Klassenswitch zu IgE. Aber IL-13 ist nicht in der Lage, eine T-Zell-Polarisierung zu bewirken. Die Übereinstimmungen in den biologischen Funktionen von IL-4 und IL-13 lassen sich durch die Ähnlichkeit der Rezeptoren für diese Cytokine erklären. Ein Beweis hierfür ist die Tatsache, dass ein monoklonaler Antikörper gegen die $\alpha$-Kette des IL-4R auch die durch IL-13 induzierten Aktionen hemmt. IL-13 kann sowohl die $\alpha$-Kette des IL-4-Rezeptors als auch die des IL-13-Rezeptors nutzen, ebenso wie IL-4 den IL-4R $\alpha / \gamma c$ oder den IL-4R $\alpha /$ IL-13R $\alpha$ (siehe Abb. 3, TAKEDA et. al., 1997). Dies erklärt, warum eine Reihe von Zellen, die nicht die $\gamma \mathrm{c}-$ Kette exprimieren, trotzdem für IL-4 sensitiv sind (OBIRI et al., 1995; DAWSON et al., 1997). Die IL-13R $\alpha$-Kette, die von diesen Zelllinien exprimiert wird, bildet zusammen mit IL-4R $\alpha$ einen IL-4-bindenden Rezeptorkomplex. In der Tat ist IL-13R $\alpha$ der Assoziationspartner von IL-4R $\alpha$ in nichthämatopoetischem Gewebe (MURATA et al., 1998). Demzufolge spielt STAT6 nicht nur in der IL-4-Signaltransduktion eine entscheidende Rolle sondern auch in der von IL-13. Alle IL-13-bedingten Funktionen finden in STAT6-defizienten Mäusen nicht statt (KAPLAN et. al., 1996; TAKEDA et al., 1999).

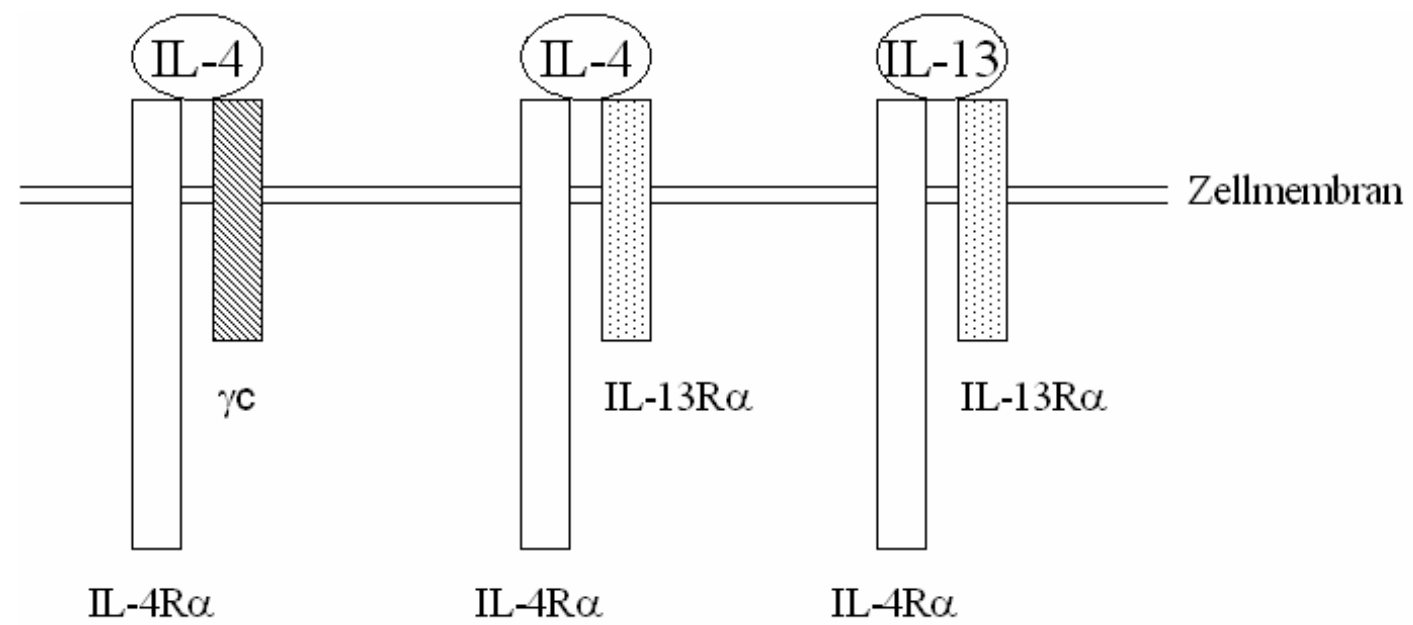

Abb. 3: Modell des IL-4- und des IL-13-Rezeptorkomplexes. IL-4 bindet den Komplex aus IL-4R $\alpha$ und $\gamma \mathrm{c}$ (Typ I IL-4R) als auch den aus IL-4R $\alpha$ und IL-13R $\alpha$ (Typ II IL-4R). IL-13 bindet den Komplex aus IL-4R $\alpha$ und IL-13R $\alpha$ (TAKEDA et al., 1997). 
IL-4R $\alpha$ ist essentiell für die Signaltransduktion beider Cytokine. Durch die Paarung von IL-4R $\alpha$ mit definierten Partnerketten und der daraus resultierenden Bildung verschiedener Rezeptorheterodimerkomplexe wird nach Bindung eines entsprechenden Liganden die jeweilige spezifische Signaltransduktion in Gang gesetzt. Man unterscheidet je nach Partnerkette den Typ I IL-4R vom Typ II IL-4R. Typ I IL-4R besteht aus IL-4R $\alpha$ und der $\gamma c-K e t t e$, die auch als Bestandteil anderer Cytokinrezeptoren auftritt, z.B. bei IL-2R, IL-7R, IL-9R und IL-15R, und deshalb als common gamma Untereinheit bezeichnet wir. Typ I IL-4R kommt auf hämatopoetischen Zellen vor und ist hochspezifisch für IL-4. Beim Typ II IL-4R bindet IL-4R $\alpha$ die Partnerkette IL-13R $\alpha 1$. Diesen Rezeptor findet man auf hämatopoetischen als auch bei nichthämatopoetischen Zellen wie dem Epithel der Atemwege. Typ II IL-4R bindet nicht nur IL-4 sondern auch IL-13. IL-13 interagiert zuerst mit IL-13R $\alpha$, welches nur eine geringe Affinität für IL-13 besitzt. Danach wird die IL-4R $\alpha$-Kette gebunden, und die Affinität für IL-13 erhöht sich um ein Vielfaches (AMAN et al., 1996). Für IL-13 existiert noch ein weiterer Rezeptor mit hoher Spezifität aber ohne erkennbare biologische Funktion im Sinne einer Signalübertragung. Dieser einkettige Rezeptor besteht nur aus der

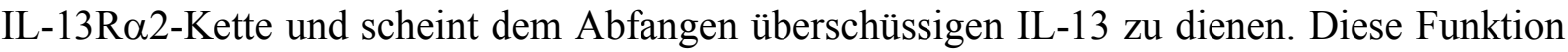
könnte als Regulation der IL-13-Wirkung angesehen werden und würde somit der Vorbeugung einer allergischen Reaktion dienen. Viele Studien offenbaren tatsächlich die Dominanz von IL-13 gegenüber IL-4 beim Induzieren von Merkmalen allergischer Atemwegserkrankungen, wie z.B. Becherzellmetaplasie, Schleimüberproduktion, Gewebseosinophilie und Ventilationstörung. Somit wäre eine entsprechende Inhibition der

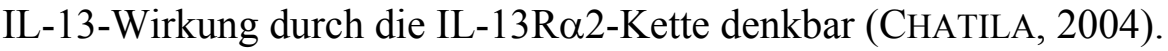

\subsubsection{Sieben-Helix-Rezeptoren (Serpentin-Rezeptoren)}

\subsubsection{Charakteristika}

Bei unreifen DC findet man Rezeptoren für inflammatorische Mediatoren, bei reifen DC Rezeptoren für das Homing in lymphatische Organe und für die Bindung an T-Lymphozyten. Anders gesagt exprimieren DC während ihrer Reifung wechselnde Muster von stadienspezifischen Oberflächenmolekülen. Hierzu gehören die so genannten Sieben-Helix-Rezeptoren. Diese spielen zusammen mit den an sie gekoppelten G-Proteinen eine zentrale Rolle bei vielen Signaltransduktionen aller Eukaryonten und besitzen eine lange Evolutionsgeschichte. Aufgrund ihres phylogenetischen gemeinsamen Ursprungs sind 
Serpentin-Rezeptoren durch gemeinsame Grundprinzipien gekennzeichnet:

- $\quad$ Sieben-Helix-Rezeptoren entfalten ihre Wirkung immer über G-Proteine. G-Proteine sind auch immer an Sieben-Helix-rezeptoren gekoppelt.

- $\quad$ Sieben-Helix-Rezeptoren haben eine zentral gelegene Ligandenbindestelle in der Höhe der Lipiddoppelschicht.

- Die Ligandenbindung löst eine Konformationsänderung aus, die durch die intrazellulären Loops des Rezeptors weitergeleitet werden. Hierbei ist vor allem die dritte cytosolische Schleife von zentraler Bedeutung für die Signalübertragung auf die entsprechenden G-Proteine.

- Werden Sieben-Helix-Rezeptoren durch einen Liganden aktiviert, kommt es zum Austausch von GTP gegen GDP unter Beteiligung der assoziierten G-Proteine.

- $\quad$ Die Bindung von GTP an ein G-Protein löst dessen Aktivierung aus und es dissoziiert in die Untereinheiten $G_{\alpha}$ und $G_{\beta \gamma}$. Dadurch wird der aktivierte Rezeptor freigegeben. Das Signal wird fast immer durch die $\mathrm{G}_{\alpha}$-Unterinheit weitergeleitet, manchmal auch durch $\mathrm{G}_{\beta \gamma}$.

- $\quad$ Aktivierte Sieben-Helix-Rezeptoren werden durch Phosphorylierung von Serin- und Threoninresten in ihrem Carboxyterminus deaktiviert.

- $\quad \mathrm{G}_{\alpha}$ hydrolysiert das gebundene GTP zu GDP und überführt das G-Protein wieder in die inaktive Form, wodurch dessen Dissoziation aufgehoben werden kann und die Bindung an die cytosolische Seite des Serpentin-Rezeptors erneut möglich wird.

- Viele G-Proteine sind gegenüber dem Choleratoxin und dem Pertussistoxin sensitiv und können durch diese unkontrolliert aktivert bzw. inaktivert werden. Das Choleratoxin stabilisiert die Bindung von GTP am G-Protein (Aktivierung), das Petussistoxin die Bindung von GDP (Inaktivierung) (STRYER, 1995).

G-Protein-basierende Signalwege induziert über Serpentinrezeptoren aktivieren den einzigen Vertreter der Klasse IB PI3K, die PI3K $\gamma(\mathrm{Abb} .5)$. Deren katalytische Untereinheit ist die p110 $\gamma$. Nur sie assoziiert mit der regulatorischen Untereinheit p101, die wiederum spezifisch an das $\beta \gamma$-Dimer des aktivierten G-Proteins bindet und dadurch die PI3K $\gamma$ stimuliert. Die mit der $\beta \gamma$-Untereinheit von G-Proteinen-assoziierende $\mathrm{PI} 3 \mathrm{~K} \gamma$ produziert vor allem Phosphatidylinositol-(3,4,5)-Triphosphat und aktiviert anschließend die Proteinkinase B (FRUMAN, CANTLEY, 2002). 


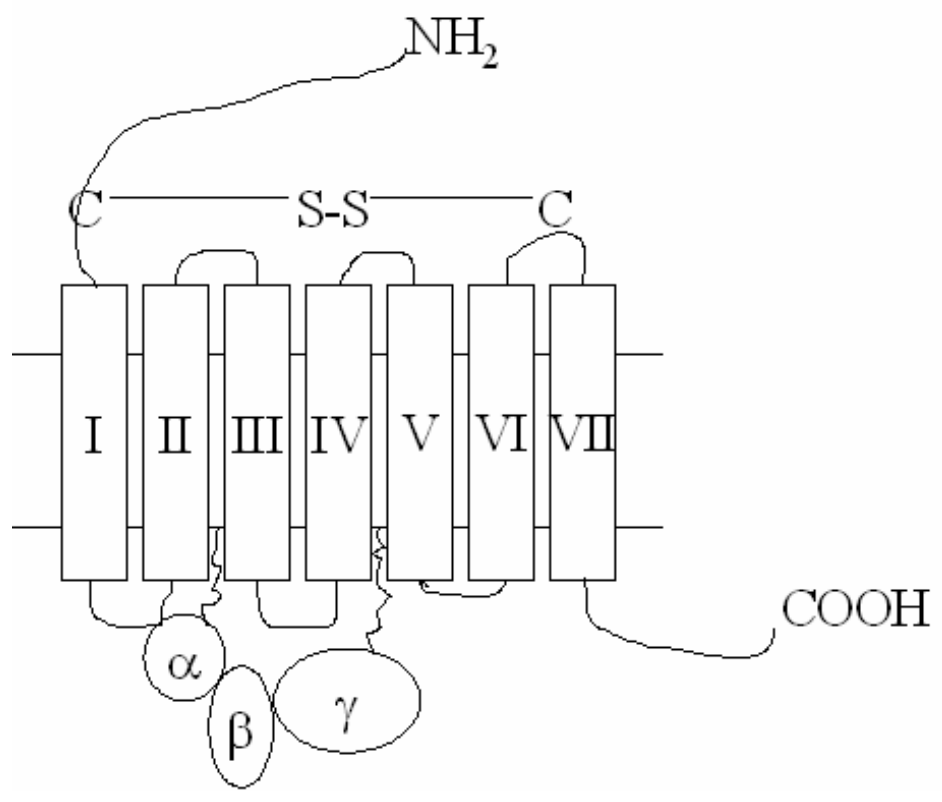

Abb. 4: Schematische Darstellung von Chemokinrezeptoren. Ligandenbindung und Spezifität werden durch die Bildung einer intramolekularen Disulfidbrückenbindung zwischen dem Aminoterminus und der dritten extrazellulären Schleife ermöglicht. Dies ist die Erkennungssequenz. Verglichen mit anderen GPCR besitzen Chemokinrezeptoren eine relativ kurze intrazelluläre dritte Schleife. Die drei intrazellulären Schleifen bilden die Binderegion für G-Proteine. Zusätzlich sind die $\mathrm{G} \alpha$ und die $\mathrm{G} \gamma$ Untereinheiten durch Myristylierung und Isoprenylierung an der Innenseite der Zellmembran verankert (Youn et al., 2002).

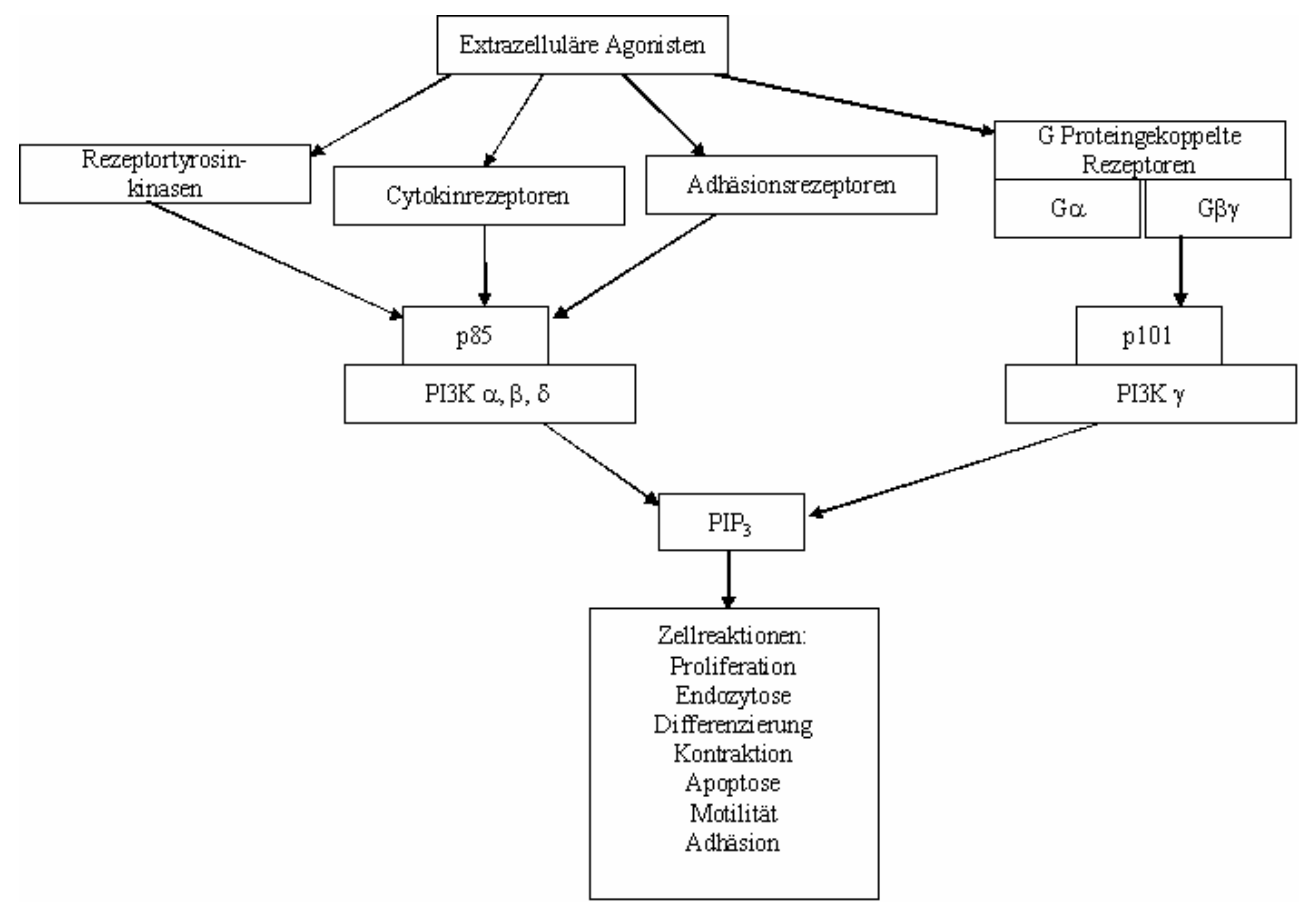

Abb. 5: Die vier PI3K-Isoenzyme in Säugerzellen als Mediatoren der Signaltransduktion. Die Lipidkinaseaktivität der PI3K wird durch spezifische Rezeptoren aktiviert (WETZKER, 2004). 


\subsubsection{Anaphylatoxine und ihre Rezeptoren}

Anaphylatoxine sind kleine Spaltprodukte von Komplementproteinen. Sie gehen nach der Aktivierung der Komplementkaskade durch proteolytische Spaltung aus den Faktoren C3, C4 und $\mathrm{C} 5$ als $\mathrm{C} 3 \mathrm{a}, \mathrm{C} 4 \mathrm{a}$ und $\mathrm{C} 5 \mathrm{a}$ hervor und gelten als proinflammatorische Peptide mit immunmodulierendem Charakter (JANEWAY, TRAVERS, 2002; WARD, 2004). Eine ihrer Hauptfunktionen ist die Rekrutierung von Leukozyten. Diese wandern dann zu den Orten von Infektionen, Entzündungen und Traumata. Gemeinsame strukturelle Merkmale der Anaphylatoxine sind drei intramolekulare Disulfidbrücken und die C-terminale Aminosäure Arginin (HUGLI, 1984). Komplementspaltprodukte werden durch spezifische Rezeptoren erkannt, die sich auf Endothelzellen, Mastzellen und Phagozyten (Monozyten, Makrophagen, unreifen DC, neutrophilen Granulozyten) befinden. Durch die Bindung der Anaphylatoxine an zugehörige Rezeptoren kommt es zum Flüssigkeitseinstrom und zur Einwanderung von inflammatorischen Zellen in den Ort der Entzündung. Eine übermäßige Produktion von Anaphylatoxinen führt zu einem generalisierten schockähnlichen Systemkollaps, der als anaphylaktischer Schock bezeichnet wird. Alle drei Anaphylatoxine bewirken eine Kontraktion der glatten Muskulatur und erhöhen die Gefäßpermeabilität. C5a und C3a induzieren die Produktion von Adhäsionsmolekülen auf Gefäßendothel und aktiveren Gewebsmastzellen. Dadurch kommt es zur Freisetzung von Histamin und TNF- $\alpha$ (JANEWAY, TRAVERS, 2002; WARD, 2004).

C5a ist, gefolgt von C3a, das Anaphylatoxin mit der höchsten biologischen Wirkung in vivo (JANEWAY, TRAVERS, 2002; WARD, 2004). Es ist ein potentes Chemotaxin für Granulozyten, Mastzellen, Monozyten und DC (McWiLliam et al., 1996; MORELLI et al., 1996; SOZZANI et al., 1995; YANG et al., 2000). In Bezug auf unreife DC verhält sich C5a wie die inflammatorischen Chemokine RANTES, MIP-1 $\alpha$ oder MCP-3. Im Unterschied zu diesen soll nach Meinung von YANG et al. das Anaphylatoxin C5a auch ein ebenso starker chemotaktischer Stimulus für reife DC sein (YANG et al., 2000).

Anaphylatoxinrezeptoren sind Mitglieder der G-Protein-gekoppelten Sieben-Helix-Rezeptoren (BOULAY et al., 1991; GERARD, GERARD, 1991; LANGKABEL et al., 1999). Ende der siebziger Jahre wurden C5aR (CHENOWETH et al., 1978) und C3aR (GLOVSKY et al., 1979) auf humanen Granulozyten beschrieben. C5aR war der erste Anaphylatoxin-Rezeptor, dessen molekulare Struktur aufgeklärt wurde. Er besteht aus 350 Aminosäuren. Der N-Terminus liegt extra-, der C-Terminus intrazellulär (WETSEL, 1995). 1996 wiesen WERFEL et al. erstmals nach, dass auch CD14 ${ }^{+}$humane Monozyten C5aR 
exprimieren (WERFEL et al., 1996A). Vier Jahre später berichteten Werfel et al. über das Vorkommen von C5aR auf humanen Mastzellen und Makrophagen der Haut (WERFEL et al., 1996B, WERFEL et al., 1997). Im Jahr 1997 gelang Gasque et al. der Nachweis von C5aR auf humanen Astrozyten, Mikrogliazellen und Endothelzellen des zentralen Nervensystems (GASQUE et al., 1997).

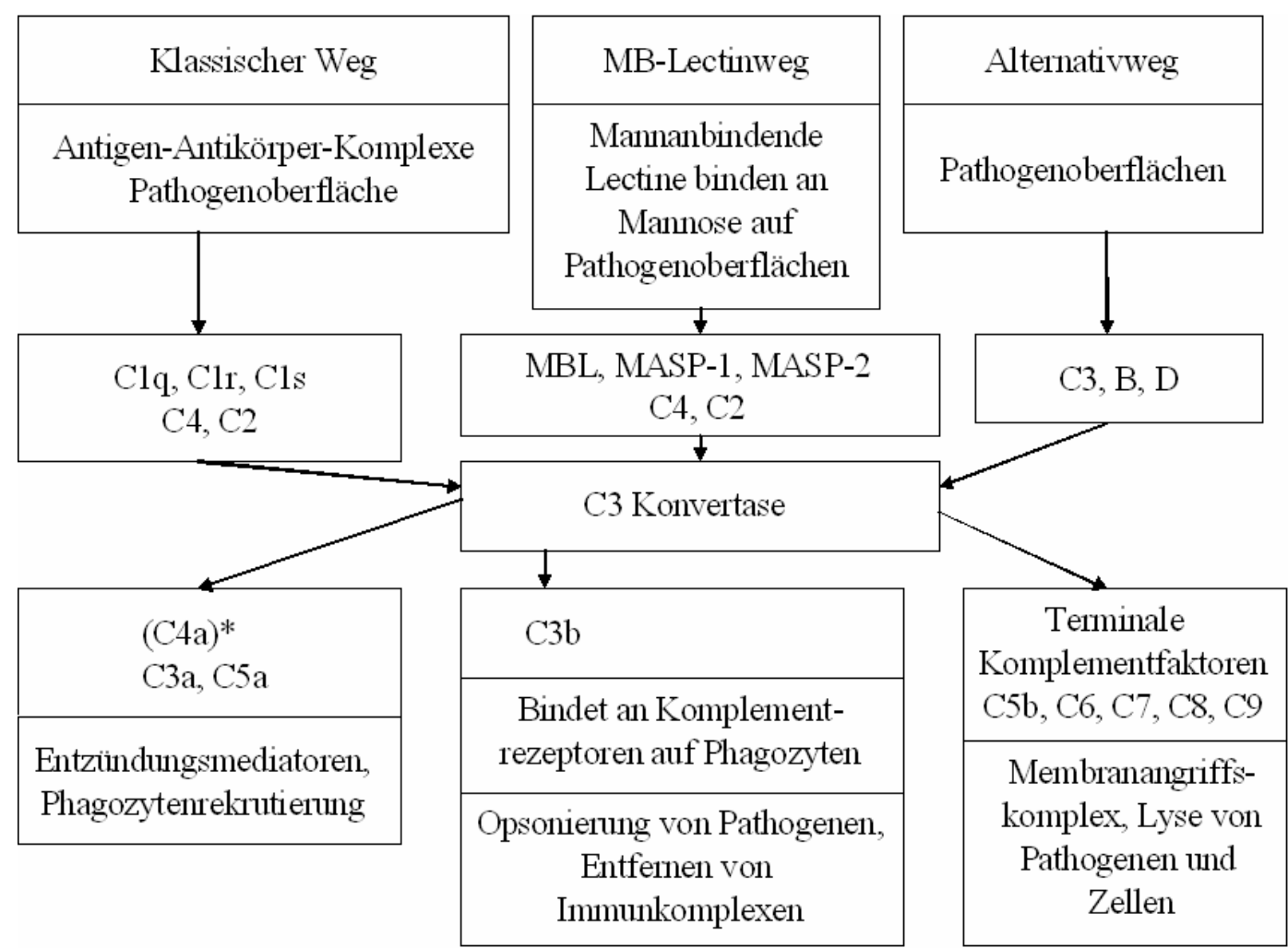

Abb. 6: Schematische Darstellung der Hauptkomponenten und Reaktionen. Die frühen Prozesse der drei Aktivierungswege enthalten eine Reihe von Spaltungsreaktionen, die alle in der Bildung von C3a und C3b aus C3 gipfeln. Diese Reaktion wird durch das Enzym C3-Konvertase katalysiert. C3b bindet kovalent an Bakterienzellmembranen und opsoniert diese dadurch, C5a und C5b entstehen bei der Spaltung von C5 durch die C5-Konvertase, die aus der C3-Konvertase und gebundenem C3b besteht. C5b treibt die späten Prozesse, die zur Bildung des Membranangriffskomplexes führen, an. Der Membranangriffskomplex bildet sich in der Membran von Zielzellen, die daraufhin ihre Zellintegrität nicht aufrechterhalten können. * C4a wird während der frühen Prozesse gebildet und nicht in Abhängigkeit von der C3-Konvertase. C4a besitzt eine schwache biologische Wirkung, C4b ist ein schwaches Opsonin (JANEWAY, TRAVERS, 2002).

\subsubsection{Chemokine und ihre Rezeptoren}

Chemokine (chemoattractant cytokines) gehören zu den Cytokinen. Sie bilden eine Familie von mehr als 50 strukturell verwandten kleinen Proteinen (6-14 kDa) mit chemotaktischer Wirkung und stimulieren Migration, Differenzierung und Aktivierung von Zellen, speziell von Phagozyten und Lymphozyten, und besitzen eine zentrale Rolle bei der Anlockung und Einwanderung von Leukozyten in Entzündungsherde und sekundäre lymphatische Organe 
(DIEU et al., 1998; DiEU-NOSJEAN et al., 1999; LUSTER, 1998; LUSTER, 2001; ZLOTNIK et al., 1999). Chemokine werden entweder konstitutiv oder im Verlauf inflammatorischer Reaktionen sezerniert (BAGGIOLINI et al., 1997). Sie können von verschiedensten Zelltypen wie Phagozyten, Lymphozyten, Endothelzellen, Keratinozyten, Fibroblasten und glatten Muskelzellen als Reaktion auf bakterielle Produkte, Viren und mechanischen Stress freigesetzt werden und fungieren als Lockstoff für Zellen mit entsprechenden Rezeptoren. Diese Zellen wandern entlang des Chemokingradienten in Richtung der höchsten Konzentration. Chemokine besitzen einen ähnlichen Grundaufbau. Sie bestehen aus einer N-terminalen Schleife, drei antiparallelen, miteinander in Verbindung stehenden $\beta$-Strängen und einer C-terminalen $\alpha$-Helix (BAGgiolini et al., 1997). Der größte Teil der Chemokine weist vier Cysteine auf, die durch Disulfidbrücken miteinander verbunden sind. Ihre Einteilung erfolgt anhand der Stellung und der Anzahl der Cysteine im N-Terminus. Man unterscheidet deshalb CXC-, CC-, C- und $\mathrm{CX}_{3} \mathrm{C}$-Chemokine.

Anhand dieses Ligandenspektrums lassen sich die vier Chemokinrezeptortypen unterteilen. Es gibt CR, CCR, CXCR, $\mathrm{CX}_{3} \mathrm{CR}$. Innerhalb einer Rezeptorgruppe ist die Sequenzähnlichkeit sehr hoch. Dies lässt vermuten, dass sie sich aus einem gemeinsamen Vorläufer entwickelt haben. Die Fähigkeit, eine große Anzahl von strukturell verschiedenen Liganden binden zu können, ist eine Eigenschaft vieler Chemokinrezeptoren (JANEWAY, TRAVERS, 2002). Chemokinrezeptoren gehören alle zu den G-Protein-gekoppelten Sieben-Helix-Rezeptoren. Auch sie enthalten Cysteinreste, die über eine Disulfidbrücke zur für die Ligandenbindung wichtigen Rezeptorkonformation beitragen. Allen Chemokinrezeptoren ist eine identische zweite intrazelluläre Schleife in der dritten transmembranen Region gemeinsam (BAGGIOLINI et al., 1997; MURPHY, 2000). Die Expression von Chemokinrezeptoren hängt ab vom Zelltyp sowie von dem Aktivitäts- und Differenzierungsgrad der Zelle (LUSTER, 2001). Beispielsweise gelten die Mitglieder der CC-Familie als typische Chemokine für die Monozytenwanderung. Die meisten Mitglieder der CC-Familie sind auf Chromosom 17 und die meisten CCRs auf Chromosom 3 codiert (JANEWAY, TRAVERS et al., 2002). Beispiele für diese Chemokine und ihre Rezeptoren sind MCP (monocyte chemotactic protein, wirkt auf T-Lymphozyten, Monozyten und basophile Granulozyten), RANTES (regulated upon activation normal T-cell expressed and secreted, wirkt auf T-Gedächtniszellen und Monozyten) und MIP-1 $\alpha$ (macrophage inflammatory protein $1 \alpha$ ) (BAGGIOLINI et al., 1997). Aktuell werden zehn CC-Rezeptoren (CCR1-10) unterschieden (LUSTER, 2001). Defizienzen in der Produktion bestimmter Cytokine oder deren Rezeptoren führen zu einer beeinträchtigten Fähigkeit, Entzündungsreaktionen $\mathrm{zu}$ initiieren. Des Weiteren sind 
Chemokinrezeptoren als Corezeptor für Pathogene wie, HIV, SIV, FIV u.a., von großem Interesse für die Forschung. 


\subsection{PROBLEMSTELLUNG}

Ein Hauptmerkmal von unreifen DC ist ihre Fähigkeit in Richtung von inflammatorischen Chemotaxinen wie Anaphylatoxinen und Chemokinen zu wandern. Dies ermöglicht den unreifen DC zu den Orten der Entzündung zu gelangen wo sie Antigen aufnehmen können. Damit wird ihre Ausreifung induziert (SOZZANI et al., 1995; SOZZANI et al., 1997). Der Reifungsprozess führt durch den Einfluss inflammatorischer Stimuli zur Herunterregulierung von Rezeptoren für inflammatorische Chemotaxine (CAUX et al., 2000) und gleichzeitig zur Hochregulation von CCR7, dem Rezeptor für die konstitutiven Chemokine CCL19 und CCL21. Dieser Prozess ist Voraussetzung für die Migration der DC zu den sekundären Lymphorganen (DIEU et al., 1998; SALLUSTO et al., 1998).

$\mathrm{PGE}_{2}$ als potenter Modulator von Immunantworten (TILLEY et al., 2001; HARRIS et al., 2002) wird derzeit zusammen mit anderen proinflammatorischen Mediatoren häufig zu Reifung von MoDC für experimentelle und klinische Zwecke eingesetzt (JONULEIT et al., 1997). Die PGE $_{2}$-abhängige CCL19/CCL21-vermittelte Signaltransduktion und Migration von DC ist durch einen anderen Mechanismus reguliert als die Modifikation der Expression des zugehörigen Rezeptors CCR7 (SCANDELLA et al., 2002; SCANDELLA et al., 2004; LUFT et al., 2002). Es ist bekannt, dass $\mathrm{PGE}_{2}$ für die DC-Mobilisierung in Richtung des proinflammatorischen Anaphylatoxin C5a zwingend benötigt wird, ohne allerdings die C5aR Expression signifikant zu beeinflussen. $\mathrm{PGE}_{2}$ scheint grundsätzlich für die Regulierung des Migrationsverhaltens von DC notwendig zu sein (LEGLER et al., 2006).

IL-4 ist in Kombination mit GM-CSF unabdingbar für die Generierung von DC aus Monozyten in vitro (SALLUSTO, LANZAVECCHIA, 1994; RoMANI et al., 1994). Monozyten kultiviert mit IL-4 und GM-CSF entwickeln sich zu unreifen DC. IL-4 ist in der Lage, die Migartionskapazität von DC zu beeinflussen, da dieses Cytokin die Expression und die Funktion der Anaphylatoxinrezeptoren $\mathrm{C} 5 \mathrm{aR}$ und $\mathrm{C} 3 \mathrm{aR}$ herunterreguliert (SORURI et al., 2003A). IL-13, ebenfalls ein prototypisches TH2-Cytokine, kann wegen seiner funktionellen Überlappung mit IL-4 durch die gemeinsame Verwendung von IL-4R $\alpha$ und der damit verbundenen Signaltransduktionswege (Janus-Kinase/Signal transducer and activator of transcription (JAK/STAT) Pfad, PI3K und MAPK Aktivierung) ebenfalls für die Generierung von unreifen DC herangezogen werden (PIEMONTI et al., 1995; CHATILA, 2004; KeLlYWELCH, 2003).

Da die Wanderungsfähigkeit eine kritische Funktion der DC darstellt, sollten in dieser Studie folgende Aspekte näher beleuchtet werden: 
(1) Einfluss von IL-4/IL-13 auf die Migrationseigenschaften von DC und Monozyten/Makrophagen in Richtung verschiedener inflammatorischer Chemotaxine

(2) Untersuchung der an der IL-4/IL-13 induzierten Modulation der chemotaktischen Rezeptoren beteiligten Signaltransduktion

(3) Untersuchung der regulatorischen Rolle von $\mathrm{PGE}_{2}$ auf die Expression und Funktion ausgewählter chemotaktischer Rezeptoren 


\section{MATERIAL UND METHODEN}

\subsection{Material}

\subsubsection{Medien, Seren, Puffer}

Adhärenzmedium

Ampullenwasser 101

Blocking-Reagenz

BMDC-Medium

BSA Fraktion 5

CB-Kryomedium

Chemotaxismedium

Erythrozytenlysispuffer

FACS-Puffer

FACS-Fix

FCS

Hämacolor Schnellfärbung

Humanes autologes Serum

IMDM

Indo-1

Krebs-Ringer-Lösung

Kulturmedium
RPMI 1640; $5 \%$ autologes Serum; 100 IU/ml

Penicillin; $100 \mu \mathrm{g} / \mathrm{ml}$ Streptomycin

zum Ansetzen von Puffern u.a., Fresenius Kabi

AG, Bad Homburg

$\gamma$-Globulin, human, Cohn-Fraktion II, III, $1 \mathrm{~g}$, Sigma

RPMI 1640; 5 \% FCS; 100 IU/ml Penicillin; 100 $\mu \mathrm{g} / \mathrm{ml}$ Streptomycin, $1 \mu \mathrm{M} \beta$-Mercaptoethanol, 1\% Non Essential Amino Acids 100x

Serva, Heidelberg

$20 \% \mathrm{FCS}, 10 \%$ DMSO in IMDM

RPMI 1640; 1\% BSA; 100 IU/ml Penicillin; 100 $\mu \mathrm{g} / \mathrm{ml}$ Streptomycin

0,15 $\mathrm{mmol} / \mathrm{l} \quad \mathrm{NH}_{4} \mathrm{Cl} ; \quad 1,0 \mathrm{mmol} / 1 \quad \mathrm{KHCO}_{3}$;

0,1 mmol/1 Na $\mathrm{N}_{2}$ EDTA; $\mathrm{pH} 7,4$

$490 \mathrm{ml} \mathrm{PBS} ; 2,5 \mathrm{ml} 20 \% \mathrm{NaN}_{3}$ (Natriumacid);

\section{$7,5 \mathrm{ml} \mathrm{FCS}$}

PBS mit $1 \%$ Formalin

Fetales Kälberserum, FCS wurde für $30 \mathrm{~min}$ bei $56^{\circ} \mathrm{C}$ inaktiviert, Cambrex, Verviers, Belgien

Merck, Darmstadt

Blutbank, Universitätsklinikum Göttingen

Cambrex, Verviers, Belgien

Invitrogen, Karlsruhe

$140 \mathrm{mM} \mathrm{NaCl}, 4 \mathrm{mM} \mathrm{KCl}, 1 \mathrm{mM} \mathrm{MgCl} 2,10 \mathrm{mM}$

D-Glucose, $10 \mathrm{mM}$ HEPES, $1 \mathrm{mM} \mathrm{CaCl}_{2}$

RPMI 1640; 10 \% FCS; 100 IU/ml Penicillin; $100 \mu \mathrm{g} / \mathrm{ml}$ Streptomycin 
Medium I

Non Essential Amino Acids 100x

PBS

PKH 26

Pluronic F127

RPMI 1640

Trypanblau
RPMI 1640; 5 \% FCS; 100 IU/ml Penicillin; 100

$\mu \mathrm{g} / \mathrm{ml}$ Streptomycin

Biochrom, Berlin

Phosphatgepufferte Kochsalzlösung Dulbecco`s

Formula, Serva, Heidelberg

Sigma-Aldrich Chemie GmbH, Taufkirchen

Invitrogen, Karlsruhe

Cambrex, Verviers, Belgien

Merck, Darmstadt

\subsubsection{Medienzusätze, Cytokine, Chemokine, Anaphylatoxine}

rh C5a

rh C3a

rh Flt3-L

fMLP

rh GM-CSF

rm GM-CSF

rh IL-4

rm IL-4

rh IL-10

rm IL-10

rh IL-13

rm IL-13

Ionomycin, Calciumsalz

JNK Inhibitor II

\section{LL37}

LPS

LY 294002

rh MCP-1

rm MCP-1

rm M-CSF
Abteilung für Immunologie, Universität Göttingen, Prof. Zwirner

Abteilung für Immunologie, Universität Göttingen, Prof. Zwirner

Pepro Tech Inc Tebu, USA

Phoenix Pharmaceuticals, Karlsruhe

R\&D Systems

Pepro Tech Inc Tebu, USA

R\&D Systems

Pepro Tech Inc Tebu, USA

Pepro Tech Inc Tebu, USA

Pepro Tech Inc Tebu, USA

Pepro Tech Inc Tebu, USA

Pepro Tech Inc Tebu, USA

Sigma, Saint Louis, USA

Calbiochem, Merck Biosciences, Schwalbach

Phoenix Pharmaceuticals, Karlsruhe

Calbiochem, Merck Biosciences, Schwalbach

Calbiochem, Merck Biosciences, Schwalbach

Pepro Tech Inc Tebu, USA

Pepro Tech Inc Tebu, USA

Pepro Tech Inc Tebu, USA 


$\begin{array}{ll}\text { rh MDC } & \text { Pepro Tech Inc Tebu, USA } \\ \text { rm MDC } & \text { Pepro Tech Inc Tebu, USA } \\ \text { rh MIP-1 } \alpha & \text { Pepro Tech Inc Tebu, USA } \\ \text { rm MIP-1 } \alpha & \text { Pepro Tech Inc Tebu, USA } \\ \text { PD 98059 } & \text { Calbiochem, Merck Biosciences, Schwalbach } \\ \text { Penicillin/Streptomycin 100x } & \text { PAA, Cölbe } \\ \text { PGE }_{2} & \text { Sigma-Aldrich Chemie GmbH, Taufkirchen } \\ \text { SB 203580 } & \text { Calbiochem, Merck Biosciences, Schwalbach } \\ \text { rh SCF } & \text { Pepro Tech Inc Tebu, USA } \\ \text { rh TNF- } \alpha & \text { R\&D Systems, Wiesbaden } \\ \text { rh TPO } & \text { Pepro Tech Inc Tebu, USA }\end{array}$

\subsubsection{Reagenzien, Testkitts, Chemikalien}

$\mathrm{NH}_{4} \mathrm{Cl}$

$\beta$-Mercaptoethanol

DMSO

Ethanol

Formalin

$\mathrm{KCl}$

$\mathrm{KHCO}_{3}$

MACS-Separationskit für CD34 ${ }^{+}$Zellen

$\mathrm{MgCl}_{2}$

$\mathrm{NaCl}$

$\mathrm{Na}_{2}$ EDTA

$\mathrm{NaN}_{3}$

Trennmedium
Merck, Darmstadt

Merck, Darmstadt

Merck, Darmstadt

absolut, unvergällt, Merck, Darmstadt

37\%ig (v/v), Merck, Darmstadt

Merck, Darmstadt

Merck, Darmstadt

Miltenyi Biotec, Bergisch Gladbach

Merck, Darmstadt

Merck, Darmstadt

Merck, Darmstadt

Merck, Darmstadt

Lymphoprep $^{\mathrm{TM}}, \mathrm{d}=1,077 \mathrm{~g} / \mathrm{ml}+/-0,001 \mathrm{~g} / \mathrm{ml}$,

Nycomed Pharma, Oslo, Norwegen

\subsubsection{Kulturgefäße, Pipetten und andere Materialien}

in vitro Chemotaxiszubehör

Einmalspritzen
$8 \mu \mathrm{m}$, Transwell ${ }^{\circledR}$ Permeable Supports, Corning, Beyer-Laborbedarf, Düsseldorf, New York, USA $1 \mathrm{ml}, 10 \mathrm{ml}, 20 \mathrm{ml}$, B. Braun, Melsungen 
Eppendorf-Varipetten

FACS-Platten

FACS-Röhrchen

Glasgeräte, Glaspipetten

Kryoröhrchen

Multi-Adapter

Pasteurpipetten

Pipettenspitzen

Pipettierhilfe

Reagiergefäße

S-Monovette Z, $9 \mathrm{ml}$

Sterilfilter

TC-Schalen

6-Well-TC-Platten

24-Well-TC-Platten

Zentrifugenröhrchen

Zentrifugenröhrchen

\subsubsection{Tierversuche}

Mausstamm Balb/c

Mausstamm C57/BL6

Mausstamm SCID CB-17

Mausstamm Balb/c-STAT6-/-
$0,1-2,5 \mu 1,1-20 \mu 1,10-100 \mu 1,100-1000 \mu 1$

Eppendorf-Netheler-Hinz, Hamburg

96 Rundbodenwells, Greiner, Nürtingen

$5 \mathrm{ml}, 75$ x $12 \mathrm{~mm} \phi$, Sarstedt, Nümbrecht, $5 \mathrm{ml}$, 75 x 12 mm $\phi, B D$, Erembodegem, Belgien

Schütt, Göttingen

$2 \mathrm{ml}$, Corning Incorporated New York

Sarstedt, Nümbrecht

Schütt, Göttingen

blau, gelb, Sarstedt, Nümbrecht

Weiß, Dunn, Asbach

IBS Integra Biosciences Pipetboy acu

0,5 ml; 1,5 ml; 2,0 ml; Sarstedt, Nümbrecht

Serummonovette, Sarstedt, Nümbrecht

0,2 $\mu \mathrm{m}, 0,45 \mu \mathrm{m}$, Minisart-plus, Sartorius, Göttingen

$1 \mathrm{ml}, 5 \mathrm{ml}, 10 \mathrm{ml}, 15 \mathrm{ml}$, Sarstedt, Nümbrecht

Sarstedt, Nümbrecht

Sarstedt, Nümbrecht

15 ml, Sarstedt, Nümbrecht

$50 \mathrm{ml}$, Sarstedt, Nümbrecht

Knochenmarksaufreinigung, syngene in vivo Wanderungsversuche mit $\mathrm{PKH}$ gefärbten Balb/c Zellen

Knochenmarksaufreinigung, syngene in vivo Wanderungsversuche mit $\mathrm{PKH}$ gefärbten C57/BL6 Zellen

xenogene in vivo Wanderungsversuche mit humanen Zellen, Gewicht 19-24 g, Charles River, Sulzfeld

Knochenmarksaufreinigung, Jackson Laboratory 
Narkose

\subsubsection{Laborgeräte}

Autoklav

Brutschrank

Durchflusszytometer

Durchlichtmikroskop

Invertmikroskop

Kamera

Kameramikroskop

Shaker

Sterilbank

Waagen

Wasserbad

Zentrifugen
Hostaket, Intervet

Rompun, Bayer, Leverkusen
Certoclav Hochdruck-Dampfsterilisator, Gruber \& Kaja, Druckguß und Metallwarenfabrik, Traun Wien, Österreich

Heraeus $\mathrm{CO}_{2}$-Auto Zero, Sollwerteinstellung, $\mathrm{CO}_{2}: 5 \%, \mathrm{~T}: 37^{\circ} \mathrm{C}$

FACS-Coulter EpicsXL-MCL

LSR II, Becton Dickinson

Calibur, Becton Dickinson

mit Halterung für NEUBAUER-Zählkammer, Zeiss, Oberkochen

Axiovert 35, Zeiss, Oberkochen

Nikon Coolpix 990

Axiophot, Zeiss, Oberkochen

Thermo Stat plus, Eppendorf, Hamburg

Herasafe, Heraeus, Hanau

Sartorius, Göttingen

GFL, Schütt Labortechnik

KBT 100-1P, HLC PROGR;

Thermomixer 5436, Eppendorf

Labofuge $400 \mathrm{R}$ mit Kühlfunktion, Heraeus, Hanau;

Plattenzentrifuge Megafuge 1.OR mit Kühlfunktion Heraeus, Hanau;

Varifuge 3.OR mit Kühlfunktion, Heraeus, Hanau;

Centrifuge 5415 D, Eppendorf

Centrifuge 5417 R, Eppendorf

Cytopro ${ }^{\mathrm{TM}}$ Cytocentrifuge 7620 , Wescor 


\subsubsection{Computersoftware}

Textverarbeitung

Tabellenkalkulation

FACS-Analyse
Word

Excell

WinMDI, FlowJo 


\subsection{Methoden}

\subsubsection{Kultivierung von humanen Zellen}

\subsubsection{Isolierung von $\mathrm{CD}^{+} 4^{+}$hämatopoetischen Vorläuferzellen aus Nabelschnurblut}

Prinzip:

Magnetpartikel gekoppelte Antikörper binden an ihr komplementäres Antigen und halten die so markierten Zellen im Magnetfeld gefangen, während nicht markierte Zellen das Magnetfeld passieren. Auf diese Weise isolierte Zellen können durch Eluieren gewonnen und weiterverarbeitet werden (Kultivierung, FACS-Färbung usw.).

$\underline{\text { Reagenzien: }}$

Waschpuffer: PBS

EDTA $2 \mathrm{mmol} / 1$

BSA $0,5 \%$

Lymphoprep $^{\mathrm{TM}}(\mathrm{RT})$

MACS Direct CD34 Progenitor Cell Isolation Kit: monoklonal Maus anti-human CD34 (Maus IgG1, Klon QBEND/10)

Durchführung:

Durch 2 M EDTA antikoaguliertes Nabelschnurblut wurde 1:4 bis 1:5 mit Waschpuffer verdünnt, gut durchmischt, jeweils $25 \mathrm{ml}$ auf $15 \mathrm{ml}$ Lymphoprep $^{\mathrm{TM}}$ (siehe auch 2.2.1.2.) in 50-ml-Röhrchen vorsichtig aufgeschichtet und für $20 \mathrm{~min}$ bei $400 \mathrm{~g}$ und RT ohne Bremse zentrifugiert. Danach wurde der Großteil des gelblichen Überstandes abgesaugt und die daran angrenzende Interphase in neuen 50-ml-Röhrchen gepoolt und mit Waschpuffer gewaschen (10 min bei $200 \mathrm{~g}$ und RT ohne Bremse). Nach Vereinigen der Pellets wurde abermals zentrifugiert für $5 \mathrm{~min}$ bei $200 \mathrm{~g}$ bei RT mit Bremse, der Überstand verworfen, das Pellet in 5 $\mathrm{ml}$ Erythrozytenlysispuffer aufgenommen und für $5 \mathrm{~min}$ bei $37^{\circ} \mathrm{C}$ inkubiert. Anschließend wurde das Röhrchen bis $50 \mathrm{ml}$ mit Waschpuffer aufgefüllt und wieder für $5 \mathrm{~min}$ bei $200 \mathrm{~g}$ und RT mit Bremse zentrifugiert. Nach Absaugen des Überstandes erfolgte das Resuspendieren 
des Pellets in $300 \mu \mathrm{l}$ Waschpuffer $/ 10^{8}$ Zellen. Durch Zugabe von $100 \mu \mathrm{l} \mathrm{Fc-Blocking-}$ Reagenz $/ 10^{8}$ Zellen und Inkubation auf Eis für 20 min sollten die Fc-Rezeptoren der Zellen abgesättigt werden, um unspezifische Bindungen mit den Anti-CD34-Antikörpern zu vermeiden. Während der Inkubationszeit wurde die Zellsuspension ab und zu vorsichtig geschwenkt, um eine gleichmäßige Verteilung der Blockantikörper zu gewährleisten. Anschließend erfolgte die Zugabe von $100 \mu \mathrm{CD}$ CD-Microbeadlösung/10 ${ }^{8}$ Zellen. Nach einer 30 minütige Inkubation bei $4^{\circ} \mathrm{C}$ unter ständigem Durchmischen wurden die Zellen vorsichtig zweimal mit Puffer gewaschen, in $1000 \mu \mathrm{l}$ Puffer aufgenommen und auf eine MS-Säule, die im Magnetfeld des MACS-Separators platziert war, pipettiert. Die Säule wurde vollständig mit Puffer durchgespült und danach mit der Zellsuspension versehen. Nachdem die Suspension die Säule passiert hat und diese drei Mal mit Puffer gespült wurde, konnte sie aus dem Magnetfeld entfernt und in einem geeigneten Auffangröhrchen platziert werden. Nun erfolgte die Zugabe einer ausreichenden Menge Waschpuffer und mit dem zur Säule gehörenden Stempel drückte man die Zellen aus der Säule heraus. Der Vorgang wurde wiederholt, um sicherzugehen, dass alle in der Säule vorhandenen Zellen ausgewaschen wurden. Nach der Bestimmung der Anzahl der eluierten Zellen, wurden diese durch Zentrifugation pellettiert, anschließend in einer entsprechenden Menge IMDM-Medium (2 bis $3 \times 10^{5}$ Zellen/ml) inklusive der Cytokine Flt3-Ligand $(25 \mathrm{ng} / \mathrm{ml})$, TPO $(10 \mathrm{ng} / \mathrm{ml})$ und SCF $(20 \mathrm{ng} / \mathrm{ml})$ aufgenommen und auf eine 6-Well-Platte überführt ( $5 \times 10^{5}$ Zellen/ml, 2 ml/Well). Alle Arbeitsschritte sind so zügig wie möglich durchzuführen. Erscheint die Zellsuspension klumpig oder treten sichtbare Gerinsel auf, so ist die Suspension durch ein vorher angefeuchtetes Sieb oder Nylonnetz zu geben, um ein Verstopfen der Separationssäule zu vermeiden.

Die Dauer der Kultivierung der hämatopoetischen Vorläuferzellen erfolgte in Abhängigkeit ihres Proliferationsverhaltens über einen Zeitraum von vier bis sechs Wochen. Danach wurden die suspendierten Zellen geerntet, gezählt und $1 \times 10^{7} / \mathrm{ml}$ in CB-Kryomedium in flüssigem Stickstoff bis zur weiteren Verwendung eingefroren oder die Zellen unter Wechsel der Cytokine vom Proliferationscocktail zu GM-CSF mit und ohne IL-4 für zwei Wochen weiterkultiviert. Anteilig wurden GM-CSF/IL-4 Zellen zwei Tage vor der Ernte mit $250 \mathrm{ng} / \mathrm{ml}$ LPS stimuliert und somit innerhalb von $48 \mathrm{~h}$ zur Ausreifung gebracht. Zweck der LPS Stimulation war es, zu überprüfen, ob die Zugabe eines Reifungsmediators zur Ausbildung DC-spezifischer Oberflächenantigene führt. 


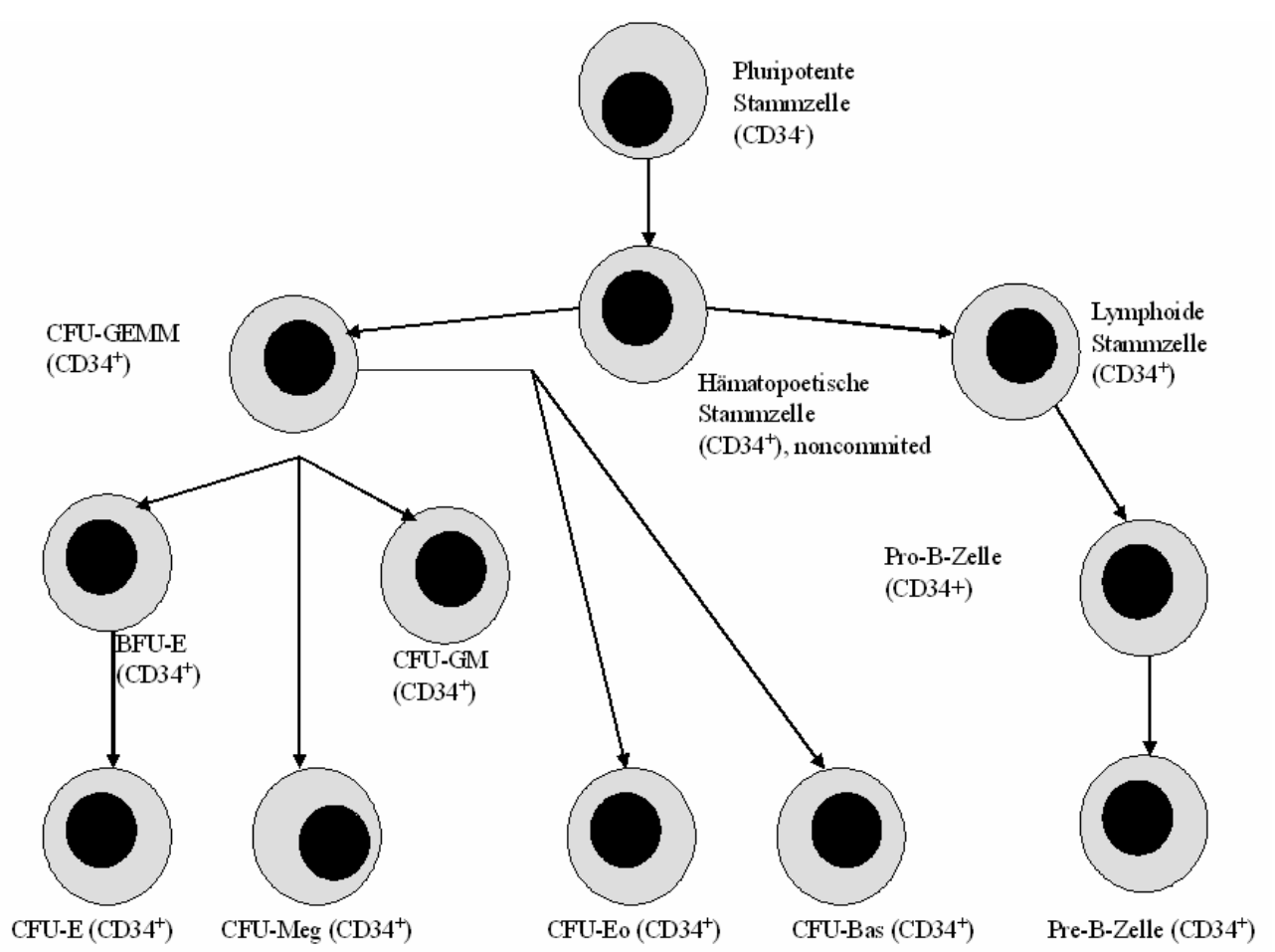

Abb. 7: CD34-Expression bei hämatopoetischen Zellen. Die pluripotenten Stammzellen sind in ihrer Entwicklung noch nicht festgelegt und können sich durch die Einwirkung spezifischer Mediatoren in verschiedene Richtungen entwickeln. Dieser Vorgang kann in vitro durch die Zugabe eines Cytokincocktails induziert werden. Je nach Art des Cocktails lassen sich Zellen verschiedener Populationen generieren. Die $\mathrm{CD}^{+}{ }^{+}$Zellen mit bereits festgelegter Entwicklungsrichtung können in vitro in Abhängigkeit ihrer Reihenzugehörigkeit überleben oder sie werden aufgrund fehlender Entwicklungs- und Differenzierungssignale apoptotisch. Auf diese Weise erhält man nach Ablauf der Kultivierung eine hohe Reinheit an gewünschten Zellen (Produktinformation MiLTENYi BiOTEC MACS).

\subsubsection{Leukaphereseaufarbeitung}

\section{Prinzip:}

Die Leukapherese oder Leukopherese ist eine Methode zur Auftrennung von Spenderblut. Hierbei gewinnt man ein Leukozytenkonzentrat. Andere Blutbestandteile, wie Plasma und Erythrozyten, werden dem Spender größtenteils zurückgegeben. Die Aufarbeitung des Leukozytenkonzentrates mittels einer Dichtegradientenzentrifugation über Lymphoprep ${ }^{\mathrm{TM}}$ $(5,6 \% \mathrm{w} / \mathrm{v})$ erlaubt die Gewinnung von peripheren blutmononukleären Leukozyten (PBMNL). Lymphoprep ist ficollhaltig. Ficoll selbst ist eine kolloidale Lösung aus Methylcellulose. Diese gewährleistet die Aggregation der noch enthaltenen Erythrozyten. Die Oberflächen der roten Blutzellen sind stark negativ geladen und stoßen sich gegenseitig ab. Diese physiologisch notwendigen Abstoßungskräfte werden vom Ficoll herabgesezt. Somit wird die Sedimentation der Erythrozyten erleichtert. In Lymphoprep ${ }^{\mathrm{TM}}$ befindet sich außer Ficoll auch Natriummetrizoat $(9,6 \% \mathrm{w} / \mathrm{v})$. Diese Verbindung mit hoher Dichte gestattet die Auftrennung der einzelnen Zellarten in Abhängigkeit ihrer jeweiligen spezifischen Dichte. 
$\underline{\text { Reagenzien: }}$

Lymphoprep $^{\mathrm{TM}}(\mathrm{RT})$

PBS

\section{Durchführung:}

Das Leukozytenkonzentrat wurde in eine sterile Flasche überführt, im Verhältnis 1:1 mit PBS (RT) vermischt und je $25 \mathrm{ml}$ der Zellsuspension auf jeweils $15 \mathrm{ml}$ Lymphoprep in 50-mlRöhrchen vorsichtig aufgeschichtet. Nach der Zentrifugation (20 min bei RT und $1000 \mathrm{~g}$ ohne Bremse) wurde der Großteil des gelblichen Überstandes abgesaugt, die daran angrenzende Interphase (sie enthält die PBMNL) gesammelt und in auf Eis vorgekühlte 50-ml-Röhrchen überführt. Diese wurden mit kaltem PBS aufgefüllt und bei $4^{\circ} \mathrm{C}$ und $1000 \mathrm{~g}$ ohne Bremse für 10 min zentrifugiert. Danach konnten die Überstände abgesaugt, die Zellpellets in 5 bis $10 \mathrm{ml}$ kaltem PBS resuspendiert, die Röhrchen aufgefüllt und anschließend bei $400 \mathrm{~g}$ und $4^{\circ} \mathrm{C}$ für 5 min mit Bremse zentrifugiert werden. Dieser Waschschritt wurde so oft wiederholt, bis die Überstände klar waren. Nach Beendigung des Waschvorganges erfolgte die Bestimmung der Gesamtzellzahl in einer Zählkammer nach Neubauer.

Zur Gewinnung von autologem Serum wurden die der Leukapherese beigegebenen Serummonovetten bei $1700 \mathrm{~g}$ und RT für $10 \mathrm{~min}$ ohne Bremse zentrifugiert, die Überstände (Serum) gesammelt und die Serummonovetten mit dem verbleibenden Blutkuchen verworfen.

\subsubsection{Gewinnung von Monozyten durch Adhärenz und ihre Kultivierung}

Prinzip:

Die Adhärenz von Monozyten ist auf speziellen Kunststoffoberflächen möglich und kann auf diesem Wege für die Gewinnung dieser Zellen ausgenutzt werden. Die Fähigkeit zur Adhärenz verlieren die Monozyten während der Kultivierung relativ schnell, wenn sie durch Zugabe von GM-CSF und IL-4 zu DC ausdifferenziert werden. Dieser Verlust der Adhärenzfähigkeit ist demzufolge reifungsabhängig (BJERKE, GAUDERNACK, 1985). Die durch die Leukaphereseaufarbeitung gewonnenen Zellen wurden in Abhängigkeit der nachfolgenden Versuche auf verschiedenen Zellkulturschalen und in unterschiedlicher Zahl ausplattiert: 
TC-Schale $1 \mathrm{ml}: 1,0 \times 10^{7}$ Zellen

TC-Schale $5 \mathrm{ml}: 2,5 \times 10^{7}$ Zellen

TC-Schale $10 \mathrm{ml}: 5,0 \times 10^{7}$ Zellen

TC-Schale $15 \mathrm{ml}: 1,0 \times 10^{8}$ Zellen

\section{$\underline{\text { Reagenzien: }}$}

Adhärenzmedium

PBS

Kulturmedium

\section{Durchführung:}

Die gewünschte Zellzahl der gewonnenen PBMNL wurde in Adhärenzmedium (1 ml für 1-ml-TC-Schalen, $3 \mathrm{ml}$ für 5-ml-TC-Schalen, $6 \mathrm{ml}$ für 10-ml-TC-Schalen, $10 \mathrm{ml}$ für 15-ml-TC-Schalen) suspendiert und auf die für den Versuch vorgesehene Anzahl TC-Schalen verteilt. Anschließend inkubierten die Kulturen eine Stunde im Brutschrank $\left(37^{\circ} \mathrm{C}, 5 \% \mathrm{CO}_{2}\right)$, um die Monozyten adhärieren zu lassen. Danach wurden die Überstände, welche die nicht adhärenten Lymphozyten enthielten, abgesaugt und die TC-Schalen wenige Male vorsichtig mit warmem PBS abgespült (5 ml PBS bei 1-ml-TC-Schalen, $15 \mathrm{ml}$ PBS bei 5-ml-TC-Schalen, $30 \mathrm{ml}$ PBS bei 10-ml-TC-Schalen, $75 \mathrm{ml}$ bei 15-ml-TC-Schalen), um die restlichen Lymphozyten zu entfernen. Dann erfolgte die Zugabe von $37^{\circ} \mathrm{C}$ warmem Kulturmedium (1 $\mathrm{ml}$ bei 1-ml-TC-Schalen, $5 \mathrm{ml}$ bei 5 -ml-TC-Schalen, $10 \mathrm{ml}$ bei 10-ml-TC-Schalen, $15 \mathrm{ml}$ bei 15-ml-TC-Schalen) und Cytokinen. Ansätze, die sieben Tage kultiviert werden sollten $\left(37^{\circ} \mathrm{C}, 5 \% \mathrm{CO}_{2}\right)$, wurden am dritten und fünften Tag gefüttert. Hierfür wurde die Hälfte des Mediums entnommen, zentrifugiert, der Überstand abgesaugt und durch neues Kulturmedium und entsprechende Cytokinmengen ersetzt. Die Aufarbeitung von Leukapheresen/Vollblut/Nabelschnurblut erfolgte zur Vermeidung von Infektionen unter der Sicherheits-Sterilbank (Klasse II). 


\subsubsection{Kulturzusätze im humanen System}

Je nach Fragestellung erfolgte die Zellkultivierung mit verschiedenen Cytokinansätzen in 6-Well-TC-Platten oder TC-Schalen.

\section{Reagenzien:}

Tab. 1: Art und Menge der verwendeten Cytokine und Mediatoren im humanen System

\begin{tabular}{|l|l|l|}
\hline Mediatoren & \multicolumn{2}{|l|}{ eingesetzte Menge } \\
\cline { 2 - 3 } & $\begin{array}{l}\text { Leukapherese bzw. } \\
\text { Vollblut }\end{array}$ & Nabelschnurblut \\
\hline - rh GM-CSF & $300 \mathrm{U} / \mathrm{ml}$ & $300 \mathrm{U} / \mathrm{ml}$ \\
- rh Flt3-L & $300 \mathrm{U} / \mathrm{ml}$ & $25 \mathrm{ng} / \mathrm{ml}$ \\
- rh IL-4 & $200 \mathrm{U} / \mathrm{ml}$ & $300 \mathrm{U} / \mathrm{ml}$ \\
- rh IL-10 & $200 \mathrm{U} / \mathrm{ml}$ & \\
- rh IL-13 & $20 \mathrm{ng} / \mathrm{ml}$ & $250 \mathrm{ng} / \mathrm{ml}$ \\
- LPS & $1 \mu \mathrm{M} / \mathrm{ml}$ & \\
- rh M-CSF & & $20 \mathrm{ng} / \mathrm{ml}$ \\
- PGE-2 & & $10 \mathrm{ng} / \mathrm{ml}$ \\
- rh SCF & & $10 \mathrm{ng} / \mathrm{ml}$ \\
- rh TPO & & \\
- rh TNF $\alpha$ & &
\end{tabular}

Durchführung:

Tab. 2: CD34 ${ }^{+}$hämatopoetische Stammzellen wurden unter folgenden Cytokinsituationen kultiviert

\begin{tabular}{|l|l|}
\hline Kultivierung & Cytokinansatz \\
\hline $\begin{array}{l}\text { bis zu } 8 \text { Wochen } \\
2 \text { Wochen }\end{array}$ & $\begin{array}{l}\text { SCF, TPO, Flt3-L } \\
\text { GM-CSF, GM-CSF/IL-4 }\end{array}$ \\
\hline
\end{tabular}


Tab. 3: Monozyten aus der Leukapherese bzw. Vollblut wurden unter folgenden Cytokinsituationen kultiviert

\begin{tabular}{|l|l|}
\hline $\begin{array}{l}\text { Dauer der } \\
\text { Kultivierung }\end{array}$ & Cytokineansätze \\
\hline 2 Tage & $\begin{array}{l}\text { ohne Cytokine, GM-CSF, IL-4, } \mathrm{PGE}_{2}, \mathrm{IL}_{-4} / \mathrm{PGE}_{2}, \mathrm{GM}-\mathrm{CSF} / \mathrm{IL}-4 ; \\
\text { GM-CSF/PGE }\end{array}$, GM-CSF/IL-4/PGE, M-CSF, M-CSF/IL-4 \\
3, 5 bzw.7 Tage & GM-CSF, GM-CSF/IL-4, GM-CSF/IL-4/PGE $2, \mathrm{MCSF}, \mathrm{M}-\mathrm{CSF} / \mathrm{IL}-4$ \\
\hline
\end{tabular}

\subsubsection{Kryokonservierung}

Prinzip:

Unter Verwendung von DMSO (Dimethylsulfoxid) können Zellen über einen langen Zeitraum in flüssigem Stickstoff eingelagert werden. Das DMSO dient der Vermeidung der Entstehung von großen Eiskristallen, welche die Zellwände zerstören würden. Durch den Einsatz einer vorgekühlten Styroporbox wird eine Einfrierkinetik von $1{ }^{\circ} \mathrm{C} / \mathrm{min}$ gewährleistet.

\subsection{Einfrieren von hämatopoetischen Vorläuferzellen aus Nabelschnurblut}

$\underline{\text { Reagenzien: }}$

CB-Einfriermedium

Durchführung:

Die Überstände der Kulturen wurden gepoolt, die 6-Well-TC-Platten mit PBS gespült und bei $400 \mathrm{~g}$ und RT für 5 min zentrifugiert. Das dabei entstandene Pellet wurde zweimal mit PBS gewaschen und anschließend in das auf Eis vorgekühlte Einfriermedium aufgenommen, in gekühlte Kryoröhrchen überführt und sofort bei $-70^{\circ} \mathrm{C}$ in einer Styroporbox eingefroren ( $1 \times 10^{7}$ Zellen/ml Einfriermedium). Am nächsten Tag war die Zellsuspension vollständig durchgefroren und die Kryoröhrchen konnten in flüssigen Stickstoff überführt werden. 


\subsection{Auftauen von hämatopoetischen Vorläuferzellen aus Nabelschnurblut}

$\underline{\text { Reagenzien: }}$

CB-Kulturmedium

Durchführung:

Ein Kryoröhrchen mit eingefrorenen Zellen wurde unter sterilen Bedingungen geöffnet und etwas kaltes CB-Kulturmedium hinzugetropft. Dadurch begann das Einfriermedium aufzutauen. Die aufgetaute Suspension wurde in CB-Kulturmedium pipettiert und abermals etwas CB-Kulturmedium in das Kryoröhrchen getropft. Der Vorgang wurde so oft wiederholt, bis das gesamte CB-Kryomedium mit den darin enthaltenen Zellen in CB-Kulturmedium überführt worden war. Das langsame Ausdünnen ist wichtig, da sonst das im Einfriermedium enthaltene DMSO nach dem Auftauen auf die Zellen toxisch wirkt. Durch die Verdünnung mit CB-Medium konnte die DMSO-Konzentration stark herabgesetzt werden. Die Suspension wurde nun bei RT und 400 g für 5 min zentrifugiert, dann die Zellen in warmem Medium aufgenommen, anschließend die Zellzahl bestimmt, mit CB-Kulturmedium auf die gewünschte Zellzahl (5 $\mathrm{x} \quad 10^{5}$ Zellen/ml) eingestellt, die entsprechenden Cytokine hinzugegeben und die Zellsuspension ausplattiert.

\subsubsection{Vitalistätstest}

Prinzip:

Der Azofarbstoff Trypanblau wird verwendet, um den Anteil vitaler Zellen nach einer Aufreinigung, Ernte oder einer ähnlich traumatisierenden Prozedur zu bestimmen. Tote Zellen weisen eine veränderte Membrandurchlässigkeit auf. Trypanblau kann deshalb ungehindert eindringen und färbt diese Zellen umgehend blau. Man kann sie dadurch im lichtmikroskopischen Bild von den hell erscheinenden vitalen Zellen sehr gut unterscheiden. Die Zählung sollte sofort nach der Anfärbung erfolgen, da auch lebende Zellen nach einiger Zeit den Farbstoff aufnehmen. 
$\underline{\text { Reagenzien: }}$

Trypanblau

Durchführung:

Ein Aliquot $(10 \mu \mathrm{l})$ der $\mathrm{zu}$ untersuchenden Zellsuspension wurde 1:1 mit Trypanblau vermischt und die Zellzahl unter dem Lichtmikroskop bei 400 facher Vergrößerung in einer Zählkammer ermittelt.

\subsubsection{Ernte der Zellen aus Leukapherese}

Die Kulturschalen der aus Leukapherese gewonnenen Zellen wurden für mindestens 30 min auf Eis gestellt, damit sich die teilweise noch adhärenten Zellen vom Boden der Schale lösen konnten. Danach wurden die Zellen mit einem kräftigen PBS-Strahl abgespült. Die 6-WellPlatten mit den aus Nabelschnurblut gewonnenen Zellen wurden nicht auf Eis inkubiert, sondern die Überstände entnommen und die Wells vorsichtig zweimal mit PBS nachgespült. $\mathrm{Ob}$ die Zellernte unter sterilen Bedingungen durchgeführt werden musste oder nicht, war abhängig von den sich anschließenden Experimenten. Für in vivo Versuche war die Sterilität unabdingbar, für alle anderen Versuche nicht.

\subsubsection{Ernte der aus Nabelschnurblut generierten Zellen}

Da es sich bei den kultivierten hämatopoetischen Vorläuferzellen um eine sehr heterogene Population handelt und ein gewisses $\mathrm{Maß}$ an Heterogenität während der gesamten Kultivierung erhalten bleibt, findet man sowohl adhärente als auch nicht adhärente Zellen vor. Von Interesse sind dabei die nicht adhärenten Zellen. Diese wurden sowohl beim Wechsel von Wachstumsfaktoren auf GM-CSF bzw. GM-CSF/IL-4 als auch bei der eigentlichen Zellernte weiter verwendet. Die Überstände wurden abgenommen und die Wells vorsichtig zweimal mit PBS nachgespült und die Zellen gepoolt. 


\subsubsection{Kultivierung von Mauszellen}

\subsubsection{Gewinnung, Kultivierung und Ernte von Mausknochenmarkszellen}

\section{Prinzip:}

Die im Knochenmark vorkommenden hämatopoetischen Stammzellen können durch definierte Cytokine in die jeweils erwünschte Entwicklungsrichtung getrieben werden.

\section{$\underline{\text { Reagenzien: }}$}

PBS

Erythrozytenlysispuffer

BMDC-Medium

\section{Durchführung:}

In Abhängigkeit von der erwünschten Anzahl an Zellen wurde die benötigte Menge an Mäusen durch den Einsatz von $\mathrm{CO}_{2}$ getötet, die Oberschenkel- und Schienbeinknochen unter sterilen Bedingungen frei präpariert und in PBS überführt. Die Knochenenden wurden angeschnitten, das Knochenmark mittels PBS-gefüllter Spritze in eine Petrischale ausgespült und die Suspension auf ein Sieb gegeben, um die restlichen Knochenstückchen und Gewebereste zu entfernen. Die Zellsuspension wurde in ein Röhrchen pipettiert und für 10 min bei $300 \mathrm{~g}$ ohne Bremse zentrifugiert. Nach dem Verwerfen des Überstandes wurde das Pellet durch das Resuspendieren in $5 \mathrm{ml}$ Erythrozytenlysispuffer und einer anschließenden Inkubation von 5 min bei $37^{\circ} \mathrm{C}$ einer Erythrozytenlyse unterzogen. Danach wurde das Röhrchen mit PBS aufgefüllt, zentrfugiert, der Überstand abgesaugt, das Pellet in $10 \mathrm{ml}$ KMDC-Medium resuspendiert und auf eine 10-ml-TC-Schale überführt. In den sich anschließenden $2 \mathrm{~h}$ konnten sich die adhärenten Zellen im Brutschrank am Boden der TCSchale anheften. Danach wurde der Überstand abgenommen, in ein neues Röhrchen überführt und die Schale einmal vorsichtig mit PBS nachgespült. Die TC-Schale konnte nun verworfen werden. Der Überstand enthielt die nicht adhärenten Zellen, zu denen auch die hämatopoetischen Stammzellen gehören. Nach der Ermittlung der Zellzahl und dem Zentrifugieren (5 Minuten bei $300 \mathrm{~g}$ ohne Bremse) der Suspension, wurden die Zellen mit 
KMDC-Medium auf $5 \times 10^{5} / \mathrm{ml}$ eingestellt. Jeweils ein Milliliter der Zellsuspension wurde pro Napf auf 24-Well-Platten ausplattiert. Die Zugabe von Cytokinen und deren Kombinationen war abhängig vom Versuchsziel.

Am dritten Tag wurden bei den GM-CSF haltigen Kulturen aus jedem Napf vorsichtig $500 \mu 1$ Medium entnommen, gepoolt, zentrifugiert, der Überstand abgesaugt, neues Medium inklusive Cytokine zugegeben und $500 \mu 1$ wieder auf die Wells verteilt. Nach weiteren zwei Tagen wurden die Zellen umgesetzt. Die Ernte der nicht adhärenten Zellen erfolgte durch Poolen und Spülen mit PBS. Nach der Zellzahlbestimmung wurde 5 Minuten bei $300 \mathrm{~g}$ zentrifugiert, der Überstand abgesaugt, die Zellen mit KMDC-Medium auf 5 x 10\% eingestellt, die entsprechenden Cytokine hinzugegeben und die Suspension zu je $3 \mathrm{ml}$ pro Well auf 6-Well-Platten ausplattiert. Nach weiteren zwei Tagen erfolgte die Ernte der suspendierten Zellen.

Bei M-CSF haltigen Kulturen wurden am dritten und fünften Tag pro Well $500 \mu$ l entnommen aber verworfen und durch frisches Medium mit Cytokinen ersetzt. Die Ernte erfolgte am siebten Tag, indem die Kulturen 30 min auf Eis gestellt und anschließend die Wells mit PBS nachgespült wurden.

\subsubsection{Kulturzusätze im Maussystem}

Tab. 4: Art und Menge der im murinen System verwendeten Cytokine und Mediatoren

\begin{tabular}{|l|l|}
\hline Cytokin bzw. Mediatoren & in Kultur eingesetzte Menge \\
\hline - rm GM-CSF & $100 \mathrm{U} / \mathrm{ml}$ \\
- rm IL-4 & $100 \mathrm{U} / \mathrm{ml}$ \\
- rm IL-10 & $200 \mathrm{U} / \mathrm{ml}$ \\
- rm IL-13 & $200 \mathrm{U} / \mathrm{ml}$ \\
- rm M-CSF & $25 \mathrm{ng} / \mathrm{ml}$ \\
- LY 294002 & $5 \mu \mathrm{M}$ \\
- SB 203580 & $5 \mu \mathrm{M}$ \\
- JNK Inhibitor II & $5 \mu \mathrm{M}$ \\
- PD 98059 & $5 \mu \mathrm{M}$ \\
\hline
\end{tabular}


Tab. 5: Cytokinsituationen bei der Kultiverung von hämatopoetischen Vorläufern aus Kochenmark von Mäusen

\begin{tabular}{|l|l|}
\hline $\begin{array}{l}\text { Dauer der } \\
\text { Kultivierung }\end{array}$ & Cytokine \\
\hline $\begin{array}{l}7 \text { Tage } \\
\text { nach Tag } 5 \text { bis } 7\end{array}$ & $\begin{array}{l}\text { GM-CSF, GM-CSF/IL-4, M-CSF, M-CSF/ IL-4, } \\
\text { Für h LY 294002; SB 203580; JNK Inhibitor II; PD 98059 }\end{array}$ \\
\hline
\end{tabular}

\subsubsection{Zellbiologie}

\subsubsection{FACS-Färbung}

\section{Prinzip:}

Bei der FACS-Färbung werden monoklonale Antikörper, die mit einem Fluoreszenzfarbstoff gekoppelt sind, für die Markierung von membranständigen und intrazellulären Antigenen verwendet. Die Fluoreszenzen können anschließend in einem Durchflußzytometer gemessen werden. Ein Durchflußzytometer ermöglicht es, gleichzeitig mehrere wichtige Informationen über die gemessenen Zellen zu erhalten. Die zu untersuchenden Zellen werden durch eine feine Kapillare gedrückt und somit vereinzelt. Sie passieren in bestimmten Abständen einen Laserstrahl, der die Fluoreszenzfarbstoffe auf den Antikörpern anregt. Dadurch wird Licht definierter Wellenlänge emittiert und der Laser wird gestreut. Photodetektoren messen die Laserstreuung, die dann in ein elektronisches Signal umgewandelt werden kann. Man erhält nicht nur Information über membranständige bzw. intrazelluläre Strukturen, sondern gleichzeitig auch über Größe und Granularität der Zellen (JANEWAY, TRAVERS, 1997). Die Stärke der Expression von definierten Oberflächenmolekülen kann anhand der durchschnittlichen Fluoreszenzintensität MFI beurteilt werden. Die verwendeten primären Antikörper waren entweder FITC- oder PE-markiert, bei der indirekten FACS-Färbung war der Sekundärantikörper FITC-markiert.

\section{$\underline{\text { Reagenzien: }}$}

FACS-Puffer

FACS-Fix

Blocking-Reagenz 
Tab.6: Für FACS-Färbung verwendete Antikörper

\begin{tabular}{|c|c|c|c|c|c|}
\hline Spezifität & Zellklon & Isotyp & Markierung & Konzentration & Firma \\
\hline hu C3aR & RZ8 & $\begin{array}{l}\text { Maus } \\
\text { IgG2b }\end{array}$ & keine & $5 \mu \mathrm{g} / \mathrm{ml}$ & $\begin{array}{l}\text { Abt. für Immunologie, } \\
\text { Universität Göttingen, } \\
\text { ZWIRNER et al., } 1999\end{array}$ \\
\hline hu C5aR & RZ1 & Maus IgG1 & keine & $5 \mu \mathrm{g} / \mathrm{ml}$ & $\begin{array}{l}\text { Abt. für Immunologie, } \\
\text { Universität Göttingen, } \\
\text { Prof. Zwirner }\end{array}$ \\
\hline hu CCR1 & 53504111 & $\begin{array}{l}\text { Maus } \\
\text { IgG2b }\end{array}$ & keine & $5 \mu \mathrm{g} / \mathrm{ml}$ & $\begin{array}{l}\text { R\&D Systems, } \\
\text { Wiesbaden }\end{array}$ \\
\hline hu CCR2 & 48607 & $\begin{array}{l}\text { Maus } \\
\text { IgG2b }\end{array}$ & keine & $5 \mu \mathrm{g} / \mathrm{ml}$ & $\begin{array}{l}\text { R\&D Systems, } \\
\text { Wiesbaden }\end{array}$ \\
\hline hu CCR5 & 2D7/CCR5 & $\begin{array}{l}\text { Maus } \\
\text { IgG2a }\end{array}$ & keine & $5 \mu \mathrm{g} / \mathrm{ml}$ & $\begin{array}{l}\text { BD Pharmingen, } \\
\text { Heidelberg }\end{array}$ \\
\hline hu CCR7 & 150503 & $\begin{array}{l}\text { Maus } \\
\operatorname{IgG} 2 \mathrm{a}\end{array}$ & keine & $5 \mu \mathrm{g} / \mathrm{ml}$ & $\begin{array}{l}\text { Abt. für Immunologie, } \\
\text { Universität Göttingen, } \\
\text { Prof. Zwirner }\end{array}$ \\
\hline hu CD14 & TÜK4 & $\begin{array}{l}\text { Maus } \\
\text { IgG2a }\end{array}$ & FITC & $5 \mu \mathrm{g} / \mathrm{ml}$ & DAKO, Dänemark \\
\hline hu CD34 & AC136 & $\begin{array}{l}\text { Maus } \\
\text { IgG2a }\end{array}$ & $\mathrm{PE}$ & $5 \mu \mathrm{g} / \mathrm{ml}$ & $\begin{array}{l}\text { Miltenyi Biotec, } \\
\text { Bergisch Gladbach }\end{array}$ \\
\hline hu CD83 & HB15a & $\begin{array}{l}\text { Maus } \\
\text { IgG2a }\end{array}$ & FITC & $5 \mu \mathrm{g} / \mathrm{ml}$ & $\begin{array}{l}\text { Immunotech Coulter, } \\
\text { Marseille, Frankreich }\end{array}$ \\
\hline hu CD86 & B-T7 & $\begin{array}{l}\text { Maus } \\
\text { IgG1 }\end{array}$ & PE & $5 \mu \mathrm{g} / \mathrm{ml}$ & $\begin{array}{l}\text { DIACLONE SAS, } \\
\text { Besancon, Frankreich }\end{array}$ \\
\hline $\begin{array}{l}\text { hu HLA- } \\
\text { DR }\end{array}$ & L243 & $\begin{array}{l}\text { Maus } \\
\text { IgG2a }\end{array}$ & $\mathrm{PE}$ & $2,5 \mu \mathrm{g} / \mathrm{ml}$ & $\begin{array}{l}\text { Leinco Technologies, } \\
\text { Inc., St. Louis, USA }\end{array}$ \\
\hline $\begin{array}{l}\text { Isotyp } \\
\text { Kontrolle }\end{array}$ & $\begin{array}{l}\text { DAK-GO1 } \\
\text { FITC } \\
\text { DAK-GO5 } \\
\text { PE }\end{array}$ & $\begin{array}{l}\text { Maus IgG1 } \\
\text { Maus gG2a }\end{array}$ & $\begin{array}{l}\text { FITC } \\
\text { PE }\end{array}$ & $5 \mu \mathrm{g} / \mathrm{ml}$ & DAKO, Dänemark \\
\hline $\mathrm{mu}$ C5aR & $20-70-30-1$ & $\begin{array}{l}\text { Ratte } \\
\operatorname{IgG} 2 b\end{array}$ & keine & $5 \mu \mathrm{g} / \mathrm{ml}$ & $\begin{array}{l}\text { Abt. für Immunologie, } \\
\text { Universität Göttingen, } \\
\text { SoRURI et al., } 2003 \text { (C) }\end{array}$ \\
\hline $\mathrm{mu} \mathrm{C3aR}$ & $1 \mathrm{G} 4$ & Ratte IgG1 & keine & $5 \mu \mathrm{g} / \mathrm{ml}$ & $\begin{array}{l}\text { Abt. für Immunologie, } \\
\text { Universität Göttingen; } \\
\text { Prof. Zwirner }\end{array}$ \\
\hline mu CCR2 & MC-21 & $\begin{array}{l}\text { Ratte } \\
\operatorname{IgG} 2 b\end{array}$ & keine & $5 \mu \mathrm{g} / \mathrm{ml}$ & $\begin{array}{l}\text { Prof. Dr. Matthias Mack } \\
\text { Universität Regensburg } \\
\text { MACK et al., } 2001\end{array}$ \\
\hline mu CCR5 & MC-68 & $\begin{array}{l}\text { Ratte } \\
\text { IgG2b }\end{array}$ & keine & $5 \mu \mathrm{g} / \mathrm{ml}$ & $\begin{array}{l}\text { Prof. Dr. Matthias Mack } \\
\text { Universität Regensburg } \\
\text { MACK et al., } 2001\end{array}$ \\
\hline $\begin{array}{c}\mathrm{F}\left(\mathrm{ab}^{\prime}\right) 2 \\
\text { Fragment }\end{array}$ & polyclonal & $\begin{array}{l}\text { Goat anti } \\
\text { rat }\end{array}$ & FITC & $5 \mu \mathrm{g} / \mathrm{ml}$ & Dianova \\
\hline
\end{tabular}




\subsection{Direkte Färbung membranständiger Antigene}

Durchführung:

Die Zellen wurden geerntet und 2 x $10^{6}$ Zellen/ml jedes Kulturansatzes für die FACS-Färbung verwendet. In eine FACS-Platte wurden für jeden Färbeansatz pro Well $10 \mu 1$ Blocking-Reagenz und $100 \mu \mathrm{l}$ Zellsuspension pipettiert und für 20 min auf Eis inkubiert. Der Fc-Teil des IgG im Blocking-Reagenz reagiert mit den Fc-Rezeptoren auf den Oberflächen der Zellen und verhindert somit spätere unspezifische Reaktionen mit den Nachweisantikörpern. Nach dem Blocken wurden die direkt markierten Antikörper pipettiert und die Ansätze für weitere $40 \mathrm{~min}$ im Dunkeln auf Eis inkubiert. Um nicht gebundene Antikörper zu entfernen, wurden die FACS-Platten bei $300 \mathrm{~g}$ und $4 \mathrm{C}^{\circ}$ für 1 min zentrifugiert, die Überstände ausgeschlagen und die Zellen in jeweils $200 \mu$ FACS-Puffer resuspendiert. Nach nochmaligem Waschen wurden die Pellets in je $400 \mu$ FACS-Fix in FACS-Röhrchen aufgenommen und diese bis zur Analyse maximal $24 \mathrm{~h}$ im Dunkeln bei $4{ }^{\circ} \mathrm{C}$ aufbewahrt.

\subsection{Indirekte Färbung membranständiger Antigene}

\section{Durchführung:}

Zellernte und Blocken erfolgt äquivalent der direkten FACS-Färbung. Statt fluoreszenzmarkierter Antikörper wurden unmarkierte verwendet. Nach einer Inkubationszeit von 40 min auf Eis wurden die FACS-Platten, wie oben aufgeführt, gewaschen, die Pellets in jeweils $100 \mu \mathrm{l}$ FACS-Puffer resuspendiert und ein markierter gegen den Primärantikörper gerichteter polyklonaler Sekundärantikörper pipettiert. Wiederum wurden die Färbeansätze für 40 min unter Lichtabschluss auf Eis inkubiert. Das Waschen der FACS-Platten erfolgte wie gehabt. Danach wurden die Pellets in je $400 \mu 1$ FACS-Fix in FACS-Röhrchen aufgenommen und bis zur Durchflußzytometeranalyse maximal $24 \mathrm{~h}$ im Dunkeln bei $4^{\circ} \mathrm{C}$ aufbewahrt. 


\subsubsection{PKH 26-Färbung}

Prinzip:

Um bei einer syngenen Zellgabe (Balb/c-KMDC-Injektion in Balb/c-Maus) die applizierten Zellen von denen des Versuchstieres, das als Chemotaxismodell dient, unterscheiden zu können, müssen erstere markiert werden. Dies geschieht mit dem Fluoreszenzfarbstoff PKH 26. Nach Ablauf der Migrationszeit werden die Zellen durch Peritoneallavage geerntet.

$\underline{\text { Reagenzien: }}$

PKH 26 Kit

PBS

FCS

Durchführung:

Pro Wanderungsansatz wurden $1 \times 10^{7}$ Zellen in $150 \mu 1$ Diluent des Färbekits resuspendiert. Anschließend erfolgte die Zugabe von $150 \mu$ PKH 26 Stocklösung $(8 \mu$ PKH 26 in $992 \mu 1$ Diluent). Die Suspension wurde 5 min bei RT unter Lichtabschluss inkubiert. Danach wurde der Färbevorgang mit $300 \mu 1$ FCS abgestoppt, die Zellen zentrifugiert (5 min, 300 g) und der Überstand verworfen. Um überschüssigen Farbstoff zu entfernen, war es wichtig, zwei weitere Waschschritte mit PBS (jeweils $600 \mu 1$ ) durchzuführen. Danach wurden die Zellen in $200 \mu 1$ PBS aufgenommen und konnten nun injiziert werden.

\subsubsection{Messung der $\mathrm{Ca}^{2+}$-Freisetzung}

\section{Prinzip:}

Das Calciumion ist für die Signaltransduktion bei Eukaryonten von zentraler Bedeutung. Die Funktion als intrazellulärer Botenstoff wird durch den steilen Konzentrationsgradienten zwischen Cytosol und Calciumspeicher im endoplasmatischen Retikulum ermöglicht. In der Membran dieses Kompartimentsystems befindet sich eine $\mathrm{Ca}^{2+}$-ATPase, die $\mathrm{Ca}^{2+}$ aus dem Cytosol in das endoplasmatische Retikulum pumpt und somit den Gradienten aufrechterhält. 
Die Ligation von Sieben-Helix-Rezeptoren, wie z.B. Chemokin- und Anaphylatoxinrezeptoren, bewirkt über die Aktivierung des rezeptorassoziierten G-Proteins die Ingangsetzung der Phosphoinositidsignalkaskade, die durch die Entstehung von Inositol-1,4,5-triphosphat in der Freisetzung von $\mathrm{Ca}^{2+}$ aus den intrazellulären Speichern resultiert. Diese Freisetzung kann durch den Einsatz eines Fluoreszenzfarbstoffs wie dem Chelator Indo-1 nachgewiesen werden. Hierbei bindet Indo-1 das freigewordene $\mathrm{Ca}^{2+}$ (STRYER, 1995). Dies hat eine Änderung der Wellenlänge des Farbstoffs zur Folge, welche nachgewiesen und gemessen werden kann. Durch den Einsatz des ionophorischen Antibiotikums Ionomycin, das als effektiver Carrier für zweiwertig positive Ionen wirkt, wird ein Vergleich zwischen dem durch das eingesetzte Chemokin ausgelösten Calciumsignals und der Gesamtmenge an intrazellulärem freiem Calcium möglich. Ionomycin bewirkt einen kompletten Calciumausstrom aus den intrazellulären Calciumspeichern ins Cytoplasma.

\section{Reagenzien:}

Krebs-Ringer-Lösung

Pluronic F127 (5\%)

Indo-1 (1 mM)

Medium I

Kulturmedium

Ionomycin

\section{Durchführung:}

Pro Messansatz wurden 1 × $10^{6}$ Zellen in $500 \mu$ Medium I benötigt. Zur Zellsuspension wurde die bereits vorbereitete Färbelösung hinzu pipettiert (200 $\mu 1$ Medium I; 2,8 $\mu 1$ 5\%iges Pluronic F127; 0,7 $\mu 11 \mathrm{mM}$ Indo-1). Unter Ausschluss von Licht erfolgte die Inkubation der Ansätze für $25 \mathrm{~min}$ bei $30^{\circ} \mathrm{C}$ im Shaker (300 rpm). Danach wurden $700 \mu$ l Kulturmedium hinzu pipettiert und die Ansätze für 10 min bei RT inkubiert. Um das nicht gebundene Indo-1 und Pluronic F127 zu entfernen, mussten die Zellen nun zweimal mit Krebs-Ringer-Lösung gewaschen werden (5 min, 300 g). Anschließend wurden die Zellen in $900 \mu 1$ Krebs-RingerLösung resuspendiert. Pro Messung benötigte man $400 \mu \mathrm{l}$ der Suspension und $40 \mu 1$ des Stimulus (z.B. C5a $1000 \mathrm{ng} / \mathrm{ml}$ Ausgangskonzentration ergaben in der Messung durch die 
Verdünnung mit der Zellsuspension als Endkonzentration $100 \mathrm{ng} / \mathrm{ml}$ ). Als Positivkontrolle wurde Ionomycin (Endkonzentration $1 \mu \mathrm{g} / \mathrm{ml}$ ) verwendet.

\subsubsection{Cytospin}

Prinzip:

Durch die Zentrifugalbeschleunigung können Zellen gezielt auf einen Objektträger aufgebracht werden. Im Gegensatz zum Ausstrich erfolgt die Verteilung der Zellen gleichmäßig und damit wird ein reproduzierbareres Resultat erzielt.

\section{Durchführung:}

Zur Gewinnung von Cytospins wurden sialinisierte Objektträger in die Vorrichtung des Rotors (AC-060 Cytopro Rotor) der Cytospinzentrifuge eingesetzt, die Cytospinkammern eingeklemmt und 2,5 x $10^{5}$ Zellen in die Reservoirs der Kammern überführt. Durch die Zentrifugation (300 g, 3 Minuten) wurden die Zellen aus den Reservoirs herausgeschleudert und damit auf die Objektträger aufgetragen. Nach zweistündiger Trocknung wurden die Objektträger für $10 \mathrm{~min}$ bei minus $20^{\circ} \mathrm{C}$ in bereits gekühltes Methanol gestellt. Nach der Trocknung über Nacht wurde eine Hämacolorschnellfärbung durchgeführt.

\subsubsection{Färbung der Cytospins}

Prinzip:

Um den Anteil der einzelnen Zellarten zueinander zu bestimmen, die Qualität einer Zellkultur zu überprüfen oder sich einen Überblick verschaffen zu können, färbt man einen Ausstrich oder Cytospin mit Eosin und Methylenblau. Der saure Farbstoff Eosin ist orange-rot und färbt basische Zellbestandteile wie Hämoglobin und eosinophile Granula. Methylenblau ist basisch, blau-violett und färbt saure Zellbestandteile wie basophile Granula und Nukleinsäuren. Die Hämacolorschnellfärbung beruht also auf Säure-Base-Reaktionen. 
$\underline{\text { Reagenzien: }}$

Hämacolorschnellfärbung: Eosin

Methylenblau

Durchführung:

Der bereits fixierte Objektträger mit den Zellen wurden nach dem Trocknen 5 x $1 \mathrm{sec}$ in Eosin getaucht, danach die Rückwand des Objektträgers mit einem weichen Zellstofftuch abgewischt, um überschüssigen Farbstoff nicht in die nächste Lösung zu übertragen. Anschließend erfolgte die Färbung mit Methylenblau auf die gleiche Weise. Zum Schluss wurde der Objektträger vorsichtig unter fließendem Wasser von überschüssiger Farbe befreit, nach dem Lufttrocknen unter dem Mikroskop (800 bis 1000 fache Vergrößerung, Immersionsobjektiv) begutachtet und fotografiert.

\subsubsection{Chemotaxis}

Die Chemotaxis ermöglicht es dem Experimentator Rückschlüsse auf die Funktion bestimmter membranständiger Oberflächenproteine, der Rezeptoren, ziehen zu können. Das Vorkommen dieser Marker und deren Ankopplung an das intrazelluläre Signaltransduktionsnetz versetzt die Zelle in die Lage, auf Reize zu reagieren. Der Einsatz von Chemotaxinen lässt Zellen mit passendem Rezeptor in Richtung des Chemotaxinkonzentrationsgradienten wandern. Somit kann der Beweis für die Funktionalität des Rezeptors erbracht werden. Eine Chemotaxis kann sowohl in vitro als auch in vivo durchgeführt werden.

\subsection{Chemotaxis in vitro}

$\underline{\text { Reagenzien: }}$

Chemotaxismedium

PBS

Chemotaxin (rh C5a, rh MIP-1 $\alpha$ )

$8 \mu \mathrm{m}$, Transwell ${ }^{\circledR}$ Permeable Supports 
Durchführung:

Die Poreneinsätze mit der gewünschten Porengröße wurden in die Näpfchen einer 24-Well-Platte des Transwell $^{\circledR}$ Systems platziert und anschließend $600 \mu \mathrm{l}$ des Chemotaxismediums, welches das $\mathrm{zu}$ testende Chemotaxin enthielt, in die Näpfchen pipettiert. Das Chemotaxismedium der Negativkontrolle enthielt kein Chemotaxin. Die zu untersuchenden Zellen wurden in Trypanblau gezählt und $1 \times 10^{6}$ lebende Zellen pro ml Chemotaxismedium aufgenommen. Von der Zellsuspension wurden $100 \mu \mathrm{l}$ in die Poreneinsätze pipettiert und die Transwell ${ }^{\circledR}$-Platte. Die Platte wurde dann für die Dauer der Inkubation (1h) in den Brutschrank $\left(37^{\circ} \mathrm{C}\right.$ und $\left.5 \% \mathrm{CO}_{2}\right)$ gestellt. Während dieser Zeit ist es den Zellen möglich in Richtung des Chemotaxins zu wandern, vorausgesetzt sie exprimieren den dafür passenden Rezeptor.

Im Anschluss daran wurden die Filtereinsätze einzeln entnommen, ihre Unterseite mit PBS in das zugehörige Näpfchen gespült, um daran haftende Zellen zu entfernen. Dann wurde die Platte für 30 min auf Eis gestellt, damit adhärente Zellen sich vom Untergrund ablösen und anschließend der Inhalt jedes Näpfchens in ein separates Röhrchen überführt. Die Näpfchen wurden mit kaltem PBS nachgespült und die Zellen wurden zentrifugiert (5 min, 300 g). Nach der Entfernung des Überstandes wurden die Zellen in $200 \mu 1$ PBS aufgenommen und gezählt.

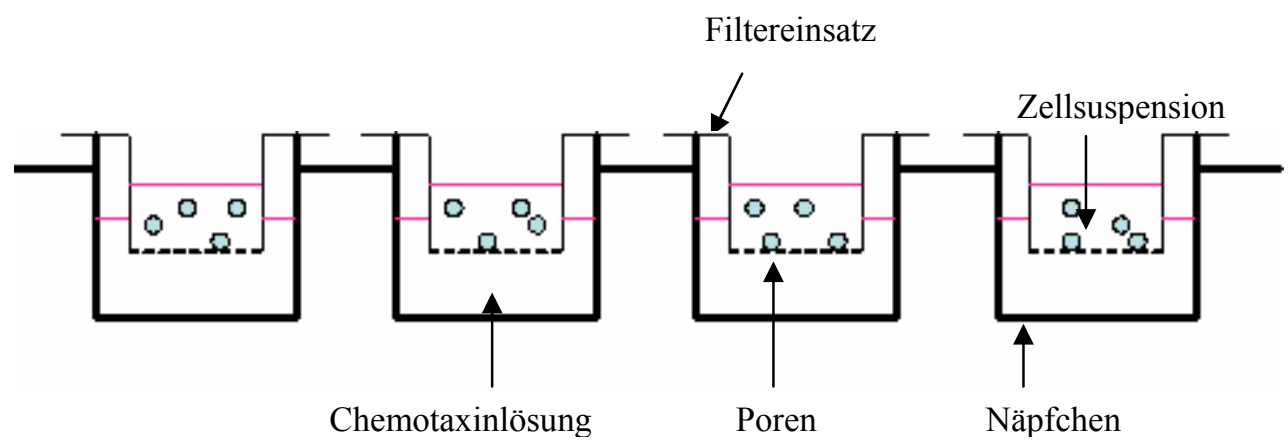

Abb. 8: Schematische Darstellung des Transwell ${ }^{\circledR}$ Systems. Beschreibung siehe Text.

\subsection{Chemotaxis in vivo}

Da die in vivo Chemotaxis ein Tierversuch ist, sind die entsprechenden Experimente mit größter Sorgfalt zu planen und durchzuführen. 
Reagenzien:

Narkosecocktail: Hostaket / Rompun / PBS =1/1/8

PBS

Zellen

Chemotaxin

Tab. 7: Einsatz von Chemotaxinen in den in vivo Versuchen

\begin{tabular}{|c|c|c|c|c|}
\hline \multirow[t]{2}{*}{ Chemotaxin } & \multirow[t]{2}{*}{ Rezeptor } & \multicolumn{3}{|c|}{ Dauer der Wanderung } \\
\hline & & $4 \mathrm{~h}$ & $24 \mathrm{~h}$ & $48 \mathrm{~h}$ \\
\hline rh C5a & C5aR (CD88) & $5,10,40 \mu \mathrm{g}$ & $10,20 \mu \mathrm{g}$ & $40 \mu \mathrm{g}$ \\
\hline rh C3a & C3aR & & $50 \mu \mathrm{g}$ & \\
\hline rh MDC & hu CCR4 & & $10 \mu \mathrm{g}$ & \\
\hline rh MCP-1 & hu CCR2 & & $10 \mu \mathrm{g}$ & \\
\hline rh MIP-1 $\alpha$ & hu CCR1, hu CCR5 & & $10 \mu \mathrm{g}$ & $10 \mu \mathrm{g}$ \\
\hline rm MCP-1 & mu CCR2 & & $10 \mu \mathrm{g}$ & \\
\hline $\mathrm{rm} \mathrm{MDC}$ & mu CCR4 & & $10 \mu \mathrm{g}$ & \\
\hline rm MIP-1 $\alpha$ & mu CCR1, mu CCR5 & $10 \mu \mathrm{g}$ & $10 \mu \mathrm{g}$ & $2 \times 10 \mu \mathrm{g}$ \\
\hline rm MIP-3 $\alpha$ & mu CCR6 & & $10 \mu \mathrm{g}$ & \\
\hline rm MIP-3 $\beta$ & mu CCR7 & & $10 \mu \mathrm{g}$ & \\
\hline fMLP & FPR & & $10 \mu \mathrm{g}$ & \\
\hline LL37 & nicht bekannt & & $10 \mu \mathrm{g}$ & \\
\hline
\end{tabular}

Durchführung:

Die im Wanderungsversuch zu untersuchenden Zellen wurden geerntet, 1 x $10^{7}$ Zellen in 250 $\mu 1$ PBS in einer 1-ml-Spritze, und $200 \mu$ PBS inklusive Chemotaxin in einer anderen 1-mlSpritze aufgenommen. Die Mäuse wurden durch die intraperitoneale Injektion von $100 \mu 1$ des Narkosecocktails sediert. Die Wirkung der Narkose setzte ca. 5 bis 10 Minuten nach der Injektion ein. Während dieser Zeit sollten die Mäuse ruhig und abgedunkelt stehen. Anschließend wurden das Chemotaxin intraperitoneal (bei Kontrolltieren PBS) und die Zellsuspension intravenös in eine der vier Schwanzvenen appliziert. In Abhängigkeit des Versuchsziels sollten die Zellen entweder 4 h oder $24 \mathrm{~h}$ bzw. $48 \mathrm{~h}$ in vivo wandern. 


\subsection{Peritoneallavage}

$\underline{\text { Reagenzien: }}$

auf Eis gekühltes PBS

Durchführung:

Nach Ablauf der Migrationszeit/Inkubationszeit wurden die Mäuse durch $\mathrm{CO}_{2}$ getötet, die Haut des Abdomens und das Peritoneum durch einen kleinen Schnitt perforiert. Kaltes PBS wurde in die Bauchhöhle pipettiert, vorsichtig resuspendiert, um nicht die Innereien zu verletzen, und das PBS aus der Bauchhöhle in ein Röhrchen überführt. Der Pipettiervorgang wurde so oft wiederholt, bis $7 \mathrm{ml}$ PBS verbraucht waren. Die so gewonnenen Zellen wurden mit Trypanblau gefärbt, gezählt und für die FACS-Färbung auf $2 \times 10^{6}$ lebendige Zellen/ml in FACS-Puffer eingestellt.

Da bei der Applikation von Balb/c-Zellen in Balb/c-Tiere (Inzuchtstamm) eine PKH-Färbung vorausging, konnten die injizierten Zellen durch ihre PKH-bedingte Eigenfluoreszenz bei der FACS-Messung von denen des Tieres, in das sie appliziert wurden, unterschieden werden. Vor der Injektion von humanen Zellen in SCID-Mäuse ist eine PKH-Färbung nicht notwendig. Hier genügt es, die Lavagezellen mit spezifischen antihumanen Antikörpern zu färben, um sie im FACS-Gerät von denen des Versuchstieres differenzieren zu können.

\subsection{Statistik}

Für die Kalkulationen der p-Werte wurde der gepaarte Student's T-Test angewandt. 


\section{ERGEBNISSE}

Durch vorangegangene Studien von SORURI et al. (2003A) konnte IL-4 bereits als kritischer Modulator für die Expression von Anaphylatoxinrezeptoren bei Monozyten und Dendritischen Zellen (DC) und deren Wanderungsverhalten gegen die entsprechenden Liganden demonstriert werden.

Aufbauend auf diesen Versuchsergebnissen war das Ziel der vorliegenden Arbeit, die Migrationseigenschaften von Monozyten, Makrophagen und DC in Abhängigkeit der TH2-Cytokine IL-4 und IL-13 sowie die regulatorische Funktion von $\mathrm{PGE}_{2}$ auf Expression und Funktion ausgewählter chemotaktischer Rezeptoren für die genannten Zellen näher zu beleuchten. Zu diesem Zweck wurde auf humanen Makrophagen, DC und Monozyten und auf murinen Makrophagen und DC die Menge ausgewählter Chemotaxinrezeptoren anhand der FACS-Analyse bestimmt. Da die Ermittlung der Rezeptorexpression allein keine Aussage über die biologische Wirkungsweise zulässt, war es unumgänglich, die biologische Funktionalität der betreffenden Rezeptoren in einem in vivo Migrationsmodell im Maussystem zu untersuchen. Ergänzend ermöglichten Versuche mit Knockout-Mäusen und mit Signaltransduktionsinhibitoren tiefere zusätzliche Einblicke in die Materie.

\subsection{Rezeptorexpression und Chemotaxis im murinen System}

\subsubsection{Der Einfluss von IL-4 und IL-13 auf Anaphylatoxinrezeptoren im murinen System}

SORURI et al. (2003A) konnten zeigen, dass IL-4 die mRNA-Expression des C5aR in murinen aus Knochenmark generierten DC herunterreguliert und deren C5a-induzierte Mobilisierung hemmt. Murine Makrophagen und DC wurden aus hämatopoetischen Knochenmarksvorläuferzellen mit M-CSF bzw. GM-CSF mit und ohne IL-4 bzw. IL-13 generiert. Die Anaphylatoxinrezeptorexpression wurde mittels indirekter FACS-Färbung und anschließender FACS-Analyse bestimmt. Für in vivo Migrationstudien wurden Makrophagen und DC aus Balb/c mit PKH26 gefärbt, i.v. in syngene Balb/c-Mäuse appliziert und C5a $(10 \mu \mathrm{g})$ oder C3a $(50 \mu \mathrm{g})$ i.p. injiziert. Nach 15-18 h wurden die Peritonealzellen durch Lavage geerntet und die PKH26-gefärbten gewanderten Zellen per FACS-Analyse identifiziert. Durch die Verwendung von Balb/c- und C57/BL6-Mäusen, zwei Mausstämme mit unterschiedlichem genetischen Hintergrund, wurde sichergestellt, dass die Versuchsergebnisse nicht durch die genetischen Besonderheiten eines Inzuchtstammes 
determiniert sind, sondern einzig und allein auf die Wirkungsweise der verwendeten Mediatoren zurückzuführen waren und damit als repräsentativ angesehen werden können.
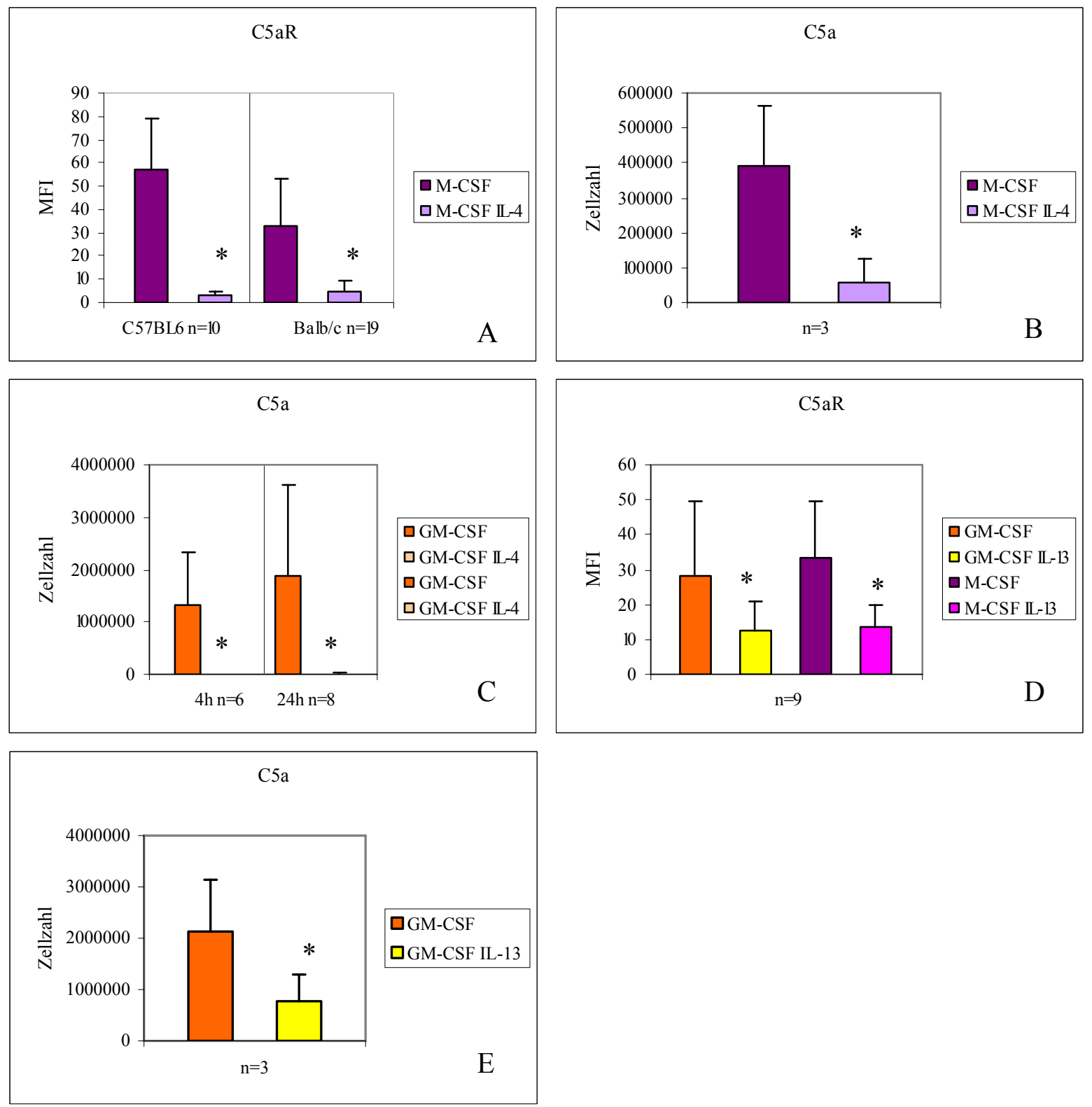

Abb. 9: IL-4 und IL-13 beeinträchtigen Expression und Funktion von Anaphylatoxinrezeptoren auf murinen DC und Makrophagen. (A) C5aR-Expression auf Makrophagen, die mit und ohne IL-4 kultiviert wurden, von C57/BL6- ( $\mathrm{n}=10)$ und Balb/c-Mäusen ( $\mathrm{n}=19)$. (B) In vivo Migration dieser Zellen gegen C5a ( $\mathrm{n}=3$ ). (C) In vivo Migration von DC gegen C5a $(4 \mathrm{~h} \mathrm{n}=6,24 \mathrm{~h} \mathrm{n}=8)$. (D) C5aR-Expression auf DC und Makrophagen (jeweils $\mathrm{n}=9$ ), die mit und ohne IL-13 kultiviert wurden. (E) In vivo Migration der DC gegen C5a ( $\mathrm{n}=3$ ). Die mittlere Fluoreszenzintensität (MFI) ist dargestellt. Die Mittelwerte und Standartabweichungen sind angegeben. $* \mathrm{p}<0,05$

In Abbildung 9A ist zu sehen, dass Makrophagen aus Balb/c und aus C57/BL6-Mäusen den C5aR auf ihrer Oberfläche als Folge des Einflusses von IL-4 herunterregulierten. Die Abnahme der C5aR-Menge korrelierte mit einer verminderten Wanderungsfähigkeit der Zellen in vivo in Richtung eines C5a-Konzentrationsgradienten (Abb. 9B). Eine 
beeinträchtigte Migration im Versuchstier konnte auch für DC nachgewiesen werden (Abb. 9C). Wie in den Abbildungen 9D und 9E zu erkennen ist, stellt auch das mit IL-4 verwandte TH2-Cytokin IL-13 einen Inhibitor der C5aR-Expression und -Funktion in murinen DC und Makrophagen dar.
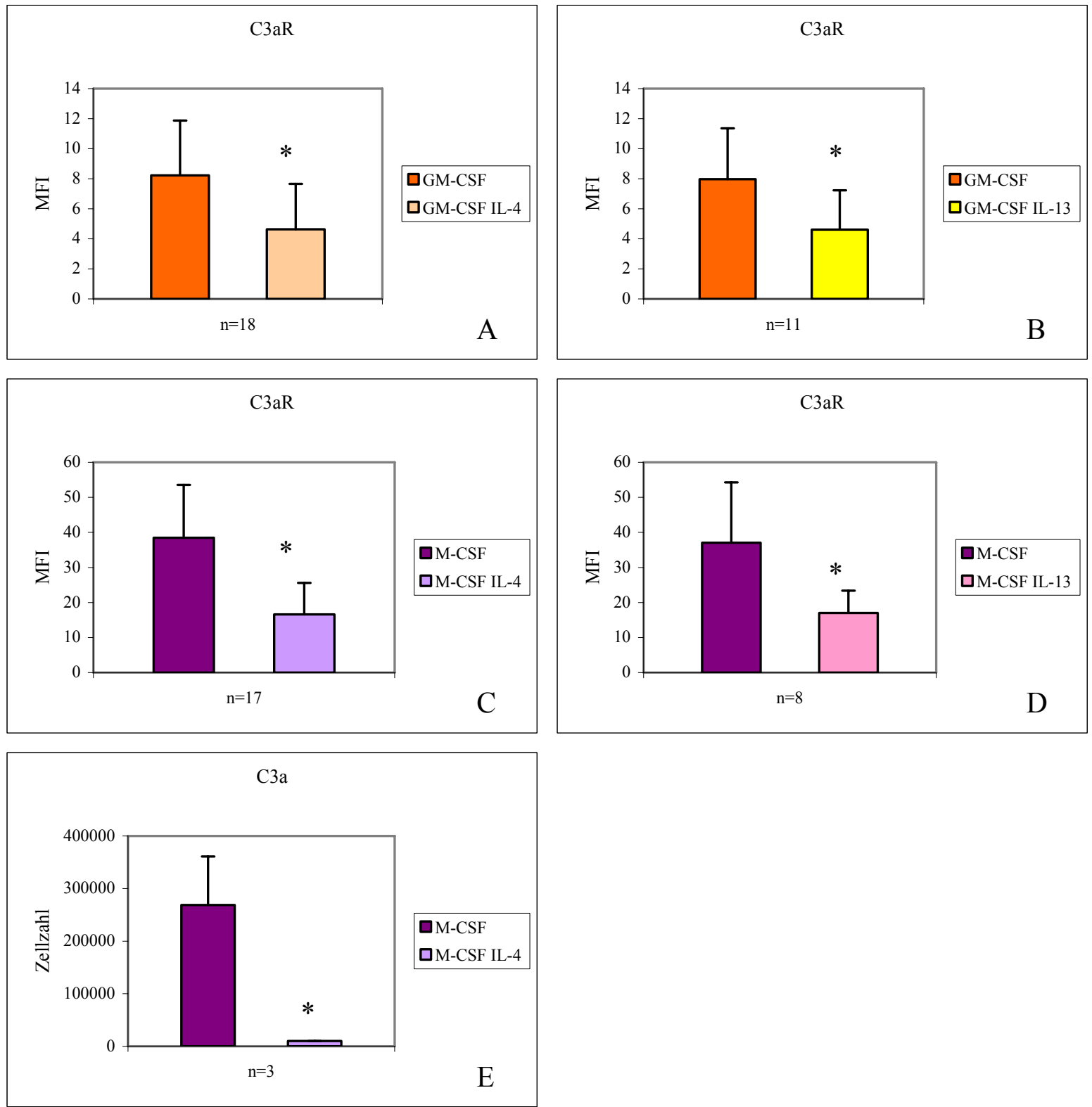

Abb. 10: IL-4 und IL-13 beeinträchtigen Expression und Funktion von Anaphylatoxinrezeptoren auf murinen DC und Makrophagen. (A) C3aR-Expression auf DC, die mit und ohne IL-4 (n=18) bzw. (B) mit und ohne IL-13 ( $\mathrm{n}=11)$ kultiviert wurden und (C) auf Makrophagen, die mit und ohne IL-4 ( $\mathrm{n}=17)$ bzw. (D) mit und ohne IL-13 ( $\mathrm{n}=8)$ kultiviert wurden. (E) In vivo Migration der Makrophagen gegen C3a ( $\mathrm{n}=3$ ). Die mittlere Fluoreszenzintensität (MFI) ist dargestellt. Die Mittelwerte und Standartabweichungen sind angegeben. $* \mathrm{p}<0,05$

Die Expression des Oberflächenproteins $\mathrm{C} 3 \mathrm{aR}$ auf Makrophagen wurde ebenso wie die C5aR-Expression durch den Einfluss von IL-4 bzw. IL-13 gehemmt (Abb. 10C, 10D). Parallel dazu führte die Kultivierung mit IL-4 $\mathrm{zu}$ einer starken Beeinträchtigung der 
Wanderungsfähigkeit der Makrophagen gegen C3a in vivo (Abb. 10E). Die Expression von $\mathrm{C} 3 \mathrm{aR}$ auf $\mathrm{DC}$, die aus hämatopoetischen Knochenmarkszellen generiert wurden, war äußerst niedrig im Vergleich zu der auf Makrophagen (Abb. 10A, 10B). Aus diesem Grund wurden die Makrophagen für die in vivo Versuche ausgewählt, da hier eher die Möglichkeit bestand einen Effekt beobachten zu können.

\subsubsection{Die in vivo Migration gegen einen Liganden ist zeit- und dosisabhängig}
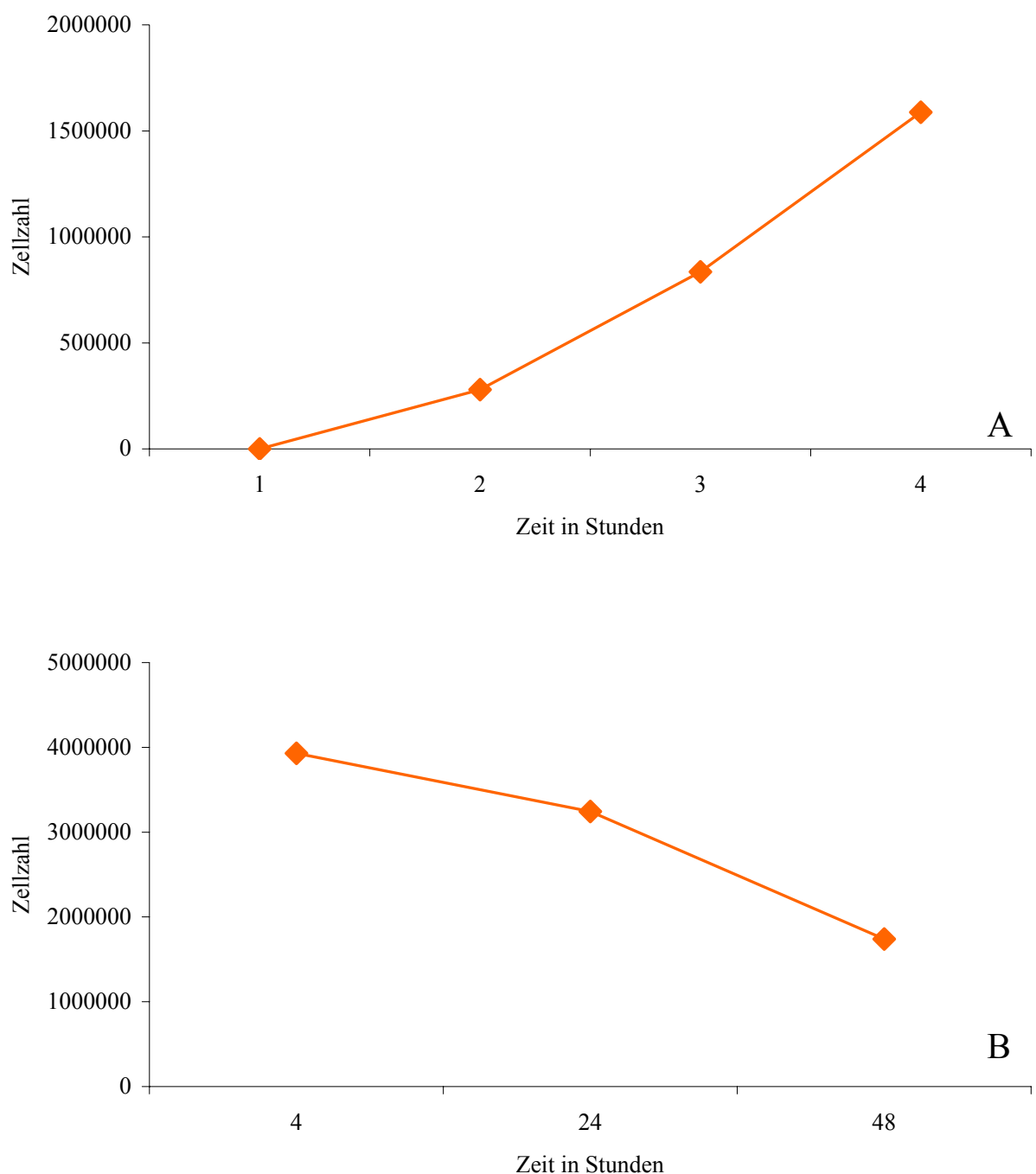

Abb. 11: Die Wanderung von GM-CSF kultivierten murinen DC gegen C5a in vivo ist zeitabhängig und spezifisch. PKH26-markierte KMDC wurden i.v. injiziert, C5a $10 \mu \mathrm{g}$ i.p. Peritonealzellen wurden geerntet nach $1 \mathrm{~h}, 2 \mathrm{~h}, 3 \mathrm{~h}$ oder $4 \mathrm{~h}$ und (B) nach $4 \mathrm{~h}, 24 \mathrm{~h}$ oder $48 \mathrm{~h}$.

PKH26-markierte murine DC, die mit GM-CSF kultiviert wurden, wanderten in vivo zeitabhängig gegen $\mathrm{C} 5 \mathrm{a}$ in das Peritoneum ein. Die peritoneale Ansammlung dieser Zellen 
konnte bereits zwei Stunden nach Injektion beobachtet werden und war noch nach 48 Stunden nachweisbar (Abb. 11A, 11B).

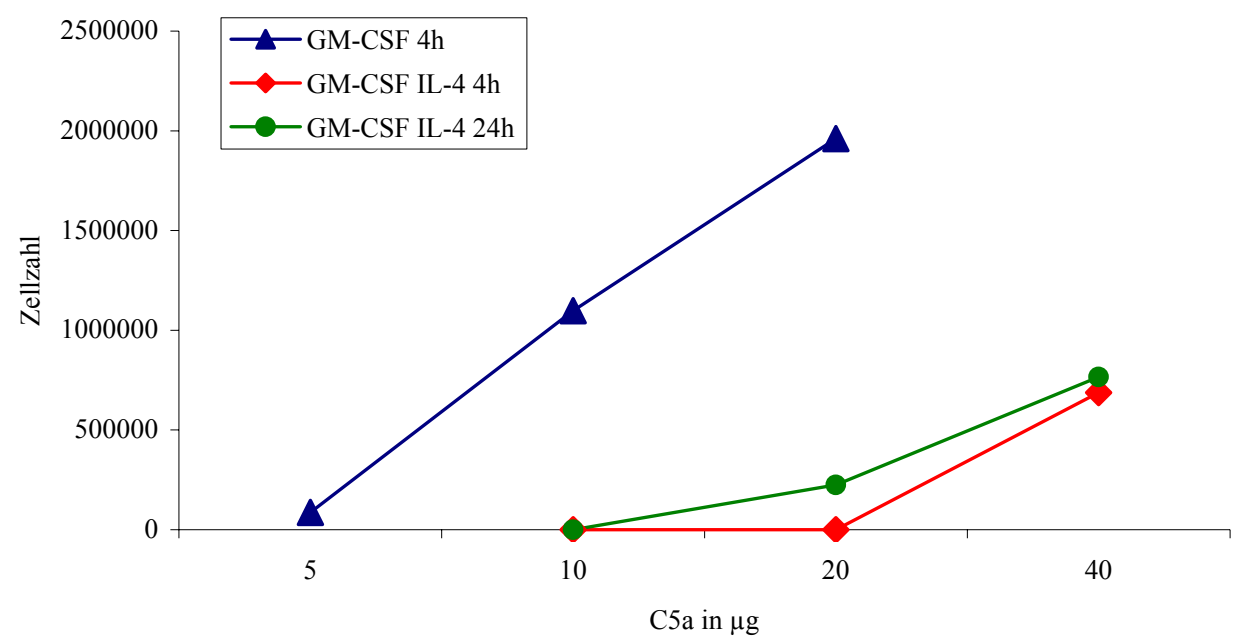

Abb. 12: Größere Mengen an C5a überwinden die IL-4 induzierte Unempfänglichkeit bei murinen DC, die mit GM-CSF und IL-4 kultiviert wurden. DC wurden mit PKH26 markiert, i.v. injiziert, variierende Mengen an C5a i.p. appliziert. Peritonealzellen wurden nach $4 \mathrm{~h}$ oder $24 \mathrm{~h}$ geerntet.

Um herauszufinden, ob höhere Dosen an C5a den hemmenden Einfluss von IL-4 auf die Wanderungseigenschaften von Zellen überwinden können, wurden zusätzlich in vivo Migrationsversuche mit $20 \mu \mathrm{g}$ und $40 \mu \mathrm{g}$ C5a durchgeführt. Abbildung 12 demonstriert, dass diese größeren C5a-Mengen tatsächlich zu einer gesteigerten Migration von mit IL-4 kultivierten murinen DC führten. Damit DC bereits nach vier Stunden in den Peritonealraum einwandern, war eine Gabe von $40 \mu \mathrm{g}$ C5a nötig. Für eine 24-h-Wanderung reichten $20 \mu \mathrm{g}$ C5a aus. Im Gegensatz dazu waren für Zellen, die nur mit GM-CSF kultiviert wurden, nur $5 \mu \mathrm{g}$ nötig, um sie in einem Zeitraum von vier Stunden ins Peritoneum einwandern zu lassen. Eine in vivo Migration wurde nur beobachtet bei gleichzeitiger Applikation von Zellen i.v. und C5a i.p.. Bei Kontrolltieren, denen anstelle von C5a PBS injiziert wurde, fand keine Zellwanderung statt. Durch diese Beobachtung konnte eine Spontanmigration in die Bauchhöhle ausgeschlossen werden.

\subsubsection{Bedeutung des Transkriptionsfaktors STAT6 in der Expression von} Anaphylatoxinrezeptoren

Knockout-Mäuse bieten die Möglichkeit, die Bedeutung von Proteinen für bestimmte physiologische Prozesse zu erkennen. Durch die Abwesenheit des Transkriptionsfaktors 
STAT6 in Zellen aus STAT6-/- Mäusen kann IL-4 seiner biologischen Funktion nicht gerecht werden, da das durch dieses Cytokin gegebene Signal seinen Bestimmungsort nicht erreicht. Der Einfluss von IL-4 bleibt damit vollständig wirkungslos.

In Abbildung 13A wird die Expression des C5a-Rezeptors auf DC und Makrophagen und in Abbildung 13B die des C3a-Rezeptors auf Makrophagen gezeigt. In der Expression der Anaphylatoxinrezeptoren besteht kein signifikanter Unterschied zwischen den Zellen die mit und ohne IL-4 kultiviert wurden. Dies demonstriert die dominante Rolle von STAT6 in der IL-4-induzierten Expressionsverringerung der chemotaktischen Rezeptoren für C5a und C3a auf DC und Makrophagen.
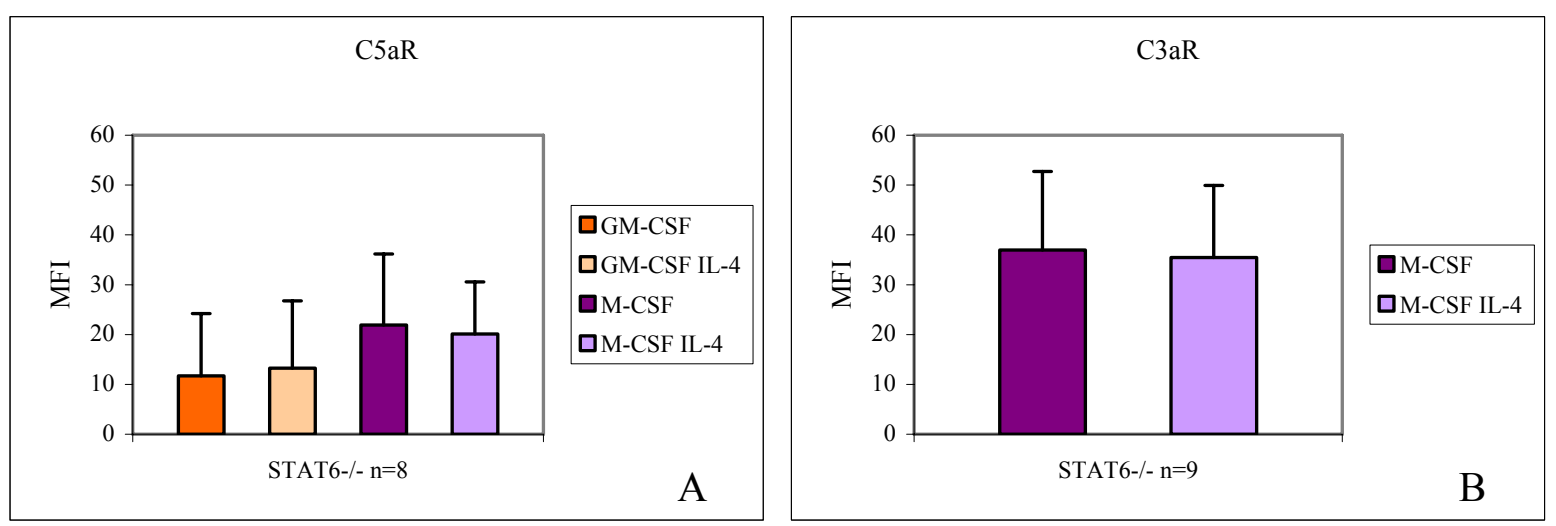

Abb. 13: Anaphylatoxinrezeptorexpression auf DC und Makrophagen in STAT6 defizienten Mäusen. Die Zellen wurden mit und ohne IL-4 kultiviert. (A) C5aR-Expression auf DC und Makrophagen. (B) C3aR-Expression auf Makrophagen. Die mittlere Fluoreszenzintensität (MFI) ist dargestellt. Die Mittelwerte und Standartabweichungen sind angegeben.

\subsubsection{Einsatz von Inhibitoren zur Klärung der Beteiligung von Signalmolekülen}

Der Einsatz von pharmakologischen Inhibitoren eröffnete die Möglichkeit PI3K als Teil der Signaltransduktionskaskade, die an der IL-4-induzierten Signalgebung beteiligt ist, zu identifizieren. LY294002 (2-(4-Morpholinyl)-8-phenyl-4H-1-benzopyran-4-eins) ist ein zellpermeabler, potenter und spezifischer Inhibitor der Phosphatidylinositol 3-Kinasen (PI3Kinasen). Seine Wirkung entfaltet dieser an der ATP-Bindestelle des Enzyms (Calbiochem Produktinformation). Um die Beteiligung weiterer Kinasen an der Regulation des C5aR festzustellen, wurden außerdem SB203580 (4-(4-Fluorophenyl)-2-(4-methylsulfinylphenyl)5-(4-pyridyl)1H-imidazol), JNK Inhibitor II (SP600125; anthra(1,9-cd)pyrazol-6(2H)-eins; 1,9-pyrazoloanthron) und PD98059 (2'-Amino-3'-methoxyflavon) verwendet. SB203580 ist ein MAP Kinase Inhibitor, JNK Inhibitor II ein selektiver und reversibler Inhibitor der c-Jun N-terminalen Kinase (JNK-1, JNK-2, JNK-3). Die Hemmung der Phosphorylierung von JNK 
ist kompetetiv mit ATP. PD98059 unterdrückt selektiv die Aktivierung der MAP Kinase Kinase (MEK) und dadurch die davon abhängige Phosphorylierung des MAP Kinase Substrates (Calbiochem Produktinformation).
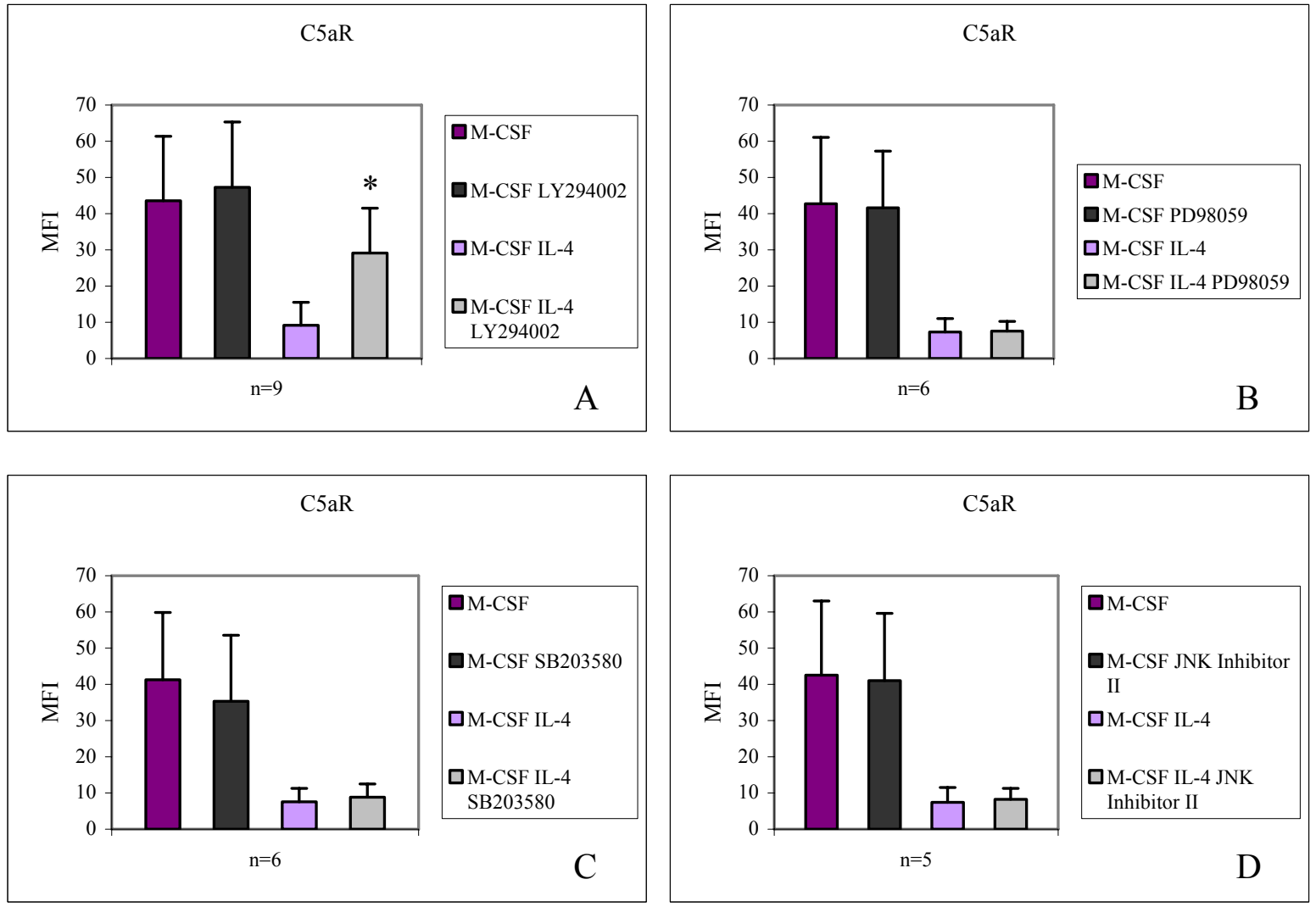

Abb. 14: C5aR-Expression auf Makrophagen, die nach 5 Tagen mit und ohne IL-4 für 48 h unter Zusatz von Inhibitoren für Signaltransduktionsmoleküle oder ohne diese kultiviert wurden. Zugabe der Inhibitoren für (A) PI3K (LY294002) (n=9), (B) ERK (PD098059) (n=6), (C) MAPK p38 (SB203580) (n=6) oder (D) JNK (JNK Inhibitor $\mathrm{II}=\mathrm{SP} 600125)(\mathrm{n}=5)$. Die mittlere Fluoreszenzintensität (MFI) ist dargestellt. Die Mittelwerte und Standartabweichungen sind angegeben. $* \mathrm{p}<0,05$

Nur unter Verwendung des PI3K-Inhibitors LY294002 konnte eine Beeinträchtigung der Expression des $\mathrm{C} 5 \mathrm{aR}$, der hierbei als Indikatorprotein für den IL-4-Effekt diente, gezeigt werden (Abb. 14A). Dies impliziert eine Beteiligung von PI3K an der IL-4-abhängigen intrazellulären Signalübertragung. Da die anderen Inhibitoren keinerlei Wirkung auf die C5aR-Expression ausübten, können die von ihnen inhibierten Proteine nicht in der IL-4 abhängigen Signaltransduktion involviert sein (Abb. 14B, 14C, 14D). Vergleicht man die C5aR-Expressionen der M-CSF-Zellen und M-CSF/IL-4/LY294002-Zellen miteinander so erkennt man eine unvollständige Hemmung des IL-4-Effektes. Trotz des PI3K-Inhibitors erfolgt eine leichte Herunterregulierung des C5aR durch IL-4. Erklärt werden könnte dies durch die PI3K Klasse II Isoenzyme PI3K-C2 $\alpha$, PI3K-C2 $\beta$ und PI3K-C2 $\gamma$. Ein Merkmal dieser Enzyme ist ihre Unempfindlichkeit gegenüber PI3K Inhibitoren mit einer ausgeprägten 
Resistenz von PI3K-C2 $\alpha$ gegen LY294002 und Wortmannin. Vieles in der Aktivierung der Klasse II PI3K ist noch nicht geklärt, aber ihre Beteiligung an diversen Signalwegen ist unumstritten. Es ist bekannt, das Insulin PI3K-C2 $\alpha$ in Adipozyten und Muskelzellen aktiviert. So könnte man spekulieren, ob durch die Aktivierung des IRS-1/2 Signals infolge der Stimulation der IL-4R $\alpha-$ Kette neben der PI3K der Klasse I nicht auch PI3K-C2 $\alpha$ aktiviert werden könnte. FALASCA et al. (2007) konnten nachweisen, dass die Signaltransduktion über PI3K-C2 $\alpha$ ausgelöst durch Insulin unabhängig von anderen PI3K Isoenzymen fungiert.

\subsubsection{Einfluss von IL-4 und IL-13 auf Chemokinrezeptoren im murinen System}

Zusätzlich zu den Anaphylatoxinrezeptoren war in dieser Studie auch der Einfluss von IL-4 und IL-13 auf ausgesuchte Chemokinrezeptoren von Interesse. Murine Makrophagen und DC wurden aus hämatopoetischen Vorläuferzellen des Knochenmarks mit M-CSF bzw. GM-CSF mit und ohne IL-4 bzw. IL-13 generiert. Die Bestimmung der Chemokinrezeptorexpression erfolgte durch indirekte Immunfluoreszenzfärbung mit anschließender FACS-Analyse. Für die in vivo Wanderungsversuche wurden Makrophagen und DC mit PKH26 gefärbt und i.v. in eine der vier Schwanzvenen in syngene Balb/c-Mäuse appliziert und die Chemokine $(10 \mu \mathrm{g})$ i.p. injiziert, d.h. die Migrationsstudien wurden nur in Balb/c-Mäusen und nicht in C57/BL6-Mäusen durchgeführt. Nach 4 h bzw. 15-18 h wurden die Peritonealzellen geerntet und die PKH26-gefärbten gewanderten Zellen per FACS-Analyse identifiziert.

Die murinen CC-Chemokinrezeptoren CCR2 und CCR5 standen im Mittelpunkt des Interesses. CCR5 reagierte sensitiv auf beide TH2-Cytokine. Die Abbildung 15A zeigt, dass IL-4 CCR5 auf DC, die aus hämatopoetischen Vorläuferzellen aus Balb/c- und C57/BL6-Mäusen generiert wurden, herunterreguliert. Damit ging eine verminderte Ansprechbarkeit der Zellen gegen den CCR5-Liganden MIP-1 $\alpha$ in vivo einher (Abb. 15B). Für Makrophagen, die unter M-CSF kultiviert wurden und ebenfalls von Knochenmarksvorläuferzellen aus Balb/c-Mäusen abstammten, wurden ähnliche Ergebnisse erzielt (Abb. 15C, 15D). Zusätzlich regulierte IL-13 die Anzahl von CCR5 in geringerem Maße als IL-4 herunter (Abb. 15E). Dies wurde parallel von einer signifikanten Hemmung der MIP-1 $\alpha$ induzierten Migration in vivo begleitet (Abb. 15F). 

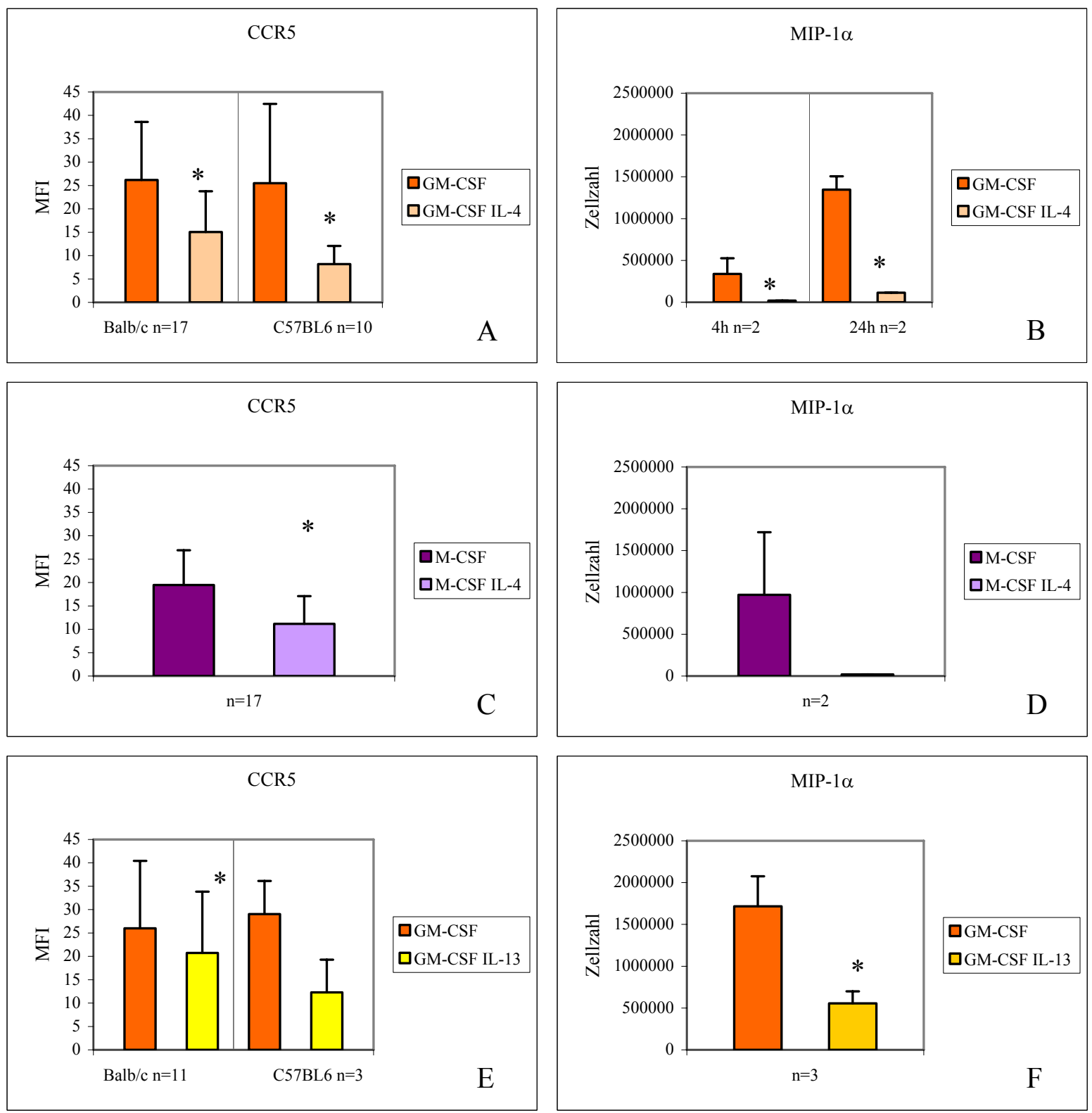

Abb. 15: IL-4 und IL-13 beeinträchtigen Expression und Funktion von Chemokinerezeptoren auf murinen DC und Makrophagen. (A) CCR5-Expression auf DC von Balb/c- $(\mathrm{n}=17)$ und C57/BL6-Mäusen (n=10) mit oder ohne IL-4. (B) In vivo Migration der DC gegen murines MIP-1 $\alpha$ (jeweils $\mathrm{n}=2$ für $4 \mathrm{~h}$ und 15-18 h). (C) CCR5-Expression auf Makrophagen ( $\mathrm{n}=17$ ), die mit und ohne IL-4 kultiviert wurden. (D) In vivo Migration von Makrophagen gegen murines MIP-1 $\alpha(\mathrm{n}=2)$. (E) CCR5-Expression auf DC, die mit und ohne IL-13 kultiviert wurden, von Balb/c- $(n=11)$ und C57/B6-Mäusen ( $n=3)$. (F) In vivo Migration der DC gegen murines MIP-1 $\alpha$ $(\mathrm{n}=3)$. Die mittlere Fluoreszenzintensität $(\mathrm{MFI})$ ist dargestellt. Die Mittelwerte und Standartabweichungen sind angegeben. $* \mathrm{p}<0,05$

Neben CCR5 wurde ebenfalls die Expression und Funktionalität von CCR2 untersucht. Wie in Abbildung 16A zu sehen ist, regulierte IL-4 die Menge an CCR2 auf der Zelloberfläche von aus hämatopoetischen Vorläuferzellen generierten DC aus Balb/c- und C57/BL6 Mäusen herunter. In Übereinstimmung mit diesen Beobachtungen zeigten die Zellen eine verminderte Fähigkeit, in vivo in Richtung des CCR2-Liganden MCP-1 zu wandern (Abb. 16B). In 
Abbildung 16C und 16D werden ähnliche Ergebnisse für die mit M-CSF generierten murinen Makrophagen gezeigt.
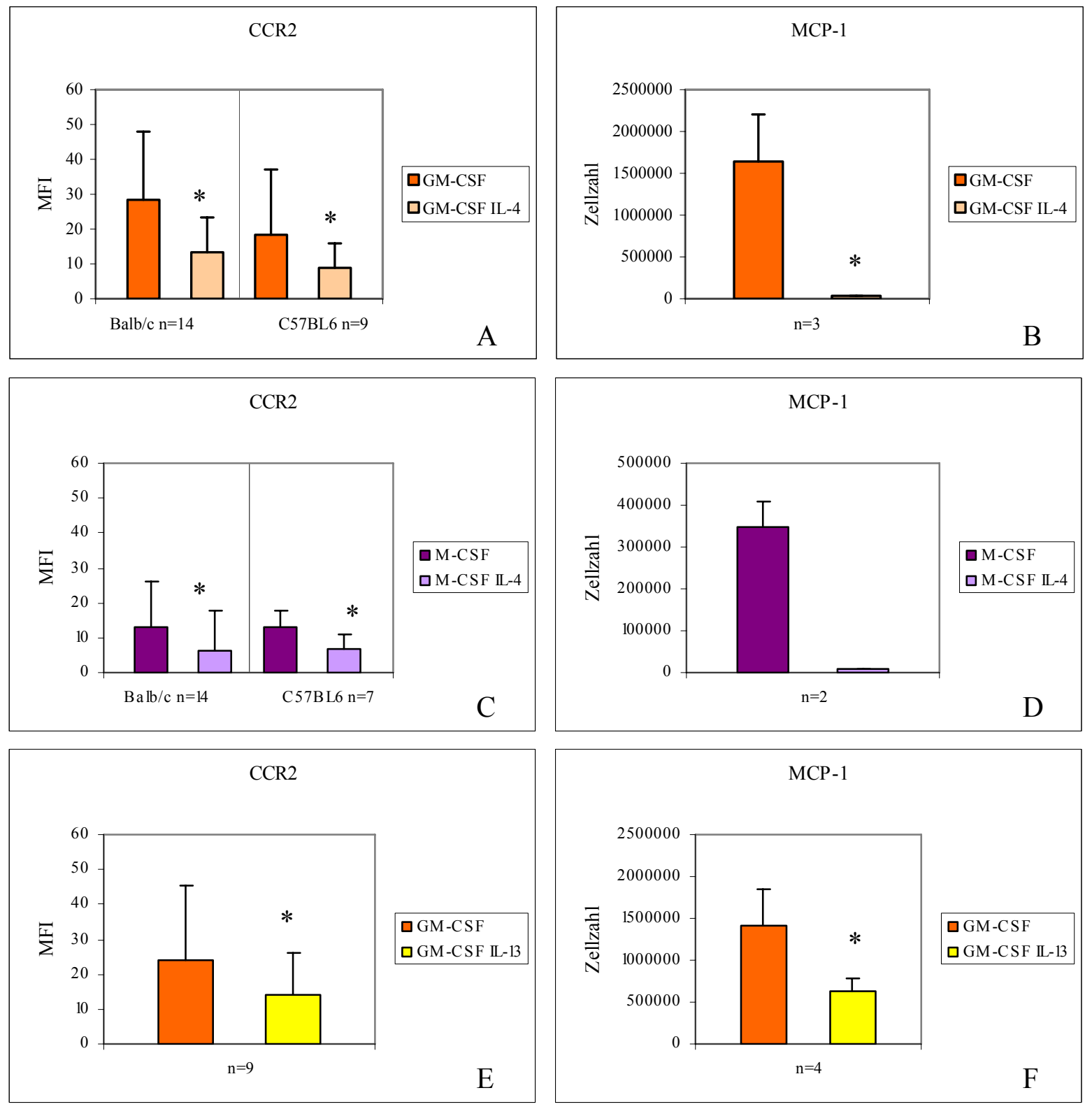

Abb. 16: IL-4 und IL-13 beeinträchtigen Expression und Funktion von Chemokinrezeptoren auf murinen DC und Makrophagen. (A) CCR2-Expression auf DC, die mit und ohne IL-4 kultiviert wurden, von Balb/c- $(\mathrm{n}=14)$ und C57/B6-Mäusen (n=9). (B) In vivo Migration der DC gegen murines MCP-1 ( $\mathrm{n}=3$ ). (C) CCR2-Expression auf Makrophagen, die mit und ohne IL-4 kultiviert wurden, von Balb/c- $(n=14)$ und C57/BL6-Mäusen ( $n=7)$. (D) In vivo Migration der Makrophagen gegen murines MCP-1 ( $\mathrm{n}=2)$. (E) CCR2-Expression auf DC $(\mathrm{n}=9)$, die mit und ohne IL-13 kultiviert wurden. (F) In vivo Migration der DC gegen murines MCP-1 ( $\mathrm{n}=4)$. Die mittlere Fluoreszenzintensität (MFI) ist dargestellt. Die Mittelwerte und Standartabweichungen sind angegeben. $* \mathrm{p}<0,05$ 

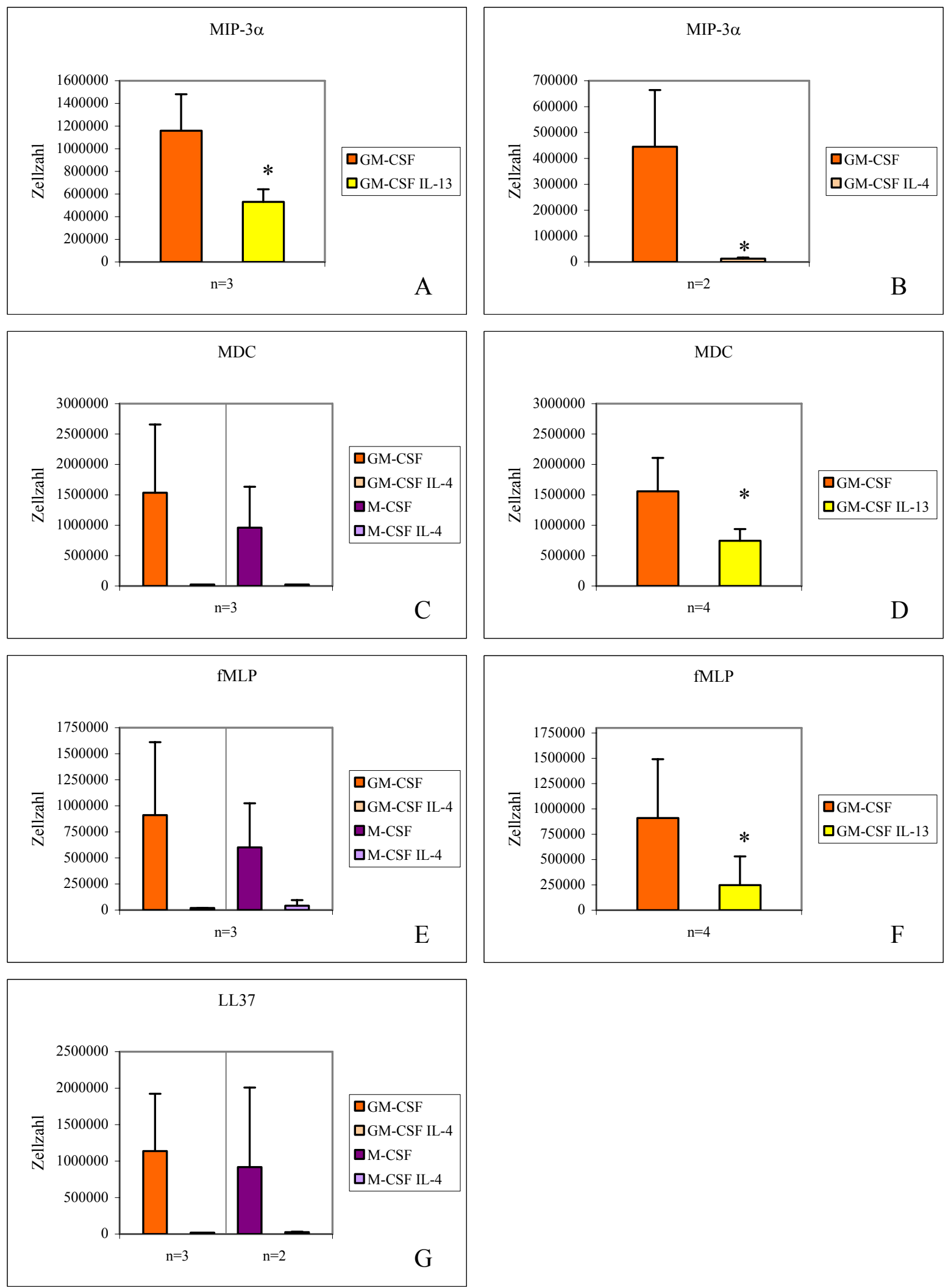

Abb. 17: IL-4 und IL-13 beeinträchtigen die Migration von murinen DC und Makrophagen gegen verschiedene inflammatorische Stimuli. (A) In vivo Migration von DC, kultiviert mit und ohne IL-13 (n=3), bzw. (B) mit und ohne IL-4 ( $\mathrm{n}=2)$, gegen murines MIP-3 $\alpha$. (C) In vivo Migration von DC und Makrophagen, kultiviert mit und ohne IL-4 (jeweils n=3), gegen murines MDC. (D) In vivo Migration von DC, kultiviert mit und ohne IL-13 $(\mathrm{n}=4)$, gegen murines MDC. (E) In vivo Migration von DC und Makrophagen (jeweils $\mathrm{n}=3$ ), kultiviert mit und ohne IL-4, gegen fMLP. (F) In vivo Migration von DC, kultiviert mit und ohne IL-13 (n=4), gegen fMLP. (G) In vivo Migration von DC ( $\mathrm{n}=3)$ und Makrophagen $(\mathrm{n}=2)$, kultiviert mit und ohne IL-4, gegen LL-37. Die mittlere Fluoreszenzintensität (MFI) ist dargestellt. Die Mittelwerte und Standartabweichungen sind angegeben. $* \mathrm{p}<0,05$ 
IL-13 verringerte ebenfalls die Menge von CCR2 auf der Zellobefläche (Abb. 16E) und hemmte die MCP-1-induzierte in vivo Chemotaxis (Abb. 16F). Weiterhin konnte gezeigt werden, dass IL-4 und IL-13 die Ansprechbarkeit von murinen DC und Makrophagen auf MIP-3 $\alpha$, welches der einzig bekannte Ligand für den Chemokinrezeptor CCR6 darstellt, verringern (Abb. 17A, 17B) (SORURI, et al., 2007).

Dies traf auch für das Chemokin MDC, das an den Chemokinrezeptor CCR4 bindet, zu (Abb. 17C, 17D). Außerdem mobilisiert fMLP, ein N-formyl Peptid bakteriellen Ursprungs mit potenter chemotaktischer Aktivität, DC und Makrophagen mit auffallend niedrigerer Effizienz, wenn die Zellen mit IL-4 oder IL-13 kultiviert wurden (Abb. 17E, 17F). Ähnliches konnte auch für das antimikrobielle Peptid LL-37 gezeigt werden (Abb. 17G). Die Peptide fMLP und LL-37 binden ebenfalls wie Anaphylatoxine und Chemokine an G-Proteingekoppelte Rezeptoren (Serpentinrezeptoren) (LE et al., 2002).
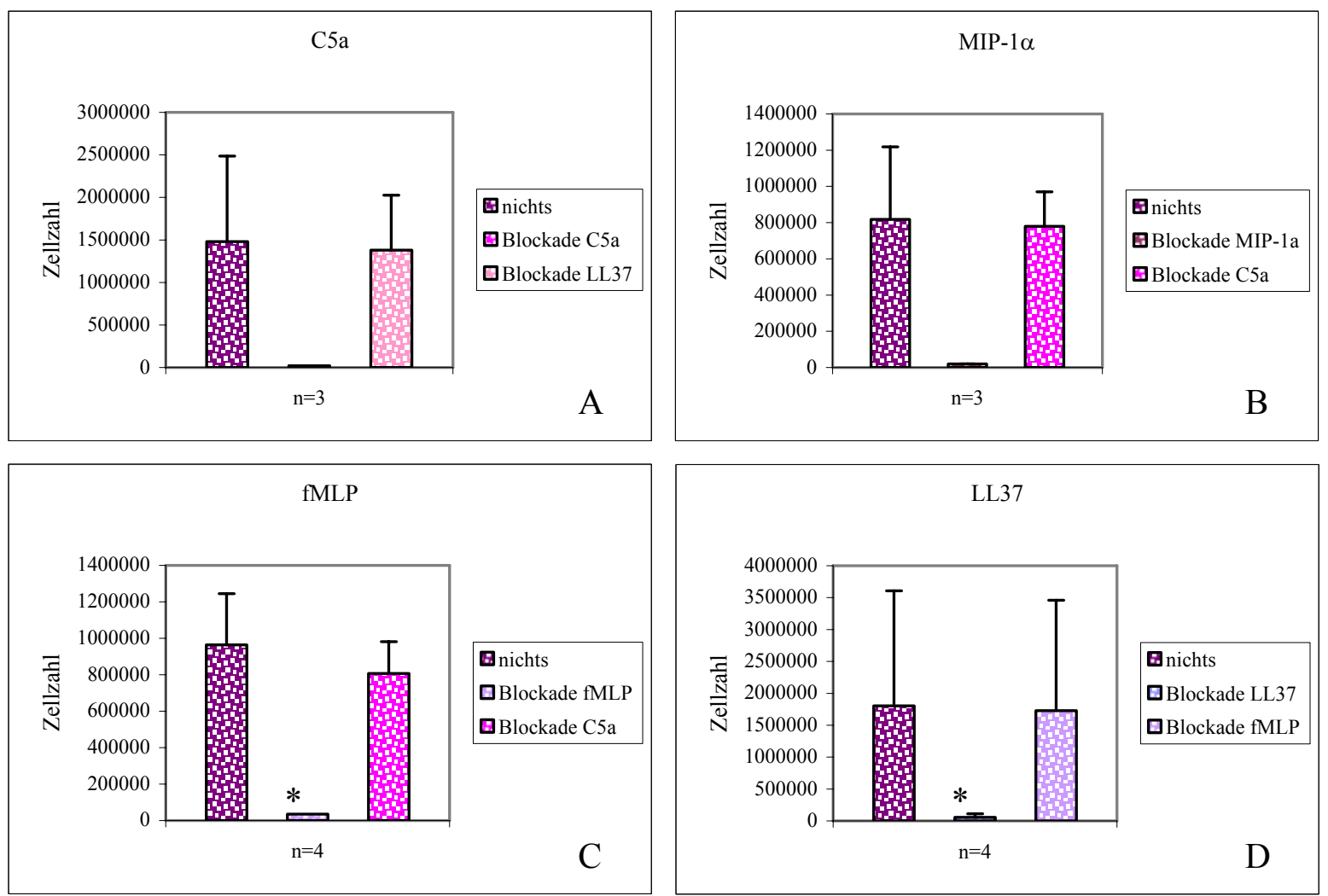

Abb. 18: Blockade durch Präinkubation bei murinen DC mit den angegebenen Chemotaxinen. Negativkontrollen mit PBS $(\varnothing)$. (A) In vivo Migration gegen C5a (n=3), (B) murines MIP-1 $\alpha(n=3),(C)$ fMLP $(n=4)$, und (D) LL-37 $(\mathrm{n}=4)$. Die mittlere Fluoreszenzintensität (MFI) ist dargestellt. Die Mittelwerte und Standartabweichungen sind angegeben. $* \mathrm{p}<0,05$

Um die Beteiligung der entsprechenden Rezeptoren an der beobachteten Zellrekrutierung in den in vivo Migrationsversuchen beweisen zu können, wurde die Tatsache genutzt, dass G-Proteingekoppelte Rezeptoren nach Liganden-Rezeptor-Interaktion internalisiert werden 
(LEFKOWITZ, 1998). Murine Makrophagen und DC wurden auch für diese Versuche aus hämatopoetischen Knochenmarksvorläuferzellen mit M-CSF bzw. GM-CSF mit und ohne IL-4 bzw. IL-13 generiert, mit PKH26 gefärbt, i.v. in syngene Balb/c-Mäuse appliziert und die Chemotaxine (10 $\mu \mathrm{g}$ MIP-3 $\alpha$ oder MDC, $20 \mu \mathrm{g}$ LL-37, $50 \mu \mathrm{g}$ fMLP ) i.p. injiziert. Nach 15-18 h wurden die Peritonealzellen geerntet und die PKH26-gefärbten gewanderten Zellen per FACS-Analyse identifiziert.

SORURI et al. (2003A) konnten zeigen, dass eine Präinkubation von Monozyten bzw. Makrophagen mit C3a die C3a-induzierte in vivo Migration vollständig blockieren kann, nicht aber die von C5a und umgekehrt. Die vorliegende Studie zeigt, dass die Chemotaxis von murinen DC in Richtung C5a, MIP-3 $\alpha$, fMLP oder LL-37 ligandenspezifisch ist, da die Wanderung durch Präinkubation der Zellen mit dem homologen Liganden unterbunden wurde (Abb. 18A, 18B, 18C, 18D). Im Gegensatz dazu gab es keinen hemmenden Effekt bei der Verwendung eines heterologen Liganden. Diese Experimente unterstreichen die in vivo Bedeutung und die rezeptorspezifische Natur der beobachteten in vivo Chemotaxis.

\subsubsection{Bedeutung des Transkriptionsfaktors STAT6 in der Expression von}

\section{Chemokinrezeptoren}
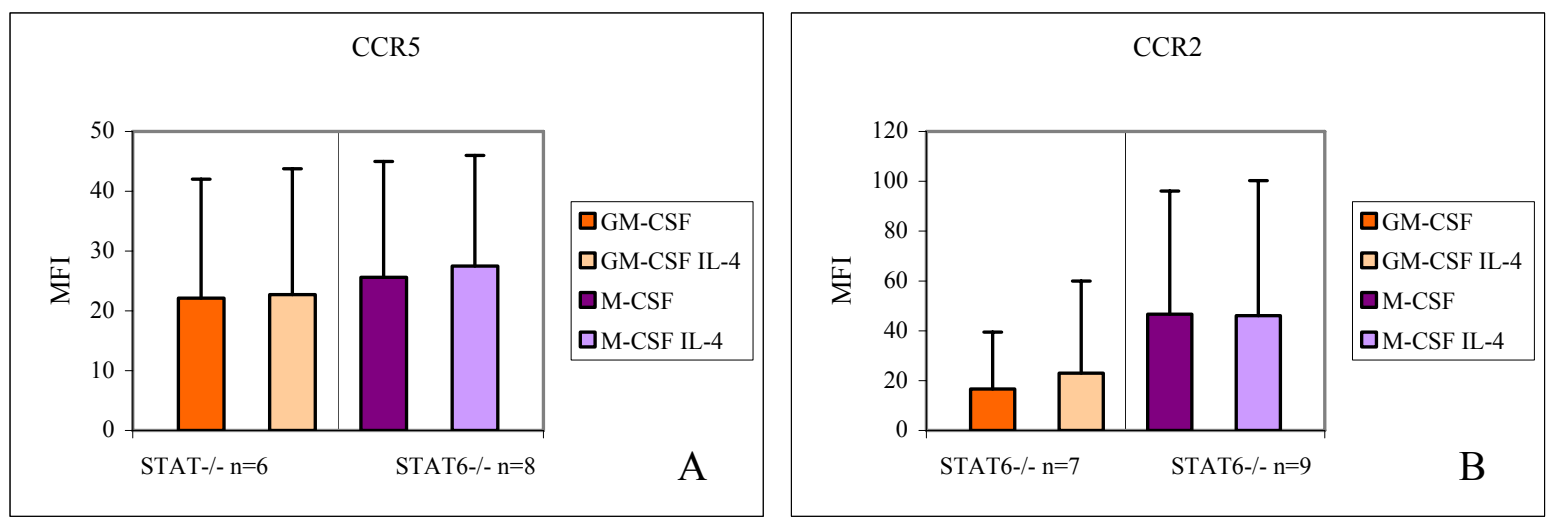

Abb. 19: Chemokinrezeptorexpression auf DC und Makrophagen in STAT6-defizienten Mäusen. (A) Expression von CCR5 auf DC $(n=7)$ und Makrophagen $(n=10)$. (B) Expression von CCR2 auf DC $(n=7)$ und Makrophagen $(n=9)$. Die mittlere Fluoreszenzintensität (MFI) ist dargestellt. Die Mittelwerte und Standartabweichungen sind angegeben. $* \mathrm{p}<0,05$

Ähnlich wie bei den Anaphylatoxinrezeptoren erwies sich STAT6 als unverzichtbar für die IL-4-induzierte Herunterregulierung der Chemokinrezeptoren CCR2 und CCR5 auf murinen DC und Makrophagen. Auch hierbei wurde durch die Untersuchung dieser Zellen aus STAT6-/- Mäusen dieses Signalmolekül als essentiell für die Rezeptorregulierung durch IL-4 
dentifiziert (Abb. 19A, 19B). In der Expression der Chemokinrezeptoren bestand kein signifikanter Unterschied zwischen den Zellen die mit und ohne IL-4 kultiviert wurden.

\subsubsection{Einfluss von IL-4 auf den Calciuminflux von murinen DC}

Zu den Reaktionen, die eine Zelle nach der Ligierung von G-Protein gekoppelten Rezeptoren durch einen Agonsiten zeigt, gehört die intrazelluläre $\mathrm{Ca}^{2+}$-Freisetzung. Sie wird unabhängig von anderen Signalwegen über die Aktivierung der Phospholipase C in Gang gesetzt. In der vorliegenden Studie sollte nicht nur der Zusammenhang zwischen IL-4-Wirkung und Migrationskapazität der Zellen dargelegt, sondern auch die Abhängigkeit der $\mathrm{Ca}^{2+}$-Freisetzung von der IL-4-induzierten Rezeptormodulation untersucht werden. In den Abbildungen 20A, 20B und 20C sind die Reaktionsverläufe der $\mathrm{Ca}^{2+}$-Freisetzung in Abhängigkeit verschiedener Mediatoren in murinen DC, die mit und ohne IL-4 kultiviert wurden, dargestellt. Die Verringerung der $\mathrm{Ca}^{2+}$-Freisetzung war bei den Zellen, die dem Einfluss von IL-4 ausgesetzt waren, zu beobachten. Dieses Resultat korreliert mit der niedrigeren Expression und der beeinträchtigten in vivo Migration in Abhängigkeit der involvierten Rezeptoren $\mathrm{C} 5 \mathrm{aR}, \mathrm{CCR} 5$ und CCR2. Alle $\mathrm{Ca}^{2+}$-Messungen waren signifikant (Abb. 21A, 21B, 21C). Die Zeitpunkte der Stimuluszugabe sind durch Pfeile (Chemotaxinzugabe nach $20 \mathrm{sec}$, Ionomycinzugabe nach $4 \mathrm{~min}$ ) gekennzeichnet. Der Messzeitraum betrug $5 \mathrm{~min}$. Das ionophorische Antibiotikum Ionomycin bewirkte den Ausstrom des gesamten Calciums aus den intrazellulären Speichern ins Cytoplasma und ermöglicht so einen zuverlässigen Vergleich zum Calciumsignal der eingesetzten Mediatoren C5a, MIP-1 $\alpha$ und MCP-1. 


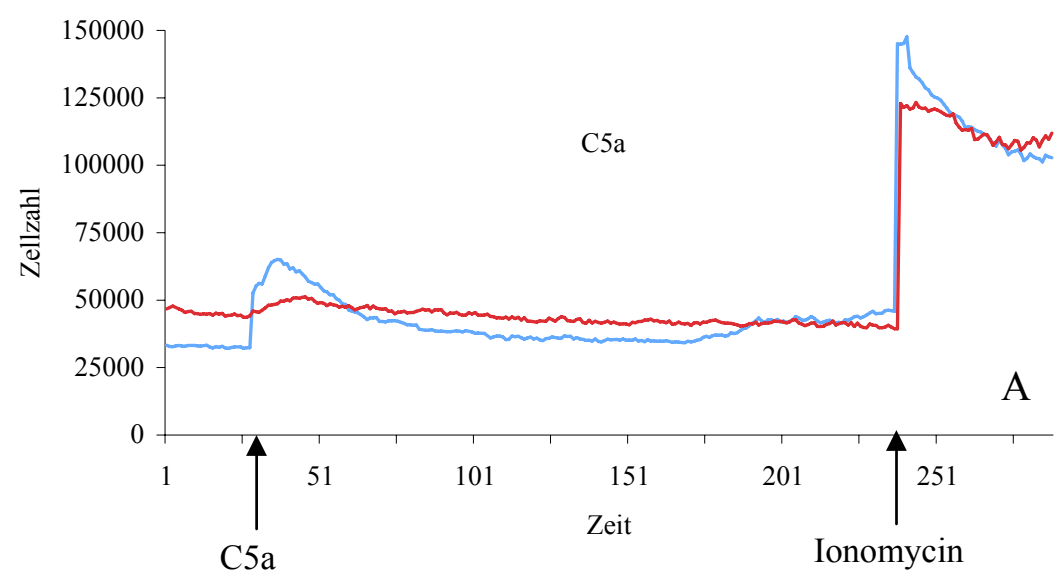

Abb. 20A: Reaktionsverlauf Calciummessung gegen C5a von KMDC aus Balb/c-Mäusen nach sieben Tagen Kultivierung mit GM-CSF (blau) und GM-CSF/IL-4 (rot). Gezeigt wird ein repräsentatives Experiment von n=4.

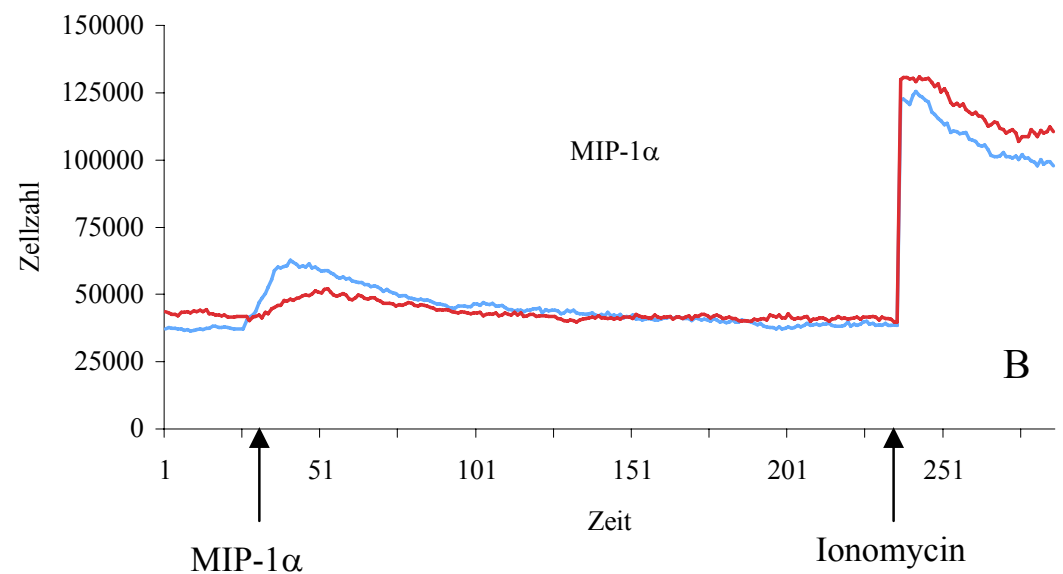

Abb. 20B: Reaktionsverlauf Calciummessung gegen MIP-1 $\alpha$ von KMDC aus Balb/c-Mäusen nach sieben Tagen Kultivierung mit GM-CSF (blau) und GM-CSF/IL-4 (rot). Gezeigt wird ein repräsentatives Experiment von n=3.

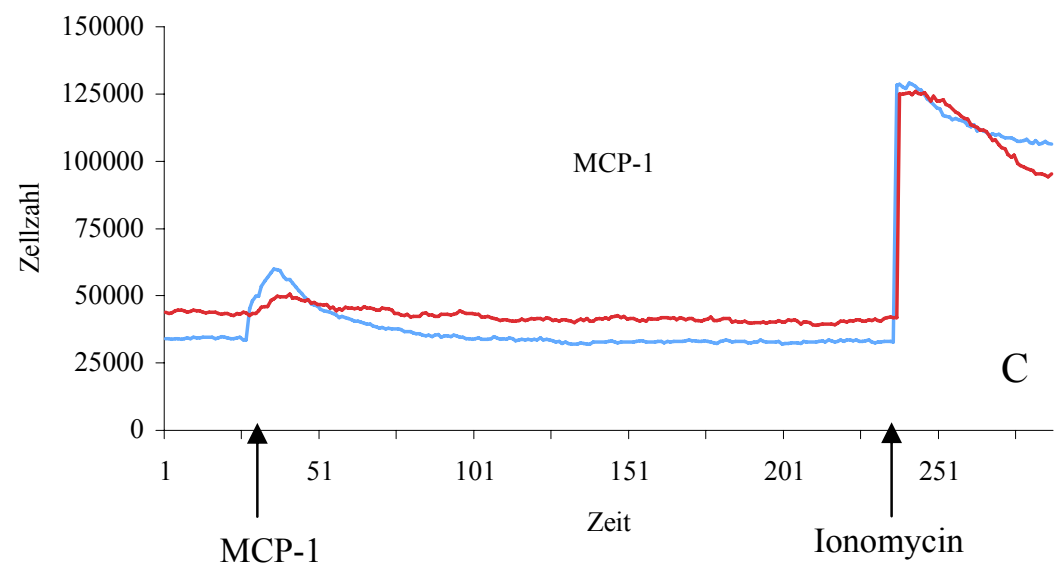

Abb. 20C: Reaktionsverlauf Calciummessung gegen MCP-1 von KMDC aus Balb/c-Mäusen nach sieben Tagen Kultivierung mit GM-CSF (blau) und GM-CSF/IL-4 (rot). Gezeigt wird ein repräsentatives Experiment von n=5. 

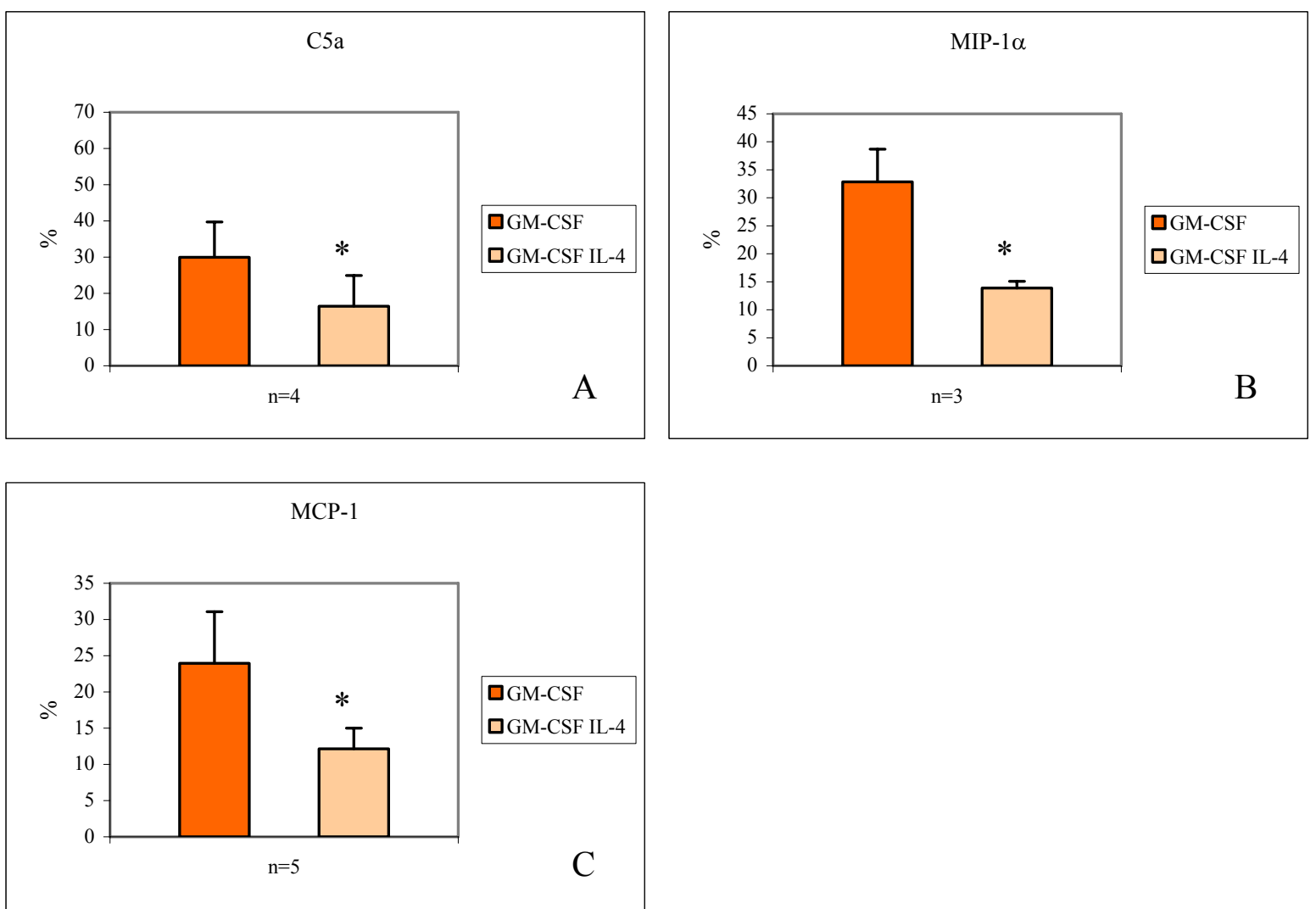

Abb. 21: IL-4 beeinträchtigt die $\mathrm{Ca}^{2+}$-Freisetzung unter dem Einfluss verschiedener Chemotaxine. (A) C5a $100 \mathrm{ng} / \mathrm{ml} \mathrm{(n=4),} \mathrm{(B)} \mathrm{MIP-1 \alpha} 100 \mathrm{ng} / \mathrm{ml}$ (n=3), (C) MCP-1 $1000 \mathrm{~g} / \mathrm{ml}$ (n=5). Die Mittelwerte und Standartabweichungen sind angegeben. $* \mathrm{p}<0,05$

\subsection{Rezeptorexpression und Chemotaxis im humanen System}

\subsubsection{Generierung von DC aus $\mathrm{CD} 4^{+}$hämatopoetischen Vorläuferzellen}
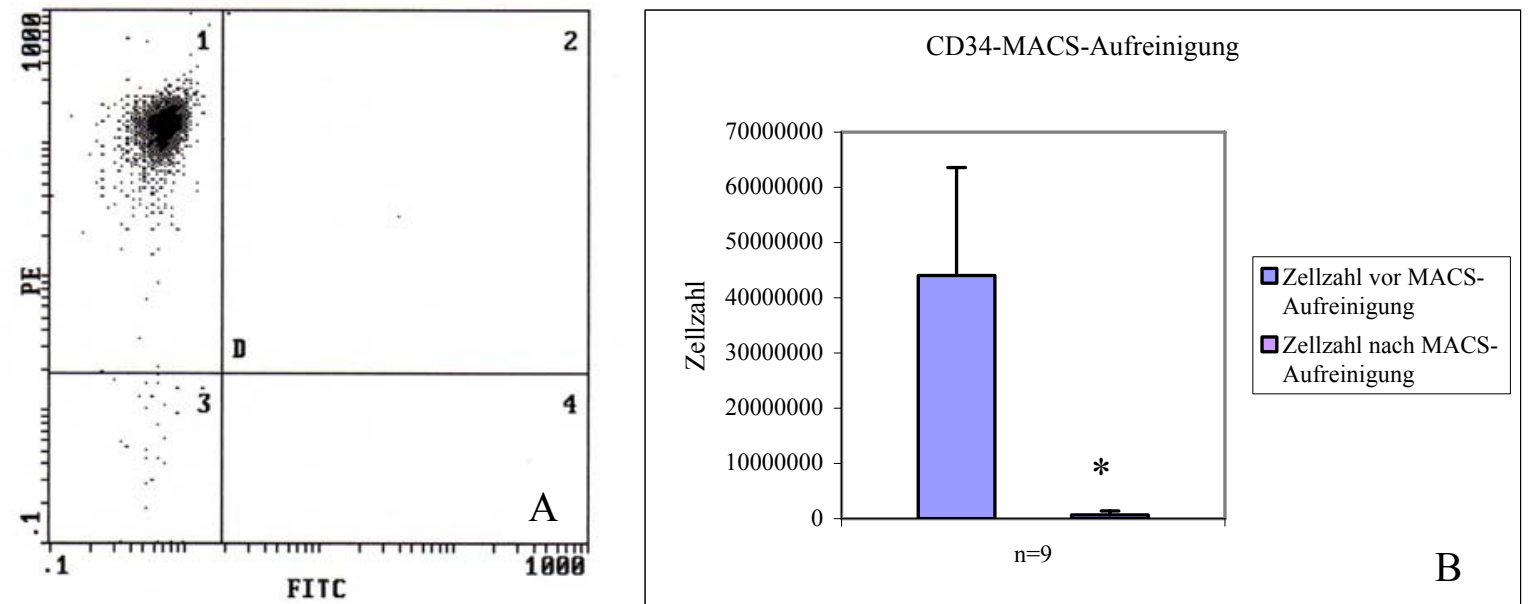

Abb. 22: $\mathrm{CD}^{+} 4^{+}$hämatopoetische Zellen wurden durch MACS-Aufreinigung aus Nabelschnurblut gewonnen. (A) Einige Proben wurden auf die Effizienz der Aufreinigung hin überprüft. Dies geschah mittels PE-markiertem antihumanen CD34-Antikörpern. Dargestellt ist ein repräsentatives Experiment von 9. (B) Die Zellzahlen vor und nach der MACS-Aufreinigung unterschieden sich um das Hundertfache. $* p<0,05$ 
Um die Genauigkeit der CD34-MACS-Aufreinigung zu überprüfen, wurden stichprobenartig Kontrollfärbungen mit einem Antikörper durchgeführt, der ebenfalls gegen humanes CD34 gerichtet war, aber ein anderes Epitop erkannte, so dass eine sterische Behinderung zwischen den Antikörpern ausgeschlossen wurde (Abb. 22A). Die durchschnittliche Reinheit der hämatopoetischen Vorläuferzellen betrug 94,7 \% und lag damit genau in dem vom Hersteller angegebenen Bereich von 85 - 98 \% (Miltenyi Biotec Produktinformation).

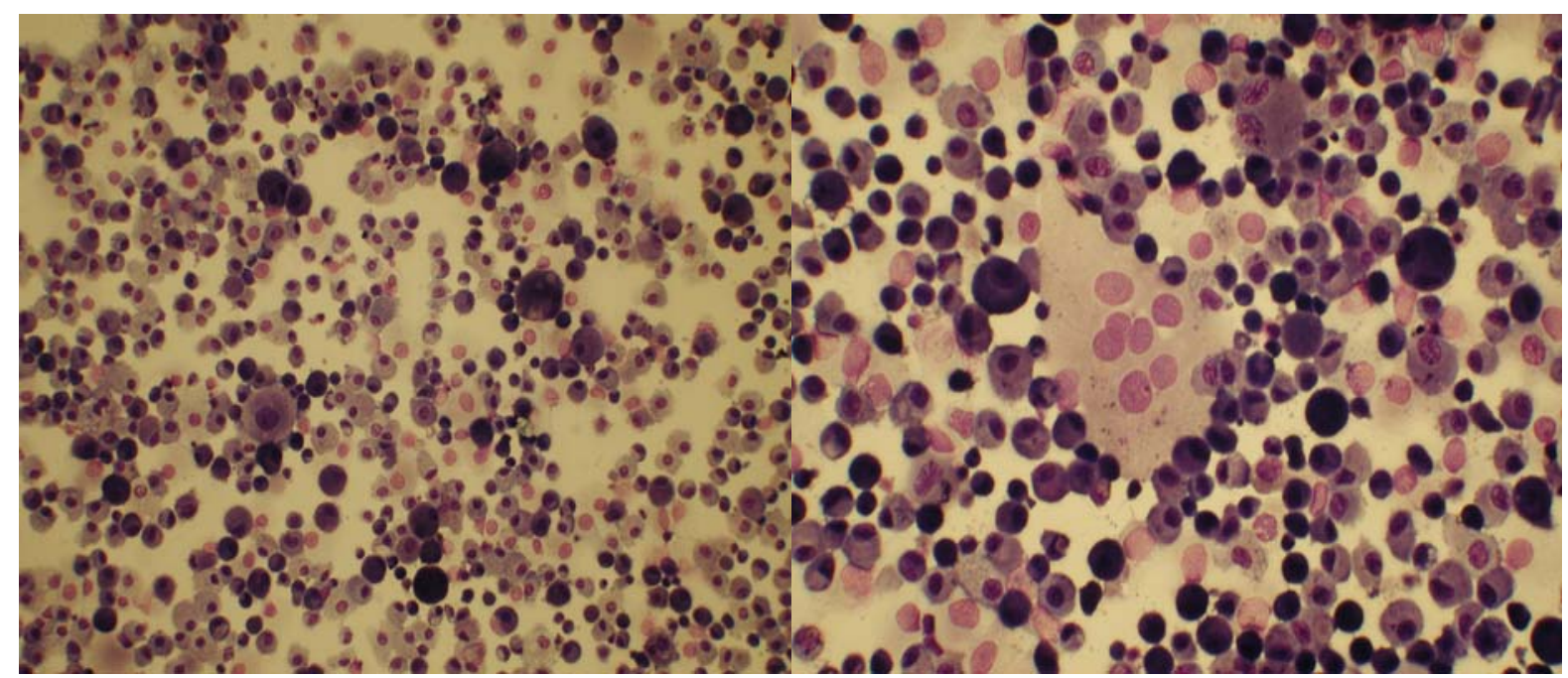

Abb. 23: Übersichtsaufnahmen Cytospin Nabelschnurblut 3 Wochen Kultivierung mit TPO, SCF, Flt3-L. Cytospins wurden gefärbt mit Eosin und Methylenblau. Die ausgeprägte Heterogenität der Kultur ist durch das Auftreten verschiedenster Zellpopulationen in unterschiedlichen Entwicklungsstadien gekennzeichnet.

Die Generierung von DC aus hämatopoetischen $\mathrm{CD}^{+} 4^{+}$Vorläufern erwies sich als sehr zeitaufwendig, da die Zellausbeute nach der MACS-Aufreinigung nur zwischen $10^{4}$ und $10^{5}$ lag (Abb. 22B). Ursache hierfür war die geringe Ausgangsmenge an Nabelschnurblut mit durchschnittlich $20 \mathrm{ml}$. Da $\mathrm{CD}^{+} 4^{+}$hämatopoetische Stammzellen verschiedenen Entwicklungslinien angehören und auch in ihrer Reihenzugehörigkeit noch nicht festgelegt sein müssen, wurde nach der MACS-Aufreinigung mit anti-CD34-Antikörpern eine stark heterogene Zellpopulation kultiviert. Um eine genügend große Zellzahl für die geplanten Versuche zu erhalten, mussten die hämatopoetischen Vorläufer für vier bis sechs Wochen kultiviert werden. Dabei entwickelten sie sich in die Richtung myeloider Vorstufen. Kulturen, die nicht umgehend gebraucht wurden, wurden nach der Proliferation eingefroren. Die Beurteilung der kultivierten Zellen erfolgte regelmäßig unter dem Mikroskop bei 400 facher Vergrößerung. In Abbildung 23 ist $\mathrm{zu}$ erkennen, dass nach 3 Wochen Kultivierung die Heterogenität der Kultur weiterhin vorhanden war. Unter dem Einfluss des Proliferationscocktails (TPO, SCF, Flt3-L) vermehrten sich die Zellen sehr rasch um das Einhundertfache. Durch eine Kontrollfärbung mit Antikörpern gegen CD3 (T-Zellmarker) 
und CD19 (B-Zellmarker) konnte das Vorhandensein von Lymphozyten ausgeschlossen werden (Daten nicht gezeigt). Des Weiteren waren keine erythrozytären Vorstufen in den Cytospins vorhanden. So konnte davon ausgegangen werden, dass es sich bei den kultivierten Zellen hauptsächlich um Vertreter der myeloiden Entwicklungsreihen handeln musste. Dies wurde durch die Anfärbung von Oberflächenmarkern, die auf myeloiden Zellen vorkommen, bestätigt (Abb. 24). Die Zellen exprimierten zu einem großen Teil CD14 und zeigten auch, in unterschiedlichem Maße, das MHC Klasse II Protein HLA-DR (Abb. 24A). Die Anaphylatoxinrezeptoren für $\mathrm{C} 5 \mathrm{a}$ und $\mathrm{C} 3 \mathrm{a}$ konnten ebenfalls nachgewiesen werden (Abb. 24B, 24C).
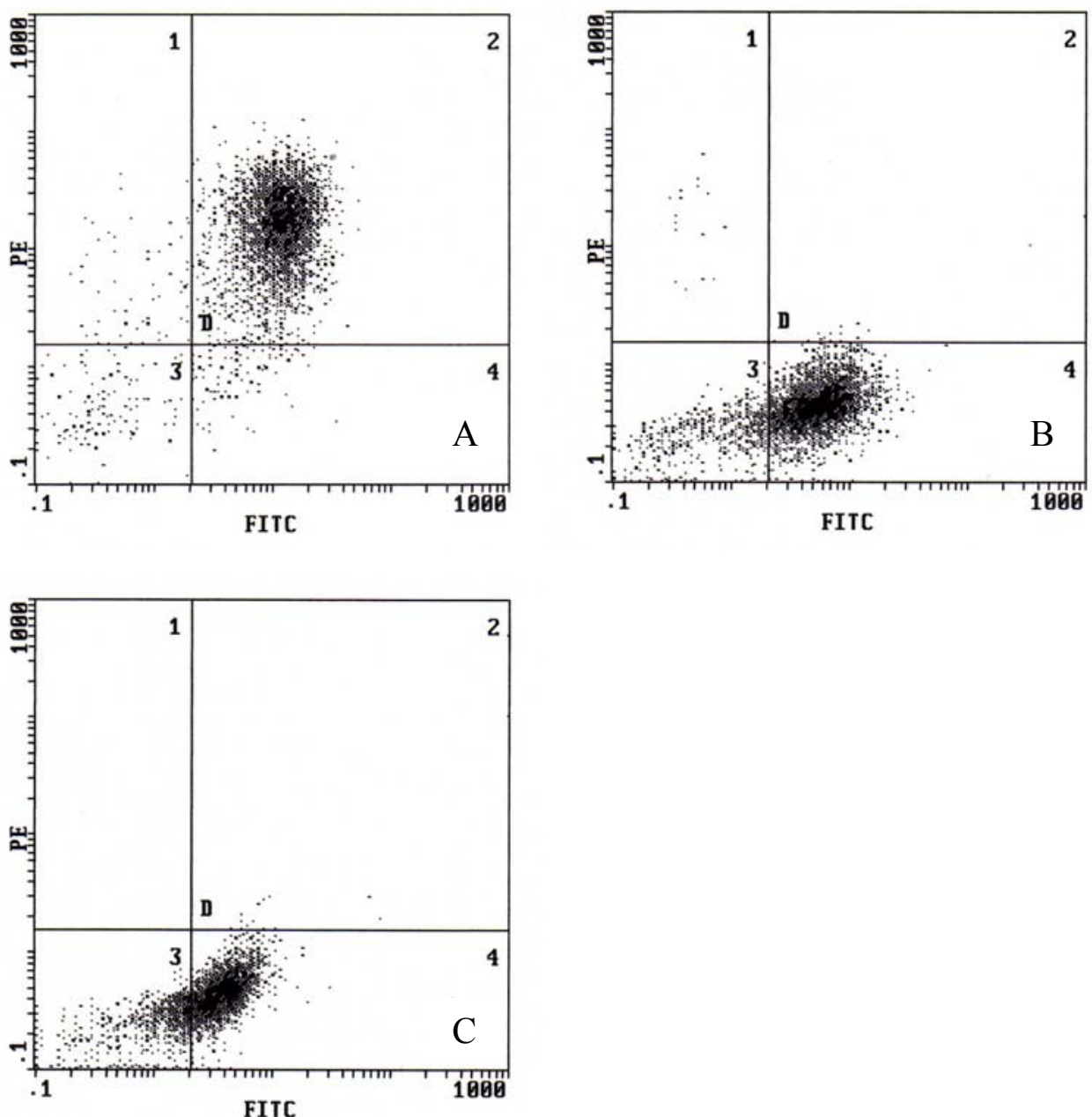

Abb. 24: $\mathrm{CD}^{+} 4^{+}$hämatopoetischen Vorläuferzellen aus Nabelschnurblut wurden 4 Wochen mit dem Proliferationscocktail (TPO, SCF, Flt3-L) kultiviert. Bevor der Cytokinwechsel zu GM-CSF mit und ohne IL-4 stattfand, wurde ein Teil der Zellen einer FACS-Färbung unterzogen. (A) Doppelfärbung HLA-DR PE und CD14 FITC. (B) C5aR-Expression. (C) C3aR-Expression. Dargestellt ist ein repräsentatives Experiment von 18.

Durch den Cytokinwechsel zu GM-CSF mit und ohne IL-4 wurden DC-Vorläuferzellen gezielt positiv selektiert. Dies garantierte die hohe Reinheit der Kultur. 

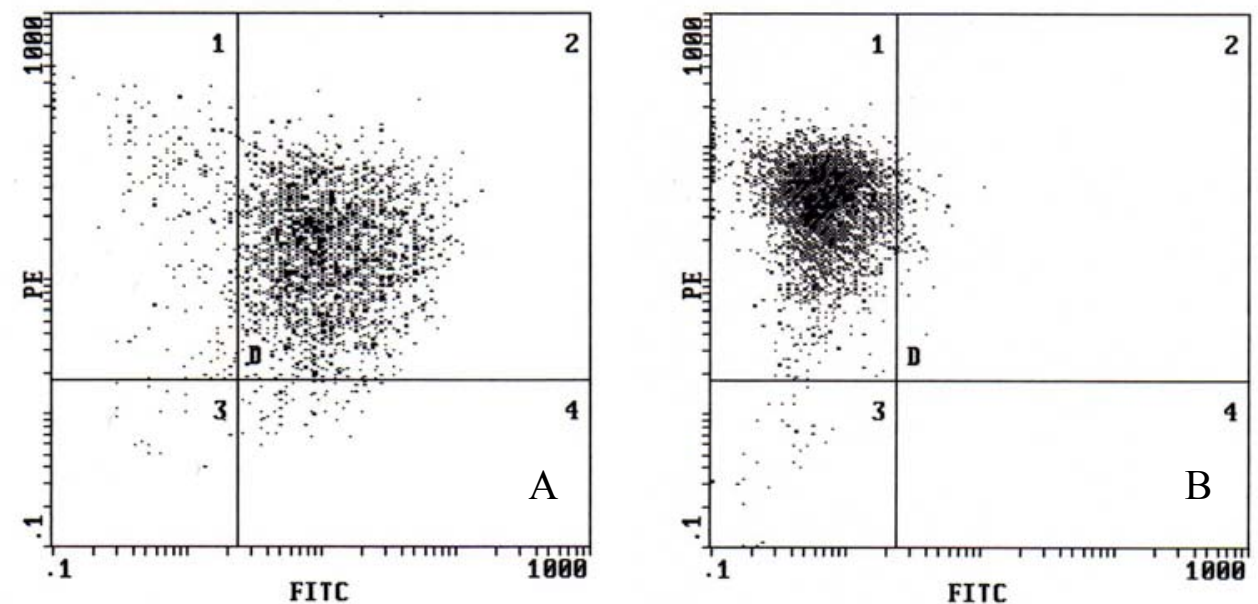

Abb. 25: IL-4 beeinträchtigt die Expression des myeloiden Markers CD14 (FITC) und erhöht die des MHC Klasse II Proteins HLA-DR (PE). (A) Expression von HLA-DR und CD14 nach vier Wochen Kultivierung mit TPO, SCF und Flt3-L und zwei Wochen GM-CSF. (B) Expression von HLA-DR und CD14 nach vier Wochen mit TPO, SCF und Flt3-L und zwei Wochen GM-CSF und IL-4. Dargestellt ist ein repräsentatives Experiment von 18.
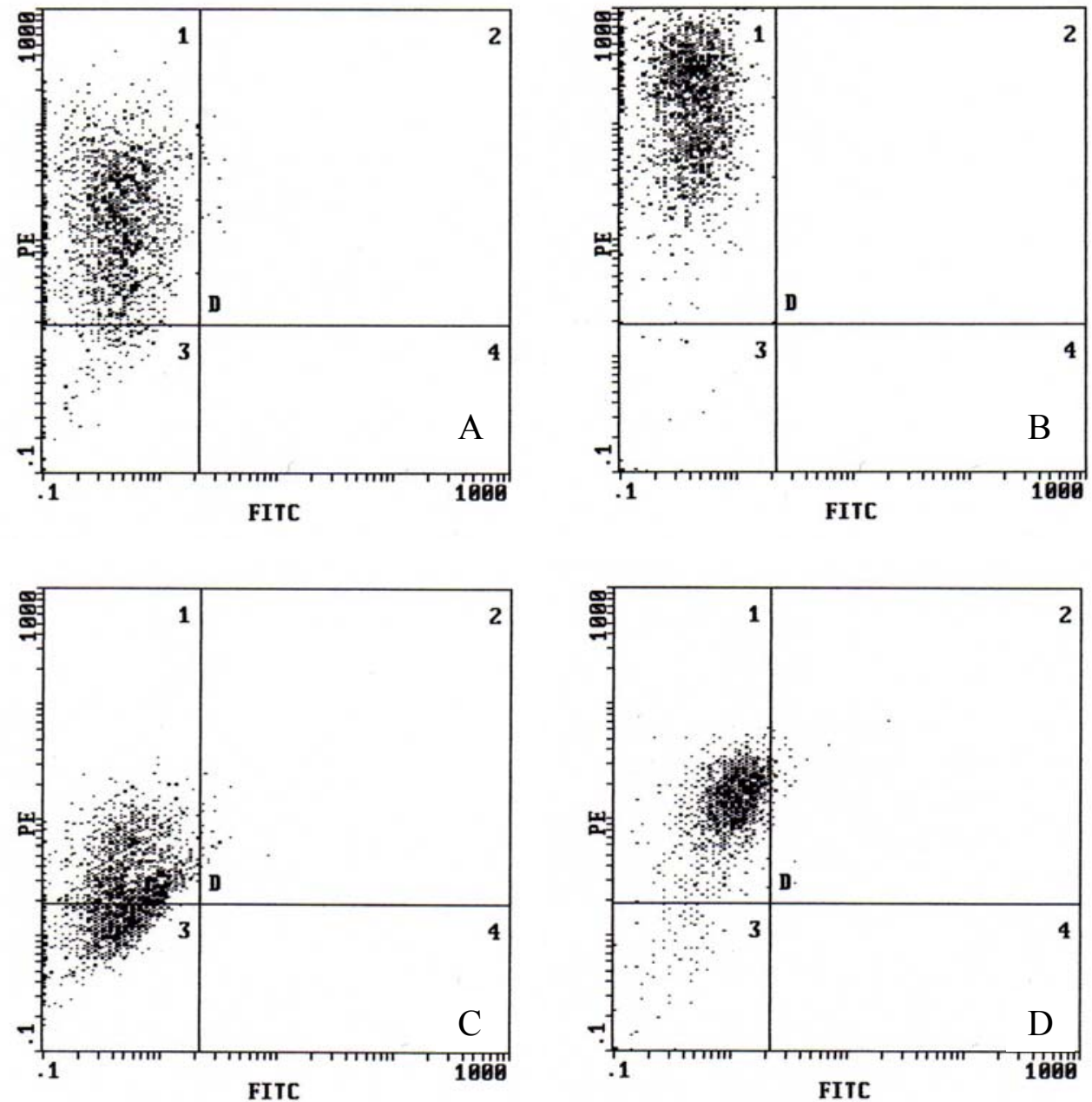

Abb. 26: LPS erhöht die Expression von HLA-DR (PE) und den kostimulatorischen Molekülen CD83 (FITC) und CD86 (PE). (A) GM-CSF/IL-4-Zellen. Expression von HLA-DR. (B) GM-CSF/IL-4 Zellen wurden 48 h mit LPS stimuliert. Expression von HLA-DR. (C) GM-CSF/IL-4-Zellen. Expression von CD83 und CD86. (D) GM-CSF/IL-4 Zellen wurden $48 \mathrm{~h}$ mit LPS stimuliert. Expression von CD83 und CD86. Dargestellt ist ein repräsentatives Experiment von 18. 
Am Tag der Ernte wurden die Zellen einer FACS-Färbung der Oberflächenmoleküle HLA-DR und CD14 (Abb. 25A, 25B), C5aR und C3aR (Abb. 28A, 28C) unterzogen. Um sicherzustellen, dass es sich tatsächlich um DC handelte, reiften einige ausgewählte GM-CSF/IL-4-Kulturen für $48 \mathrm{~h}$ unter dem Einfluss von LPS (250 ng/ml). Dies bewirkte eine gesteigerte Expression von HLA-DR und das Auftreten von CD83 und CD86 auf der Zelloberfläche (Abb. 26). Eine große Menge an MHC Klasse II und die Expression von kostimulatorischen Molekülen sind typische Merkmale reifer Dendritischer Zellen.

\subsubsection{Einfluss von IL-4 und IL-13 auf Anaphylatoxinrezeptoren auf humanen MoDC}
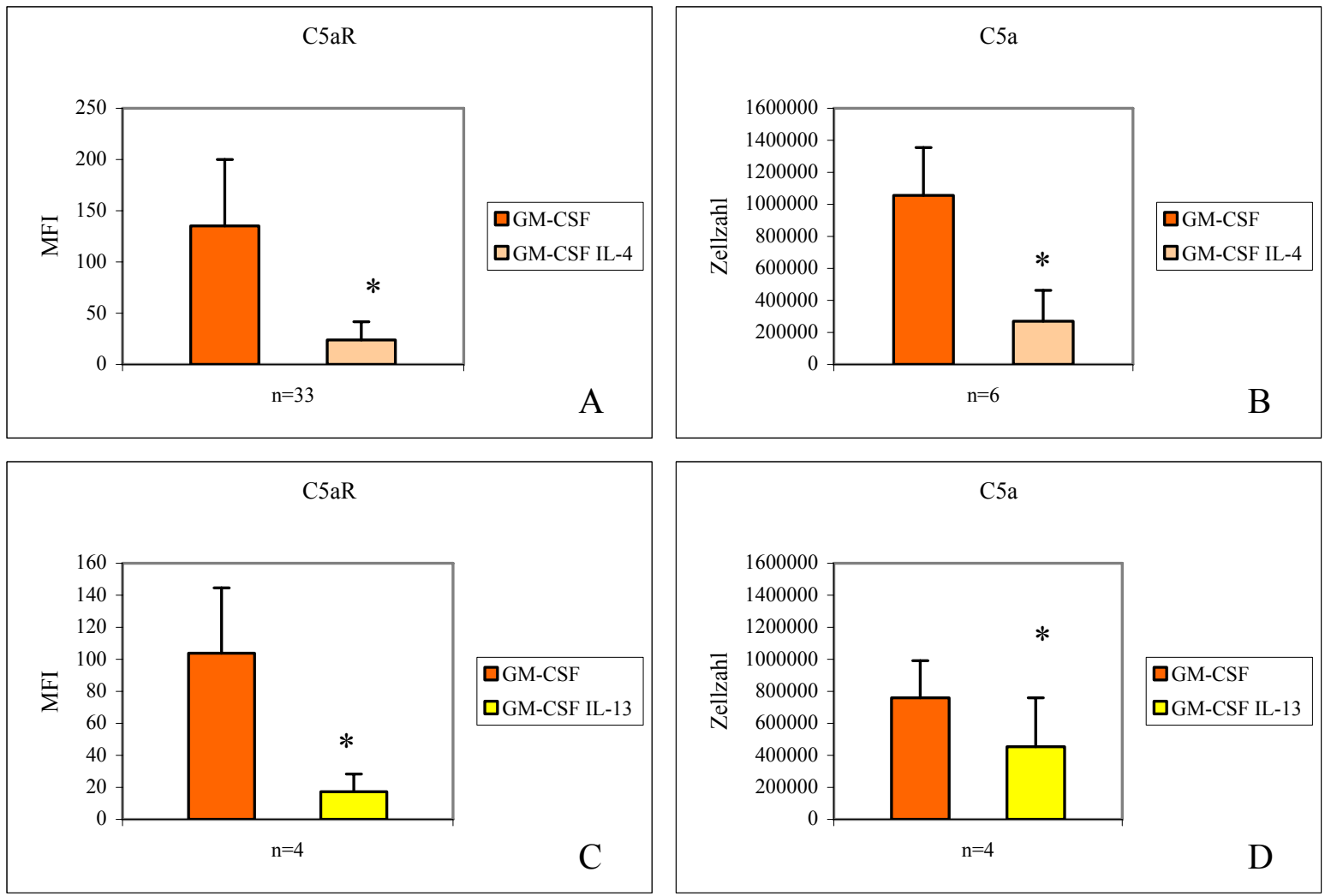

Abb. 27: IL-4 und IL-13 beeinträchtigen Expression und Funktion von C5aR auf humanen aus Monozyten generierten DC. (A) C5aR-Expression auf DC, die mit IL-4 kultiviert wurden $(\mathrm{n}=33)$. (B) In vivo Migration dieser Zellen gegen C5a (n=6). (C) C5aR-Expression auf DC, die mit IL-13 kultiviert wurden (n=4). (D) In vivo Migration dieser Zellen gegen C5a $(n=4)$. Die mittlere Fluoreszenzintensität (MFI) ist dargestellt. Die Mittelwerte und Standartabweichungen sind angegeben. $* \mathrm{p}<0,05$

Humane Monozyten wurden für zwei Tage mit und ohne IL-4 oder für sieben Tage unter Zugabe von GM-CSF mit und ohne IL-4 bzw. IL-13 kultiviert. Die Anaphylatoxinrezeptorexpression wurde mittels indirekter FACS-Färbung und anschließender FACS-Analyse ermittelt. Für die in vivo Migrationsstudien wurden die humanen Zellen in SCID-Mäuse in eine der Schwanzvenen i.v. appliziert und die Anaphylatoxine i.p. injiziert. 
Nach 15-18 h wurden die Peritonealzellen mittels Lavage geerntet und durch die Verwendung von anti-HLA-DR-PE in Kombination mit anti-CD14-FITC bzw. anti-CD86-FITC gefärbt, um die gewanderten humanen Zellen per FACS-Analyse identifizieren zu können.

SORURI et al. (2003A) haben bereits gezeigt, dass IL-4 den humanen C5aR auf Monozyten und auf DC, die aus Monozyten generiert wurden, herunterreguliert und ebenfalls die C5a-induzierte Migration dieser Zellen hemmt.
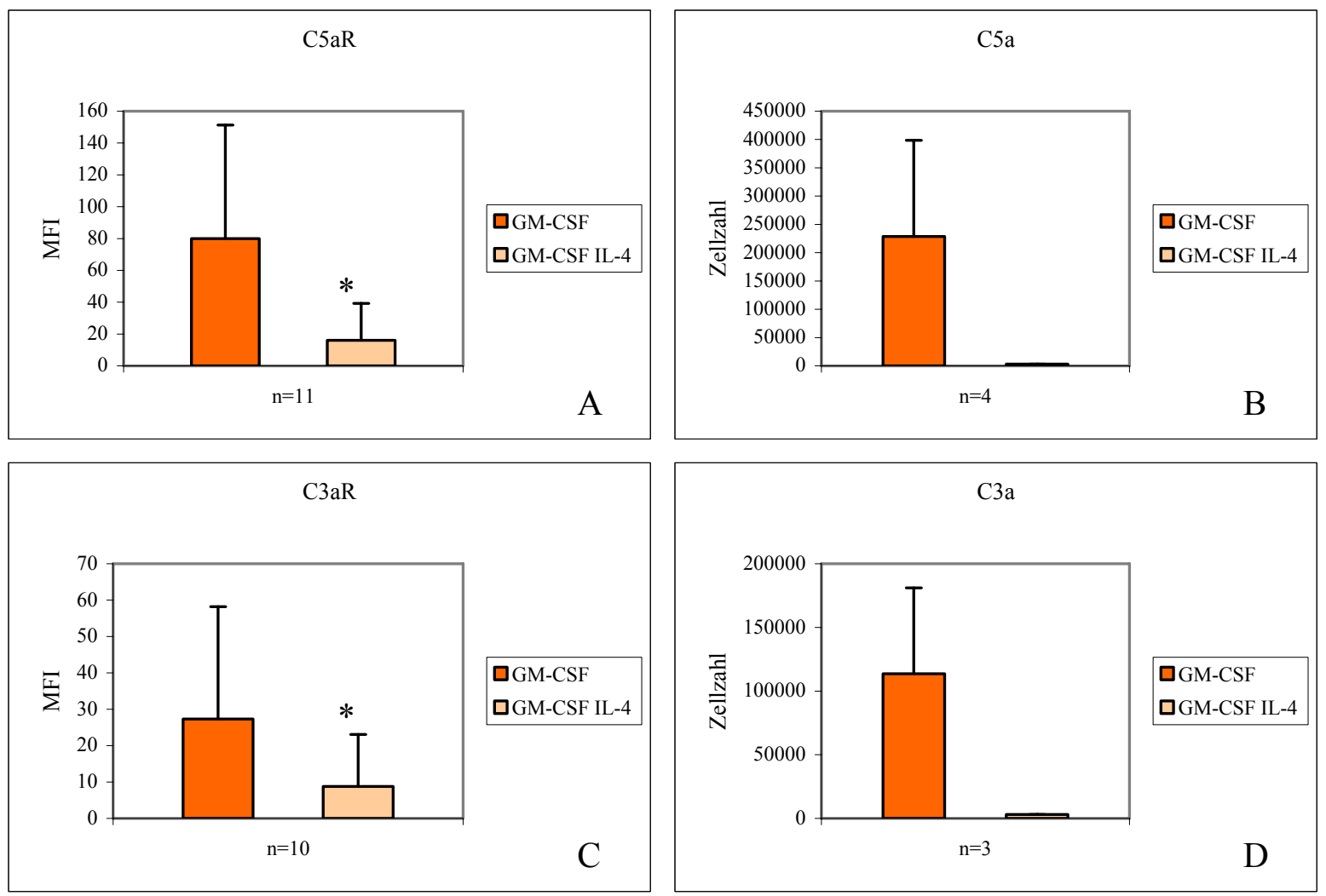

Abb. 28: IL-4 beeinträchtigt die Expression von Anaphylatoxinrezeptoren auf DC, die von CD34 hämatopoetischen Vorläuferzellen aus Nabelschnurblut abstammen. (A) C5aR-Expression mit und ohne IL-4. (B) In vivo Migration gegen C5a. (C) C3aR-Expression mit und ohne IL-4. (D) In vivo Migration gegen C3a $(40 \mu \mathrm{g})$. Die mittlere Fluoreszenzintensität (MFI) ist dargestellt. Die Mittelwerte und Standartabweichungen sind angegeben. $* \mathrm{p}<0,05$

In der vorliegenden Studie konnte gezeigt werden, dass die Verringerung der Menge des C5aR und die Hemmung seiner Funktion sowohl auf MoDC als auch auf DC, die aus CD34 ${ }^{+}$ hämatopoetischen Stammzellen aus Nabelschnurblut generiert wurden, ein Resultat des Effektes von IL-4 (Abb. 27A, 27B, 28A) und bei MoDC auch von IL-13 war (Abb. 27C, 27D). Ähnliches konnte für den $\mathrm{C} 3 \mathrm{aR}$ auf nabelschnurblutgenerierten DC gezeigt werden (Abb. 28C, 28D). 


\subsubsection{Einfluss von IL-4 auf Chemokinrezeptoren von humanen Monozyten und MoDC}

Auch für die Untersuchung der Chemokinrezeptoren wurden humane Monozyten für zwei Tage mit und ohne IL-4 oder für sieben Tage unter Zugabe von GM-CSF mit und ohne IL-4 kultiviert. Die Rezeptorexpression wurde mittels indirekter FACS-Färbung und nachfolgend durch FACS-Analyse untersucht. Für die in vivo Wanderungsversuche wurden die humanen Zellen in SCID-Mäuse i.v. in eine Schwanzvene appliziert und die Chemokine (jeweils $10 \mu \mathrm{g}$ ) i.p. injiziert. Nach 4 h bzw. 15-18 h wurden die Peritonealzellen mittels Lavage geerntet und durch die Verwendung von anti-HLA-DR-PE in Kombination mit anti-CD14-FITC bzw. antiCD86-FITC gefärbt, um die gewanderten humanen Zellen per FACS-Analyse identifizieren zu können.
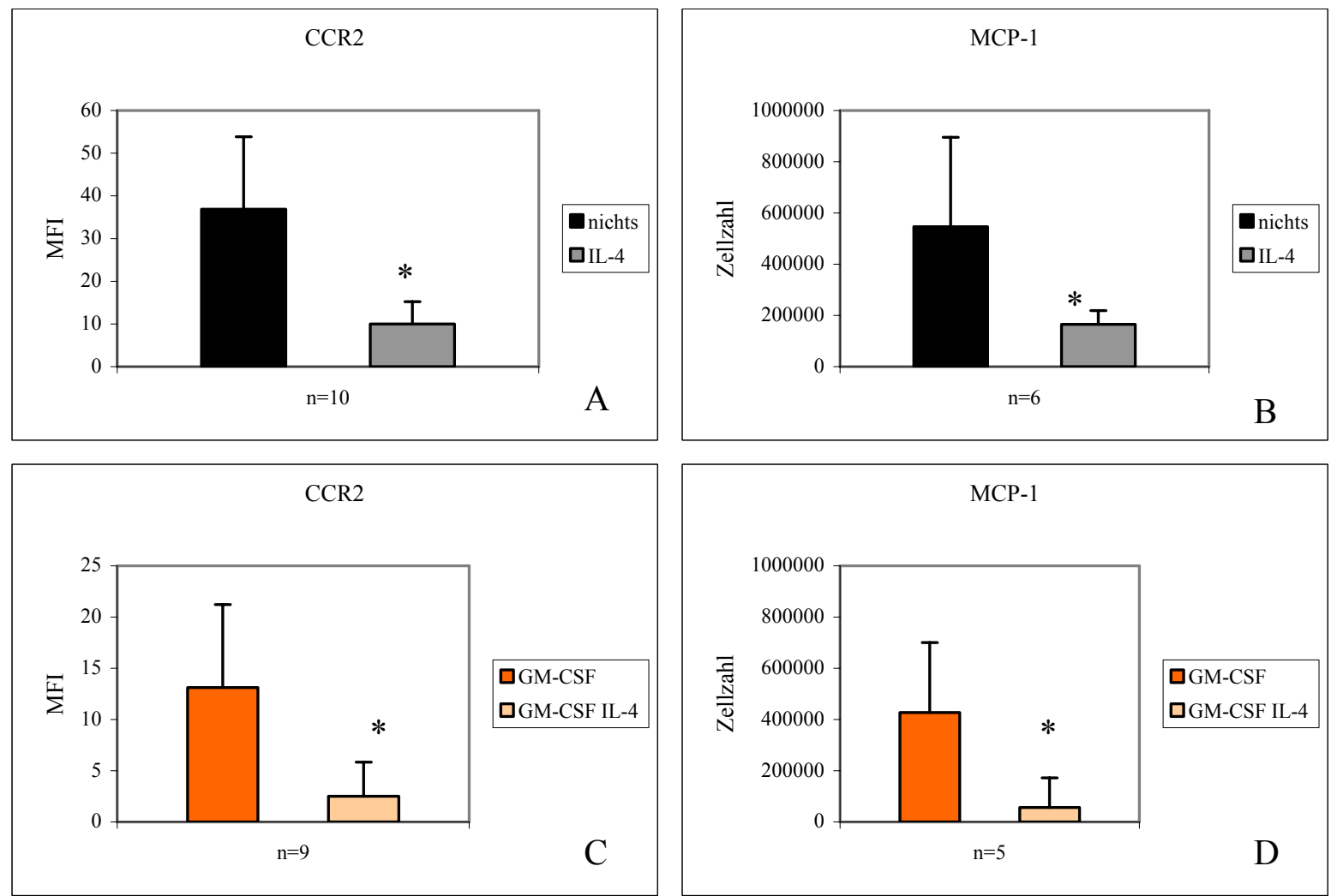

Abb. 29: IL-4 beeinträchtigt die Expression von Chemokinrezeptoren auf Monozyten und DC. (A) CCR2-Expression auf Monozyten, die für zwei Tage kultiviert wurden $(n=10)$. (B) In vivo Migration dieser Zellen gegen humanes MCP-1 (n=6). (C) CCR2-Expression auf DC (n=9). (D) In vivo Migration dieser Zellen gegen humanes MCP-1 ( $n=5)$. Die mittlere Fluoreszenzintensität (MFI) ist dargestellt. Die Mittelwerte und Standartabweichungen sind angegeben. $* \mathrm{p}<0,05$

Ähnlich wie im Mausversuch war der IL-4-Effekt auf die humanen Zellen nicht auf die Anaphylatoxinrezeptoren $\mathrm{C} 5 \mathrm{aR}$ und $\mathrm{C} 3 \mathrm{aR}$ beschränkt. IL-4 verminderte ebenso die Expression von CCR2 auf humanen Monozyten (Abb. 29A, 29B) und monozytengenerierten DC (Abb. 29C, 29D). Es inhibierte auch die MCP-1-induzierte Migration dieser Zellen in 
vivo. Die Migration von monozytengenerierten DC in Richtung des CCR4-Liganden MDC war ebenfalls durch die Kultivierung der Zellen mit IL-4 vermindert (Daten nicht gezeigt).

Die Oberflächenexpression der Chemokinrezeptoren CCR1 und CCR5 auf Monozyten wurde unter dem Einfluss von IL-4 verringert (Abb. 30A, 30B). Dazu passend konnte eine signifikant reduzierte Zellrekrutierung durch den Liganden MIP-1 $\alpha$ beobachtet werden (Abb. 30C). Ebenso zeigten die monozytengenerierten DC eine weniger effiziente MIP-1 $\alpha$-induzierte Mobilisierung im Vergleich zu den Zellen, die nur mit GM-CSF kultiviert wurden. Allerdings war keine ausgeprägte Abnahme von CCR1 und CCR5 auf den DC durch die Zugabe von IL-4 zu verzeichnen (Abb. 31A, 31B). Die eingeschränkte in vivo Migration (Abb. 31C) trotz relativ gleich bleibender Rezeptorexpression ließe sich durch eine Rezeptorentkopplung von den zugehörigen Signaltransduktionswegen oder aber durch eine Blockade oder einen Mangel involvierter Signalmoleküle erklären.
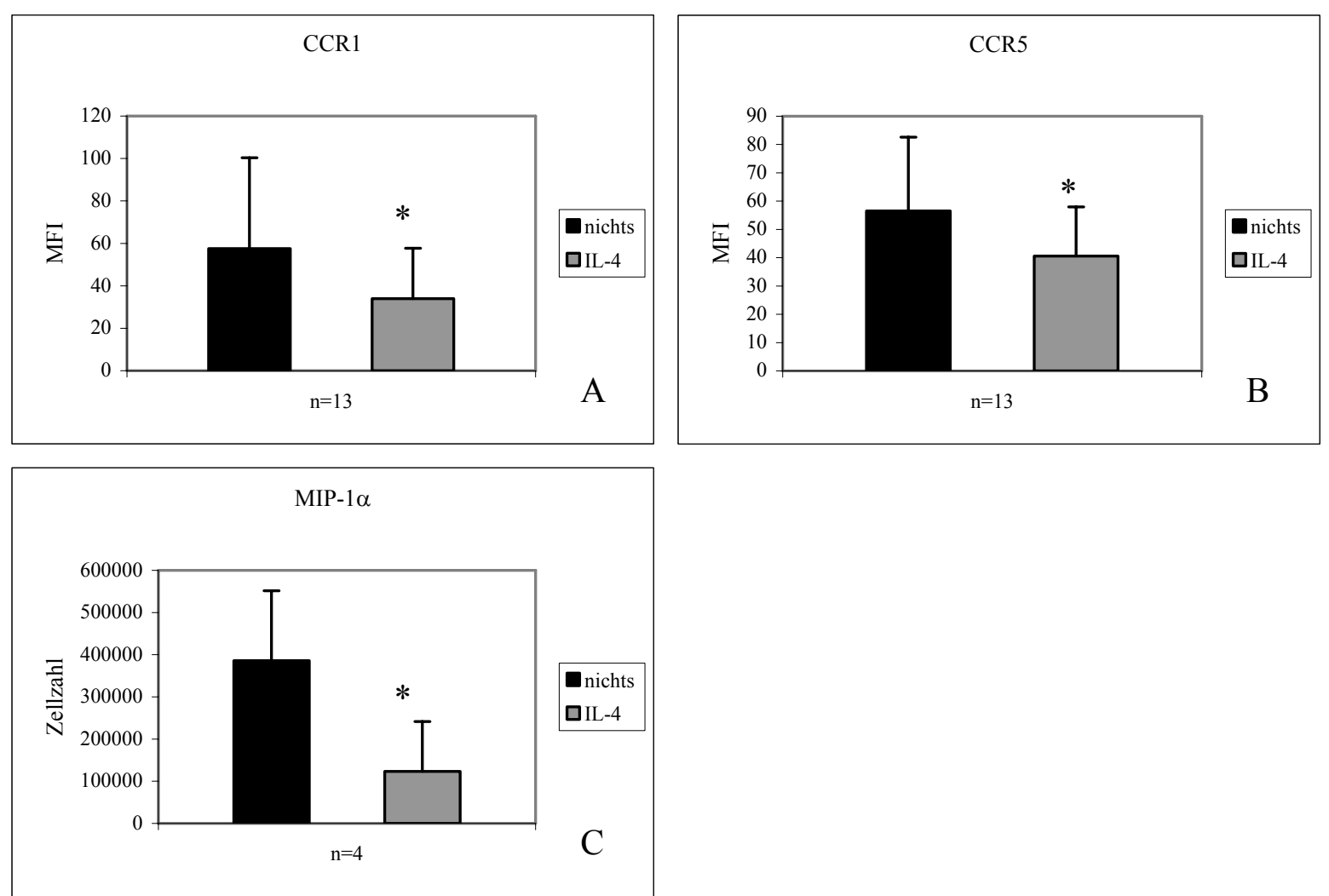

Abb. 30: IL-4 beeinträchtigt die Expression von Chemokinrezeptoren auf Monozyten, die für zwei Tage kultiviert wurden. (A) Expression von CCR1 ( $\mathrm{n}=13)$ und (B) von CCR5 ( $\mathrm{n}=13)$. (C) In vivo Migration dieser Zellen gegen humanes MIP-1 $\alpha(n=4)$. Die mittlere Fluoreszenzintensität (MFI) ist dargestellt. Die Mittelwerte und Standartabweichungen sind angegeben. $* \mathrm{p}<0,05$ 

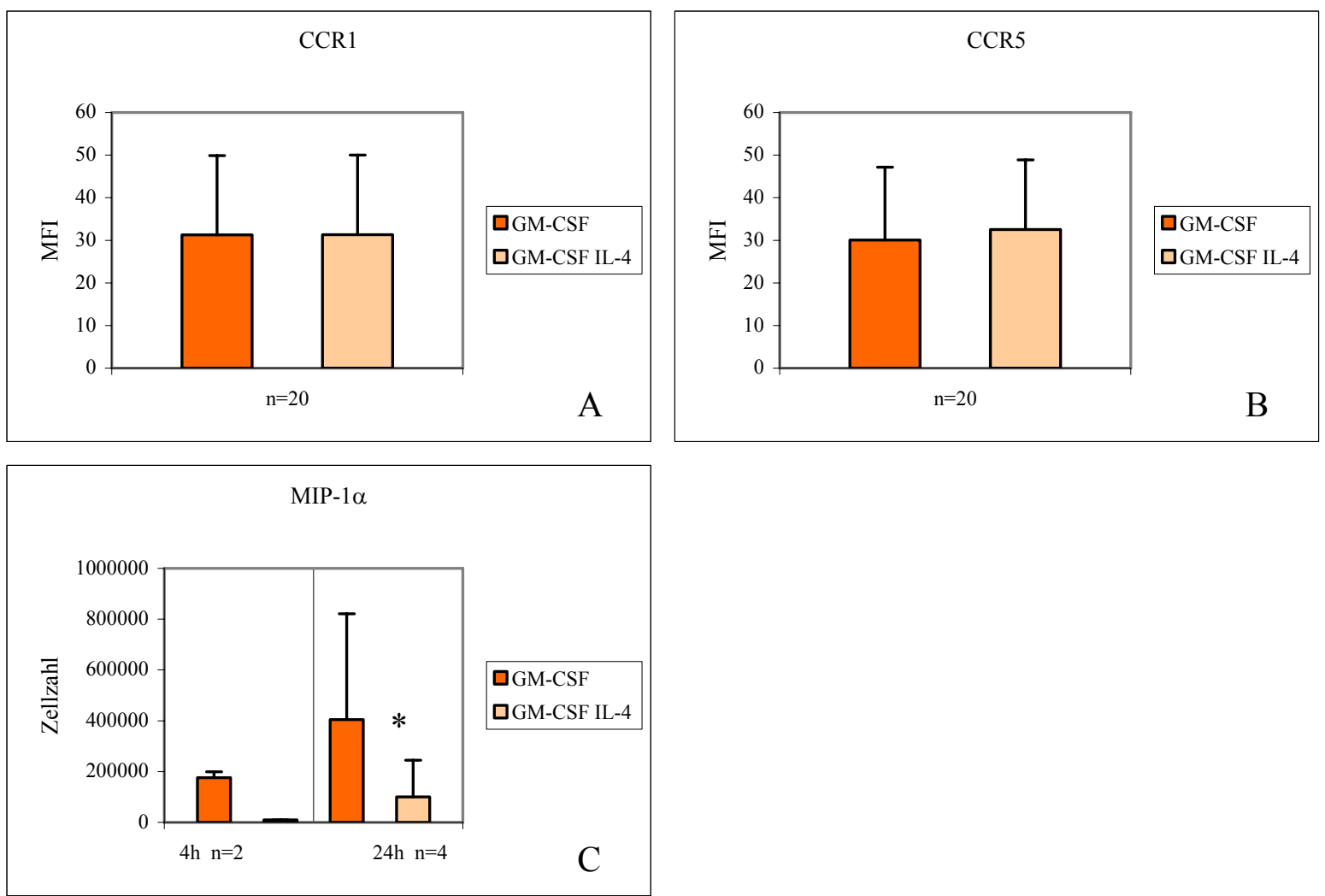

Abb. 31: IL-4 beeinträchtigt die Expression von Chemokinrezeptoren auf DC. (A) Expression von CCR1 (n=20) und (B) von CCR5 ( $\mathrm{n}=20)$. (C) In vivo Migration dieser Zellen gegen humanes MIP-1 $\alpha(4 \mathrm{~h} n=2$ und 15-18 h $\mathrm{n}=4$, für $\mathrm{n}=6$ gilt $* \mathrm{p}<0,05)$. Die mittlere Fluoreszenzintensität (MFI) ist dargestellt. Die Mittelwerte und Standartabweichungen sind angegeben.

\subsubsection{Einfluss von $\mathrm{PGE}_{2}$ auf chemotaktische Rezeptoren auf humanen monozytengenerierten Dendritischen Zellen}

Um den Einfluss von $\mathrm{PGE}_{2}$ auf die Expression von Chemotaxinrezeptoren untersuchen zu können, wurden humane Monozyten für zwei Tage mit und ohne IL-4 bzw. PGE 2 und für sieben Tage mit GM-CSF plus IL-4 mit und ohne $\mathrm{PGE}_{2}$ kultiviert. Die Analyse der Rezeptorexpression und die in vivo Migrationsstudien wurde wie oben angegeben durchgeführt.

LEGLER et al. (2006) zeigten, dass $\mathrm{PGE}_{2}$ in vitro in seiner Funktion als inflammatorischer Mediator MoDC in Richtung des Anaphylatoxins C5a mobilisieren kann ohne die C5aR Expression signifikant zu beeinträchtigen. In Ergänzung dazu demonstriert die vorliegende Studie $\mathrm{PGE}_{2}$ als potenten Modulator für die C5aR-Menge auf der Zelloberfläche von Monozyten (Abb. 32C), MoDC (Abb. 33A) und DC aus hämatopoetischen Vorläuferzellen (Abb. 34), wenn diese mit IL-4 kultiviert wurden. Parallel zur Erhöhung der C5aR-Menge war die in vivo Chemotaxis gegen C5a in mit IL-4 und $\mathrm{PGE}_{2}$ kultivierten Monozyten (Abb. 32D) und MoDC (Abb. 33B) ebenfalls stark erhöht. In Abwesenheit von IL-4 blieb $\mathrm{PGE}_{2}$ 
ohne Einfluss auf die C5aR-Expression auf Monozyten in vitro und auf die C5a-induzierte Wanderung in vivo (Abb. 32A, 32B).
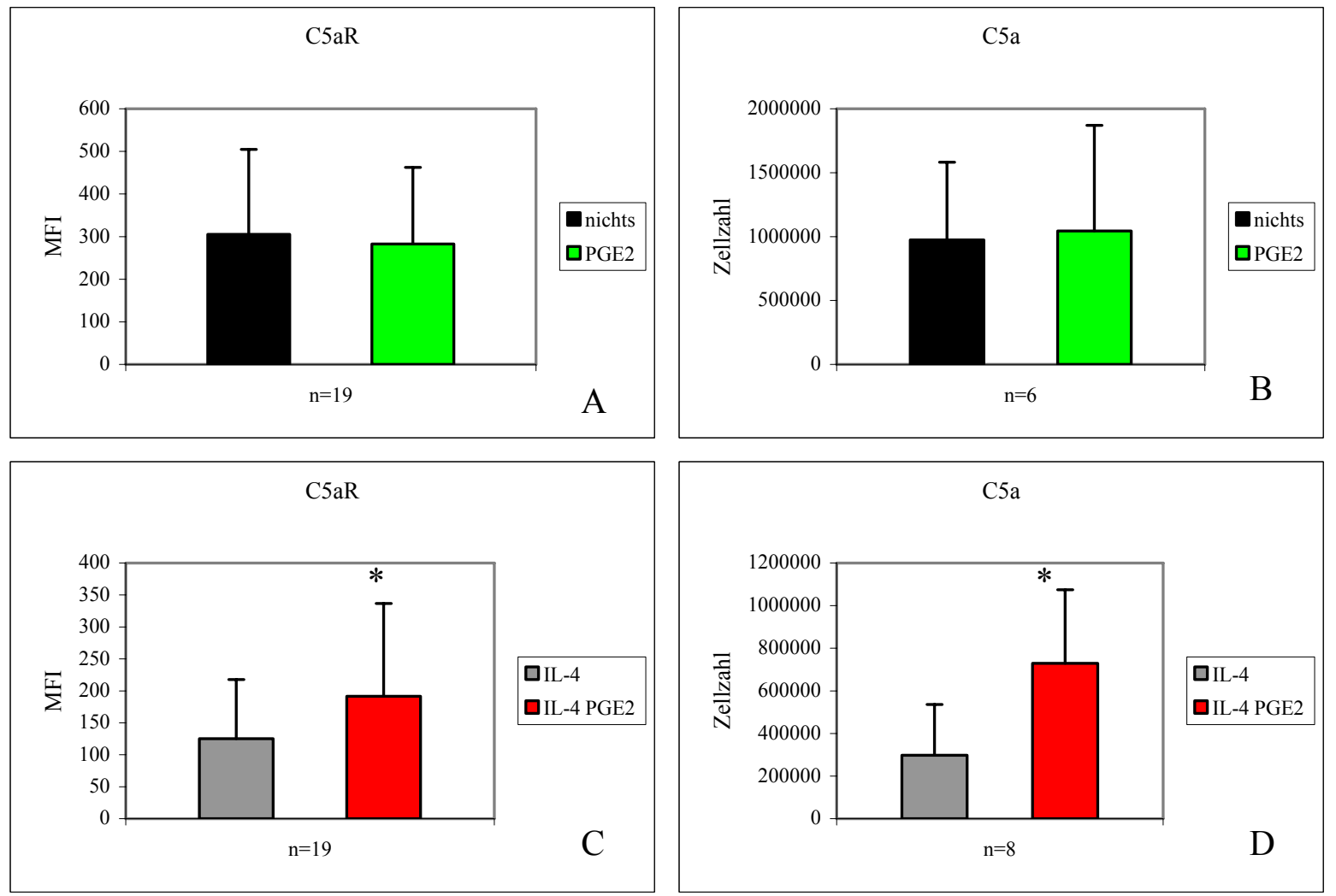

Abb. 32: $\mathrm{PGE}_{2}$ moduliert die Expression und Funktion vom C5aR auf humanen Monozyten, die für zwei Tage kultiviert wurden. (A) C5aR-Expression auf Monozyten ( $\mathrm{n}=19)$. (B) In vivo Migration gegen $\mathrm{C} 5 \mathrm{a}(\mathrm{n}=6)$. (C) C5aR-Expression auf Monozyten ( $\mathrm{n}=19)$. (D) In vivo Migration gegen C5a $(\mathrm{n}=8)$. Die mittlere Fluoreszenzintensität (MFI) ist dargestellt. Die Mittelwerte und Standartabweichungen sind angegeben. $* \mathrm{p}<0,05$
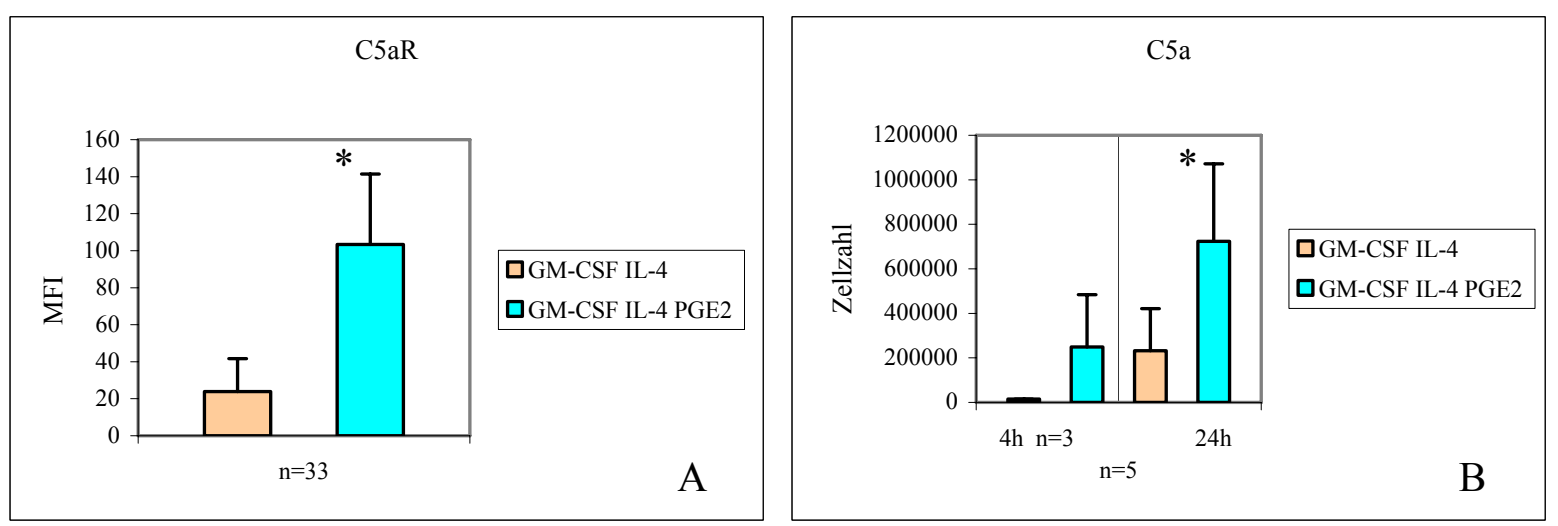

Abb. 33: $\mathrm{PGE}_{2}$ moduliert die Expression und Funktion vom C5aR auf humanen DC. (A) C5aR-Expression auf $\mathrm{DC}(\mathrm{n}=33)$. (B) In vivo Migration gegen C5a $(4 \mathrm{~h} \mathrm{n}=3$ und $15-18 \mathrm{~h} \mathrm{n}=5$, für $\mathrm{n}=8$ gilt $* \mathrm{p}<0,05)$. Die mittlere Fluoreszenzintensität (MFI) ist dargestellt. Die Mittelwerte und Standartabweichungen sind angegeben. 

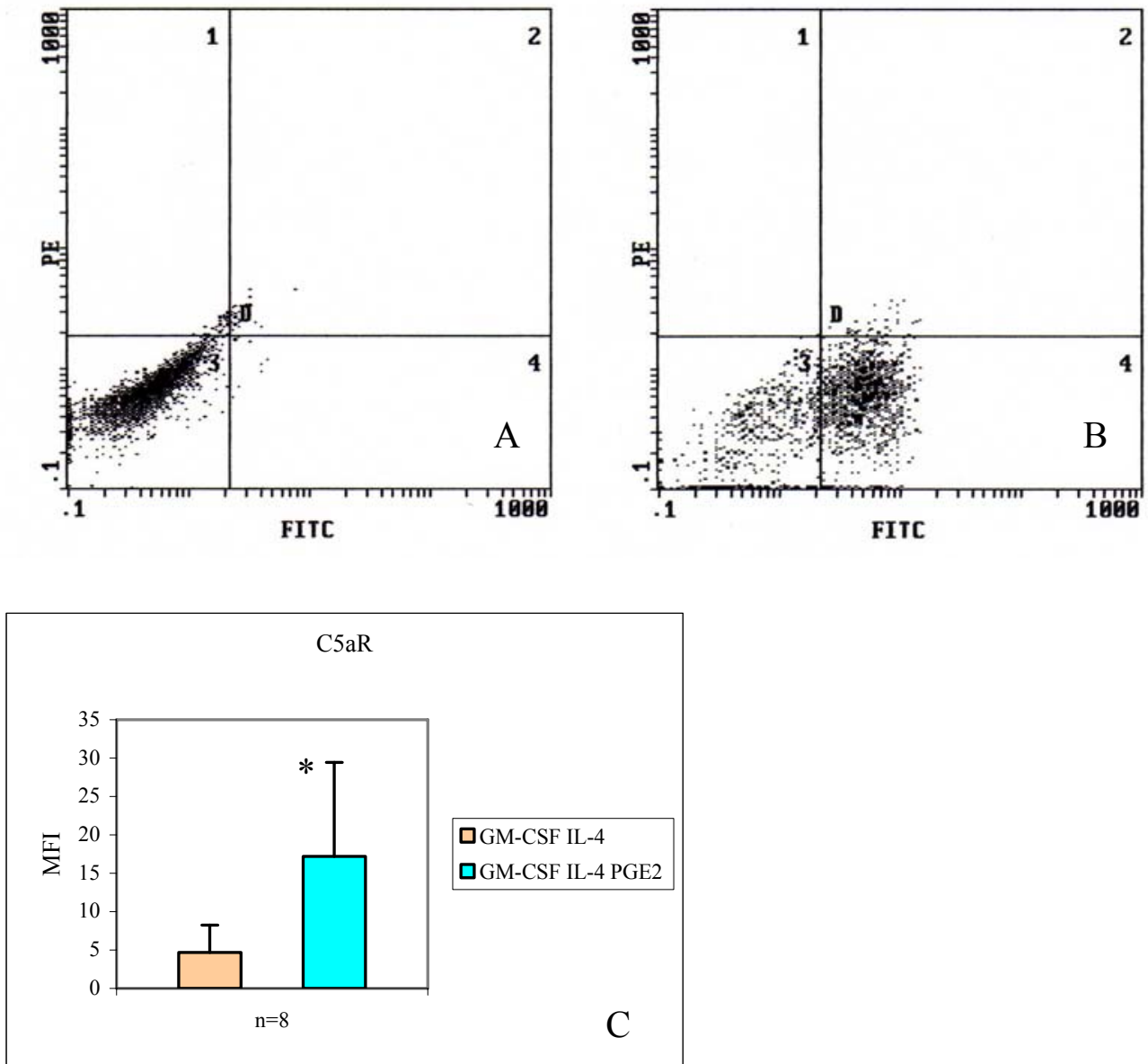

Abb. 34: $\mathrm{PGE}_{2}$ moduliert die Expression und Funktion vom C5aR auf humanen DC, die aus CD34 ${ }^{+}$ hämatopoetischen Vorläuferzellen aus Nabelschnurblut generiert wurden. (A) C5aR-Expression auf mit GM-CSF und IL-4 kultivierten Zellen. (B) C5aR-Expression auf mit GM-CSF, IL-4 und PGE 2 kultivierten Zellen. (C) C5aR-Expression auf DC. Die mittlere Fluoreszenzintensität (MFI) ist dargestellt. Die Mittelwerte und Standartabweichungen sind angegeben. $* \mathrm{p}<0,05$ 

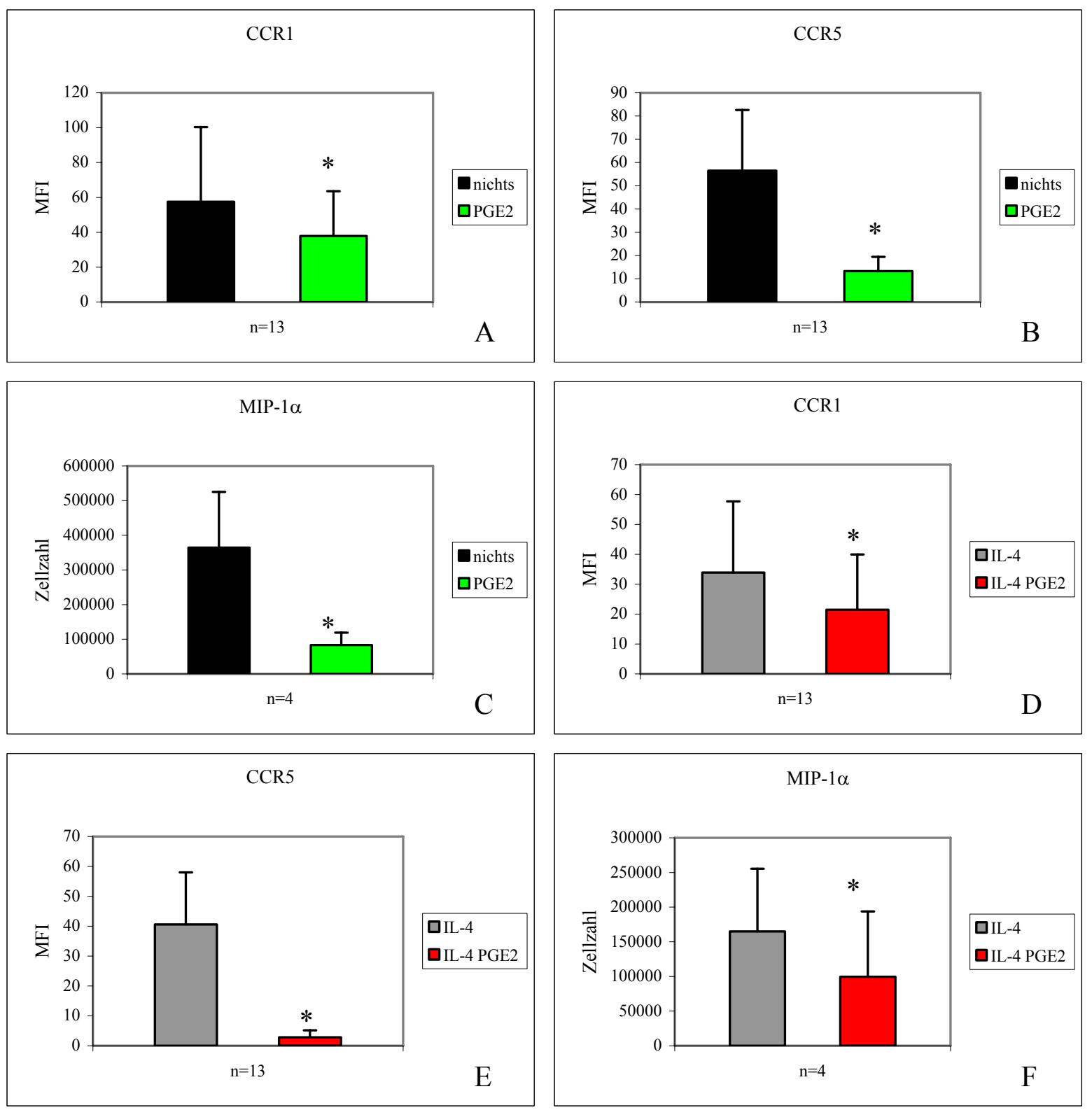

Abb. 35: $\mathrm{PGE}_{2}$ moduliert die Expression und Funktion von Chemokinrezeptoren auf humanen Monozyten, die für zwei Tage kultiviert wurden. (A) CCR1- $(n=13)$ und (B) CCR5-Expression ( $\mathrm{n}=13)$. (C) In vivo Migration gegen MIP-1 $\alpha(n=4)$. (D) CCR1- $(n=13)$ und (E) CCR5-Expression $(n=13)$. (F) In vivo Migration gegen MIP-1 $\alpha(n=4)$. Die mittlere Fluoreszenzintensität (MFI) ist dargestellt. Die Mittelwerte und Standartabweichungen sind angegeben. $* \mathrm{p}<0,05$

Da vermutet wird, dass $\mathrm{PGE}_{2}$ grundsätzlich für die DC-Migration von Bedeutung ist, wurde zusätzlich der Einfluss von $\mathrm{PGE}_{2}$ auf die MIP-1 $\alpha$-induzierte Chemotaxis in vivo sowie auf die Expression der MIP-1 $\alpha$ Rezeptoren CCR1 und CCR5 in vitro untersucht. Werden Monozyten und aus Monozyten generierte DC mit IL-4 kultiviert, reagieren beide Zelltypen auf externes $\mathrm{PGE}_{2}$ mit einer moderaten Erniedrigung der CCR1-Menge (Abb. 35D, 36A), aber mit einem starken Abfall von CCR5 auf der Zelloberfläche (Abb. 35E, 36B). Parallel zur Abnahme von CCR5 wurde die in vivo Chemotaxis gegen MIP-1 $\alpha$ signifikant gehemmt (Abb. 35F, 36C). Der inhibierende Effekt von $\mathrm{PGE}_{2}$ auf die Expression und die Funktion von CCR1 und CCR5 
wurde auch in Abwesenheit von IL-4 beobachtet (Abb. 35A, 35B, 35C). Demnach moduliert $\mathrm{PGE}_{2}$ die Expression und Funktion vom $\mathrm{C} 5 \mathrm{aR}$ und von Chemokinrezeptoren auf humanen DC und Monozyten in unterschiedlicher Weise.
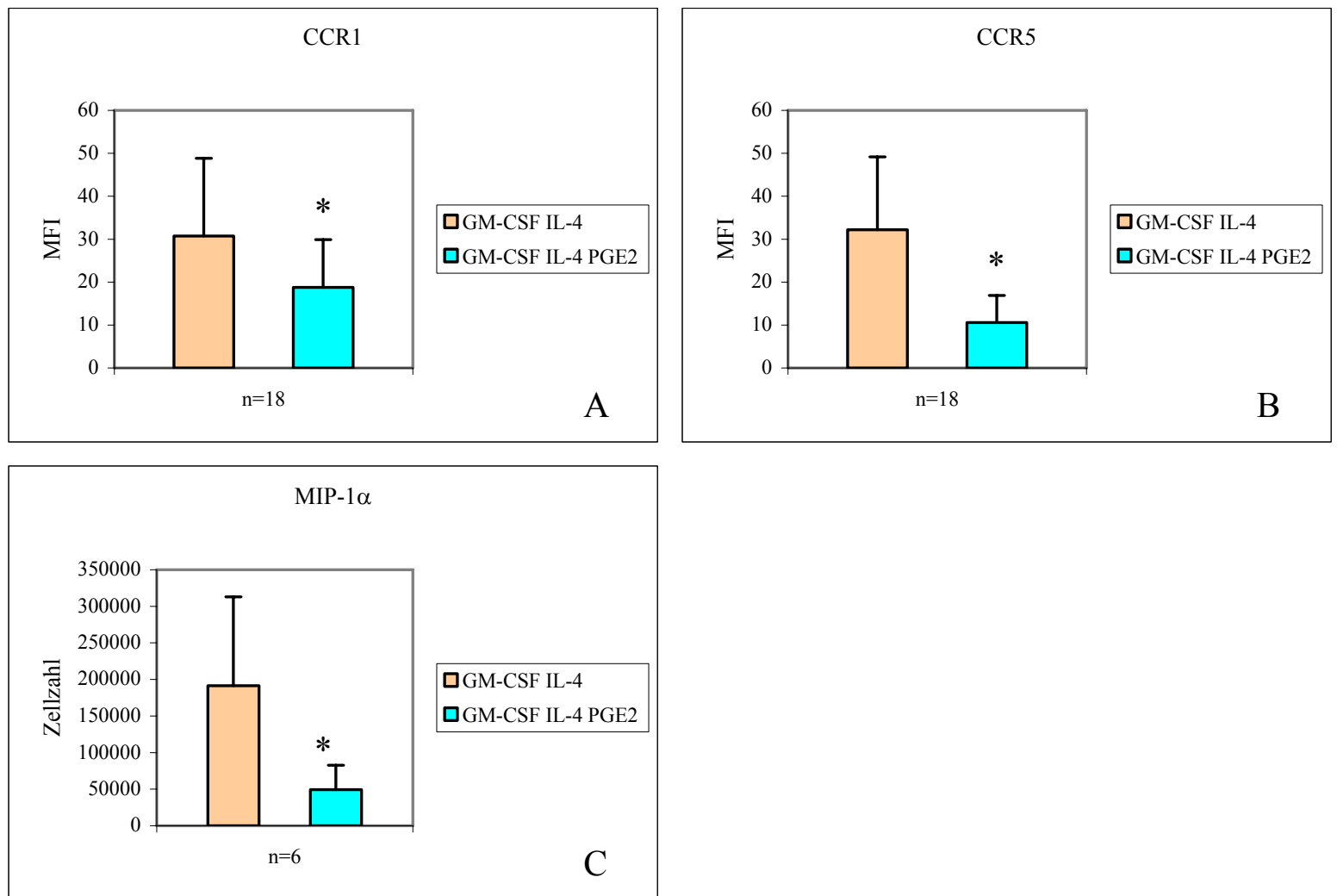

Abb. 36: $\mathrm{PGE}_{2}$ moduliert die Expression und Funktion von Chemokinrezeptoren auf humanen DC. (A) CCR1$(\mathrm{n}=18)$ und (B) CCR5-Expression $(\mathrm{n}=18)$. (C) In vivo Migration gegen MIP-1 $\alpha \quad(\mathrm{n}=6)$. Die mittlere Fluoreszenzintensität (MFI) ist dargestellt. Die Mittelwerte und Standartabweichungen sind angegeben. $* \mathrm{p}<0,05$

\subsubsection{Einfluss von $\mathrm{PGE}_{2}$ auf C5aR und CCR7 im SCID-Mausmodell}

Es ist bekannt, dass $\mathrm{PGE}_{2}$ zusammen mit TNF- $\alpha$ eine schnelle Differenzierung von humanen Monozyten in reife DC im SCID-Mausmodell bewirkt (SORURI et al., 2003B). Diese Erkenntnis war die Grundlage für die Untersuchung des Einflusses von $\mathrm{PGE}_{2}$ auf $\mathrm{C}^{2} \mathrm{aR}$ im Vergleich zur CCR7-Expression auf humanen Monozyten in vivo. In Abbildung 36 werden FACS-Daten präsentiert, welche die Umwandlung von wandernden Monozyten in reife CCR7-exprimierende Dendritische Zellen unter dem Einfluss von PGE $_{2}$ und TNF- $\alpha$ in vivo dokumentieren. Dieser Reifungsprozess ist charakterisiert durch die signifikante Reduktion des C5aR (Abb. 37E) und des Monozyten-/Makrophagenmarkers CD14 (Abb. 37A), durch die Erhöhung der Expression der kostimulatorischen Moleküle CD86 (Abb. 37B) und CD83 (Abb. 37C) und durch die Ausbildung des Chemokinrezeptors CCR7 (Abb. 37D) auf der Zelloberfläche. Die Änderung der Ausprägung dieser Oberflächenproteine ist Ausdruck der 
Entwicklung der unreifen DC zu reifen antigenpräsentierenden Zelle. Der Einsatz von $\mathrm{PGE}_{2}$ allein hat keinen Effekt auf die Expression der Rezeptoren C5aR und CCR7 (Daten nicht gezeigt).

Für diese Versuchsreihe wurden Monozyten $\left(1 \times 10^{7}\right)$ in SCID-Mäuse in eine der Schwanzvenen injiziert und humanes MIP-1 $\alpha(10 \mu \mathrm{g})$ i.p. appliziert. Nach $24 \mathrm{~h}$ erfolgte eine Wiederholung der Injektion mit MIP-1 $\alpha(10 \mu \mathrm{g})$. Zusammen mit der MIP-1 $\alpha$-Injektion wurden die Mäuse zusätzlich mit TNF- $\alpha$ (2 x 500 ng) plus PGE 2 (2 x 500 ng) behandelt. Die Kontrolltiere erhielten MIP-1 $\alpha$ i.p. und PBS i.v. (Ø). Nach weiteren $24 \mathrm{~h}$ wurden die Peritonealzellen durch Lavage geerntet, gezählt, gefärbt und mittels Durchflusszytometrie analysiert. Die Gates wurden auf HLA-DR ${ }^{+}$humane Zellen gesetzt.

$\varnothing$

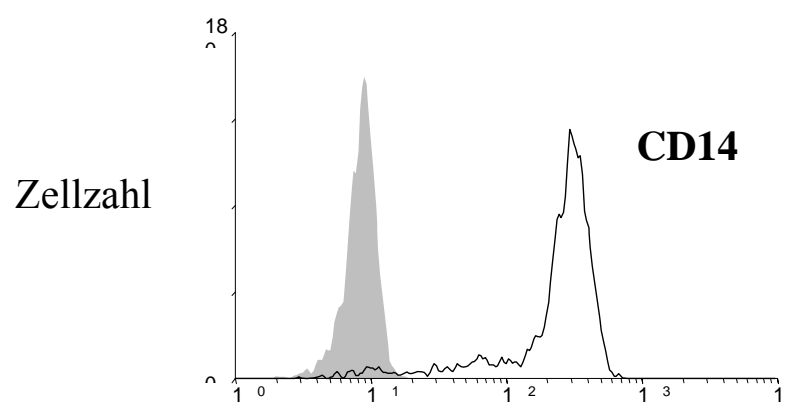

TNF- $\alpha$ und PGE 2

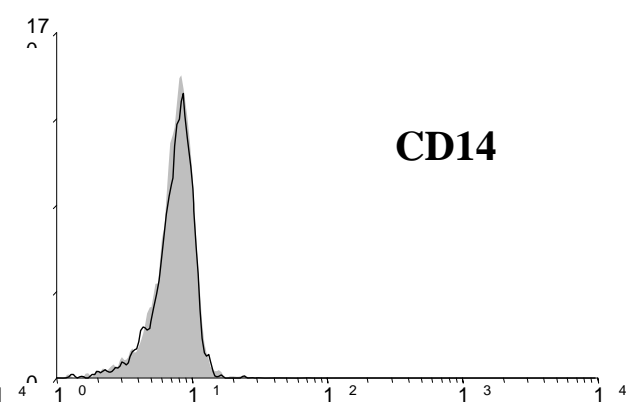

Fluoreszenzintensität

Abb. 37A: Monozytendifferenzierung durch TNF- $\alpha$ und $\mathrm{PGE}_{2}$. TNF- $\alpha$ und $\mathrm{PGE}_{2}$ induzieren in vivo die Differenzierung von humanen Monozyten in DC. Graue Histogramme stellen die Isotypkontrolle dar, offene Histogramme die Färbung mit monoklonalen Antikörpern gegen CD14. Gezeigt wird ein repräsentatives Experiment von $\mathrm{n}=3$.

$\varnothing$

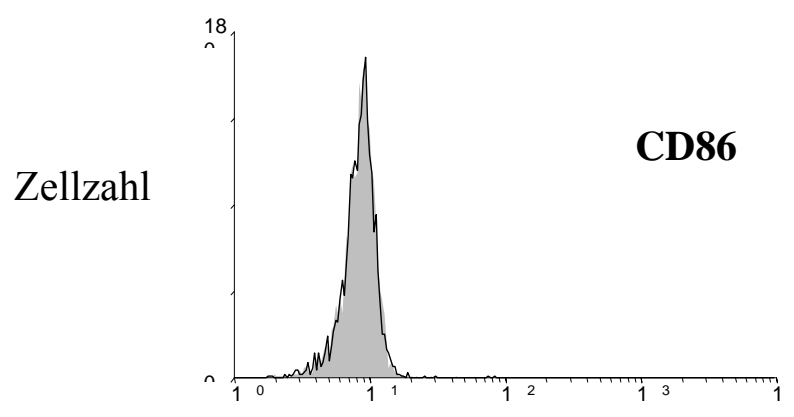

TNF- $\alpha$ und PGE 2

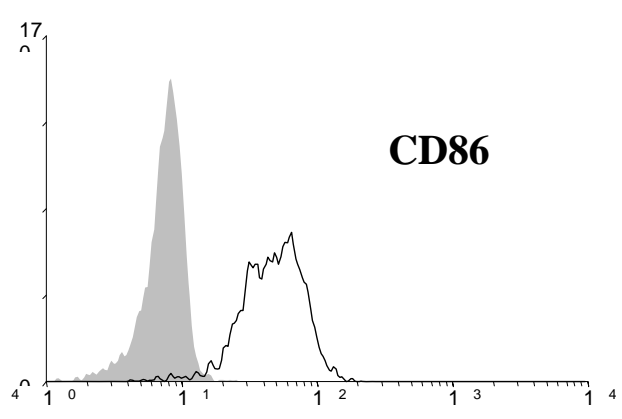

Fluoreszenzintensität

Abb. 37B: Monozytendifferenzierung durch TNF- $\alpha$ und $\mathrm{PGE}_{2}$. TNF- $\alpha$ und $\mathrm{PGE}_{2}$ induzieren in vivo die Differenzierung von humanen Monozyten in DC. Graue Histogramme stellen die Isotypkontrolle dar, offene Histogramme die Färbung mit monoklonalen Antikörpern gegen CD86. Gezeigt wird ein repräsentatives Experiment von $\mathrm{n}=3$. 
$\varnothing$

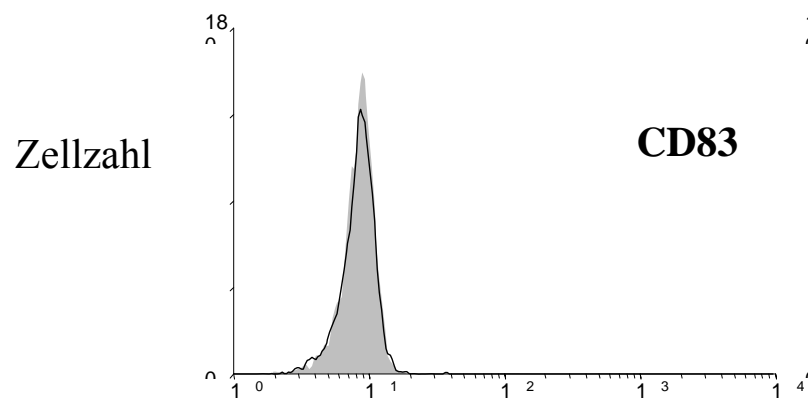

TNF- $\alpha$ und PGE 2

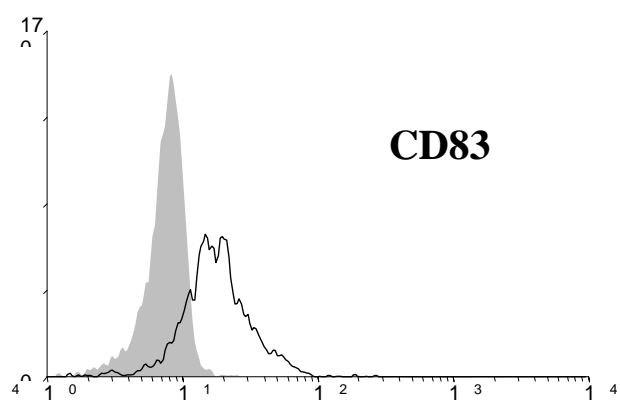

Fluoreszenzintensität

Abb. 37C: Monozytendifferenzierung durch TNF- $\alpha$ und $\mathrm{PGE}_{2}$. TNF- $\alpha$ und $\mathrm{PGE}_{2}$ induzieren in vivo die Differenzierung von humanen Monozyten in DC. Graue Histogramme stellen die Isotypkontrolle dar, offene Histogramme die Färbung mit monoklonalen Antikörpern gegen CD83. Gezeigt wird ein repräsentatives Experiment von $n=3$.

$\varnothing$

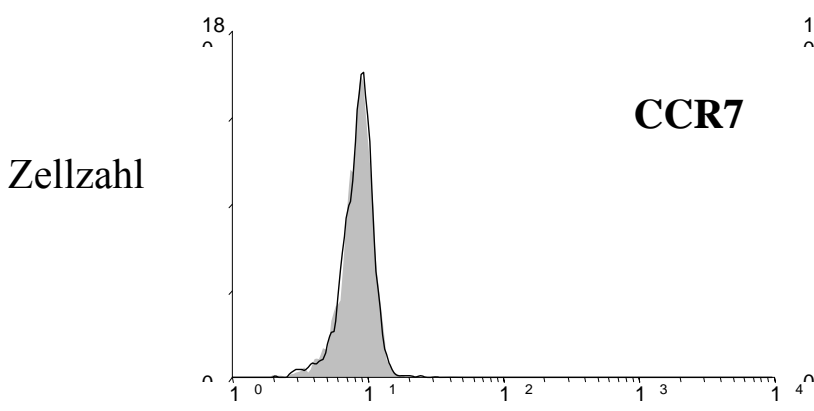

TNF- $\alpha$ und PGE 2

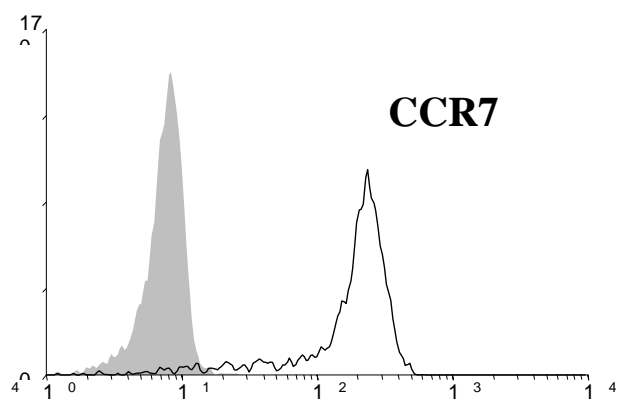

Fluoreszenzintensität

Abb. 37D: Monozytendifferenzierung durch TNF- $\alpha$ und $\mathrm{PGE}_{2}$. TNF- $\alpha$ und $\mathrm{PGE}_{2}$ induzieren in vivo die Differenzierung von humanen Monozyten in DC. Graue Histogramme stellen die Isotypkontrolle dar, offene Histogramme die Färbung mit monoklonalen Antikörpern gegen CCR7. Gezeigt wird ein repräsentatives Experiment von $\mathrm{n}=3$.

$\varnothing$

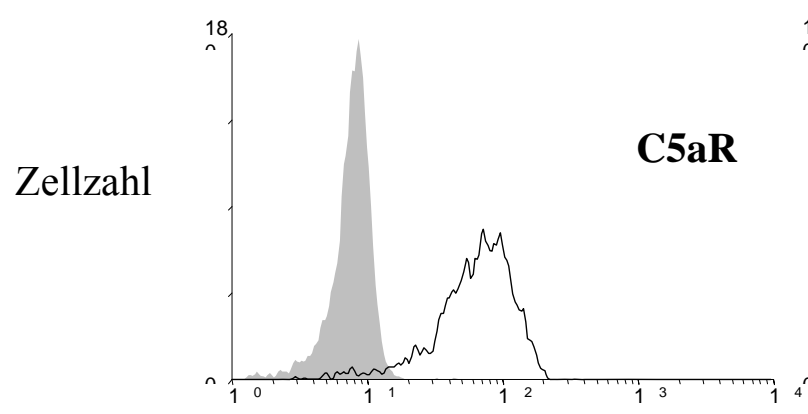

TNF- $\alpha$ und PGE 2

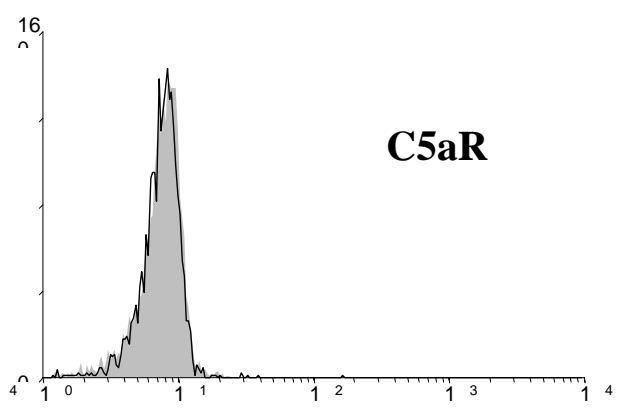

Fluoreszenzintensität

Abb. 37E: Monozytendifferenzierung durch TNF- $\alpha$ und PGE . TNF- $\alpha$ und $\mathrm{PGE}_{2}$ induzieren in vivo die Differenzierung von humanen Monozyten in DC. Graue Histogramme stellen die Isotypkontrolle dar, offene Histogramme die Färbung mit monoklonalen Antikörpern gegen C5aR. Gezeigt wird ein repräsentatives Experiment von $\mathrm{n}=3$. 


\subsubsection{Einfluss von IL-4 und $P G E_{2}$ auf das Wanderungsverhalten von DC in vitro}
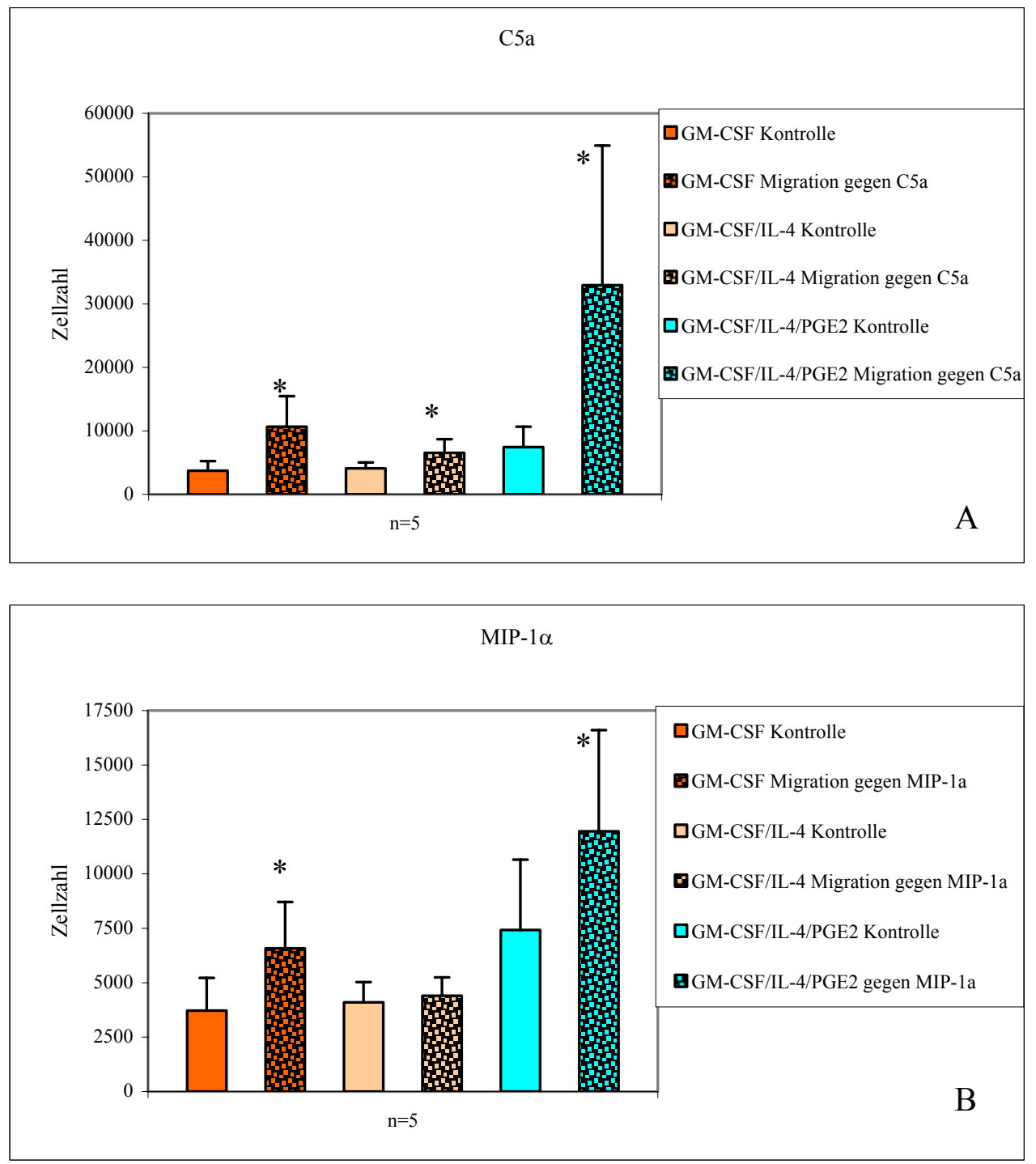

Abb. 38: Leukapheresezellen wurden für 48 h kultiviert. Die Zellen wanderten in vitro entweder ohne Zugabe eines Chemotaxins (Kontrolle) oder unter dem Einfluss von C5a bzw. MIP-1 $\alpha$. (A) In vitro Wanderung gegen

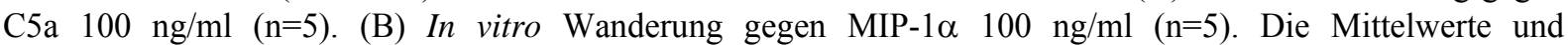
Standartabweichungen sind angegeben. Vergleich Kontrolle mit Wanderung gegen Chemotaxin $* p<0,05$.

Die Migration der Zellen in vitro gegen C5a korrelierte annähernd mit der Expression des C5aR. Zellen, die mit $\mathrm{PGE}_{2}$ kultiviert wurden, regulierten den $\mathrm{C} 5 \mathrm{aR}$ herauf und zeigten in der Chemotaxis in vitro ein ungleich ausgeprägtes Vermögen in Richtung des C5a-Gradienten zu wandern (Abb. 38A). Da auch die Zellen in den Kontrollansätzen eine große Motilität aufwiesen, ist anzunehmen, das $\mathrm{PGE}_{2}$ die Beweglichkeit von DC positiv beeinflussen kann. Dies könnte essentiell sein für das Migrationsverhalten der DC in vivo. Die Zellen, die mit GM-CSF und IL-4 kultiviert wurden, waren hingegen nur sehr eingeschränkt in der Lage, auf 
den Reiz durch C5a zu reagieren. Es bestand eine Korrelation zwischen der geringen Menge von C5aR auf der Zelloberfläche und der verminderten Wanderungsfähigkeit dieser Zellen.

Die Migration gegen MIP-1 $\alpha$ ist insgesamt schwächer als die gegen C5a (Abb. 38B). Allerdings sind auch hier die mit $\mathrm{PGE}_{2}$ kultivierten Zellen am besten in der Lage, auf den Liganden zu reagieren. Dies widerspricht den FACS-Ergebnissen, da PGE $_{2}$ CCR5 sehr deutlich herunterreguliert (Abb.36). Weiterhin könnte die oben erwähnte Möglichkeit der vermuteten $\mathrm{PGE}_{2}$-induzierten unspezifischen Motilitätssteigerung bestehen.

Die Wanderung der mit $\mathrm{PGE}_{2}$ kultivierten Zellen in den Kontrollen ist signifikant erhöht gegenüber den Zellen, die mit GM-CSF bzw. GM-CSF und IL-4 kultiviert wurden $(\mathrm{p}<0,05)$. Da $\mathrm{PGE}_{2}$ die Kontrollmigration der Zellen in etwa verdoppelt, wird dadurch das Ergebnis der in vitro Chemotaxis insgesamt beeinträchtigt und verliert dadurch an Aussagekraft.

\subsubsection{Einfluss von IL-4 und $\mathrm{PGE}_{2}$ auf den Calciuminflux in humanen DC}

Im humanen System sollte nicht nur die Abhängigkeit des $\mathrm{Ca}^{2+}$-Fluxes von der IL-4-induzierten Rezeptormodulation untersucht werden sondern auch der Einfluss von PGE $_{2}$ auf diesen Prozess. In den Abbildungen 39A und 39B sind die Reaktionsverläufe der $\mathrm{Ca}^{2+}$-Freisetzung in Abhängigkeit unterschiedlicher Stimuli in humanen Monozyten, die drei Tage mit und ohne IL-4 und mit und ohne PGE $_{2}$ kultiviert wurden, dargestellt.

Wie auch bei den murinen DC war hier eine Verringerung der $\mathrm{Ca}^{2+}$-Freisetzung bei den Zellen, die der IL-4-Wirkung ausgesetzt waren, zu verzeichnen. Die Resultate für die Ansätze mit $\mathrm{PGE}_{2}$ waren weniger klar. Der $\mathrm{Ca}^{2+}$-Flux in diesen Zellen durch die Stimulation mit C5a war sehr prägnant. Der $\mathrm{Ca}^{2+}$-Einstrom erwies sich als kongruent mit der erhöhten Expression des $\mathrm{C} 5 \mathrm{aR}$ als auch mit dem gesteigerten Migrationsverhalten in vitro in Richtung des C5a Gradienten.

Die $\mathrm{Ca}^{2+}$-Messung der mit $\mathrm{PGE}_{2}$ kultivierten Zellen gegen MIP-1 $\alpha$ demonstrierte einen ähnlichen Verlauf wie die gegen C5a. Aber bezogen auf CCR5 widerspricht sie ebenso den FACS-Ergebnissen wie die in vitro Migrationsrate, d.h. trotz der drastischen Abnahme von CCR5 unter dem Einfluss von $\mathrm{PGE}_{2}$ war hierbei gleichzeitig die stärkste Zellreaktion auf den Liganden MIP-1 $\alpha$ zu beobachten. Abermals könnte man eine gesteigerte CCR1-vermittelte Aktivität oder einen unbekannten MIP-1 $\alpha$-Rezeptor vermuten.

Alle $\mathrm{Ca}^{2+}$-Messungen im humanen System waren signifikant (Abb. 40A, 40B). Die Zeitpunkte der Stimuluszugabe sind durch Pfeile (Mediatorenzugabe nach $20 \mathrm{sec}$, Ionomycinzugabe nach $4 \mathrm{~min}$ ) gekennzeichnet. Der Messzeitraum betrug $5 \mathrm{~min}$. Ionomycin 
initiierte den Ausstrom der gesamten Calciummenge aus den intrazellulären Speichern, so dass ein zuverlässiger Vergleich mit dem Calciumsignal der eingesetzten Mediatoren C5a und MIP-1 $\alpha$ möglich war.

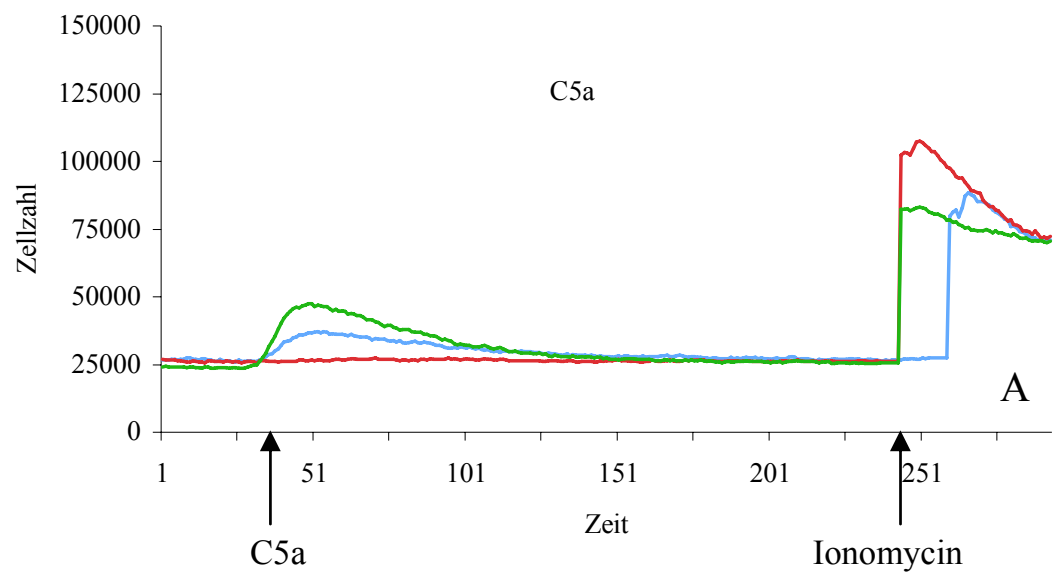

Abb. 39A: Reaktionsverlauf Calciummessung gegen C5a bei Leukapheresezellen nach drei Tagen Kultivierung mit GM-CSF (blau), GM-CSF/IL-4 (rot) und GM-CSF/IL-4/PGE 2 (grün). Gezeigt wird ein repräsentatives Experiment von $\mathrm{n}=3$

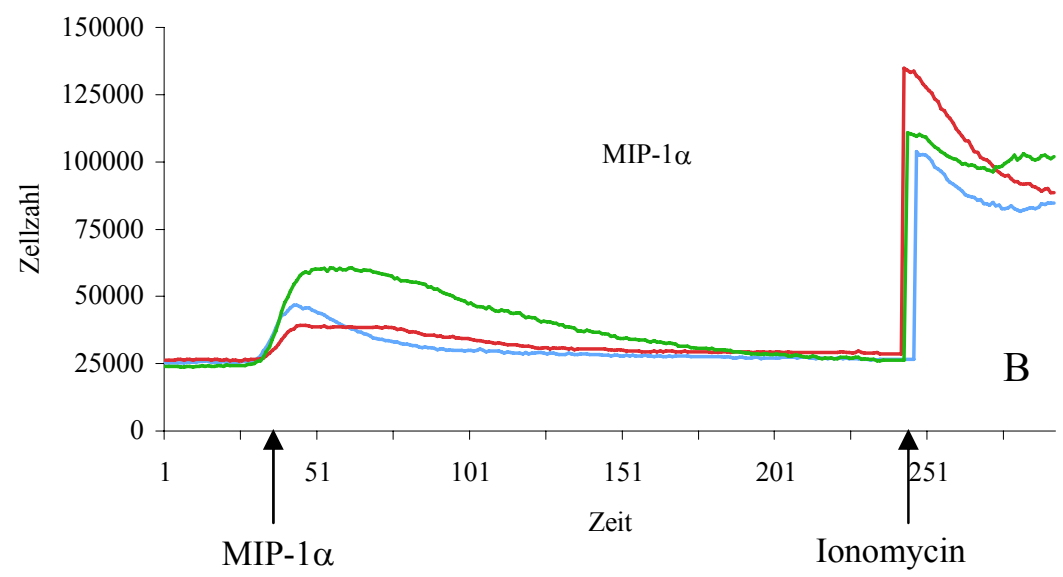

Abb. 39B: Reaktionsverlauf Calciummessung gegen MIP-1 $\alpha$ bei Leukapheresezellen nach drei Tagen Kultivierung mit GM-CSF (blau), GM-CSF/IL-4 (rot) und GM-CSF/IL-4/PGE 2 (grün). Gezeigt wird ein repräsentatives Experiment von $n=6$ 

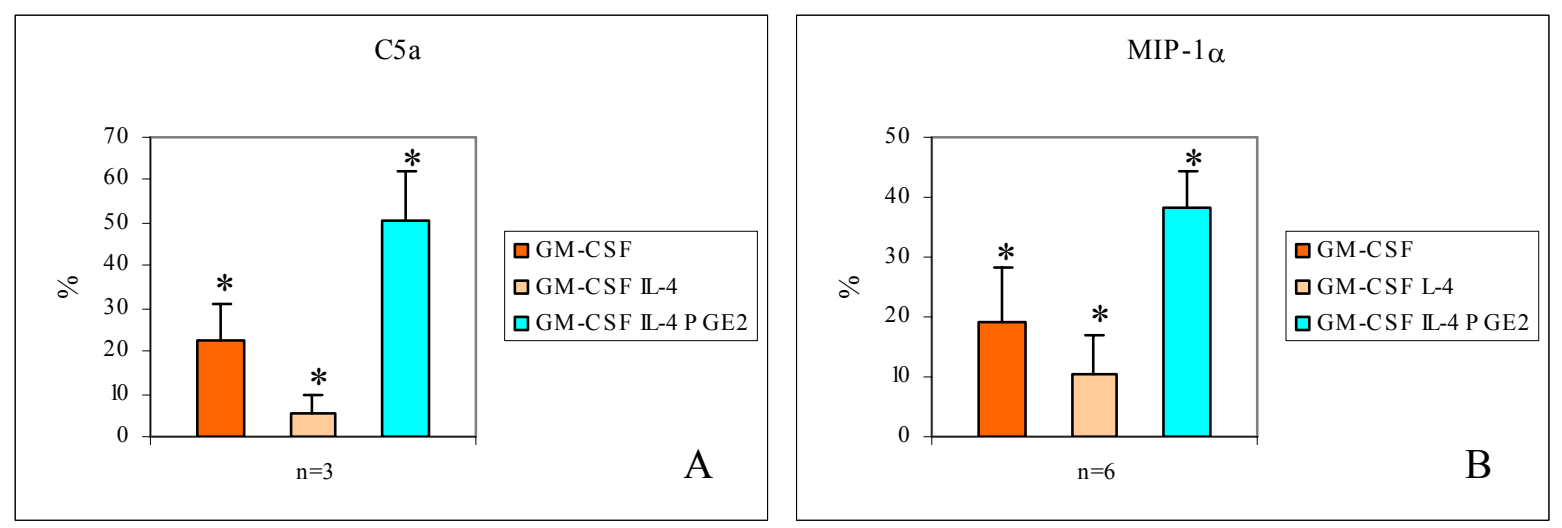

Abb. 40: IL-4 beeinträchtigt die $\mathrm{Ca}^{2+}$-Freisetzung unter dem Einfluss verschiedener Chemotaxine in Leukapheresezellen, die drei Tage kultiviert wurden. (A) C5a $10 \mathrm{ng} / \mathrm{ml}$ (n=3), (B) MIP-1 $\alpha 1000 \mathrm{ng} / \mathrm{ml}$ (n=6). Die Mittelwerte und Standartabweichungen sind angegeben. $* \mathrm{p}<0,05$ 


\section{DISKUSSION}

Um Antigene aufnehmen und prozessieren und sie dadurch Lymphozyten präsentieren zu können, müssen DC an den Orten von Infektion, Entzündung und Trauma einwandern und dort akkumulieren (CAUX et al., 2000). Da die in vivo Wirkung von IL-4 auf das Wanderungsverhalten der DC noch weitgehend ungeklärt ist, besteht ein großes Interesse an der Aufklärung des Zusammenspiels dieses TH2-Cytokins mit antigenpräsentierenden Zellen. Dies ist vor allem im Hinblick auf den Einsatz von DC, die in vitro mit IL-4 aus Monozyten generiert wurden, gegen maligne Tumore in Patientenstudien von Bedeutung. Es muss hierbei gewährleistet sein, dass die applizierten Abwehrzellen ihren biologischen Funktionen in gewünschter Weise gerecht werden. SORURI et al. (2003A) konnten beobachten, dass IL-4 die chemotaktischen Fähigkeiten von murinen DC, die aus $\mathrm{CD}^{+} 4^{+}$hämatopoetischen Vorläuferzellen in vitro generiert wurden, in Richtung C5a beeinflusst (SORURI et al., 2003 A). Andere Arbeitsgruppen fanden heraus, dass IL-4 einen negativen Einfluss auf die CCR6 Expression und Funktion hat (CARRAMOLINO et al., 1999; DIEU-NOSJEAN et al., 2001). In der vorliegenden Studie war der Einfluss von IL-4 und IL-13 und die regulatorische Funktion von $\mathrm{PGE}_{2}$ auf Monozyten, DC und Makrophagen im humanen und murinen System Gegenstand des Interesses.

\subsection{Expression und Funktionalität von Chemotaxinrezeptoren im murinen System}

Das TH2-Cytokin IL-4 verringerte die chemotaktische Reaktivität von murinen DC, die aus hämatopoetischen Vorläuferzellen des Knochenmarks generiert wurden. Die Wanderungsfähigkeit dieser Zellen gegen diverse inflammatorische Mediatoren, wie die Chemokine MIP-1 $\alpha$, MCP-1, MDC, MIP-3 $\alpha$, das bakterielle Peptid fMLP, das antimikrobielle Peptid LL-37 und die Anaphylatoxine C3a und C5a, wurde gehemmt. Weiterhin konnte gezeigt werden, dass IL-13 seine Wirkung in ähnlicher Art und Weise entfaltetet wie IL-4. Die funktionelle Überlappung von IL-4 und IL-13 reflektiert deren gemeinsame Nutzung der Rezeptorkomponente IL-4R $\alpha$.

Bemerkenswerterweise waren die Aktivitäten von IL-4 und IL-13 nicht auf DC beschränkt. Die Mobilisierung von murinen Makrophagen, die ebenfalls aus hämatopoetischen Vorläuferzellen des Knochenmarks generiert wurden, gegen ausgesuchte Chemotaxine wurde in gleicher Weise beeinflusst wie die Migrationsfähigkeit der murinen DC. Die Erklärung für 
die beobachtete Wanderungsdefizienz ist in der Reduktion der Expression der Chemotaxinrezeptoren C5aR, C3aR, CCR2 und CCR5 zu sehen. Durch die Verwendung von spezifischen monoklonalen Antikörpern konnte die Abnahme dieser Oberflächenproteine nachgewiesen werden.

Knockout Mäuse, die kein IL-4 (KUHN et al., 1991) bzw. keinen IL-4 Rezeptor (NOBENTRAUTH et al., 1997) exprimieren, und Mäuse, denen das spezifische Substrat der Signaltransduktion des IL-4 Rezeptors, das STAT6, fehlt (SHIMODA et al., 1996, KAPLAN et al., 1996; AKIRA, KISHIMOTO, 1997), sind nicht in der Lage in ausreichendem Umfang IgE zu bilden. IL-4-Rezeptor-knockout Mäuse (NOBEN-TRAUTH et al., 1997) und STAT6-knockout Mäuse (AKIRA, S., KISHIMOTO, T., 1997) entwickeln keine IL-4-produzierenden T-Zellen, wenn sie mit parasitischen Helminthen infiziert werden, da IL-4 unter physiologischen Bedingungen an der Entwicklung einer effektiven Immunantwort gegen Helminthen und andere extrazelluläre Parasiten beteiligt ist. Es zeigte sich am Beispiel der Anaphylatoxinrezeptoren $\mathrm{C} 3 \mathrm{aR}$ und $\mathrm{C} 5 \mathrm{aR}$ und der Chemokinrezeptoren CCR2 und CCR5, dass der Transkriptionsfaktor STAT6 unverzichtbar ist für die IL-4-induzierte Rezeptorverringerung. Bemerkenswerterweise sind nicht nur Antikörperproduktion und IL-4-Produktion von STAT6 abhängig sondern auch die Regulation der untersuchten Chemotaxinrezeptoren.

Die Beteiligung eines PI3K-Isoenzyms an der IL-4-induzierten Signaltransduktion konnte durch den Einsatz von Signalmolekülinhibitoren verifiziert und andere wie MAPK ausgeschlossen werden. Einige frühere Studien mit Wortmannin und LY294002 beschrieben die Hemmung der Wanderungsfähigkeit gegen fMLP. Genau wie Anaphylatoxine, wirkt auch fMLP über G-Protein-gekoppelte Serpentinrezeptoren. DEL PRETE et al. (2004) konnten zeigen, dass sowohl unreife als auch reife PI3K $\gamma$-/- murine DC in ihrer Wanderungsfähigkeit gegen die inflammatorischen Chemokine CCL3 (MIP-1 $\alpha$ ) und CCL5 (RANTES) bzw. gegen das konstitutive Chemokin CCL19 stark eingeschränkt waren. PI3K $\gamma$ spielt damit eine entscheidende Rolle in der Rekrutierung von Leukozyten sowohl an Orte von Entzündung und Infektion als auch in Richtung der sekundären Lymphorgane (HIRSCH et al., 2000; LI et al., 2000). Passend zu den Ergebnissen der vorliegenden Studie wurde schon von DAI et al. gezeigt, dass IL-4 die Expression des murinen Formylpeptidrezeptor-1 auf der mRNA-Ebene durch einen STAT6-abhängigen Mechanismus in Makophagen, die durch die Verwendung von Thyoglycolat gewonnen wurden, hemmt (DAI et al., 2005). Weiterhin werden STAT6 und PI3K für die IL-4-induzierte Herunterregulierung von c-Kit (Stemm Cell Factor Receptor) auf Mastzellen benötigt (MIRMONSEF et al., 1999). 
Klassischerweise wird die IL-4-induzierte Signalgebung in zwei Hauptwege unterteilt: JAK-STAT-Weg und IRS-1/2-PI3K-Weg. Die Rolle eines dritten Hauptsignalweges mit Beteiligung von MAPK bleibt kontrovers. Zwei Mitglieder der MAPK Familie, nämlich p38 MAPK und JNK, werden durch eine Reihe von hämatopoetischen Cytokinen wie IL-2, IL-3, IL-7, G-CSF und Erythropoetin aktiviert. IL-4 scheint zwischen den wachstumsauslösenden Cytokinen eine Ausnahme zu sein und zeigt keine Beteiligung von JNK oder p38 MAPK an der Aktivierung von Mastzellen. Obwohl die Stimulierung von p38 MAPK durch IL-4 in murinen Pro-B-Zellen BA/F3 gezeigt werden konnte, wird p38 in der humanen B-Zell-Line RAMOS 2G6 nicht aktiviert. Es gibt eine Reihe von Genen, die unabhängig von STAT6 und PI3K durch IL-4 reguliert werden. Am besten bekannt ist hierbei der Suppressor für Cytokinsignaling (SOCS) 3. Die Hochregulierung der SOCS3 Expression in murinen B-Zellen durch IL-4-Stimulation ist abhängig von der Aktivität von p38 MAPK und JNK. Außerdem wird p38 MAPK direkt und schnell STAT6-unabhängig von IL-4 aktiviert. Die Blockade dieser Wege ist möglich durch die Verwendung des JNK Inhibitors II (SP600125) bzw. p38 MAPK Inhibitors (SB203580) (CANFIELD et al., 2005).

\subsection{Expression und Funktionalität von Chemotaxinrezeptoren im humanen System}

Es ist unumstritten, dass IL-4 die Expression und Funktion des Chemokinrezeptors CXCR4 in humanen Monozyten hemmt (CREERY et al., 2006; WANG et al., 1998, WANG et al., 2001), aber es existieren kontroverse Resultate hinsichtlich der IL-4-Wirkung auf CCR5 (WANG et al., 1998A; CREERY et al., 2006). Beide Oberflächenproteine sind HIV-Corezeptoren. In der vorliegenden Studie wird der negative Effekt von IL-4 auf CCR5, CCR1 und CCR2 auf kultivierten Monozyten und deren Chemotaxis in vivo gegen MIP-1 $\alpha$ und MCP-1 demonstriert. Außerdem konnte gezeigt werden, dass IL-4 die Rekrutierung von DC, die aus Monozyten generiert wurden, in Richtung MIP-1 $\alpha$ und MCP-1 behindert. Die Kultivierung mit IL-4 führte nur zur Reduktion der Expression von CCR2, aber nicht zur Abnahme von CCR1 und CCR5 auf diesen Zellen.

Humane MoDC als auch Monozyten waren in der Lage gegen C5a zu wandern. Die Zellen konnten auch nach der Kultivierung mit IL-4 in den Peritonealraum der Versuchstiere migrieren, auch wenn dieser Prozess aufgrund der starken Herunterregulierung des C5aR erheblich verzögert war. Vorangegangene Untersuchungen zeigten, dass IL-4 die Funktion als auch die Expression der Anaphylatoxinrezeptoren C3aR und C5aR auf monozytengenerierten 
DC behindert (SORURI et al., 2003A). Weiterhin gelang SORURI et al. durch die Isolierung und durchflusszytometrische Analyse der eingewanderten Zellen der Nachweis, dass diese sich innerhalb von 24 bis 48 Stunden zu reifen DC differenzierten, die neben der Expression DC-typischer Oberflächenmarker (HLA-DR, CD86, CD83 und CCR7) große Mengen an TNF- $\alpha$ produzierten (SORURI et al., 2003B).

YANG et al. (2000) konnten zeigen, dass nicht nur unreife sondern auch reife DC den C5aR exprimieren. Für unreife DC ist dies nicht unbedingt überraschend, da C5a als Entzündungsmediator unterschiedlichste Immunzellen anlocken kann. Ungewöhnlich erschien jedoch die Tatsache, dass der C5aR auf reifen DC vorhanden sein soll, da diese Zellen eigentlich nur Rezeptoren für konstitutive (nicht-inflammatorische) Chemotaxine benötigen, damit sie zur Antigenpräsentation in die lymphatischen Organe einwandern können (SAlluSto et al., 1998; CHAN et al. 1999; SOZZANi et al. 1998). Obwohl es offensichtlich ist, dass die Modulation der Expression der chemotaktischen Rezeptoren für die Regulierung der Migrationseffizienz von DC wichtig ist, könnten aber auch andere Mechanismen wie die funktionelle Entkopplung von Chemokinrezeptoren greifen. Dies wurde bereits bei IL-10 und Vitamin-D3-behandelten DC beobachtet (D'AMICO et al., 2000; GAUZZI et al., 2005). Zukünftige Studien haben diesen Sachverhalt zu klären.

Der Einfluss von IL-4 und IL-13 auf Makrophagen kann als alternative Aktivierung angesehen werden, welche die Induktion der Expression von MHC Klasse II und Mannoserezeptor als auch die Hemmung der Sekretion proinflammatorischer Cytokine beinhaltet (GORDON et al., 2003). Die Daten der vorliegenden Studie lassen vermuten, dass eine Hemmung der Mobilisierung gegen eine Vielzahl von inflammatorischen Chemotaxinen wie Chemokine, Anaphylatoxine, antmikrobielle Peptide und N-Formylpeptide ein integrales Merkmal der alternativen Aktivierung von Makrophagen ist, aber nicht auf diesen Zelltyp beschränkt bleibt.

DC werden in gleicher Weise durch IL-4 und IL-13 beeinflusst. Bemerkenswerterweise spielt IL-4 als Schlüsselcytokin für die Bildung der TH2-Effektorzellen aus naiven T-Zellen eine zentrale Rolle in der Generierung von DC in vitro, wenn Monozyten als DC-Vorläuferzellen genutzt werden (SALLUSTO et al., 1994; ROMANI et al., 1994). Es könnte angenommen werden, dass IL-4 die Expression von Anaphylatoxinrezeptoren inhibiert, weil diese zu TH1-assoziierten Chemotaxinrezeptoren gehören. Zumindest der C5a Rezeptor scheint ein solcher Chemotaxinrezeptor zu sein. In Tierexperimenten konnte gezeigt werden, dass die Blockade von C5aR zur Hemmung der Bildung von IL-12, einem TH1-Cytokin, führt (KARP et al., 2000). Die Resultate dieser Studie lassen vermuten, dass IL-4-behandelte DC 
möglicherweise nicht die migratorischen DC repräsentieren, die in vivo in den Entzündungsherd migrieren, da ihre Kapazität gegen inflammatorische Stimuli zu wandern allgemein gestört ist.

\subsection{Der Einfluss von Prostaglandin $E_{2}$ auf Chemotaxinrezeptoren im humanen System}

Ein anderes Molekül mit DC-modulierender Aktivität ist $\mathrm{PGE}_{2}$. In Makrophagen und DC induziert $\mathrm{PGE}_{2}$ die Bildung von IL-10 und verringert die Expression von Chemokinen und Cytokinen, inklusive IL-12, die eine TH1-Antwort charakterisieren. Die Polarisierung der naiven T-Zellen erfolgt zugunsten der TH2-Antwort (HARRIS et al., 2002; HARIZI et al., 2006; TAKAYAMA et al., 2002; JING et al., 2003). Es wird angenommen, dass $\mathrm{PGE}_{2}$ generell ein unverzichtbarer Faktor für die Entwicklung von migratorischen, aus Monozyten generierten DC in vivo darstellt, da die Wanderung gegen CCL21 (6Ckine), CXCL12 (SDF-1) und $\mathrm{C} 5 \mathrm{a}$ in vitro strickt abhängig ist von der Anwesenheit von $\mathrm{PGE}_{2}$, aber es wird kein offensichtlicher Effekt auf die Rezeptormenge durch den Einfluss von $\mathrm{PGE}_{2}$ beobachtet (LEGLER et al., 2006). Die monozytengenerierten DC, die durch LEGLER et al. beschrieben wurden (LEGLER et al., 2006), zeigten Merkmale wie das Fehlen der mRNA des fMLP-Rezeptors und den Mangel an C5aR auf der Zelloberfläche begleitet von einer fehlenden Ansprechbarkeit gegen fMLP und C5a. Diese von LEGLER et al. beschriebenen DC-Merkmale stimmen allerdings nicht mit anderen veröffentlichten Daten überein (SOzZANI et al., 1995; SALLUSTO et al., 1998; WEINMAN et al., 2003; KIRCHHOFF et al., 2001; SORURI et al., 2003A; YANG et al., 2000).

Die Bemühungen zur detaillierteren Untersuchung des Sachverhaltes enthüllten, dass $\mathrm{PGE}_{2}$ ein Gegenspieler von IL-4 ist, da es die C5a-induzierte Chemotaxis von mit IL-4 behandelten Monozyten und monozytengenerierten DC in vivo deutlich verbessert und parallel dazu den C5aR stark hochreguliert. In Abwesenheit von IL-4 zeigte PGE $_{2}$ keinen Effekt auf den C5aR. Diese Daten stimmen überein mit den Ergebnissen von WEINMAN et al. (WEINMAN et al., 2003). Sie demonstrierten, dass $\mathrm{PGE}_{2}$ den C5aR auf DC, die in vitro mit IL-4 aus Monozyten generiert wurden, hochreguliert und ebenso als Gegenspieler der TNF- $\alpha$-induzierten Herunterregulierung während der Reifung der DC fungiert.

Zur Unterstützung der Hypothese, dass $\mathrm{PGE}_{2}$ die DC-Mobilisierung durch Regulierung der Expression der chemotaktischen Rezeptoren beeinflusst, konnte in der vorliegenden Studie eine leichte Herunterregulierung von CCR1, aber eine dramatische Abnahme der Menge von 
CCR5 auf der Oberfläche von monozytengenerierten DC in vitro durch $\mathrm{PGE}_{2}$ verzeichnet werden. Parallel zur verringerten CCR5 Expression war auch die in vivo Wanderung dieser Zellen gegen MIP-1 $\alpha$ beeinträchtigt. Passend $\mathrm{zu}$ diesen Ergebnissen wurde die essentielle Rolle von $\mathrm{PGE}_{2}$ in der LPS-induzierten Herunterregulierung von inflammatorischen Chemokinrezeptoren und der damit verbundenen chemotaktischen Funktion der DC von CHEN et al. postuliert (CHEN et al., 2004).

Der negative Effekt von $\mathrm{PGE}_{2}$ auf die CCR1- und CCR5-Expression und -Funktion war nicht auf die aus Monozyten generierten DC beschränkt, sondern auch auf Monozyten selbst nachzuweisen. Der additive Effekt von IL-4 und $\mathrm{PGE}_{2}$ auf die Abnahme der Expression von CCR5 führte zu einer nahezu totalen Eliminierung dieses Rezeptors von der Zelloberfläche. $\mathrm{PGE}_{2}$ allein löste einen solch dramatischen Effekt nicht aus. In zwei vorangegangenen Studien wurde eine $\mathrm{PGE}_{2}$-induzierte Hemmung der CCR5-Expression und -Funktion für Monozyten bereits beschrieben (THIVIERGE et al., 1998; ZEIDLER et al., 2000). Im Gegensatz dazu berichteten PANZER et al., dass $\mathrm{PGE}_{2}$ eine höhere funktionelle Ansprechbarkeit gegen RANTES, einen weiteren CCR5-Liganden, induziert trotz der offensichtlichen Abnahme der Expression von CCR5 (PANZER et al., 2004). Mögliche Gründe für diese offensichtlichen Diskrepanzen wurden bisher nicht präsentiert. Die Verwendung des SCID-Mausmodells, welches die Untersuchung von Zellwanderung in einem in vivo Milieu erlaubt, ermöglichte die eindeutige Bestätigung der Versuchsergebnisse innerhalb des Konzeptes der $\mathrm{PGE}_{2}$-induzierten Herunterregulierung der CCR5-Expression und -Funktion. Damit gehen die Versuchsergebnisse der vorliegenden Arbeit mit den Daten von THIVIERGE et al. (1998) und ZEIDLER et al. (2000) Hand in Hand.

$\mathrm{PGE}_{2}$ beeinflusst anscheinend nicht nur die Expression von Rezeptoren für Anaphylatoxine und inflammatorische Chemokine, sondern ist ebenfalls essentiell für die Hochregulierung von CCR7 in mit LPS gereiften DC, die aus Monozyten in Anwesenheit von GM-CSF und IL-4 in vitro generiert wurden (CHEN et al., 2004). Es wurde bereits postuliert, dass $\mathrm{PGE}_{2}$ auf DC die Sensitivität von CCR7 für seine Liganden CCL19 und CCL21 verbessert ohne die Höhe der CCR7-Expression signifikant zu modulieren (SCANDELLA et al., 2002; SCANDELLA et al., 2004; LUFT et al., 2002). Studien haben die Rolle von $\mathrm{PGE}_{2}$ für die Regulation der Migration von DC in Richtung sekundärer Lymphorgane, den Orten der Produktion der CCR7-Liganden CCL19 (MIP-3ß) und CCL21 (6Ckine), aufgezeigt (JONULEIT et al., 1997; LEE et al., 2002). Im Gegensatz dazu ist $\mathrm{PGE}_{2}$ für die Anlockung unreifer DC in Richtung anderer Chemokine wie CCL3 (MIP-1 $\alpha$ ) nicht nötig (CHEN et al., 2004). Interessanterweise induziert $\mathrm{PGE}_{2}$ in Kombination mit TNF- $\alpha$ im SCID-Mausmodell direkt die Differenzierung 
von CCR7-negativen Monozyten in CCR7-exprimierende reife DC innerhalb von 2 Tagen (SORURI et al., 2003B und Abb. 31). Diese in vivo Differenzierung ist mit einem starken Anstieg von TNF- $\alpha$ und $\mathrm{PGE}_{2}$ im Serum der Mäuse assoziiert. Mittels eines neutralisierenden anti-TNF- $\alpha$-Antikörpers bzw. des Cyclooxygenase-Inhibitors Indomethacin wiesen SORURI et al. nach, dass eine simultane Einwirkung von TNF- $\alpha$ und $\mathrm{PGE}_{2}$ für die Reifung dendritischer Zellen in vivo notwendig ist. Auch durch die MIP-1 $\alpha$ induzierte Wanderung von Monozyten konnten diese Zellen in reife DC differenziert werden, wenn TNF- $\alpha$ und $\mathrm{PGE}_{2}$ exogen in den Peritonealraum der Versuchstiere appliziert wurden (SORURI et al., 2003B und Abb. 31).

Die Ergebnisse der Studie bestätigen zusammen mit den Resultaten von SORURI et al. die Hypothese, dass $\mathrm{PGE}_{2}$ ein potenter Modulator der Expression von chemotaktischen Rezeptoren ist (SORURI et al., 2003B). Durch die Nutzung des in vivo Modells, welches als Ersatz für die langwierigere Kultivierung von Monozyten mit GM-CSF und IL-4 in vitro diente, wurde überraschenderweise herausgefunden, dass der $\mathrm{C} 5 \mathrm{aR}$ von der Oberfläche der Monozyten verschwindet wenn diese sich rapide zu DC differenzieren. Dies ist der gegenteilige Effekt von $\mathrm{PGE}_{2}$ auf die C5aR-Expression von $\mathrm{DC}$, die in vitro aus Monozyten generiert wurden. Die komplexe Rolle von $\mathrm{PGE}_{2}$ wird weiterhin reflektiert durch seine regulierende Wirkung auf die Expression von CD14. Auf konventionellen DC, die in vitro aus Monozyten hergestellt werden, verhindert $\mathrm{PGE}_{2}$ die Abnahme von CD14 durch IL-4 (KALINSKI et al., 1997; eigene unveröffentlichte Daten), wohingegen es im SCID-Mausmodell zusammen mit TNF- $\alpha$ die Herunterregulierung von CD14 auf der Oberfläche von differenzierten Monozyten induziert (SORURI et al., 2003B und Abb. 31). Die Resultate der vorliegenden Studie lassen vermuten, dass $\mathrm{PGE}_{2}$ eine duale Rolle in der Regulierung der Chemotaxis von DC und Monozyten spielt. Erstens könnte es sein, dass $\mathrm{PGE}_{2}$ zusammen mit IL-4 einen anderen Effekt auf die Expression von inflammatorischen chemotaktischen Rezeptoren in vitro hat. Dies würde in der Verringerung von CCR1 und CCR5 und in der Hochregulierung von C5aR münden, mit $\mathrm{PGE}_{2}$ als Gegenspieler von IL-4. Zweitens könnte $\mathrm{PGE}_{2}$ als integraler Teil eines entzündlichen Mikromilieus zur schnellen Induktion der DC-Differenzierung aus Monozyten führen. Dies wäre kombiniert mit einer Reduzierung von inflammatorischen chemotaktischen Rezeptoren und einer Hochregulierung von CCR7.

Die Ergebnisse dieser Studie stimmen überein mit der Annahme, dass die Reifung von DC durch unterschiedliche Regulation von Chemokinrezeptorexpression charkterisiert ist (CAUX et al., 2000). Weiterhin sollte der C5aR in die Reihe der inflammatorischen chemotaktischen Rezeptoren, die während der DC-Reifung in vivo einer Herunterregulierung unterliegen, 
aufgenommen werden trotz der Tatsache, dass kontroverse Resultate für die C5aR-Expression bei unreifen versus reifen DC in vitro existieren (YANG et al., 2000, SALLUSTO et al., 1998, KIRCHHOFF et al., 2001, WEINMANN et al., 2003).

Viele der beobachteten Effekte von $\mathrm{PGE}_{2}$ auf DC sind mit der Aktivierung der Adenylatcyclase und der daraus resultierenden cAMP-abhängigen Aktivierung der Proteinkinase A verbunden. Aber auch PI3K und die von ihr abhängige Proteinkinase B (Akt) sind involviert (SCANDELla et al., 2004; MEI et al., 2002). Da über die Aktionen der Proteinkinase B Überlebens- und Proliferationssignale in Gang gesetzt werden, bedeutet dies, dass über eine EP2/EP4 bedingte Erhöhung des intrazellulären cAMP-Spiegels ein antiapoptotischer Effekt ausgelöst wird. Dieser ist zurückzuführen auf die $\mathrm{PGE}_{2}$-bedingte Stabilisierung der Mitochondrienmembranen und der signifikanten Expressionsreduktion proapoptotischer Moleküle wie Caspase und Granzyme B. Exogenes $\mathrm{PGE}_{2}$ ist demnach lokal am Überleben der DC im Entzündungsmilieu beteiligt. Dadurch und durch seinen Einfluss auf die Migration der DC in Richtung sekundärer Lymphorgane stellt $\mathrm{PGE}_{2}$ einen Initiator der adaptiven Immunität dar (VASSILIOU et al., 2004).

Durch die Beteiligung von IL-4, IL-13 und auch von $\mathrm{PGE}_{2}$ an der Initiierung der TH2-Antwort stehen diese Mediatoren im Fokus der Erforschung TH2-assoziierter Erkrankungen wie Asthma bronchiale und anderer allergischer Prozesse. T-Zell- und IgE-vermittelte Immunantwort sind bekannt als Schlüsselreaktionen von allergischen Vorgängen. Dendritische Zellen sind durch die Antigenprozession die Brücke zwischen Allergenen und T-Zellen. Ein Ungleichgewicht zwischen der TH2- und der TH1-Antwort wird verantwortlich gemacht für die Entstehung von atopischen Erkrankungen wie Asthma bronchiale. Atopische Patienten zeigen eine erhöhte Menge an IL-4, welches für die Induktion der TH2-Antwort verantwortlich ist. Diese bedingt wiederum die IgE-Produktion. T-Helferzellen sind aber nicht die einzige Quelle für proallergische Cytokine. Mastzellen, basophile und eosinophile Granulozyten, T-Killerzellen, Bronchialzellen, Fibroblasten und glatte Muskelzellen können inflammatorische Moleküle produzieren. Die Mediatoren IL-4, IL-5, IL-9 und IL-13 werden vom 5q Cytokincluster codiert (MALERBA, PIGNATTI, 2005).

\section{ZUSAMMENFASSUNG}

Myeloide Dendritische Zellen dienen als Vermittler zwischen angeborener und erworbener Immunität. Sie migrieren zum Ort der Entzündung, phagozytieren dort Antigene und wandern als akzessorische Zellen zu den sekundären lymphatischen Organen, wie den Lymphknoten, 
wo sie T-Lymphozyten prozessierte Antigene präsentieren und durch Kostimulation die Proliferation und Differenzierung der T-Lymphozyten initiieren. Voraussetzung für die Funktionen der DC ist deren Wanderungsfähigkeit in Richtung chemotaktischer Mediatoren wie Chemokine und Anaphylatoxine, deren chemotaktische Eigenschaften über spezifische G-Protein-gekoppelte Serpetinrezeptoren vermittelt werden. Durch das die Zellen umgebende Cytokinmikromilieu erfolgt die Regulation der Rezeptoren. Die zugrunde liegenden Mechanismen sind noch in großen Teilen ungeklärt und bedürfen weiterer detaillierter Forschung. Obwohl Monozyten sich in vitro durch die Zugabe von GM-CSF und IL-4 in DC differenzieren können, sind die Bedingungen, die in vivo zur DC-Entstehung führen noch weitgehend unbekannt. So spielt IL-4 zumindest in vitro eine herausragende Rolle und ist gegenwärtig für die Generierung von DC in vitro unverzichtbar (SALLUSTO, LANZAVECCHIA, 1994). Die Entwicklung von DC in vitro aus CD14 ${ }^{+}$Monozyten oder CD34 ${ }^{+}$Vorläuferzellen eröffnet die Möglichkeit zur Gewinnung größerer Mengen dieser antigenpräsentierenden Zellen. MoDC unter Kultivierung mit GM-CSF und IL-4 entsprechen in ihren Funktionen unreifen DC. Durch den Einsatz von IL-4 als Wachstumsfaktor für DC ist deren Verwendung für experimentelle als auch für klinische Zwecke möglich. Dies birgt die Hoffnung zur erfolgreichen Therapie von malignen Tumoren. Es gibt eine große Anzahl an Studien zur Tumorimmunität in Tiermodellen, in denen DC in vitro mit tumorassoziierten Antigenen beladen wurden und in der Lage waren, eine Abwehrreaktion gegen den Tumor in vivo auszulösen. Unter dem Strich lassen diese Studien erkennen, dass die Vaccinierung mit definierten Populationen von in vitro generierten DC nach ihrer ex vivo Beladung mit Tumorantigenen in einer effektiven Antitumorimmunantwort münden könnte (SORURI, ZWIRNER, 2005). PGE 2 und IL-4 sind an der Reifung von Dendritischen Zellen und an der Modulation ihrer Migration beteiligt. In der vorliegenden Studie wurde demonstriert, dass IL-4 und auch IL-13 die Wanderungsfähigkeit von murinen DC und Makrophagen gegen verschiedene inflammatorische Mediatoren wie die Chemokine MIP-3 $\alpha$, MIP-1 $\alpha$, MCP-1, MDC, aber auch gegen die Peptide fMLP und LL-37 und die Anaphylatoxinen C5a und C3a beeinflussen. Ergänzend dazu konnten eine STAT6- und PI3K-abhängige Reduktion der Expression von C5aR, C3aR, CCR2 und CCR5 festgestellt werden. IL-4 behinderte ebenfalls die Chemotaxis von human Monozyten und monozytengenerierten DC gegen MIP-1 $\alpha$ und MCP-1. Es regulierte die Expression der Chemokinrezeptoren CCR1, CCR2, CCR5 auf Monozyten herunter. Auf MoDC verringerte sich die CCR2 Menge ebenfalls, aber nicht die von CCR1 und CCR5. Der negative Einfluss von IL-4 auf die Migrationsfähigkeit von monozytengenerierten Zellen gegen MIP-1 $\alpha$ wurde verbessert durch PGE $_{2}$ obwohl dieser 
Mediator die Oberflächenexpression von CCR1 und CCR5 vermindert. Im Gegensatz dazu tritt $\mathrm{PGE}_{2}$ als Gegenspieler der IL-4-induzierten Abnahme der C5aR Expression und Funktion bei monozytengenerierten $\mathrm{DC}$ und Monozyten auf. $\mathrm{PGE}_{2}$ beseitigt in vivo die C5aR-Expression auf Monozyten während es die schnelle Differenzierung dieser Zellen zu reifen CCR7-exprimierenden DC im SCID-Mausmodell in Kombination mit TNF- $\alpha$ vorantreibt.

Zusammenfassend ist zu sagen, dass die TH2-Cytokine IL-4 und IL-13 allgemein die Kapazität von DC und Monozyten/Makrophagen gegen Chemokine, Anaphylatoxine, formylund antimikrobieller Peptide zu wandern, kompromittieren, hingegen $\mathrm{PGE}_{2}$ eine komplexe Rolle in der Regulation der DC Chemotaxis durch differenzierte Beeinflussung der Expression chemotaktischer Rezeptoren spielt. 


\section{LITERATURQUELLEN}

- $\quad$ Aabakken, L., Dybdahl, J. H., Eidsaunet, W., HaAland, A., Larsen, S., OSNES, M., 1989: Optimal assessment of gastrointestinal side effects induced by nonsteroidal anti-inflammatory drugs: endoscopic lesions, faecal blood loss, and symptoms not necessarily correlated, as observed after naproxen and oxindanac in healthy volunteers. Scand. J. Gastroenterol. 24: 1007 - 1013

- $\quad$ AKIRA, S., KISHIMOTO, T., 1997: NF-IL6 and NF-kappa B in cytokine gene regulation. Adv. Immunol. 65: 1 - 46

Allavena, P., Sica, A., Vecchi, A., Locati, M., Sozzani, S., Mantovani, A., 2000: The chemokine receptor switch paradigm and dendritic cell migration: its significance in tumor tissues. Immunol. Rev. 177: 141 - 149

- $\quad$ Alvaro-Gracia, J. M., Zvaifler, N. J., Firestein, G. S., 1989: Cytokines in chronic inflammatory arthritis. IV. Granulocyte-macrophage colony stimulating factor mediated induction of class II MHC on human monocytes: A possible role in rheumatoid arthritis. J. Exp. Med. 170: 865 - 875

Aman, M. J., TAYebi, N., Obiri, N. J., Puri, R. K., Modi, W. S. LeOnard, W. J., 1996 : cDNA cloning and characterization of the human interleukin-13 receptor alpha chain. J. Biol. Chem. 271 (46): 29265 - 29270

- $\quad$ Baggiolini, M., Dewald, B., Moser, B., 1997: Human chemokines: an update. Annu Rev Immunol 15: 675-705

- $\quad$ Banchereau, J., Briere, F., Caux, C., Davoust, J., Lebeque, S., Liu, Y. J., Pulendran, B., PAluckA, K., 2000: Immunobiology of Dendritic Cells. Annu. Rev. Immunol. 18: 767 - 811

- Banchereau, J., Steinman, R. M., 1998: Dendritic cells and the control of immunity. Nature. 392 (19): 245 - 252

- $\quad$ Bennett, B. L., Cruz, R., Lacson, R. G., Manning, A. M., 1997: Interleukin-4 suppression of tumor necrosis factor alpha-stimulated E-selectin gene transcription is mediated by STAT6 antagonism of NF-kappaB. J. Biol. Chem. 272: 10212 - 10219

- $\quad$ BJerke, S., GAUdernack, G., 1985: Dendritic cells and Monocytes as Accessory Cells in T-Cell Responses in Man. Scand. J. Immunol. 21: 501 - 508

Boise, L. H., Minn, A. J., June, C. H., Lindsten, T., Thompson, C. B., 1995: Growth factors can enhance lymphocyte survival without committing the cell to undergo cell devision. Proc. Natl. Acad. Sci. USA 92: 5491 - 5495 
- $\quad$ Boulay, F., Mery, L., TArdif, M., Brouchon, L., Vignais, P., 1991: Expression cloning of a receptor for C5a anaphylatoxin on the differentiated HL-60 cells. Biochemistry 30: 2993 - 2999

Burgess, A. W., MEtCALF, D., 1980: The nature and action of granulpcyte-macrophage colony stimulating factors. Blood 56: 947 - 958

Canfield, S., Youngnam, L., Schröder, A., Rothman, P., 2005: Cutting edge: IL-4 induces suppressor of cytokine signaling-3 expression in B cells by a mechanism dependent on activation of p38 MAPK. J. Immunol., 174: 2494 - 2498

- $\quad$ Carramolino, L., Kremer, L., Goya, I., VArona, R., Buesa, J. M., Gutierrez, J., Zaballos, A., Martinez-A, C., Marquez, G., 1999: Down-regulation of the betachemokine receptor CCR6 in dendritic cells mediated by TNF-alpha and IL-4. J. Leukoc. Biol. 66: 837 - 844

- $\quad$ CauX, C., Ait-Yahia, S., Chemin, K., de Bouteiller, O., Dieu-Nosjean, M. C., Homey, B., Massacrier, C., VANDERVliet, B., ZlotniK, A., ViCARI, A., 2000 : Dendritic cell biology and regulation of dendritic cell trafficking by chemokines. Springer Semin. Immunopathol. 22 (4): 345 - 369

Caux, C., Dezutter-Dambuyant, C., Schmitt, D., Banchereau, J., 1992: GMCSF and TNF $\alpha$ cooperate in the generation of dendritic Langerhans cells. Nature 360: $258-261$

- ChAtila, T. A., 2004: Interleukin-4 receptor signaling pathways in asthma pathogenesis. Trends in Molecular Medicine 10: 493 - 499

- $\quad$ ChatterJeE-Kishore, M., van den ACKer, F., StARK, G. R., 2000: Association of STATs with relatives and friends. Trends Cell. Biol. 10: $106-111$

- $\quad$ Chan, V.W., Kothakota, S., Rohan, M. C., Panganiban-Lustan, L., Gardner, J. P., WaChOWicz, M. S., WinTER, J.A., Williams, L. T., 1999: Secondary lymphoid-tissue chemokine (SLC) is chemotactic for mature dendritic cells. Blood 93: 3610 - 3616

- $\quad$ Chen, X. H., PATel, B., K., Wang, L. M., Frankel., M., Ellmore, N., Flavell, R. A., LaRochelle, W. J., PIERCE, J. H., 1997: Jak-1 expression is required for mediating interleukin-4-induced tyrosine phosphorylation of insulin receptor substrate and STAT6 signaling molecules. J. Biol. Chem. 272: 6556 - 6560

Chen, T., Guo, J., Yang, M., Han, C., Zhang, M., Chen, W., LiU, Q., Wang, Y., CAO, X., 2004: Cyclosporin A impairs dendritic cell migration by regulating chemokine expression and inhibiting cyclooxygenase-2 expression. Blood 103: 413 - 421 
- Chenoweth, D. E., Goodman, M. G., Hugli, T. E., 1978: Demonstration of specific C5a receptors on intact human polymorphonuclear leukocytes. Proc Natl Acad Sci USA 75: 3943-3947

- $\quad$ Coffman, R. L., Ohara, J., Bond, M. W., Carty, J., Zlotnik, A., Paul, W. E., 1986: B cell stimulation factor-1 enhances the IgE response of lipopolysaccharide-activated B cells. J. Immunol. 136: 4538 - 4541

- $\quad$ Creery, D., Weiss, W., Graziani-Bowering, G., Kumar, R., Aziz, Z., Angel, J. B., KUMAR, A., 2006: Differential regulation of CXCR4 and CCR5 expression by interleukin (IL)-4 and IL-13 is associated with inhibition of chemotaxis and human immunodeficiency Virus (HIV) type 1 replication but not HIV entry into human monocytes.Viral. Immunol. 19: $409-423$

Cyster, J. G., 1999: Chemokines and the homing of dendritic cells to the T cell araes of lymphoid organs. J. Exp. Med. 3: 447 - 450

- $\quad$ Dai, Y., Major, J., Novotny, M., Hamilton, T. A., 2005: IL-4 inhibits expression of the formyl peptide receptor gene in mouse peritoneal macrophages. J. Interferon Cytokine Res. 25: $11-19$

D’Amico, G., Frascaroli, G., Bianchi, G., Transidico, P., Doni, A., Vecchi, A., Sozzani, S., Allavena, P., Mantovani, A., 2000: Uncoupling of inflammatory chemokine receptors by IL-10: generation of functional decoys. Nature Immunology 1: $387-391$

- $\quad$ Dancescu, M., Rubio-Trujillo, M., Biron, G., Bron, D., Delespesse, G., SARFATI, M., 1992: Interleukin 4 protects chronic lymphocytic leukemic B cells from death by apoptosis and upregulates Bcl-2 expression. J. Exp. Med. 176: 1319 - 1326

- $\quad$ DARNELL, J. E., 1997: STATs and gene regulation. Science 277: 1630 - 1635

- $\quad$ David, M., Chen, H. E., Goelz, S., LARner, A. C., NeEl., B. G., 1995: Differential regulation of the alpha/beta interferon-stimulated Jak/STAT pathway by the $\mathrm{SH} 2$ domain-containing tyrosine phosphatase SHPTP1. Mol. Cell. Biol. 15: 7050 - 7058

- $\quad$ Dawson, C. H., Brown, B. L., Dobson, P. R., 1997: A 70-kDa protein facilitates interleukin-4 signal transduction in the absence of the common gamma receptor chain. Biochem. Biophys. Res. Commun. 233 : $279-282$

Del Prete, A., Vermi, W., Dander, E., Otero, K., Barberis, L., Luini, W., Bernasconi, S., Sironi, M., SAntoro, A., Garlanda, C., FACChetti, F., Wymann, M. P., Vecchi, A., Hirsch, E., Mantovani, A., SozZAni, S., 2004: Defective dendritic cell 
migration and activation of adaptive immunity in PI3K $\gamma$-deficient mice. EMBO 23: $3505-3515$

Dhand, R., Hara, K., Hiles, I., Bax, B., Gout, I., Panayotou, G., Fry, M. J., Yonezawa, K., Kasuga, M., Waterfield, M. D., 1994: PI 3-kinase: structural and functional analysis of intersubunit interactions EMBO J. 13: 511 - 521

- Dieu, M. C., VAndervliet, B., Vicari, A., Bridon, J. M., Oldham, E., Ait-Yahia, Briere, F., ZlotniK, A., LeBeque, S., CAUX, C., 1998: Selective recruitment of immature and mature dendritic cells by distinct chemokines expressed in different anatomic sites. J. Exp. Med. 188: 373 - 386

Dieu-Nosjean, M. C., ViCARI, A., Lebeque, S., CauX, C., 1999: Regulation of dendritic cell trafficking: a process that involves the participation of selective chemokines. J Leukoc Biol 66: 252 - 256

- Dieu-Nosjean, M. C., Massacrier, C., Vandervliet, B., Fridman, W. H., CAUX, C., 2001 : IL-10 induces CCR6 expression during Langerhans cell development while IL-4 and IFN-gamma suppress it. J. Immunol. 167: 5594 - 5602

Duronio, V., Welham, M. J., ABraham, S., Dryden, P., Schrader, J. W., 1992: p21ras activation via hemopeoietin receptors and c-kit requires tyrosin kinase activity but not tyrosin phoshphorylation of p21ras GTPase-activating protein. Proc. Natl. Acad. Sci. USA 89: $1587-1591$

- $\quad$ Ehret, G. B., Reichenbach, P., Schindler, U., Horvath, C. M., Fritz, S., NABHOLZ, M., BUCHER, P., 2001: DNA binding specificity of different STAT proteins. Comparison of in vitro specificity with natural target sites. J. Biol. Chem. 276: 6675 - 6688

Endo, T. A., Masuhara, M., Yokouchi, M, Suzuki, R., Sakamoto, H., Mitsui, K., Matsumoto, A., Tanimura, S., Ohtsubo, M., Misawa, H., Miyazaki, T., LeOnor, N., Taniguchi, T., Fujita, T., Kanakura, Y, KomiYa, S., Yoshimura, A., 1997: A new protein containing an SH2 domain that inhibits JAK kinases. Nature 387: 921 - 924

- $\quad$ Falasca, M., Hughes, W. E., Dominguez, V., Sala, G., Fostira, F., Fang, M. Q., Cazzolli, R., Shepherd, P. R., James, D. E., Maffucci, T., 2007: The role of phosphoinositide 3-kinase C2alpha in insulin signaling. J. Biol. Chem. 282 (38): $28226-28236$

Fiorentino, D. F., Zlotnik, A., Vieira, P., Mosmann, T. R., Howard, M., MOORE, K. W., O'GARRA, A., 1991: IL-10 acts on the antigen-presenting cell to inhibit cytokine production by TH1 cells. J. Immunol. 146: 3444 - 3451 
- $\quad$ Förster, R., Schubel, A., Breitfeld, D., Kremmer, E., RenNer-Müller, I., WOLF, E., LIPP, M., 1999: CCR7 coordinates the primary immune response by establishing functional microenvironments in secondary lymphoid organs. Cell 99: 23 - 33

Franke, T., F., Kaplan, D. R., Cantley, L. C., TOKER, A., 1997: Direct regulation of the Akt proto-oncogen product by phosphatidylinositol-3,4-bisphosphate. Science 275: $665-668$

- $\quad$ Fruman, D. A., CAntley, L. C., 2002: Phosphoinositid 3-kinase in immunological systems. Seminars in Immunology, Vol. 14: 7 - 18

- $\quad$ Gascan, H., Gauchat, J. F., Roncarolo, M. G., Yssel, H., Spits, H., de VRIES, J. E., 1991: Human B cell clones can be induced to proliferate and to switch to IgE and IgG4 synthesis by interleukin 4 and a signal provided by activated CD4+ T cell clones. J. Exp. Med. 173: 7474 - 750

- Gasque, P., Singhrao, S. K., Neal, J. W., Götze, O., Morgan, B. P. 1997: Expression of the receptor for complement C5a (CD88) is up-regulated on reactive astrocytes, microglia, and endothelial cells in the inflamed human central nervous system. Am J Pathol 150: $31-41$

- $\quad$ Gately, M. K., Renzetti, L. M., Magram, J., Stern, A. S., Adorini, L., Gubier, U., PRESKY, D. H., 1998: The IL-12/IL-12-receptor system role in normal and pathologic immune responses. Ann. Rev. Immunol. 16: 495 - 521

- $\quad$ Gauzzi, M. C., Purificato, C., Donato, K., Jin, Y., Wang, L., Daniel, K. C., MaghaZaChi, A. A., Belardelli, F., Adorini, L., Gessani, S., 2005: Suppressive effect of 1a,25-dihydroxyvitamin D3 on type 1 IFN-mediated monocyte differentiation into dendritic cells: impairment of functional activities and chemotaxis. J. Immunol. 174: $270-276$

GERARD, N. P., GERARD, C., 1991: The chemotactic receptor for human C5a anaphylatoxin. Nature 349: 614 - 617

- Gerrard, T. L., Dyer, D. R., Mostowski, H. S., 1990: IL4 and Granulocytemacrophage colony-stimulating factor selectively increase HLA-DR and HLA-DP antigens but not HLA-DQ antigens on human monocytes. J. Immunol. 144: 4670 - 4674

GILROY, D. W., 1999: Inducible cyclooxygenase may have anti-inflammatory properties. Nat. Med. 5: 698 - 701

Glovsky, M. M., Hugli, T. E., Ishizaka, T., LiChtenstein, L. M., ERiCKson, B. W., 1979: Anaphylatoxin-induced histamine release with human leukocytes: studies of C3a leukocyte binding and histamine release. J Clin Invest 64: 804 - 811 
- GORDON, S., 2003: Alternative activation of macrophages, Nature Reviews 3: 23-35

- $\quad$ Gough, N. M., Gough, J., Metcalf, D., Kelso, A., Grail, D., Nicola, N. A., Burgess, A. W., DunN, A. R., 1984: Molecular cloning of cDNA encoding a murine haematopoetic growth regulator, granulocyte-macrophage colony stimulating factor. Nature 309: $763-767$

Groux, H., Bigler, M., de Vries, J. E., Roncarolo, M. G., 1998: Inhibitory and stimulatory effects of IL-10 on human CD8+ T cells. J. Immunol. 160: 3188 - 3193

- $\quad$ Gunn, M. D., Kyuwa, S., Tam, C., Kakiuchi, T., Matsuzawa, A., Williams, L. T., NAKANO, H. 1999: Mice lacking expression of secondary lymphoid organ chemokine have defects in lymphocyte homing and dendritic cell localization. J Exp Med 189: 451 - 460

Gustafson, T. A., He, W., Craparo, A., Schaub, C. D., O’Neill, T. J., 1995: Phosphotyrosine-dependent interaction of SHC and insulin receptor substrate 1 with the NPEY motif of the insulin receptor via a novel non-SH2 domain. Mol. Cell. Biol. 15: $2500-2508$

- $\quad$ Haque, S. J., Harbor, P., TABrizi, M., Yi, T., Williams, B. R., 1998: Protein-tyrosine phosphatase SHP-1 is a negative regulator of IL-4 and IL-13 dependent signal transduction. J. Biol. Chem. 273 (51): 33893 - 33896

- $\quad$ Harizi, H., Juzan, M., Grosset, C., Rashedi, M., Gualde, N., 2001: Dendritic cell issued in vitro from bone marrow produce PGE2 that contributes to the immunmodulation induced antigen-presenting cells. Cell. Immunol. 209: 19 - 28

- $\quad$ Harizi, H., Juzan, M., Pitard, V., Moreau, J.-F., Gualde, N., 2002: Cyclooxigenase-2-issued prostaglandin E2 enhances the production of endogenous IL-10, which down-regulates dendritic cell functions. J. Immunol. 168: 2255 - 2263

- $\quad$ Harizi, H., Grosset, C., Gualde, N., 2003: Prostaglandin E2 modulates dendritic cell function via EP2 and EP4 receptor subtypes. J. Leukoc. Biol. 73: 756 - 763

- $\quad$ HARIZI, H., GUALDE, N., 2006: Pivotal role of PGE2 and IL-10 in the cross-regulation of dendritic cell-derived inflammatory mediators. Cellular and Molecular Immunology 3: $271-277$

- Harris, S. G., Padilla, J., Koumas, L., Ray, D., PhiPPS, R. P., 2002: Prostaglandins as modulators of immunity. Trends Immunol. 23: 144 - 150

Hershey, G. K., Friedrich, M. F., Esswein, L. A., Thomas, M. L., Chatila, T. A., 1997: The association of atopy with a gain-of-function mutation in the alpha subunit of the interleuki-4 receptor. N. Engl. J. Med. 337: 1720 - 1725 
- Hilkens, G. M., Snijders, M. U. A., Vermeulen, H., Meide, P. H. V. D., WierengA, E. A., KAPSEnBERG, M. L., 1996: Accessory cell-derived IL-12 and prostaglandin E2 determine the IFN- $\gamma$ level of activated human $\mathrm{CD}^{+}{ }^{+} \mathrm{T}$ cells. J. Immunol. 156: $1722-1727$

- $\quad$ Hirsch, E., Katanaev, V. L., Garlanda, C., Azzolino, O., Pirola, L., Silengo, L., Sozzani, S., Mantovani, A., Altruda, F., Wymann, M. P., 2000: Central role for G protein-coupled phosphoinositid 3-kinase gamma in inflammation. Science 287 (5455): $1049-1053$

Howard, M., FARrar, J., Hilfiker, M., Johnson, B., TAKATsu, K., HAMAOKA, T., PAUL, W. E., 1982: Identification of a T-cell derived B-cell growth factor distinct from interleukin 2. J. Exp. Med. 155: 914 - 923

Hsieh, C. S., Heimberger, A. B., Gold, J. S., O'Garra, A., MurPhy, K. M., 1992: Differential regulation of T-helper phenotype development by interleukin-4 and interleukin-10 in an alpha-beta-T-cell-receptor transgenic system. Proc. Natl. Acad. Sci. USA 89: $6065-6069$

HuGLI, T. E., 1984: Structure and function of the anaphylatoxins. Springer Semin Immunopathol 7: 193 - 219

- $\quad$ Illera, V. A., Perandones, C. E., Stunz, L. L., Mower, J., IR, D. A., Ashman, R. F., 1993: Apoptosis in splenic B lymphocytes: regulation by protein kinase C and IL-4. J. Immunol. 151: 2965 - 2973

- Inaba, K., Inaba, M., Romani, N., Aya, H., Deguchi, M., Ikehara, S., Muramatsu, S., SteinMAN, R. M., 1992: Generation of large numbers of dendritic cells from mouse bone marrow cultures supplemented with granulocyte macrophage colony stimulating factor. J. Exp. Med. 176: 1693 - 1702

- Janeway, C. A., Travers, P., Walport, M., Shlomchik, M. Immunologie. Spektrum Akademischer Verlag, Heidelberg 2002

- Jansen, J. H., Wientjens, G. J., FibBe, W. E., Willemze, R., Kluin-Nelemans, H. C., 1989: Inhibition of human macrophage colony formation by interleukin 4. J. Exp. Med. 170: $577-582$

Jgietseme, J. U., Ananaba, G. A., Bolier, J., Bowers, S., Moore, T., Belaye, T., EKO, O. F., LYN, D., BLACK, M. C., 2000: Suppression of endogenous IL-10 gene expression in dendritic cells enhances antigen presentaion for specific TH1 induction: potential for cellular vaccine development. J. Immunol. 164: 4212 - 4219 
- $\quad$ Jing, H., VASSILIOU, E., GANEA, D., 2003: Prostaglandin E2 inhibits production of the inflammatory chemokines CCL3 and CCL4 in dendritic cells. J. Leukocyte Biol. 74: $868-879$

Jonuleit, H., Kuhn, U., Muller, G., Steinbrink, K., PArAgniK, L., Schmitt, E., KNOP, J., ENK, A. H., 1997: Pro-inflammatory cytokines and prostaglandins induce maturation of potent immunostimulatory dendritic cells under fetal calf serum-free conditions. Eur. J. Immunol. 27: 3135 - 3142

- JOzefowski, S., BOBEK, M., MARCINKIEWICZ, J., 2003: Exogenous but not endogenous prostanoids regulate cytokine secretion from murine bone marrow dendritic cells: EP2, DP, and IP but not EP1, EP3, and FP prostanoid receptors are involved. Int. Immunopharmacol. 3: 865 - 878

- Kabashima, K., Sakata, D., Nagamachi, M., Miyachi, Y., InABA, K., NARUMIYA, S., 2003: Prostaglandin E2-EP4 signaling initiates skin immun response by promoting migration and maturation of Langerhans cells. Nat. Med. 9: 744 - 749

- $\quad$ Kalinski, P., Hilkens, C. M., Snijders, A., Snijdewint, F. G., KapsenberG, M. L., 1997: IL-12-deficient dendritic cells, generated in the presence of prostaglandin E2 promote type 2 cytokine production in maturing human naive T helper cells. J. Immunol. 159: $28-35$

- $\quad$ A) KaPeller, R., CANtley, L. C., 1994: Phosphatidyinositol 3-kinase. Bioessays 16: $565-576$

- $\quad$ B) Kapeller, R., Prasad, K. V., Janssen, O., Hou, W., Schaffhausen, B. S., RudD, C. E., CANTley, L. C., 1994: Identification of two SH3-binding motifs in the regulatory subunit of phosphatidyinositol 3-kinase. J. Biol. Chem. 269: 1927 - 1933

- $\quad$ Kaplan, M. H., Schindler, U., Smiley, S. T., Grusby, M. J., 1996: STAT6 is required for mediating responses to IL-4 and for development of TH2 cells. Immunity 4: $313-319$

- $\quad$ Kaplan, G., Walsh, G., Guido, L. S., Meyn, P., Burkhardt, R. A., Abalos, R. M., Barker, J., Frindt, P. A., Fajardo, T. T., Celona, R., Cohn, Z. A., 1992: Novel responses of human skin to intradermal recombinant granulocyte/macrophage colony stimulating factor: Langerhans cell recruitment, keratinocyte growth, and enhanced wound healing. J. Exp. Med. 175: 1717 - 1728

Kaplan, M. H., Schindler, U., Smiley, S. T., Grusby, M. J., 1996: STAT6 is required for mediating responses to IL-4 and for the development of $\mathrm{TH}_{2}$ cells. Immunity, 4: $313-319$ 
- $\quad$ Karp, C. L., Grupe, A., Schadt, E., Ewart, S. L., Keane-Moore, M., CuOmo, P. J., KÖHL, J., Wahl, L., Kuperman, D., Germer, S., Aud, D., Peltz, G., Wills-KarP, M., 2000: Identification of complement factor 5 as a susceptibility locus for experimental allergic asthma. Nat Immunol 1: 221 - 226

Kashiwada, M., Giallourakis, C. C., Pan, P.-Y., Rothman, P. B., 2001: Immunreceptor tyrosin-based inhibitory motif of the IL-4 receptorassociates with $\mathrm{SH} 2$ containing phophatases and regulates Il-4 induced proliferation. J. Immunol. 167: 6382 - 6387 - $\quad$ Keegan, A. D., Nelms, K., White, M., Wang, L. M., Pierce, J. H., Paul, W. E., 1994: An IL-4 receptor region containing an insulin receptor motif is important for IL-4-mediated IRS-1 phosphorylation and cell growth. Cell 76: 811 - 820

- Kelly-Welch, A. E., 2003: Interleukin-4 and interleukin-13 signaling connection maps. Science 300: 1527 - 1528

- $\quad$ Kirchhoff, K., Weinmann, O., Zwirner, J., Begemann, G., Götze, O., KaPP, A., WERFEL, T., 2001: Detection of anaphylatoxin receptors on CD83+ dendritic cells derived from human skin. Immunology 103: 210 - 217

- $\quad$ Kirchner, H., Kruse, A., Neustock, P., RinK, L., 1994: Cytokine und Interferone. 1. Aufl., Heidelberg, Berlin, Oxford: Spektrum

- Klippel, A., Escobedo, J. A., Hu, Q., Williams, L. T., 1993: A region of the 85-kilodalton (kDa) subunit of phosphatidylinositol 3-kinase binds the 110-kDa catalytic subunit in vivo. Mol. Cell. Biol. 13: 5560 - 5566

- KuHn, R., RAJEWSKY, K., MulleR, W., 1991: Generation and analysis of interleukin-4 deficient mice. Science 254: 707 - 710

- Kuroda, E., Sugiura, T., OKadA, K., ZeKi, K., Yamashita, U., 2001: Prostaglandin E2 up-regulates macrophage-derived chemokine production but suppresses IFN-inducible protein-10 production by APC. J. Immunol. 166: 1650 - 1658

- LANGKABel, P., ZWIRnER, J., OPPERMANN, M., 1999: Ligand-induced phosphorylation of anaphylatoxin receptors $\mathrm{C} 3 \mathrm{aR}$ and $\mathrm{C} 5 \mathrm{aR}$ is mediated by $\mathrm{G}$ protein-coupled receptor kinases. Eur J Immunol 29: 3035 - 3046

- $\quad$ Lauener, R. P., Goyert, S. M., Geha, R. S., Vercelli, D., 1990: Interleukin 4 down-regulates the expression of CD14 in normal human monocytes. Eur. J. Immunol. 20: $2375-2381$

LE, Y., MurPhy, P. M., WANG, J. M., 2002 : Formyl-peptide receptors revisited. Trends Immunol. 23: 541 - 548 
- $\quad$ Lee, A. W., Truong, T., Bickham, K., Fonteneau, J. F., Larsson, M., Da Silva, J., Somersan, S., Thomas, E. K., BhardwaJ, N., 2002: A clinical grade cocktail of cytokines and PGE2 results in uniform maturation of human monocyte-derived dendritic cells: implications for immunotherapy. Vaccine 20 (Suppl. 4): A8 - A22

LEFKOWITZ, R. J.. 1998. G protein-coupled receptors. III. New roles for receptor kinases and betaarrestins in receptor signaling and desensitization. J. Biol. Chem. 273: $18677-18680$

- $\quad$ Legler, D. F., Krause, P., Scandella, E., Singer, E., Groettrup, M., 2006: Prostaglandin E2 is generally required for human dendritic cell migration and exerts is effect via EP2 and EP4 receptors. J. Immunol. 176: 966 - 973

Lemmon, M. A., Ferguson, K. M., Sigler, P. B., Schlessinger, J., 1995: Specific and high-affinity binding of inositol phosphates to an isolated pleckstrin homology domain. Proc. Natl. Acad. Sci. USA 92: 10472 - 10476

- $\quad$ Li, Z., JiAnG, H., Xie, W., Zhang, Z., SmrckA, A. V., WU, D., 2000: Roles of PLC-beta2 and -beta3 and PI3K gamma in chemoattractant-mediated signal transduction. Science 287 (5455): 1046 - 1049

Livnah, O., Stura, E. A., Johnson, D. L., Midleton, S. A., Mulcahy, L. S., Wrighton, N. C., Dower, W. J. , Jolliffe, L., K., Wilson, I. A., 1996: Functional mimicry of a protein hormone by a peptide agonist: the EPO receptor complex at $2.8 \mathrm{~A}$ (see comments). Science 273: 464 - 471

- $\quad$ Luft, T., Jefford, M., Luetjens, P., Toy, T., Hochrein, H., Masterman, K. A., Maliszewski, C., Shortman, K., Cebon, J., Mawaskovsky, E., 2002: Functionally distinct dendritic cell (DC) populations induced by physiologic stimuli: prostaglandin E2 regulates the migratory capacity of specific DC subsets. Blood 100: 1362 - 1372

- $\quad$ LUSTER, A. D., 1998: Chemokines--chemotactic cytokines that mediate inflammation. N Engl J Med 338: 436 - 445

- $\quad$ Luster, A. D., (2001): Chemokines regulate lymphocyte homing to the intestinal mucosa. Gastroenterology 120: 291 - 294

- $\quad$ Mack, M., Cihak, J., Simonis, C., Luckow, B., Proudfoot, A. E., Plachy, J., Bruhl, H., Frink, M., Anders, H. J., Vielhauer, V., Pfirstinger, J., Stangassinger, M., SCHLONDORFF, D.. 2001. Expression and characterization of the chemokine receptors CCR2 and CCR5 in mice. J. Immunol. 166: 4697 - 4704.

MAlerbA, G., PignAtTi, P. F., 2005: A review of asthma genetics: gene expression studies and recent candidates. J. Appl. Genet. 46 (1): 93 - 104 
- $\quad$ McCOLL, S. R., 2002: Chemokines and denritic cells: a crucial alliance. Immunol. Cell Biol 80 (5): 489 - 496

McWilliam, A. S., NAPOli, S., Marsh, A. M., PeMPer, F. L., Nelson, D. J., PimM, C. L., Stumbles, P. A., Wells, T. N. C., Holt, P. G., 1996: Dendritic cells are recruited into the airway epithelium during the inflammatory response to a broad spectrum of stimuli. $\mathrm{J}$ Exp Med 184: 2429 - 2434

- $\quad$ Mei, F. C., Qiao, J., Tsygankova, O. M., Meinkoth, J. L., Quilliam, L. A., CHENG, X., 2002: Differential signaling of cyclic AMP: opposing effects of exchange protein directly activated by cyclic AMP and cAMP-dependent protein kinase on protein kinase B activation. J. Biol. Chem. 277: 11497 - 11504

Metcalf, D., Begley, C. G., Johnson, G. R., Nicola, N. A., Vadas, M. A., Lopez, A. F., Williamson, D. J., Wong, G. G., Clark, S. C., WANG, E. A., 1986: Biologic properties in vitro of a recombinant human granulocyte-macrophage colony-stimulating factor. Blood 67: 37 - 45

- $\quad$ Mikita, T., CAmpbell, D., Wu, P. G., Williamson, K., Schindler, U., 1996: Requirements for interleuki-4-induced gene expression and functional characterization of STAT6. Mol. Cell. Biol. 16: 5811 - 5820

- $\quad$ Minami, Y., Kono, T., Yamada, K., Kobayashi, N., KaWAhara, A., Perlmutter, R. M., TANiguChI, T., 1993: Association of p56 (lck) with IL-2 receptor beta chain is critical for the IL-2 induced activation of p56 (1ck). EMBO J. 12: 759 - 768

- $\quad$ Minshall, C., Arkins, S., Straza, J., Connors, J., Dantze, R., Freund, G. G., KELLEY, K. W., 1997: IL-4 and insulin-like growth factor-1 inhibit the decline in Bcl-2 and promote the survival of IL-3-deprived myeloid progenitors. J. Immunol. 159: 1225 - 1232

- $\quad$ Mirmonsef, P., Shelburne, C. P., Yeatman, I. I. F., ChOnG, H. J., Ryan, J. J., 1999: Inhibition of Kit expression by IL-4 and IL-10 in murine mast cells: role of STAT6 and phosphatidylinositol 3'-kinase. J. Immunol. 163: 2530 - 2539

- $\quad$ Mitsuyasu, H., Izuhara, K., MaO, X.-Q., GAO, P.-S., Arinobu, Y., EnOmoto, T., Kawai, M., Sasaki, S., Dake, Y., Hamasaki, N., Shirakawa, T., Hopkin, J. M., 1998: Ile50Val variant of IL-4Ralpha upregulates IgE synthesis and associates with atopic asthma. Nature Med. 19: 119 - 120

Miyajima, A., Kitamura, T., HaradA, N., Yokota, T., Arai, K., 1992: Cytokine receptors and signal transduction. Annu. Rev. Immunol. 10: 295 - 331

- $\quad$ Miyazaki, T., Kawahara, A., Fuji, H., Nakagawa, Y., Minami, Y., LiU, Z., Oishi, I., Silvennoinen, O., Witthahn, B. A., Ihle, J. N. et al., 1994: Functional 
activation of Jak1 and Jak3 by selective assiciation with IL-2 receptor subunits. Science 266: $1045-1047$

Moore, K. W., de WaAl Malefyt, R., Coffman, R. L., O'Garra, A., 2001: Interleukin-10 and interleukin-10 receptor. Annu. Rev. Immunol. 19: 683 - 765

- Morelli, A., Larrengina, A., Chuluyan, I., Kolkowski, E., Fainboim, L., 1996: Expression and modulation of C5a receptor (CD88) on skin dendritic cells. Chemotactic effect of C5a on skin migratory dendritic cells. Immunology 89: 126 - 134

- $\quad$ Murakami, M., NARAZAKi, M., HiBi, M., Yawawata, H., Yasukawa, K., Hamaguchi, M., Taga, T., Kishimoto, T., 1991: Critical cytoplasmatic region of the interleukin 6 signal transducer gp130 is conserved in the cytokine receptor family. Proc. Natl., Acad., Sci. USA 88: 11349 - 11353

- $\quad$ Murata, T., Taguchi, J., Puri, R. K., 1998: Interleukin-13 receptor alpha' but not alpha chain: a functional component of interleukin-4 receptors. Blood 91: 3884 - 3891

- $\quad$ MurPhy, F. J., HAYES, M. P., BuRD, P. R., 2000: Disperate intracellular processing of human IL12 preprotein subunits: Atypical processing of the p35 signal peptide. J. Immunol. 164: 839 - 847

- $\quad$ NAKAnishi, K., Yoshida, N., Kishimoto, T., AKIRA, S., 1996: Essential role of STAT6 in IL-4 signaling. Nature 380: 627 - 630

- $\quad$ Nakata, T., Narazaki, M., Hirata, M., Matsumoto, T., Minamoto, S., Aono, A., Nishimoto, N., Kajita, T., TAgA, T., Yoshizaki, K., AKIRA, S., Kishimoto, T., 1997: Structure and function of a new STAT-induced STAT inhibitor. Nature 387: 924 - 929

- $\quad$ NARumiYA, S., Sugimoto, Y., Ushikubi, F., 1999: Prostanoid receptors: structures, properties, and functions. Physiol. Rev. 79: 1193 - 1226

Nelms, K, KeEgan, A. D.; ZAMORANO, J.; RYAN, J. J.; PAUL, W. E.; 1999: The IL-4 Receptor: Signaling Mechanisms and Biological Functions. Annu. Rev. Immunol.17: $701-738$

- $\quad$ NiCOLA, N. A., Structural aspects of cytokine/receptor interactions. Ann N Y Acad Sci, 1995. 766: 253 - 262

- $\quad$ Noben-Trauth, N., Shultz, L. D., Brombacher, F., Urban, J. F. Jr., Gu, H., PAUL, W. E., 1997: An interleukin 4 (IL-4)-independent pathway for CD4+ T cell IL-4 production is revealed in IL-4 receptor-deficient mice. Proc. Natl. Acad. Sci. USA 94: $10838-10843$ 
- $\quad$ ObIRI N. I., Debinski, W., LeONARD, W. J., PURI, R. K. 1995: Receptor for IL-13. Interaction with interleukin 4 by a mechanism that does not involve the common gamma chain shared by receptors for interleukins 2,4,7,9 and 15. J. Biol. Chem. 270: 8797 - 8804

OHARA, J., PAUL, W. E., 1988: Up-regulation of interleukin 4/B-cell stimulatory factor 1 receptor expression. Proc. Natl. Acad. Sci. USA 85: 8221 - 8225

- PAlmblaD, J., 1990: Eicosanoids and modulation of inflammatory and immune responses. Scand. J. Clin. Lab., 50: 168 - 171

- PAnZer, U., UGuCCIONI, M. 2004: Prostaglandin E2 modulates the functional responsiveness of human monocytes to chemokines. Eur. J. Immunol. 34: 3682 - 3689

- $\quad$ PAUL, W., 1991: Interleukin-4: A prototypic immunoregulatory lymphokine. Blood 77: $1859-1870$

PAZ, K. Hemi, R, LeRoith, D., KARAsiK, A., ElhanAny, E., KAnety, H., ZiCK, Y., 1997: A molecular basis for insulin resistance. Elevated serine/threonin phosphorylation of IRS-1 and IRS-2 inhibits their binding to juxtamembrane region of the insulin receptor and impairs their ability to undergo insulin-induced tyrosin phosphorylation. J. Biol. Chem. 272: $29911-29918$

Piemonti, L., Bernasconi, S., Luini, W., TrobonjacA, Z., Minty, A., AllaVENA, P., MANTOVANI, A., 1995: IL-13 supports differentiation of dendritic cells from circulating precursors in concert with GM-CSF. Eur. Cytokine Netw. 6(4): 245 - 252

- $\quad$ RANE, S. G., REDDY, E. P., 2000: Janus kinases: components of multiple signaling pathways. Oncogene 19 (49): 5662 - 5679

- $\quad$ Romani, N., Gruner, S., Brang, D., Kampgen, E., LenZ, A., Trockenbacher, B., Konwalinka, G., Fritsch, P. O., Steinman, R. M., Schuler, G., 1994: Proliferating dendritic cell progenitors in human blood. J. Exp. Med. 180: 83 - 93

- ROPER, R. L., PHIPPS, R.P., 1994: Prostaglandin E2 regulation of the immune response. Adv. Prostaglandin Thromboxane Leukotriene Res. 22: 101 - 111

- Ryan, J. J., McReynolds, L. J., Keegan, A., WAng, L. H., GARfein, E., Rothman, P., Nelms, K., Paul, W. E., 1996: Growth and gene expression are predominantly controlled by distinct regions of the human IL-4 receptor. Immunity 4: $123-132$

SALLUSTO, F., LANZAVECCHIA, A., 1994: Efficient presentation of solubel antigen by cultured human dendritic cells is maintained by granulocyte/macrophage colony-stimulating factor plus interleukin-4 and downregulated by tumor necrosis factor- $\alpha$. J. Exp. Med. 179: $1109-1118$ 
- $\quad$ Sallusto, F., LANZAVECChiA, A., 1999: Mobilizing dendritic cells for tolerance, priming, and chronic inflammation. J. Exp. Med. 4: 611 - 614

- $\quad$ Sallusto, F., Schaerli, P., Loetscher, P., Schaniel, C., Lenig, D., Mackay, C. R., QIN, S., LANZAVECCHIA, A., 1998: Rapid and coordinated switch in chemokine receptor expression during dendritic cell maturation. Eur. J. Immunol. 28: 2760 - 2769

- $\quad$ SANTIAGO-SCHWARZ, F., 1999: Positive and negative regulation of myeloid dendritic cell lineage. J. Leuk. Biol. 66: 209 - 216

- $\quad$ Santiago-Schwarz, F., Belilos, E., Diamond, B., Carsons, S. E., 1992: TNF in combination with GMCSF enhances the differentiation of neonatal cord blood stem cells into dendritic cells and macrophages. J. Leuk. Biol. 52: 274 - 281

- Scandella, E., Men, Y., Gillessen, S., Förster, R., GroetrupP, M., 2002: Prostaglandin E2 is a key factor for CCR7 surface expression and migration of monocytederived dendritic cells. Blood 100: 1354 - 1361

- $\quad$ Scandella, E., Men, Y., Legler, D. F., Gillessen, S., Prikler, L., Ludewig, B., GROetTRUP, M., 2004: CCL19/CCL21-triggered signal transduction and migration of dendritic cells requires prostaglandin E2. Blood 103: 1595 - 1601

SChARENBERG, A. M., KinET, J. P., 1996: The emerging field of receptor-mediated inhibitory signaling: SHP or SHIP? Cell 87: 961 - 964

- $\quad$ Seder, R. A., Paul, W. E., Davis, M. M., De, S. T., Groth, B. F., 1992: The presence of interleukin-4 during in vitro priming determines the lymphokine-producing potential of CD4+ T-cells from T-cell receptor transgenic mice. J. Exp. Med. 176: $1091-1098$

- $\quad$ Seidel, H. M., Milocco, L. H., LAmb, P., DARnell, J., E., Stein, R. Jr., Rosen, J., 1995: Spacing of palindromic half sites as determinant of selective STAT (signal transducers and activators of transcription) DNA binding and transcriptional activity. Proc. Natl. Acad. Sci. USA 92: 3041 - 3045

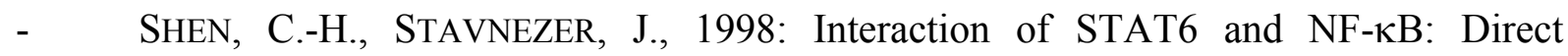
association and synergistic activation of interleukin-4-induced transcription. Mol. Cell. Biol. 18 (6): 3395 - 3404

- $\quad$ Shimoda, K., van Deursen, J., SAngSter, M. Y., SARAwar, S. R., CARSON, R. T., et al., 1996: Lack of IL-4-induced TH2 response and IgE class switching in mice with disrupted STAT6 gene. Nature 380: 630 - 633 
- $\quad$ Snijdewint, F. G. M., Kalinski, P., Wierenga, E. A., Bos, J. D., KapsenberG, M. L., 1993: Prostaglandin E2 differentially modulate cytokine secretion profiles of human TH lymphocytes. J. Immunol. 150: 5321 - 5329

- $\quad$ A) Soruri, A., Kiafard, Z., Dettmer, C., Riggert, J., Köhl, J., Zwirner, J., 2003: IL-4 down-regulates anaphylatoxin receptors in monocytes and dendritic cells and impairs anaphylatoxin-induced migration in vivo. J. Immunol. 170: 3306 - 3314

- $\quad$ B) Soruri, A., Riggert, J., Schlott, T., Kiafard, Z., DetTMer, C., Zwirner, J., 2003: Anaphylatoxin C5a induces monocyte recruitment and differentiation into dendritic cells by TNF-alpha and prostaglandin E2-dependent mechanisms. J Immunol. 171: $2631-2636$

C) SORURI, A., KIM, S., KiAfARD, Z., ZWIRnER, J., 2003: Characterization of C5aR expression on murine myeloid and lymphoid cells by the use of a novel monoclonal antibody. Immunol. Lett. 88: 47 - 52

- $\quad$ SORURI, A., ZWIRNER, J., 2005: Dendtiric cells: limited potential in immunotherapy. IJBCB 37: 241 - 245

- $\quad$ Soruri, A, Grigat, G., Forssmann, U., Riggert, J., Zwirner, J., 2007: $\beta$-Defensins chemoattract macrophages and mastcells but not lymphocytes and dendritic cells: CCR6 is not involved, Eur. J. Immunol. 37: 2474 - 2486

- $\quad$ Sozzani, S., Allavena, P., D`Amico, G., Luini, W., Bianchi, G., Kataura, M., Imai, T., Yoshie, O., Bonecchi, R., Mantovani, A., 1998: Differential regulation of chemokine rec eptors during dendritic cell maturation: a model for their trafficking properties. J. Immunol. 161: 1083 - 1089

- $\quad$ Sozzani, S., Luini, W., Borsatti, A., Polentarutti, N., Zhou., D., Piemonti, L., D`Amico, G., Power, C. A., Wells, T. N., GobBi, M., Allavena, P., Mantovani, A., 1997: Receptor expression and responsiveness of human dendritic cells to a defined set of CC and CXC chemokines. J. Immunol. 159: 1993 - 2000

- $\quad$ Sozzani, S., Sallusto, F., Luini, W., Zhou, D., Piemonti, L., Allavena, P., Damme, J. V., Valitutti, S., Lanzavecchia, A., Mantovani, 1995: Migration of dendritic cells in response to formyl peptides, C5a, and a dirstinct set of chemokines. J. Immunol. 155: 3292 - 3295

Starr, R., Willson, T. A., Viney, E. M., Murray, L. J., RAYNer, J. R., JENKins, B. J., Gonda, T. J., AleXander W. S., Metcalf, D., Nicola, N. A., Hilton, D. J., 1997: A family of cytokine-inducible inhibitors of signaling. Nature 387: 917 - 921 
- $\quad$ SteinMAN, R. M., 1991: The dendritic cell system and its role in immunogenicity. Annu. Rev. Immunol. 9: 271 - 296

- $\quad$ Steinman, R. M., InABA, K., 1999: Myeloid dendritic cells. J. Leuk. Biol. 66: $205-208$

Stolina, M., Sharma, S., Lin, Y., Dohadwala, M., GARdner, B., LuO, J., Zhu, L., Kronenberg, M., Miller, P. W., Portanova, J., Lee, J. C., Dubinett, S. M., 2000: Specific inhibition of cylcooxygenase- 2 restores antitumor reactivity by alteration the bilance of IL-10 and IL-12 synthesis. J. Immunol. 164: 361 - 370

- $\quad$ Straussmann, G., Koota, V. P., Finkelman, F., Fong, M., Kambayashi, T., 1994: Evidence fort the involvement of interleukin-10 in the differential deactivation of murine peritoneal macrophages by PGE2. J. Exp. Med. 180: 2365 - 2370

- $\quad$ STRYer, L.: Biochemie. Spektrum Akademischer Verlag. Heidelberg, Berlin, Oxford. 4. Auflage, 1995

- $\quad$ Sun, X., J., Rothenberg, P., Kahn, C. R., Backer, J. M., Araki, E., Wilden, P. A., CAhill, D. A., Goldstein, B. J., White, M. F., 1991: Structure of the insulin receptor substrate IRS-1 defines a unique signal transduction protein. Nature 352: 73 - 77

Sun, X. J., Crimmins, D. L., MYers, M. G, MiralpeiX, M., White, M. F., 1993: Pleiotropic insulin signals are engaged by multisite phosphorylation of IRS-1. Mol. Cell. Biol. 13: $7418-7428$

- $\quad$ Sun, X. J., WAng, L.M., Zhang, Y., Yenush, L., MYers, M. G. J., Glasheen, E., LANe, W. S., Pierce, J. H., White, M. F., 1995: Role of IRS-2 in insulin and cytokine signaling. Nature 377: 173 - 177

- Takayama, K., Garcia-Cardena, G., Sukhova, G. K., Comander, J., Gimbrone, M. A., Jr., LiBBY, P., 2002: Prostaglandin E2 supresses chemokine production in human macrophages through the EP4 receptor. J. Biol. Chem. 277: 44147 - 44154

- $\quad$ Takeda, K., Kamanaka, M., Tanaka, T., Kishimoto, T., Akira, S., (1999): Impaired IL-13-mediated functions of macrophages in STAT6 deficient mice. J Immunol 157: $3220-3223$

- $\quad$ TAKedA, K., Kishimoto, T., AKIRA, S., 1997: STAT6: Its role in interleukin 4mediated biological functions. J. Mol. Med. 75: 317 - 326

TANIGUCHI, T., 1995: Cytokine signaling through nonreceptor protein tyrosine kinases. Science 268: $251-255$ 
- $\quad$ Te Velde, A. A., Klomp, J. P. G., Yard, B. A., De VRies, J. E., Figdor, C. G., 1988: Modulation of phenotypic and functional properties of human peripheral blood monocytes by IL4. J. Immunol. 140: 1548 - 1554

Thivierge, M., Le Gouill, C., Tremblay, M. J., Stankova, J., RolaPLESZCZYNSKI, M., 1998 : Prostaglandin E2 induces resistance to human immundeficiency virus-1 infection in monocyte-derived macrophages: downregulation of CCR5 expression by cyclic adenosine monophosphate. Blood 92: 40 - 45

- $\quad$ Thornhill, M. H., Wellicoms, S. M., MAhiouZ, D. L., LANChBURY, J. S., KyANAUNG, U., HASKARD, D. O., 1991: Tumor necrosis factor combines with IL-4 or IFNgamma to selectively enhance endothelial cell adhesiveness for $\mathrm{T}$ cells. The contribution of vascular cell adhesion molecule-1-dependent and -independent binding mechanisms. J. Immunol. 146: $592-598$

Tilley, S., L., Coffman, T., M., Koller, B. H., 2001: Mixed messages: modulation of inflammation and immune responses by prostaglandins and thromboxans. J. Clin. Invest. 108: $15-23$

- $\quad$ Urban, J. F. Jr., Noben-Trauth, N., Donaldson, D. D., Madden, K. B., Morris, S. C., Collins, M., Finkelman, F. D., 1998: IL-13, IL-4R alpha, and STAT6 are required fort he expulsion of the gastrointestinal nematode parasite Nippostrongylus brasiliensis. Immunity 8: 255 - 264

- $\quad$ Van der Pouw KraAn, T. C., Boeije, L. C., SmeenK, R. J., Wijdens, J., Arden, L. A., 1995: Prostaglandin E2 is a potent inhibitor of human interleukin-12 production. J. Exp. Med. 181: 775 - 779

- $\quad$ VAssiliou, E., Jing, H., GANEA, D., 2003: Prostaglandin E2 inhibits TNF production in murine bone marrow-derived dendritic cells. Cell. Immunol. 223: 120 - 132

- Vassiliou, E., Sharma, V., Jing, H., Sheibanie, F., GaneA, D., 2004: Prostaglandin E2 promotes the survival of bone marrow-derived dendritic cells. J. Immunol. 173: $6955-6964$

- Vella, A. T., Dow, S., Potter, T. A., KAPPler, J., Marrack, P., 1998: Cytokine-induced survival of activated T cells in vitro and in vivo. Proc. Natl. Acad. USA 95: $3810-1815$

- $\quad$ Vieira, P. L., D Jong E. C., Wierenga, E. A., KapsenberG, M. L., Kalinski, P., 2000: Development of TH1-inducing capacity in myeloid dendritic cells reqires environmental instruction. J. Immunol. 164: 4507 - 4512 
- $\quad$ Vitetta, E. S., Ohara, J., Myers, C. D., Layton, J. E., Krammer, P. H., Paul, W. E., 1985: Serological, biochemical, and functional identity of B cell-stimulatory factor 1 and B cell differentiation factor for IgG1. J. Exp. Med. 162: 1726 - 1731

Wang, L. M., Myers, M. G. Jr., Sun, X. J., Aaronson, S. A., White, M., Pierce, J. H., 1993: IRS-1: essential for insulin- and IL-4-stimulated mitogenesis in hematopoetic cells. Science 261: $1591-1594$

- $\quad$ Wang, J., Roderiquez, G., Oravecz, T., Norcross, M. A., 1998 : Cytokine regulation of human immundeficency virus type 1 entry and replication in human monocytes/macrophages through modulation of CCR5 expression. J. Virol. 72 (9): $7642-7647$

Wang, H. Y., Zamorano, J., Yoerkie, J. L., Paul, W. E., Keegan, A. D., 1997 : The IL-4 induced tyrosine phosphorylation of the insulin receptor substrate is dependent on Jak-1 expression in human carcinoma cells. J. Immunol. 158 (3): 1037 - 1040

- $\quad$ WARD, P. A., 2004: The dark side of C5a in sepsis. Nature Reviews 4: 133 - 141

- Weinmann, O., GutzMer, R., ZWirner, J., Wittmann, M., LAnGer, K., LISEWSKI, M., MOMMERT, S., KAPP, A., WERFEL, T., 2003: Up-regulation of C5a receptor expression and function on human monocyte derived dendritic cells by prostaglandin E2. Immunology 110: 458 - 465

- $\quad$ A) Welham, M. J., Duriono, V. Leslie, K. B., Bowtell, D., Schrader, J. W., 1994: Multiple hemopoietins, with the exception of interleukin-4, induces modification of Shc and mSos1, but not their translocation. J. Biol. Chem. 269: 21165 - 21176

- $\quad$ B) Welham, J. M., Duriono, V., Schrader, J. W., 1994: Interleukin-4 dependent proliferation dissociates p44 erk1, erk2, and p21ras activation from cell growth. J. Biol. Chem. 269: 5865 - 5873

Welham, M. J., LEARMONTH, L., BONE, H., SCHRADER, J. W., 1995: Interleukin-13 signal transduction in lymphohemopoietic cells. Similarities and differences in signal transduction with interleukin-4 and insulin. J. Biol. Chem. 270: 12286 - 12296

- A) Werfel, T., Zwirner, J., Oppermann, M., Sieber, A., Begemann, G., Drommer, W., KAPP, A., GÖTZE, O., 1996: CD88 antibodies specifically bind to C5aR on dermal CD117+ and CD14+ cells and react with a desmosomal antigen in human skin. J Immunol 157: 1729 - 1735

B) Werfel, T., Oppermann, M., Butterfield, J. H., Begemann, G., Elsner, J., GÖTZE, O., ZWIRNER, J. 1996: The human mast cell line HMC-1 expresses C5a receptors and responds to C5a but not to C5a (desArg). Scand J Immunol 44: 30 - 36 
- $\quad$ Werfel, T., Oppermann, M., Begemann, G., GÖtZe, O., Zwirner, J., 1997: C5a receptors are detectable on mast cells in normal human skin and in psoriatric plaques but not in wheal and flare reactions or in urticaria pigmentosa by immunohistochemistry. Arch Dermatol Res 289: 83 - 86

- WeTSEL, R. A., 1995 Structure, function and cellular expression of complement anaphylatoxin receptors. Curr Opin Immunol 7: 48 - 53

- WetzKer, R., 2004: Irrungen und Perspektiven der Phosphoinositid 3-Kinase-Forschung. BioSpektrum. 5/04, 10. Jahrgang: 620 - 622

- Williams, J. A. W., Shacter, E., 1997: Regualtion of macropage cytokine production by PGE2. J. Biol. Chem. 272: 25693 - 25699

- Witmer-Pack, M. D., Oliver, W., VAlinsky, J., Schuler, G., Steinman, R. M., 1987: Granulocyte/macrophage colony-stimulating factor is essential for the viability and function of cultured murine epidermal Langerhans cells. J. Exp. Med. 166: 1484 - 1498

- $\quad$ Witthuhn, B. A., Silvennoinen, O., Miura, O., Lai, K. S., CwiK, C., LiU, E. T., IHLE, J. N., 1994: Involvement of the Jak-3 Janus kinase in signalling by interleukin 2 und 4 in lymphoid and myeloid cells. Nature 370: 153 - 157

Xu, L. L., Warren, M. K., Rose, W. L., Gong, W., Wang, J. M., 1996: Human recombinant monocyze chemotactic protein and other $\mathrm{CC}$ chemkines bind and induce directional migration of dendritic cells in vitro. J. Leuk. Biol. 60: 365 - 371

- $\quad$ Yang, D., Chen, Q., Stoll, S., Chen, X., Howard, O. M., Oppenheim, J. J., 2000: Differential regulation of responsiveness to fMLP and C5a upon dendritic cell maturation correlation with receptor expression. J. Immunol. 165: 2694 - 2702

- $\quad$ YIN, T., TSANG, M. L., YANG, Y. C., 1994: Jak-1 kinase forms complexes with interleukin-4 receptor and 4PS/insulin receptor substrate-1-like protein and is activated by interleukin-4 and interleukin-9 in T-lymphocytes. J. Biol. Chem. 269: 26614 - 26617

- $\quad$ Youn, B.-S., Yu, K.-Y., OH, J., LeE, J., LEe, T.-H., BroXMEYER, H. E., 2002: Role of the CC Chemokine receptor 9/TECK interaction in apoptosis. Apoptosis 7: $271-276$

- $\quad$ Zamorano, J., Wang, H. Y., Wang, L. M., Pierce, J. H., Keegan, A. D., 1996: IL-4 protects cells from apoptosis via the insulin receptor substrate pathway and a second independent signaling pathway. J. Immunol. 157: 4926 - 4934

Zeidler, R., Csanady, M., Gires, O., LAng, S., Schmitt, B., WollenberG, B., 2000: Tumor cell-derived prostaglandin E2 inhibits monocyte function by interfering with CCR5 and Mac-1. FASEB J. 14: 661 - 668 
- $\quad$ ZHOU, L. J., TEDDER, T. F., 1995: Human blood dendritic cells selectively express CD83, a member of the immunglobulin superfamily. J. Immunol. 154: 3821 - 3835

- ZHOU, L. J., TEDDER, T. F., 1996: CD14+ blood monocytes can differentiate into functionally mature CD83+ dendritic cells. Proc. Natl. Acad. Sci. USA 93: 2588 - 2592

- $\quad$ Zlotnik, A., Fischer, M., RoehM, N., Zipori, D., 1987: Evidence for effects of interleukin 4 (B cell stimulatory factor 1) on macrophages: Enhancement of antigen presenting ability of bone marrow-derived macrophages. J. Immunol. 138: 4275 - 4279

- $\quad$ ZlotniK, A., Morales, J., Hedrick, J. A., 1999: Recent advances in chemokines and chemokine receptors.Crit Rev Immunol 19: 1 - 47

- ZlotniK, A., Yoshie, O., 2000: Chemokines: a new classification system and their role in immunity. Immunity 12 (2): $121-127$

- Z Zirner, J., Götze, O., Begemann, G., Kapp, A., Kirchhoff, K., Werfel, T., 1999: Evaluation of C3a receptor expression on human leukocytes by the use of novel monoclonal antibodies. Immunology 97: 166 - 172 


\section{LEBENSLAUF}

Persönliche Angaben:

Name: Claudia Dettmer-Richardt, geborene Dettmer

Geburtsort: Mühlhausen/Thüringen

Geburtstag: 13.06.1971

Staatsangehörigkeit: deutsch

Familienstand: verheiratet

Kinder: Tochter Jana, geboren am 14.01.2007

\section{Schulbildung:}

Sept. 1978 - Juli 1988

POS Thomas Müntzer in Mühlhausen/Thür.

Sept. 1988 - Juli 1990

EOS Erich Weinert in Mühlhausen/Thür., Abitur

\section{Ausbildung:}

Sept. 1990 - Juli 1993

Okt. 1996 - Nov. 2001

\section{Berufstätigkeit:}

Nov. 1993 - Okt. 1996

Ausbildung zur Medizinisch-technischen

Laborassistentin an der Medizinischen Fachschule Erfurt

Studium der Biologie an der Georg-August-Universität in Göttingen

Diplomarbeit: „Charakterisierung der Immunantwort nach induzierter Migration Dendritischer Zellen in vivo“ in der Abteilung für zelluläre und molekulare Immunologie der Georg-August-Universität Göttingen, Arbeitsgruppe Fr. PD Dr. rer. nat. Afsaneh Soruri und Prof. Dr. med. Jörg Zwirner

Berufliche Tätigkeit als MTA und Tierarzthelferin

Dez. 2001 - Sept. 2006

Tätigkeit als wissenschaftliche Mitarbeiterin in der Abteilung für zelluläre und molekulare Immunologie der Georg-August-Universität Göttingen, Arbeitsgruppe Fr. PD Dr. rer. nat. Afsaneh Soruri und Prof. Dr. med. Jörg Zwirner

Okt. 2002 - Sept. 2006 praktisches Arbeiten zum Zweck der Dissertation zum Thema: „Untersuchung zur wechselseitigen Beeinflussung von Chemotaxinen und Dendritischen Zellen“ 
Studienbegleitende Tätigkeiten: Honorardozententätigkeit (Chemie, Labormedizin) bei Arzt- und Tierarzthelferinnen in der Ausbildung an der BBS für Gesundheit und Soziales in Mühlhausen/Thür.

Studentische Hilfskraft in der Abteilung für Zoologie und Anthropologie der Georg-August-Universität Göttingen bei Prof. Willmann

Studentische Hilfskraft in der Abteilung für zelluläre und molekulare Immunologie der Georg-August-Universität Göttingen, Arbeitsgruppe Fr. Prof. Dr. rer nat. Afsaneh Soruri und Prof. Dr. med. Jörg Zwirner

Praktika:

Mikroskopierkurs der Hämatologie, Prof. Dr. med. Kunze, Medizinische $\quad$ Fakultät der Georg-August-Universität Göttingen

Blockpraktikum „Endokrinologie“, Prof. Dr. rer. nat. Hubertus Jarry, Frauenklinik Medizinische Fakultät der Georg-August-Universität Göttingen

Labormedizinische Praktika im Kreiskrankenhaus Unstrut-Hainich-Kreis Zentrallabor in Mühlhausen/Thür.

Sprachkenntnisse:

\section{Veröffentlichungen:}

Englisch (fließend)

Russisch (Grundkenntnisse)

Französisch (Grundkenntnisse)

Poster: Interleukin-4 inhibits dendritic cell migration induced by inflammatory chemotaxis in vivo, 11th International Congress of Immunology, 22. - 27. Juli 2001, Stockholm, Schweden

Poster: IL-4 exerts broad and potent inhibitory effects on the chemotactic mobilization of dendritic cells and macrophages, 16. European Congress of Immunology, 6. - 9. September 2006, Paris, Frankreich

Paper: IL-4 down-regulates anaphylatoxin receptors in Monocytes and Dendritic Cells and impairs anaphylatoxin-induced migration in vivo, Journal of Immunology, 2003 Mar 15; 170 (6): 3306 - 14 
Paper: Anaphylatoxin C5a induces Monocyte recruitment and differentiation into Dendritic Cells by TNF- $\alpha$ and Prostaglandin $E_{2}$-dependent mechanisms, Journal of Immunology, 2003 Sep 1; 171 (5): 2631 - 6 